UNIVERSIDADE DE BRASÍLIA

FACULDADE DE EDUCAÇÃO FÍSICA

PROGRAMA DE PÓS-GRADUAÇÃO EM EDUCAÇÃO FÍSICA

EFEITO IMEDIATO DE UMA SESSÃO DE TREINO RESISTIDO NA FUNÇÃO AUTONÔMICA CARDÍACA EM JOVENS ADULTOS SAUDÁVEIS

GILIARD LAGO GARCIA

Orientadora: Prof. Dra. Keila Elizabeth Fontana Co-Orientador: Prof. Dr. Guilherme Eckhardt Molina 
GILIARD GARCIA LAGO

\title{
EFEITO IMEDIATO DE UMA SESSÃO DE TREINO RESISTIDO NA FUNÇÃO AUTONÔMICA CARDÍACA EM JOVENS ADULTOS SAUDÁVEIS
}

\author{
Dissertação de mestrado apresentada ao \\ Programa de Pós-graduação Stricto Sensu da Faculdade \\ de Educação Física da Universidade de Brasília como \\ requisito parcial para a obtenção do Grau de Mestre em \\ Educação Física
}

Orientadora: Prof. Dra. Keila Elizabeth Fontana Co-Orientador: Prof. Dr. Guilherme Eckhardt Molina

\section{BRASÍLIA}




\section{DEDICATÓRIA}

Existem pessoas que passam por nossas vidas por uma razão, por um momento ou por uma vida inteira. E nesse processo de formação, tenho a felicidade de ter cruzado com muitas pessoas, que me ajudaram e continuam a me ajudar, nesse longo caminho. Este trabalho é fruto de todas estas pessoas, que de alguma maneira, contribuiram para que eu pudesse amadurecer intelectualmente e pessoalmente. Em especial dedico este trabalho a duas mulheres importantes em minha vida. Primeiro a mulher que me fez ser quem eu sou, que sempre me incentivou a buscar meus sonhos, sempre esteve ao meu lado me apoiando e é meu porto seguro, a minha mãe, amiga e companheira Maria das Graças lago. E em segundo, a mulher que escolhi para estar ao meu lado, que sempre apoia as minhas loucuras, me compreende nos momentos difíceis e, é a minha parceira para vida, Cássia Borges. 


\section{AGRADECIMENTOS}

Aos meus familiares, pela compreensão, pelo respeito e apoio na decisão de ingressar no mestrado.

A todos os voluntários que disponibilizaram, um dos bens mais preciosos, o tempo para participar da pesquisa.

Aos colegas de Mestrado, Edgard Soares e Lúcia Kobayashi, pelos grandes debates e contribuições para a construção deste trabalho.

À Academia Unique pela compreensão em minha rotina de trabalho nestes anos de mestrado.

Ao professor, Dr. Luiz Fernando Junqueira Jr que sempre de forma humilde e respeitosa, esteve disposto em contribuir com sua vasta experiência e conhecimento, não só sobre fisiologia, mas em diversos momentos sobre a vida. Muito obrigado!

À professora, Dra. Keila Elizabeth Fontana, por ter dado a oportunidade de ingressar no mestrado e ter acreditado em meu potencial. Muito obrigado por todos os puxões de orelha, aprendi com cada um, e por ser um exemplo de pesquisadora. Espero ter suprindo às expectativas de orientação. Neste momento, a corda já apertou. Muito obrigado!

Ao professor, Dr. Guilherme Eckhardt Molina, por ser mais que um orientador, e me dar a oportunidade de aprender a ser um pesquisador com uma formação robusta, e não só a ter um título no curriculum. Obrigado por quase sete anos de amizade, companheirismo e aprendizado que vou levar para a vida. Espero ter suprido as expetativas, em mais esta etapa ao seu lado. Muito obrigado, por seu um exemplo de homem e profissional.

Aos orientadores, o verdadeiro mestre não é aquele que ensina, mas o que mostra ao seu aluno as muitas vias de acesso até a estrada que ele precisará percorrer para encontrar-se com seu destino. Os mestres ensinam, deixam o exemplo e mostram o caminho. Muito obrigado! 
"Desistir... eu já pensei seriamente nisso, mas nunca me levei realmente a sério; é que tem mais chão nos meus olhos do que o cansaço nas minhas pernas, mais esperança nos meus passos, do que tristeza nos meus ombros, mais estrada no meu coração do que medo na minha cabeça".

\section{Cora Coralina}




\section{SUMÁRIO}

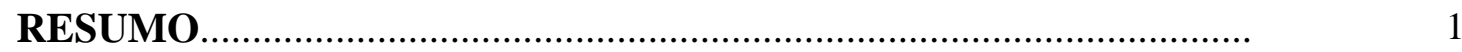

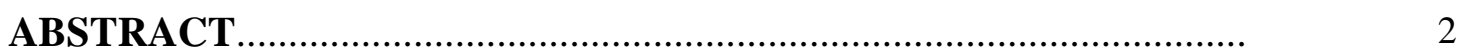

1. INTRODUÇÃO

11 Fundamentação teórica.......................................................................

1.1.1 Visão panorâmica da regulação cardiovascular.............................................

1.1.2 Avaliação clínica da função autonômica cardíaca de repouso.............................

1.1.3 Avaliação clínica da função autonômica cardíaca após o esforço................... 13

1.1.4 Visão panorâmica do treino resistido na resposta cardiovascular.....................

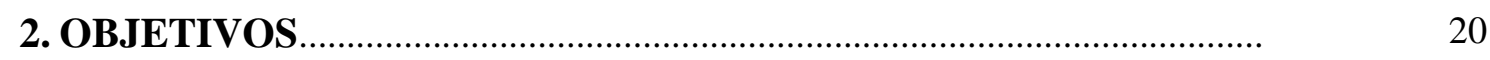

3. MATERIAIS E MÉTODOS .............................................................. 21

3.1 Amostra Estudada................................................................................ 21

3.2. Aspectos metodológicos gerais ................................................................. 25

3.3 Avaliação do eletrocardiograma de repouso............................................................. 28

3.4 Avaliação das variáveis hemodinâmicas na condição de repouso...................... 29

3.5 Caracterização da função autonômica cardíaca .................................................

3.6 Caracterização da capacidade física por meio do teste cardiopulmonar............. 31

3.7 Caracterização do decremento da frequência cardíaca durante o período de

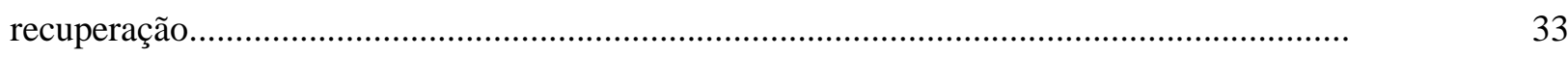

3.8 Caracterização da força por meio do teste do dinamômetro isocinético............. 34

3.9 Caracterização da familiarização e sessão de treino resistido........................... 36

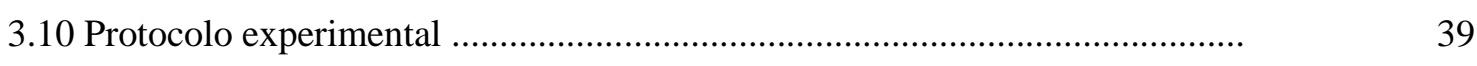

3.11 Procedimento estatístico ............................................................................

4. RESULTADOS ..............................................................................

4.1 Resposta da frequência cardíaca e do consumo de oxigênio antes, durante e

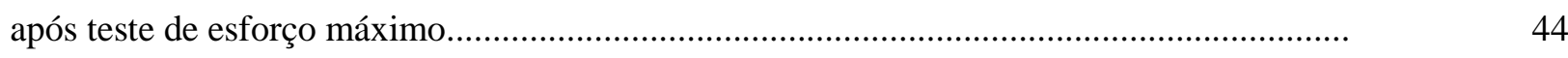

4.1.1 Frequência cardíaca inicial, durante e após teste de esforço máximo.............

4.1.2 Consumo de oxigênio no repouso, durante e após teste de esforço máximo

4.2 FAC avaliada pelos índices de poincaré, no domínio temporal e espectral da VFC durante cinco minutos na posição supina e ortostática no período de caracterização da amostra.

4.2.1 FAC na condição de repouso avaliada pelos índices de poincaré da VFC, nas posições supina e ortostática.

4.2.2 FAC na condição de repouso avaliada pelos índices do domínio temporal da VFC, nas posições supina e ortostática 
4.2.3 FAC na condição de repouso avaliada pelos índices do domínio espectral da VFC, nas posições supina e ortostática

4.3 Análise da $\mathrm{FAC}_{\text {repouso }}$ e da $\mathrm{FAC}_{\text {inicial }}$ avaliada pelos índices de poincaré, no domínio temporal e espectral.

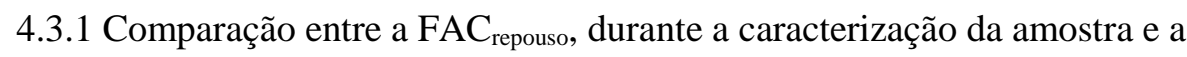
FAC $_{\text {inicial }}$ antes da sessão de TR, avaliada pelos índices de poincaré da VFC.

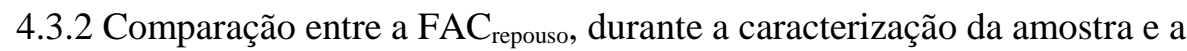
FAC $_{\text {inicial }}$ antes da sessão de TR, avaliada pelos índices temporais da VFC.

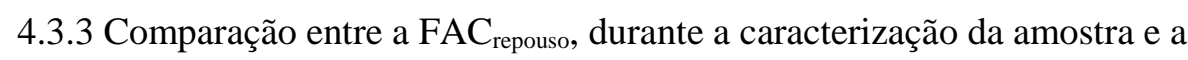
$\mathrm{FAC}_{\text {inicial }}$ antes da sessão de TR, avaliada pelos índices espectrais da VFC.

4.4 A força e variáveis de controle de sobrecarga durante uma sessão de treino resistido

4.4.1 Valores amostrais da força durante a caracterização da amostra

4.4.2 Análise comparativa entre as variáveis de controle da sobrecarga durante a sessão de treino resistido

4.5 Função autonômica cardíaca antes e após a sessão de treino resistido, avaliada pelos índices de poincaré, no domínio temporal e espectral.

4.5.1 FAC avaliada pelos índices de poincaré da VFC, antes e ao longo de 15 minutos após a sessão de TR

4.5.2 FAC avaliada pelos índices temporais da VFC antes e ao longo de 15 minutos, após a sessão de TR

4.5.3 FAC avaliada pelos índices espectrais da VFC antes e ao longo de 15 minutos, após a sessão de TR

4.6 Correlação entre as variáveis da função autonômica cardíaca avaliada pelos índices de poincaré, nos domínios temporal e espectral.

4.6.1 Correlação entre a FAC, avaliada pelos índices de poincaré da VFC, antes da sessão de TR e ao longo de 15 minutos após sessão de TR

4.6.2 Correlação entre a FAC, avaliada pelos índices temporais da VFC, antes da sessão de TR e ao longo de 15 minutos após sessão de TR

4.6.3 Correlação entre a FAC, avaliada pelos índices espectrais da VFC, antes da sessão de TR e ao longo de 15 minutos após sessão de TR

4.7 Correlações da função autonômica cardíaca, avaliada pelos índices de poincaré, no domínio temporal e domínio espectral com a resposta cronotrópica cardíaca após sessão de treino resistido.

4.7.1 Correlação entre a FAC avaliada pelos índices de poincaré da VFC com a resposta cronotrópica cardíaca após sessão de TR. 
4.7.2 Correlação entre a FAC avaliada pelos índices temporais da VFC com a resposta cronotrópica cardíaca após sessão de TR.

4.7.3 Correlação entre a FAC avaliada pelos índices espectrais da VFC com a resposta cronotrópica cardíaca após sessão de TR.

5.1 Caracterização amostral e resposta da frequência cardíaca e do consumo de oxigênio antes, durante e após teste de esforço máximo

5.1.1 Caracterização amostral.

5.1.2 Resposta da frequência cardíaca e do consumo de oxigênio antes, durante e após teste de esforço máximo

5 .2 FAC avaliada pelos índices de poincaré, no domínio temporal e espectral, na posição supina e ortostática iniciais

5.3 $\mathrm{FAC}_{\text {repouso }}$ na caracterização da amostra e $\mathrm{FAC}_{\text {inicial }}$ antes da sessão de TR, avaliada pelos índices de poincaré, no domínio temporal e espectral.

5.4 Força e variáveis de controle de sobrecarga durante a sessão de treino resistido

5.4.1 Caracterização dos valores amostrais da força

5.4.2 Análise das variáveis de controle de sobrecarga durante sessão de treino resistido.

5.5 FAC antes e após a sessão de treino resistido, avaliada pelos índices de poincaré, no domínio temporal e espectral da VFC.

5.6 Correlações entre a FAC inicial e a FAC ao longo de 15 minutos, após sessão de TR, avaliada pelos índices de poincaré, no domínio temporal e espectral.

5.7 Correlações entre a FAC inicial, avaliada pelos índices de poincaré, no domínio temporal e espectral e a resposta cronotrópica cardíaca após sessão de TR.

6. CONCLUSÃO.

7. REFERÊNCIAS BIBLIOGRÁFICAS.

I. Termo de consentimento livre e esclarecido.

II. Parecer do Comitê de Ética em Pesquisa - CEP................................................ 


\section{LISTA DE ABREVEATURAS}

1. ACMS: American College Sports Medicine

2. AF: alta frequência espectral (área de)

3. AT: área total

4. AV: atrioventricular

5. BF: baixa frequência espectral (área de)

6. bpm: batimentos por minuto

7. cm: centímetros

8. $\mathbf{C V}$ : coeficiente de variação

9. DP: desvio padrão

10. ECG: eletrocardiograma

11. FAC: função autonômica cardíaca

12. FC: frequência cardíaca

13. $\mathbf{F C}_{\text {rep: }}$ frequência cardíaca de repouso

14. $\mathbf{F C}_{\text {inicial: }}$ frequência cardíaca no início do esforço

15. FCpico: frequência cardíaca no pico do esforço

16. FCR: frequência cardíaca de recuperação

17. FR: frequência respiratória

18. I: inicial

19. IMC: índice de massa corporal (calculado pela razão entre o peso expresso em quilos, dividido pelo quadrado da altura expresso em metros)

20. Inf: inferior

21. iRR: intervalo RR

22. irpm: incursões por minuto

23. kg: quilograma

24. $\mathbf{k m} / \mathbf{h}$ : quilômetro por hora

25. Max: valor amostral máximo

26. Min: mínimo 
27. min: minuto

28. ml: mililitros

29. mmHg: milímetros por mercúrio

30. ms: milissegundos

31. Nor: normalizada

32. NTS: núcleo trato solitário

33. ORT: posição ortostática

34. PAS: pressão arterial sistólica

35. PAD: pressão arterial diastólica

36. pNN50: percentual de intervalos R-R adjacentes com diferença superior a 50ms

37. PT: pico de torque

38. QR: quociente respiratório, relação entre a quantidade de dióxido de carbono produzida, pelo consumo de oxigênio: $\dot{\mathrm{VO}}_{2} / \mathrm{VCO}_{2}$

39. Qtl: quartil

40. Razão BF/AF: razão entre a área absoluta de baixa frequência pela área espectral absoluta de alta frequência

41. rMSSD: raiz quadrada da média do quadrado das diferenças sucessivas dos intervalos R-R do ECG

42. rs: coeficiente de Spearman

43. SA: sino atrial

44. SD1: desvio vertical

45. SD2: desvio horizontal

46. SD1/SD2: razão entre o desvio vertical pelo horizontal

47. SUP: posição supino

48. sup: superior

49. SNA: sistema nervoso autônomo

50. TR: treino resistivo

51. $\mathbf{V C O}_{2}$ : volume expirado de dióxido de carbono

52. VE/VO 2 : equivalente ventilatório para o oxigênio 
53. VFC: variabilidade da frequência cardíaca

54. $\dot{\mathbf{V}} \mathbf{O}_{2}$ : consumo de oxigênio

55. $\dot{\mathbf{V}} \mathbf{O}_{2}$ pico: consumo de oxigênio no pico do esforço

56. $\triangle$ absFC: variação absoluta da frequência cardíaca individual

57. $\Delta \% \mathrm{FC}$ : variação relativa da frequência cardíaca individua; 


\section{LISTA DE FIGURAS}

Figura 01: Representação da plotagem de Poincaré. Dados obtidos a partir do registro de um voluntário do presente estudo.

Figura 02 Representação gráfica das amplitudes e suas frequências, dentro de escalas do espectro de potências (análise espectral), com a representação de muito baixa frequência na cor rosa, baixa frequência na cor roxa e alta frequência na cor amarela. Dados obtidos a partir do registro de um dos voluntários do presente estudo. Acima os dados na posição supina e abaixo os dados na posição ortostática...

Figura 03

Critérios de inclusão dos voluntários na amostra

Critérios de exclusão dos voluntários na amostra.

Figura 08 Ilustração da execução do movimento de leg press por um voluntário. Acima a ilustração do movimento inicial no leg press e abaixo a ilustração do movimento final no leg press

Figura 09 Esquema ilustrativo do desenho experimental.

Figura 11 Comportamento da frequência cardíaca na condição repouso, no início e fim do teste de esforço e durante a recuperação após o teste de esforço máximo $(n=14)$

Figura 12 Comportamento do consumo de oxigênio na condição de repouso, no início e fim do teste de esforço e durante a recuperação após o teste de esforço máximo, estão indicados a mediana, quartis superior e inferior, e os valores extremos $(\mathrm{n}=14)$

Figura 13 Pico de torque, absoluto e relativo, da perna dominante no teste de força máxima na extensão de joelho durante a caracterização da amostra. Estão indicados a mediana e os valores extremos $(n=14)$

Figura 14 Controle da sobrecarga durante uma sessão de treino resistido, estão indicados a mediana e extremos $(n=14)$.

Figura 15 C Comportamento da função autonômica cardíaca na condição inicial e durante a recuperação após a sessão de treino resistido. Estão indicados a mediana, quartis superior e inferior, e os valores extremos $(n=14)$.

Figura 16 Comportamento da função autonômica cardíaca na condição inicial e durante a recuperação após a sessão de treino resistido. Estão indicados a mediana, quartis superior e inferior, e os valores extremos $(n=14)$. 
Figura 17 Comportamento da função autonômica cardíaca na condição inicial e durante a recuperação após a sessão de treino resistido. Estão indicados a mediana, quartis superior e inferior, e os valores extremos $(n=14)$

Figura 18 Comportamento da função autonômica cardíaca na condição inicial e durante a recuperação após a sessão de treino resistido. Estão indicados a mediana, quartis superior e inferior, e os valores extremos $(n=14)$.

Figura 19 Comportamento da função autonômica cardíaca na condição inicial e durante a recuperação após a sessão de treino resistido. Estão indicados a mediana, quartis superior e inferior, e os valores extremos $(n=14)$.

Figura 20 Comportamento da função autonômica cardíaca na condição inicial e durante a recuperação após a sessão de treino resistido. Estão indicados a mediana, quartis superior e inferior, e os valores extremos $(n=14)$

Figura 21 Comportamento da função autonômica cardíaca na condição inicial e durante a recuperação após a sessão de treino resistido $(\mathrm{n}=14)$.

Figura 22 Comportamento da função autonômica cardíaca na condição inicial e durante a recuperação após a sessão de treino resistido. Estão indicados a mediana, quartis superior e inferior, e os valores extremos $(n=14)$.

Figura 23 Comportamento da função autonômica cardíaca na condição inicial e durante a recuperação após uma sessão de treino resistido. Estão indicados a mediana, quartis superior e inferior, e os valores extremos $(n=14)$.

Figura 24 Comportamento da função autonômica cardíaca na condição inicial e durante a recuperação após uma sessão de treino resistido. Estão indicados a mediana, quartis superior e inferior, e os valores extremos $(n=14)$.

Figura 25 Comportamento da função autonômica cardíaca na condição inicial e durante a recuperação após uma sessão de treino resistido. Estão indicados a mediana, quartis superior e inferior, e os valores extremos $(\mathrm{n}=14)$.

Figura 26 Comportamento da função autonômica cardíaca na condição inicial e durante a recuperação após uma sessão de treino resistido. Estão indicados a mediana, quartis superior e inferior, e os valores extremos $(n=14)$.

Figura 27 Correlações entre função autonômica cardíaca na posição supina na condição inicial, com a função autonômica cardíaca após 5 (0 a 5) min (círculo verde), 10 (5 a 10) min (círculo vermelho) e 15 (10 a 15) min (círculo azul) de uma sessão de treino resistido, avaliada pelos índices de Poincaré.

Figura 28 Correlações entre função autonômica cardíaca na posição supina na condição inicial, com a função autonômica cardíaca após 5 ( 0 a 5) min (círculo verde), 10 (5 a 10) min (círculo vermelho) e 15 (10 a 15) min (círculo azul) de uma sessão de treino resistido, avaliada pelos, avaliada pelos índices de temporais. 
Figura 29 Correlações entre função autonômica cardíaca na posição supina na condição inicial, com a função autonômica cardíaca após 5 ( 0 a 5) min (círculo verde), 10 (5 a 10) min (círculo vermelho) e 15 (10 a 15) min (círculo azul) de uma sessão de treino resistido, avaliada pelos, avaliada pelos índices de temporais.

Figura 30 Correlações entre função autonômica cardíaca na posição supina na condição inicial, com a função autonômica cardíaca após 5 (0 a 5) min (círculo verde), 10 (5 a 10) min (círculo vermelho) e 15 (10 a 15) min (círculo azul) de uma sessão de treino resistido, avaliada pelos, avaliada pelos índices de temporais.

Figura 31 Correlações entre função autonômica cardíaca na posição supina na condição inicial, com a função autonômica cardíaca após 5 (0 a 5) min (círculo verde), 10 (5 a 10) min (círculo vermelho) e 15 (10 a 15) min (círculo azul) de uma sessão de treino resistido, avaliada pelos, avaliada pelos índices de temporais.

Figura 32 Correlações entre função autonômica cardíaca na posição supina na condição inicial, com a função autonômica cardíaca após 5 (0 a 5) min (círculo verde), 10 (5 a 10) min (círculo vermelho) e 15 (10 a 15) min (círculo azul) de uma sessão de treino resistido, avaliada pelos, avaliada pelos índices espectrais.

Figura 33 Correlações entre função autonômica cardíaca na posição supina na condição inicial, com a função autonômica cardíaca após 5 (0 a 5) min (círculo verde), 10 (5 a 10) min (círculo vermelho) e 15 (10 a 15) min (círculo azul) de uma sessão de treino resistido, avaliada pelos, avaliada pelos índices espectrais.....

Figura 34 Correlações entre função autonômica cardíaca na posição supina na condição inicial, com a função autonômica cardíaca após 5 (0 a 5) min (círculo verde), 10 (5 a 10) min (círculo vermelho) e 15 (10 a 15) min (círculo azul) de uma sessão de treino resistido, avaliada pelos, avaliada pelos índices espectrais.

Figura 35 Correlações entre função autonômica cardíaca na posição supina na condição inicial, com a função autonômica cardíaca após 5 (0 a 5) min (círculo verde), 10 (5 a 10) min (círculo vermelho) e 15 (10 a 15) min (círculo azul) de uma sessão de treino resistido, avaliada pelos, avaliada pelos índices espectrais.

Figura 36 Correlações entre função autonômica cardíaca na posição supina inicial, avaliada pelos índices de Poincaré da variabilidade da frequência cardíaca, com a resposta cronotrópica cardíaca após $5^{\circ} \min$ (círculo verde), $10^{\circ} \mathrm{min}$ (círculo vermelho) e $15^{\circ} \min$ (círculo azul) de uma sessão de treino resistido

Figura 37 Correlações entre função autonômica cardíaca na posição supina inicial, avaliada pelos índices temporais da variabilidade da frequência cardíaca, com a resposta cronotrópica cardíaca após $5^{\circ} \min$ (círculo verde), $10^{\circ} \min$ (círculo vermelho) e $15^{\circ} \min$ (círculo azul) de uma sessão de treino resistido.

Figura 38 Correlações entre função autonômica cardíaca na posição supina inicial, avaliada pelos índices temporais da variabilidade da frequência cardíaca, com a resposta cronotrópica cardíaca após $5^{\circ} \min$ (círculo verde), $10^{\circ} \min$ (círculo vermelho) e $15^{\circ}$ min (círculo azul) de uma sessão de treino resistido 
Figura 39 Correlações entre função autonômica cardíaca na posição supina inicial, avaliada pelos índices Espectrais da variabilidade da frequência cardíaca, com a resposta cronotrópica cardíaca após $5^{\circ} \mathrm{min}$ (círculo verde), $10^{\circ} \mathrm{min}$ (círculo vermelho) e $15^{\circ} \min$ (círculo azul) de uma sessão de treino resistido

Figura 40 Correlações entre função autonômica cardíaca na posição supina inicial, avaliada pelos índices Espectrais da variabilidade da frequência cardíaca, com a resposta cronotrópica cardíaca após $5^{\circ} \min$ (círculo verde), $10^{\circ} \mathrm{min}$ (círculo vermelho) e $15^{\circ} \min$ (círculo azul) de uma sessão de treino resistido 


\section{LISTA DE TABELAS}

Tabela 01: Características antropométricas e funcionais na condição de repouso $(\mathrm{n}=14) \ldots . .$.

Tabela 02 Características eletrocardiográficas individuais obtidas durante o repouso na posição supina $(\mathrm{n}=14)$.

Tabela 03 Frequência cardíaca na condição repouso, no início e fim do teste de esforço e durante a recuperação após o teste de esforço máximo $(n=14)$

Tabela 04 Consumo de oxigênio previamente, durante e após o teste de esforço máximo $(n=14)$.

Tabela 05 Índices de Poincaré da variabilidade da frequência cardíaca durante 5 minutos na posição supina e ortostática, na condição de repouso, no período de caracterização da amostra $(\mathrm{n}=14)$.

Tabela 06 Índices temporais da variabilidade da frequência cardíaca durante 5 minutos na posição supina e ortostática, na condição de repouso, no período de caracterização da amostra $(n=14)$

Tabela 07 Índices temporais da variabilidade da frequência cardíaca durante 5 minutos na posição supina e ortostática, na condição de repouso, no período de caracterização da amostra $(\mathrm{n}=14)$.....

Tabela 08 Função autonômica cardíaca durante a caracterização da amostra com a função autonômica cardíaca antes da sessão de treino resistido, avaliada pelos índices de Poincaré da variabilidade da frequência cardíaca $(n=14)$.

Tabela 09 Função autonômica cardíaca durante a caracterização da amostra com a função autonômica cardíaca antes da sessão de treino resistido, avaliada pelos índices temporais da variabilidade da frequência cardíaca $(n=14)$

Tabela 09.1 Função autonômica cardíaca durante a caracterização da amostra com a função autonômica cardíaca antes da sessão de treino resistido, avaliada pelos índices temporais da variabilidade da frequência cardíaca $(n=14)$

Tabela 10 Função autonômica cardíaca durante a caracterização da amostra com a função autonômica cardíaca antes da sessão de treino resistido, avaliada pelos índices espectrais da variabilidade da frequência cardíaca $(n=14)$.

Tabela 10.1 Função autonômica cardíaca durante a caracterização da amostra com a função autonômica cardíaca antes da sessão de treino resistido, avaliada pelos índices espectrais da variabilidade da frequência cardíaca $(n=14)$.

Tabela 11 Variáveis de controle de sobrecarga durante uma sessão de treino resistido $(n=14)$.

Tabela 12 Função autonômica cardíaca antes e ao longo de 15 minutos, após sessão de treino resistido, avaliada pelos índices de Poincaré da variabilidade da frequência cardíaca $(\mathrm{n}=14)$.

Tabela 13 Função autonômica cardíaca antes e ao longo de 15 minutos, após sessão de treino resistido, avaliada pelos índices de temporais da variabilidade da frequência cardíaca $(\mathrm{n}=14)$ 
Tabela 13.1 Função autonômica cardíaca antes e ao longo de 15 minutos, após sessão de treino resistido, avaliada pelos índices de temporais da variabilidade da frequência cardíaca $(\mathrm{n}=14)$.

Tabela 14 Função autonômica cardíaca previamente a uma sessão de treino resistido com a função autonômica cardíaca, ao longo de 15 minutos, após uma sessão de treino resistido, avaliada pelos índices espectrais da variabilidade da frequência cardíaca $(\mathrm{n}=14)$

Tabela 15 Correlações entre os índices de Poincaré das séries de intervalo RR, na posição supina na condição inicial, com a função autonômica cardíaca, ao longo de 15 minutos, após sessão de treino resistido $(\mathrm{n}=14)$.

Tabela 16 Correlações entre os índices temporais das séries de intervalo RR, na posição supina na condição inicial, com a função autonômica cardíaca, ao longo de 15 minutos, após uma sessão de treino resistido $(\mathrm{n}=14)$.

Tabela 17 Correlações entre os índices espectrais das séries de intervalo RR, na posição supina na condição inicial, com a função autonômica cardíaca, ao longo de 15 minutos, após uma sessão de treino resistido $(\mathrm{n}=14)$

Tabela 18 Correlações entre os índices de Poincaré das séries de intervalo RR, na posição supina inicial, com a resposta cronotrópica cardíaca após $5^{\circ}, 10^{\circ}$ e $15^{\circ}$ minuto de uma sessão de treino resistido $(n=14)$.

Tabela 19 Correlações entre os índices temporais das séries de intervalo RR, na posição supina inicial, com a resposta cronotrópica cardíaca após $5^{\circ}, 10^{\circ}$ e $15^{\circ}$ minutos de uma sessão de treino resistido $(n=14)$

Tabela 20 Correlações entre os índices espectrais das séries de intervalo RR, na posição supina inicial, com a resposta cronotrópica cardíaca após $5^{\circ}, 10^{\circ}$ e $15^{\circ}$ minutos de uma sessão de treino resistido $(n=14)$ 


\section{RESUMO}

INTRODUÇÃO: Uma sessão de TR parece ser capaz de induzir alterações na função autonômica cardíaca (FAC), avaliada por meio da variabilidade da frequência cardíaca (VFC), durante o período de recuperação. Nesse contexto, os dados sobre o mínimo de estímulo capaz de induzir alterações na FAC, bem como, o comportamento da FAC após sessão de TR, são insuficientes. O conhecimento sobre esse tópico, pode fornecer informações acerca da segurança/risco na adequada prescrição do TR. OBJETIVO: Comparar a FAC no repouso com a FAC nos 5, 10 e 15 minutos, após uma sessão de TR, em homens adultos clinicamente normais. MÉTODO: Foram avaliados 14 homens adultos clinicamente normais $(24,1 \pm 5,6$ anos e 24,9 $\pm 1,9$ $\mathrm{kg} / \mathrm{m}^{2}$ ). Todos realizaram o registo curto (5 min) dos intervalos $R R(i R R)$ antes da sessão de TR (repouso) e nos 5, 10 e 15 minutos, imediatamente após a sessão de TR (recuperação), ambos na posição supina. A sessão de TR foi composta por 3 séries de 8-12RM com 1 min de intervalo de recuperação no exercício de leg press. A gravação dos iRR foi realizada por meio do frequencímetro Polar RS $800^{\circledR}$ e posteriormente, os iRR foram processados e analisados, off-line, pelo software Kubios HRV. A FAC foi avaliada por meio da VFC pelos índices do mapa de Poincaré, domínio temporal e espectral. Dada a distribuição não-normal (teste Shapiro-Wilk) utilizou-se teste de Friedman com post hoc Dunn ao nível de significância de $p \leq 0,05$. RESULTADOS: Observou-se uma taquicardia, com uma progressiva redução ao longo dos 15 minutos após sessão de TR, e maiores valores de média iRR na condição de repouso $(p<0,01)$ comparativamente ao período de recuperação. Os valores dos marcadores de atividade vagal, em todas as formas de análise da VFC, apresentaram diferenças estatísticas $(p<0,01)$ e maiores valores na condição de repouso comparada ao período de recuperação após a sessão de TR. Os marcadores de modulação global apresentaram progressivo aumento durante 15 minutos após a sessão de TR, e menores valores, em todas as formas de análise da VFC, nos dez e quinze minutos da fase de recuperação após sessão de TR comparativamente ( $p$ $<0,01$ ) a condição de repouso. CONCLUSÃO: Com base nos resultados, uma sessão de TR, induz a uma taquicardia que vai progressivamente reduzindo até os 15 minutos após sessão de TR. E, o comportamento da atividade vagal e da modulação global, apresentam um aumento progressivo ao longo de 15 minutos após sessão de TR, com menores valores por até 15 minutos em comparação a condição de repouso.

Palavras chave: Função autonômica cardíaca, variabilidade da frequência cardíaca, treino resistido, parassimpático 


\section{ABSTRACT}

INTRODUCTION: The TR session seems to be able to induce changes in cardiac autonomic function (CAF), assessed by heart rate variability (HRV) during the recovery period. In this context the data on minimal stimulus to induce changes in the CAF, as well as the behavior of the CAF after TR session, are insufficient. Knowledge about this topic, can offer information about the safety / risk in the appropriate prescription of TR. OBJECTIVE: To compare CAF at rest with the CAF in 5, 10 and 15 minutes after a TR session, in clinically normal adult men. METHOD: We evaluated 14 clinically healthy male adults $(24,1 \pm 5,6$ years and 24,9 $\pm 1,9 \mathrm{~kg} / \mathrm{m} 2)$. All patients underwent short register ( $5 \mathrm{~min}$ ) RR interval (RRi) before the TR session (rest) and 5,10 and 15 minutes immediately after the session TR (recovery), both in the supine position. The TR session consisted of 3 series 8-12RM with 1 min recovery interval in the leg press exercise. The recording of iRR was performed by means of a Polar $R S 800^{\circledR}$ and later the iRR were processed and analyzed off-line by Kubios HRV software. The CAF was evaluated by HRV indexes by the Poincaré map, temporal and spectral domain. Given the nonnormal distribution (Shapiro-Wilk test) it was used Friedman test with post hoc Dunn to significance level $p \leq$ 0,05. RESULTS: We observed a tachycardia, with a progressive reduction throughout the 15 minutes session $R T$, and higher average values iRR in resting condition $(p<0,01)$ compared to recovery period. The values of vagal activity markers in all forms of HRV analysis showed statistical differences $(p<0,01)$, and higher values at rest compared to the recovery period after TR session. The global modulation markers showed progressive increase for 15 minutes after the TR session, and lower values in all forms of HRV analysis, the ten and fifteen minutes of the recovery phase after TR session compared $(p<0,01)$ the rest condition. CONCLUSION: Based on the results, a TR session induces a tachycardia progressively reduced until 15 minutes after RT session. And, the behavior of the vagal activity modulation and overall, have a progressive increase over the course of 15 minutes TR session, with lower values by up to 15 minutes in comparison to the rest condition.

Keywords: cardiac autonomic function, heart rate variability, resistance training and parasympathetic 


\section{INTRODUÇÃO}

O treino resistido (TR) é seguramente recomendado para diversas populações por promover ganho de força muscular e reduzir as demandas cardiovasculares ao longo do dia (1-6). A manipulação das variáveis do treinamento resistido, como a carga, escolha dos exercícios, ordem dos exercícios, número de séries, número de repetições, intervalo de recuperação, volume (número de repetições $\times$ número de séries $\times$ carga), tempo de tensão e velocidade de execução (6) podem determinar o tipo e a magnitude da resposta imediata ao TR (7).

Assim, durante uma sessão de TR, o recrutamento de unidades motoras para a produção de força, produz uma deformação mecânica nas fibras musculares, estimulando a liberação hormonal, respostas imunes e respostas inflamatórias (7). Neste cenário, também ocorre o aumento da frequência cardíaca (FC), devido interação coordenada da retirada do sistema nervoso autônomo parassimpático ou vagal, e entrada do sistema nervoso autônomo simpático (8-10), por meio do controle do sistema nervoso central com sinais provenientes de integrantes do cérebro (comando central) e da periferia (contração muscular voluntária) através de mecanismos reflexos, como o "muscle pressor reflex"(mecanorreceptores e quimiorreceptores) e o barorreflexo $(11,12)$.

Durante o período de recuperação, o decremento da FC após o exercício é determinado pela interação coordenada da reativação do sistema nervoso autônomo parassimpático e gradual retirada do sistema nervoso autônomo simpático. A reativação vagal ocorre mais rapidamente e, portanto, desempenha o papel importante na desaceleração rápida FC após o exercício (8, 12-18).

Diante dessas alterações associadas à atividade autonômica cardíaca, recentes estudos $(19,20)$ aplicaram o método da variabilidade da frequência cardíaca (VFC) e abordaram a influência de diferentes modelos de exercício físico sobre a função autonômica cardíaca (FAC) no período de recuperação após o exercício. Assim, a análise da VFC pelos índices de Poincaré, no domínio temporal e espectral, baseada nas series dos intervalos RR (iRR), é uma ferramenta válida e não invasiva na avaliação da FAC em diversos momentos e condições funcionais. Desta forma, permite 
inferir indiretamente a influência da atividade vagal e o balanço simpatovagal sobre o nodo sino atrial $(21,22)$.

O grande interesse na avaliação da FAC reside na capacidade prognóstica de risco cardiovascular, assim, uma predominância da atividade vagal demonstra exercer um efeito cardioprotetor através de uma melhor estabilidade eléctrica cardíaca (23). Contudo, uma sustentada atividade simpática e/ou redução da atividade vagal cardíaca, após o exercício, pode apresentar uma condição de arritmias ventriculares malignas e morte súbita (22-26).

Recentes estudos que aplicaram o método da VFC na análise da FAC, demostraram que uma sessão de TR parece ser capaz de causar alterações na FAC durante o período de recuperação (27, 28), entretanto, a comparação entre os estudos, torna-se muito difícil devido à heterogeneidade entre as amostras e protocolos de treino aplicados, forma de análise da VFC e tempo de monitoramento após a sessão de TR. Além disso, os dados disponíveis na literatura sobre o curso temporal da restauração da FAC, bem como a magnitude do comportamento e/ou o cenário da FAC após uma sessão imediata de TR $(19,29)$ são insuficientes. Os conhecimentos relacionados a este tópico tem grande valor profissional, devido a prescrição mais adequada de TR para indivíduos saudáveis, com ou sem risco de doença cardiovascular.

Também, com o melhor de nosso conhecimento sobre este tema, não há nenhum estudo que realizou a correlação entre a FAC, avaliada pela VFC, na condição de repouso com a FAC, avaliada pela VFC, e a resposta cronotrópica, após uma sessão de TR, com vistas à compreensão dos possíveis mecanismos fisiológicos envolvidos na regulação cardiovascular.

Não é de nosso conhecimento a existência de estudos que realizaram a correlação entre a FAC, avaliada pela VFC, na condição de repouso com a FAC, avaliada pela VFC, e a resposta cronotrópica, após uma sessão de TR, principalmente no que se refere à compreensão dos possíveis mecanismos fisiológicos envolvidos na regulação cardiovascular. Em outras palavras, acredita-se que o status autonômico cardíaco e a resposta cronotrópica, após uma sessão de TR dependam do status autonômico cardíaco avaliado na condição de repouso. 
Nesse contexto, o presente trabalho tem como objetivo verificar as alterações na função autonômica cardíaca de homens adultos clinicamente normais a cada 5 minutos $(0-5,5-10$ e $10-15$ min) durante 15 minutos após uma sessão de treino resistido e comparar com a condição inicial.

\subsection{FUNDAMENTAÇÃO TEÓRICA}

\subsubsection{VISÃO PANORÂMICA DA REGULAÇÃO CARDIOVASCULAR}

O sistema cardiovascular é composto por uma bomba (o coração), uma série de tubos coletores e distribuidores (vasos sanguíneos) e uma extensa rede de vasos finos (capilares) que permitem o transporte rápido entre os tecidos e os canais vasculares. Eles participam de mecanismos homeostáticos como a regulação da temperatura corporal, manutenção do balanço de fluidos, ajuste do fornecimento de oxigênio e de nutrientes sob vários estados fisiológicos (30).

$\mathrm{Na}$ condição de repouso, o sistema cardiovascular é responsável pelo fornecimento de oxigênio, hormônios e nutrientes, para cada célula corporal, assim como, para a remoção de produtos metabólicos, como o dióxido de carbono (31). E, durante uma condição de estresse, como por exemplo o exercício físico, o fluxo sanguíneo aumenta para atender as demandas dos músculos esqueléticos envolvidos na atividade contrátil, bem como, os músculos respiratórios e cardíacos. Assim, o aumento do trabalho cardiovascular é fundamental, afim de assegurar o fornecimento adequado de oxigênio para os músculos esqueléticos ativos, na remoção dos subprodutos metabólicos, no controle da termorregulação e na regulação da pressão arterial, para manter a perfusão adequada dos órgãos vitais, sem variações de pressão excessivas (32).

Para o adequado funcionamento do sistema cardiovascular, em diferentes condições (posição supina e ortostática) e momentos funcionas (condição de repouso e exercício), o sistema cardiovascular sofre influência reguladora de diversas estruturas do sistema nervoso central, as quais modificam o estado funcional e as propriedades dos órgãos. Como por exemplo, no coração modificando as propriedades elétricas (automatismo, excitabilidade e condutibilidade) e mecânicas (contratilidade e relaxamento) ou nos vasos induzindo vasoconstricção ou vaso dilatação, por meio 
da liberação em seus terminais de neurotransmissores estimuladores (noradrenalina) ou inibidores (acetilcolina) (33).

Os nervos do sistema nervoso central, que influenciam o funcionamento do sistema cardiovascular, fazem parte do sistema nervoso autônomo, que divide-se em sistema nervoso autônomo simpático (nervos simpáticos) e o sistema nervoso autônomo parassimpático (nervo vago). Essas divisões do sistema nervoso autônomo influenciam de modo tônico o nodo sinoatrial (SA). O sistema simpático, que tem função estimuladora sobre as propriedades funcionais, intensifica o automatismo, enquanto o parassimpático, que tem efeito funcional inibidor sobre as propriedades funcionais, o inibe. As variações na FC, geralmente envolvem a ação recíproca dessas duas divisões do sistema nervoso autônomo, desse modo, a FC, na maioria das vezes, aumenta com a combinação da diminuição da atividade parassimpática e aumento da atividade simpática, e a diminuição da FC, se dá pela variações opostas da atividade autonômica neural $(11,30,34)$.

Os neurônios simpáticos pré-ganglionares estão localizados nos segmentos torácicos e lombares superiores da medula, onde inervam a base do coração distribuídas para as várias câmaras com um extenso plexo epicárdico dentro do miocárdio. O início da resposta cardíaca à estimulação simpática começa de modo lento, já que as fibras pós-ganglionares liberam o neurotransmissor norepinefrina lentamente pelas terminações nervosas simpáticas, onde os efeitos cardíacos da norepinefrina liberada de forma neural, são mediados, em grande parte, por um sistema de segundos mensageiros relativamente lento. Consequentemente, a atividade simpática altera a frequência cardíaca e a condução do nodo atrioventricular (AV). Embora a atividade vagal possa exercer controle batimento a batimento da função cardíaca, a atividade simpática não é capaz de regular a função cardíaca batimento a batimento (30).

Os neurônios simpáticos pré-ganglionares estão localizados nos segmentos torácicos e lombares superiores da medula, onde inervam a base do coração distribuídas para as várias câmaras com um extenso plexo epicárdico dentro do miocárdio. O início da resposta cardíaca à estimulação simpática começa de modo lento, já que as fibras pós-ganglionares liberam o neurotransmissor 
norepinefrina lentamente pelas terminações nervosas simpáticas, onde os efeitos cardíacos da norepinefrina liberada de forma neural, são mediados, em grande parte, por um sistema de segundos mensageiros relativamente lento. Consequentemente, a atividade simpática altera a frequência cardíaca e a condução do nodo AV. Embora a atividade vagal possa exercer controle batimento a batimento da função cardíaca, a atividade simpática não é capaz de regular a função cardíaca batimento a batimento (30).

Além da regulação do sistema nervoso central, os reflexos periféricos são sistemas de "feedback" (retroalimentação) que são capazes de detectar alterações nos níveis pressóricos na condição metabólica, no volume sanguíneo e na atividade muscular do organismo atuando para corrigir essas alterações. São esses reflexos periféricos, o barorreflexo arterial e os reflexos decorrentes das contrações musculares esqueléticas, o chamado "muscle pressor reflex", ou seja, o metaboreflexo e mecanorreflexo (32).

As fibras aferentes a partir de músculo esquelético subdividem-se em quatro grupos (I a IV) com base na sua anatomia e características eletrofisiológicas. As fibras nervosas dos grupos III e IV são pensadas para serem excitáveis por estimulação mecânica e química (35). O mecanorreflexo estimulado pelas fibras nervosas do grupo III, atuam principalmente como mecanorreceptores, e o metaborreflexo estimulado pelas fibras nervosas do grupo IV atuam principalmente como metaborreceptores (11).

Os mecanorreceptores e metaborreceptores atuam estimulando o mecanismo de "muscle pressor reflex", que regula as respostas ventilatórias e hemodinâmicas no organismo $(11,36)$, ou seja, ao iniciar o trabalho mecânico, as aferências desencadeiam inputs excitatórios para o núcleo do trato solitário estimulando o centro vasomotor, com o desfecho do aumento na atividade simpática para a periferia e inputs de aferências inibitórias para o centro cardio-inibidor, com respectiva diminuição da atividade parassimpática $(37,38)$.

As terminações nervosas na parede do seio carotídeo e arco aórtico são chamados barorreceptores arteriais, onde traduzem as mudanças da pressão arterial (distensão da artéria na 
região dos barorreceptores) e fornece informações neurais no sistema nervoso central, ou seja, o controle barorreflexo é importante para o ajustes no coração e dos vasos sanguíneos, para o controle da pressão artéria, batimento a batimento (32).

Durante o aumento da pressão arterial, ocorre a distensão vascular e o aumento na atividade do nervo depressor aórtico e do nervo sinusal, com aderência no núcleo do trato solitário (NTS). O NTS estimula o núcleo dorsomotor do vago e núcleo ambíguo, como resposta do aumento da atividade vagal no coração e redução do cronotropismo. Reciprocamente, ocorre a estimulação do bulbo ventrolateral caudal, que por sua vez, inibe o bulbo ventrolateral rostral, como resposta da redução da atividade simpático no coração e a redução do inotropismo, e nos vasos sanguíneos, a redução da resistência vascular periférica (39), ocasionando a redução da pressão arterial.

Durante a queda da pressão arterial, os barorreceptores aórticos e carotídeos são menos distendidos e os neurônios do NTS deixam de estimular o núcleo dorsomotor do vago e núcleo ambíguo reduzindo a atividade vagal e aumentando a atividade nervosa simpática no coração, como consequência, observa-se o aumento do cronotropismo, inotropismo e da resistência vascular periférica, restabelecendo assim, os níveis normais de pressão arterial (39).

Durante o exercício físico, ocorre o aumento da FC e o aumento da pressão arterial. Estes aumentos podem ser explicados pela curva de função baroreflexa, onde o ponto de operação do barorreflexo é deslocado para a direita e para cima de acordo com o aumento na intensidade do esforço, e a atividade autonômica é modulada de modo que a pressão arterial e a frequência cardíaca movam para um novo ponto de operação na curva de função baroreflexa. Nesse cenário, a pressão arterial e a frequência cardíaca aumentam simultaneamente (32).

Assim, o eixo que norteia está pesquisa, foi focado na avaliação da capacidade homeostática da modulação nervosa sobre o aparelho cardiovascular (regulação em curto prazo), englobando os componentes autonômicos, parassimpático e simpático, que compõem a FAC. 


\subsubsection{AVALIAÇÃO CLÍNICA DA FUNÇÃO AUTONÔMICA CARDÍACA DE REPOUSO}

Dados históricos, relatam que os primeiros seres humanos observaram que o coração batia de forma diferente, aumentando durante o esforço físico ou durante a excitação sexual. Entretanto, a primeira descrição da FC (medidos pelo pulso), foi encontrada em escritos fragmentários do antigo médico grego e cientista Herophilos (335 - 280 a.C.) (40).

No ano de 170 d.C., o médico/cientista Galeno escreveu 18 livros sobre o pulso, no qual, alguns destes livros descreviam a utilização do pulso como forma de diagnóstico e o prognóstico de doenças. Ainda nestes livros, Galeno explica que o pulso pode ser alterado por diversas causas, como o banho ou sono e observou que o exercício realizado com moderação torna o pulso vigoroso, grande, rápido e frequente $(40,41)$.

Com o desenvolvimento do conhecimento sobre o pulso, em 1895, Enthoven desenvolveu o eletrocardiógrafo, possibilitando o surgimento de técnicas de processamento digital de sinais. Assim, na década de 1960 as investigações da VFC e sua relação com a saúde e a doença começou a expandir. A relevância clínica da VFC foi observada pela primeira vez em 1965, quando pesquisadores observaram que o sofrimento fetal era precedido por alterações nos intervalos entre as batidas antes de qualquer alteração no próprio ritmo cardíaco $(21,40)$.

Durante a década de 1970, diversos pesquisadores realizaram testes simples, observando as diferenças do iRR de curto prazo afim de detectar neuropatia autonômica em pacientes diabéticos e a associação entre aumento do risco de mortalidade após infarto com a redução da VFC. Desde que estes estudos pioneiros foram desenvolvidos, o interesse no campo da VFC cresceu rapidamente com a utilização das técnicas do domínio temporal e espectral para quantificar a VFC. Recentemente, técnicas derivadas da nova ciência do "caos" são utilizadas na avaliação das características não lineares da VFC $(21,40)$.

Diversos estudos experimentais e clínicos demonstraram que certas medidas da FAC, na patogênese de doenças cardiovasculares, estão associadas com um prognóstico desfavorável. Em 
particular, uma sustentada atividade simpática e/ou redução da atividade vagal cardíaca, pode apresentar uma condição de surgimentos de arritmias ventriculares malignas e morte súbita. O envelhecimento precoce e diversas patologias podem caracterizar um quadro de desequilíbrio autonômico. Assim, o desequilíbrio autonômico pode ser uma via comum para o aumento da morbidade e mortalidade por uma série de condições e doenças, incluindo a doença cardiovascular $(21,22,24-26,42)$.

Esta ligação entre o sistema nervoso autônomo e morte súbita, tem estimulado a avaliação da FAC por meio da VFC como um método potencial para a identificação de pacientes com alto risco de morte súbita e risco cardiovascular. Embora a FAC possa ser susceptível na importância da morte súbita cardíaca, ela continua a ser difícil de medir ou quantificar. Apesar de uma relação simples entre um marcador fisiológico e a atividade autonômica ser bastante atraente, o sistema nervoso autonômico é extremamente complexo, dificultando assim, elucidar essa relação tão simples (42).

Assim, diante do seu potencial de exploração e por ser um método não-invasivo, o uso da análise da VFC é amplamente usado nas pesquisas e análises diversas com gravações de curto prazo dos iRR (5 a 15 minutos), realizadas sob condições controladas, por exemplo, na mudança postural (da posição supina para a ortostática), Tilt teste ou em resposta a intervenções terapêuticas como o exercício físico, sendo dessa forma capaz de elucidar respostas fisiológicas e/ ou alterações patológicas em função do sistema nervoso autônomo $(21,43)$.

Uma série de técnicas foram desenvolvidas para quantificar VFC a partir de um registro dos iRR em um período de tempo, a fim de fornecer índices de regulação autonômica cardíaca na saúde e na doença. A indicação gráfica dos valores obtidos do registro dos iRR em função do tempo é caracterizado por um periodograma. Esses registros podem ser obtidos em curta duração (até cerca de 5 minutos), ou em longa duração (24 horas). Os registros de curta duração são normalmente de 2 minutos, 5 minutos ou equivalentes a 256 iRR. Entretanto, visando a padronização metodológica e para evitar possíveis prejuízos de registros muito curtos, recomenda-se que os registros de curto prazo tenham pelo menos 5 minutos de duração (21). 
A plotagem de Poincaré é um método geométrico no qual cada iRR é plotado contra o iRR prévio formando um diagrama (de dispersão), que não necessita de sinal estacionário (44). A forma da plotagem de Poincaré pode ser usada para a extração dos dados, onde a análise computadorizada implica na montagem de uma elipse, com centro coincidindo com o ponto central das marcações. O eixo 2 mostra a inclinação do eixo longitudinal, ao passo que, o eixo 1 define a inclinação transversal, que é perpendicular ao eixo 2. A plotagem de Poincaré é ligada pela primeira vez a $45^{\circ}$ no sentido horário, e o desvio padrão dos dados da plotagem é então calculado em torno do eixo horizontal (eixo 2), que passa através do centro de dados. O marcador desvio vertical (SD1) mostra a variabilidade instantânea batimento a batimento dos dados e o desvio padrão do iRR a longo prazo contínuo é quantificada por transformar a plotagem $45^{\circ}$ no sentido anti-horário (SD2), pelo cálculo dos pontos de dados em torno do eixo horizontal (eixo 1), que passa através do centro de dados (44).

Os índices retirados desta plotagem de dados são a variável desvio vertical (SD1), que expressa a modulação vagal amostral, a variável desvio horizontal (SD2), expressa o grau de modulação global e a razão entre desvio vertical pelo horizontal (SD1/SD2), expressa o balanço da função autonômica cardíaca durante o período de análise da VFC.

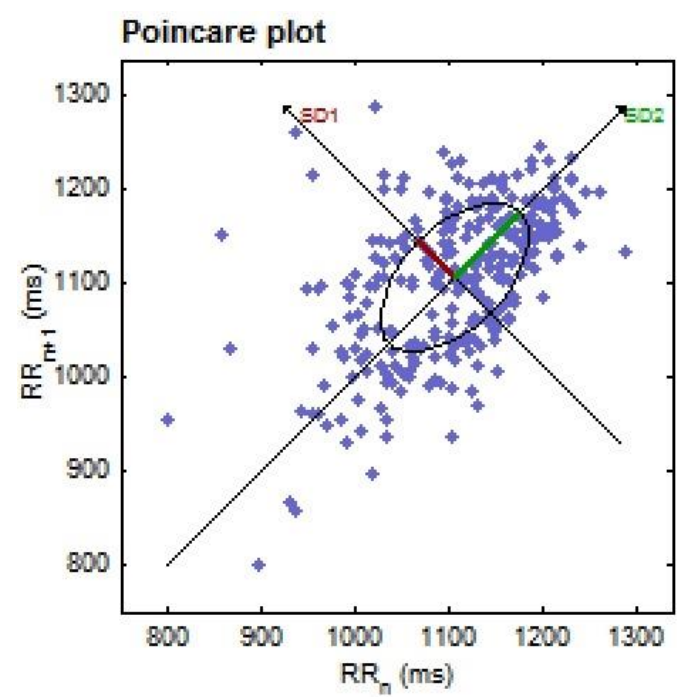

FIGURA 01 - Representação da plotagem de Poincaré. Dados obtidos a partir do registro de um voluntário do presente estudo.

Outra possibilidade de processar os iRR é no domínio do tempo a partir do método estatístico. A análise temporal da VFC baseia-se em índices estatísticos comuns de séries de iRR registrados 
continuamente em um determinado período de tempo. São exemplos de índices temporais comumente utilizados em registros de curta duração a média da duração dos iRR em um determinado período de tempo (Média) em milissegundos (ms), desvio padrão dos iRR normais (DP), o coeficiente de variação $(\mathrm{CV})$, a porcentagem de $\mathrm{iRR}$ com duração superior à 50 milissegundos (pNN50) e a raiz quadrada da média do quadrado das diferenças entre o iRR normais adjacentes (rMSSD). Os três primeiros índices (média, SD e CV do iRR) traduzem a modulação autonômica simpatovagal global e os dois últimos índices (pNN50 e rMSSD) a modulação vagal (21, 43).

Conforme pesquisas anteriores publicadas por nosso grupo, a análise ideal do domínio espectral, dever ser realizada com os segmentos submetidos a filtragem com janelas de Hanning e processada pela modelagem autorregressiva de ordem fixa que corresponde a 16, para a conversão dos componentes de sinal de oscilação em espectro de potência (45).

A análise do domínio espectral é expressa por suas amplitudes (power) e por suas frequências, dentro de escalas do espectro de potências. Os estudos da FAC no domínio espectral têm definido três faixas de atividade principais, faixa de muito baixa frequência $(0,003$ a $0,004 \mathrm{~Hz})$, faixa de baixa frequência $(0,004$ a $0,15 \mathrm{~Hz})$ e faixa alta frequência $(0,15$ a $0,4 \mathrm{~Hz})$. A partir dessas faixas de frequência os índices de potência total (área sob a curva em uma frequência de até 0,4 Hz), razão baixa frequência / alta frequência (BF/AF), baixa frequência (BF) em unidades normalizadas (BFun: BF/AT x 100) e a alta frequência (AF) em unidades normalizadas (AFun: AF/AT x 100), relacionadas ao componente simpático e parassimpático. Contudo ainda existem controvérsias na literatura, principalmente em relação a algumas bandas ou faixas específicas $(21,43,46)$.

A área total expressa a FAC global combinada simpática e parassimpática, a razão BF/AF representa o balanço relativo simpatovagal, baixa frequência (BF) em unidades normalizadas expressa a modulação simpatovagal combinada e a alta frequência em unidades normalizadas expressa a modulação predominante vagal $(21,43)$. 

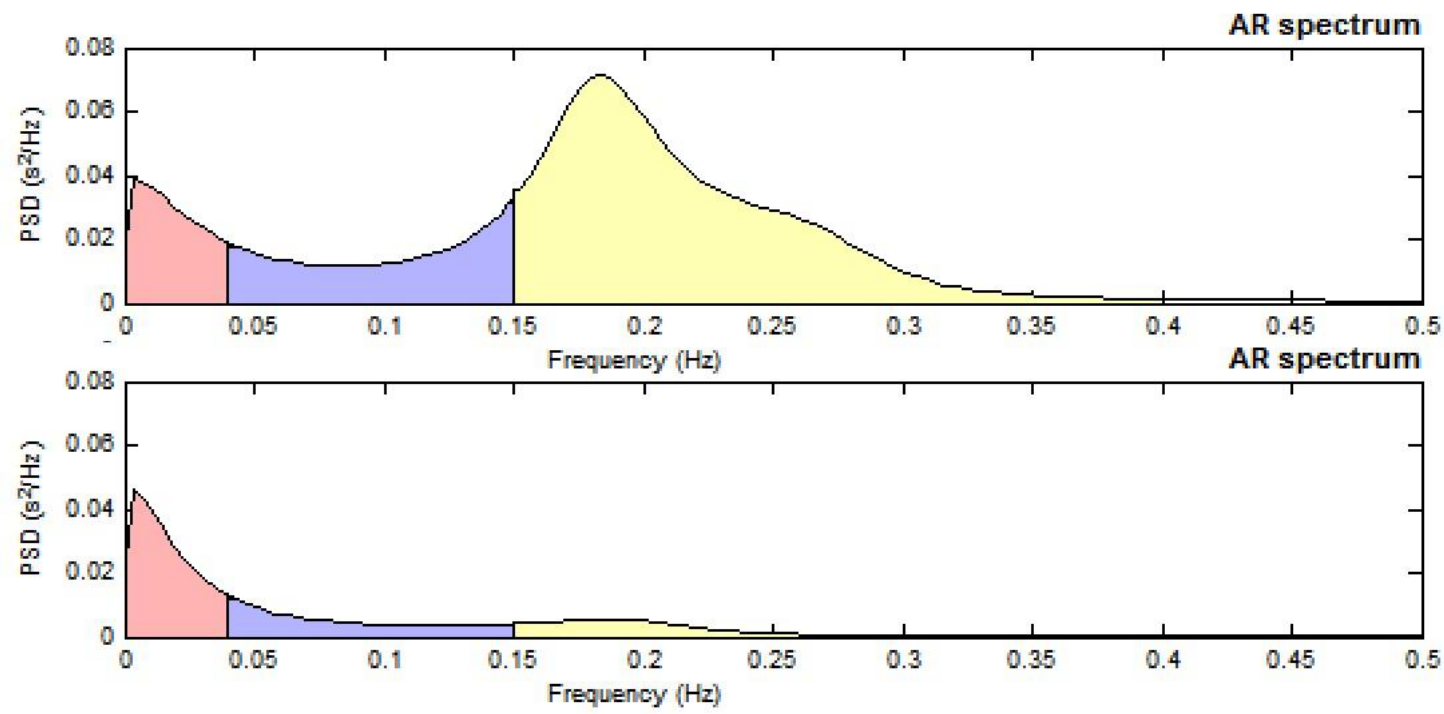

FIGURA 02 - Representação gráfica das amplitudes e suas frequências, dentro de escalas do espectro de potências (análise espectral), com a representação de muito baixa frequência na cor rosa, baixa frequência na cor roxa e alta frequência na cor amarela. Dados obtidos a partir do registro de um dos voluntários do presente estudo. Acima os dados na posição supina e abaixo os dados na posição ortostática.

\subsubsection{AVALIAÇÃO CLÍNICA DA FUNÇÃO AUTONÔMICA CARDÍACA APÓS O ESFORÇO}

O período de recuperação, após uma sessão de exercício, é associado com modificações no sistema nervoso autônomo cardíaco. Uma sustentada atividade simpática e/ou redução da atividade vagal cardíaca pode apresentar uma condição de surgimentos de arritmias ventriculares malignas e morte súbita (22-26).

A redução da FC, imediatamente após o exercício, é decorrente a uma interação entre a reativação da atividade vagal com uma retirada da atividade simpática (15). Assim, a FC de recuperação (FCR), após o exercício, emerge como um novo índice de prognóstico no cenário das doenças do aparelho cardiovascular e na avaliação funcional da FAC. Logo, novas investigações sobre a base fisiológica e o significado prognóstico da FAC, durante a recuperação, pode ajudar a delinear a sua relação com o risco de mortalidade e morte súbita cardíaca (22).

Cole et al. (47) constataram que após o teste de esforço máximo a lenta redução da frequência cardíaca durante o primeiro minuto de recuperação, em indivíduos sem história prévia de insuficiência cardíaca, revascularização coronariana e angiografia coronariana, se tornou um poderoso preditor de mortalidade. No ano seguinte, Cole et al. (48) constataram, que após teste de 
esforço submáximo, a lenta redução da FC durante o segundo minuto de recuperação, também, foi um poderoso preditor de mortalidade.

Outros pesquisadores afim de confirmar estes achados, observaram o mesmo fenômeno apresentado por Cole et al., ou seja, constataram que a lenta queda da $\mathrm{FC}$ nos primeiros minutos de recuperação, em diversas populações com e sem problemas cardiometabólicos, apresentam um risco aumentado de mortalidade (49-52). Dessa forma, o rápido decremento da FC nos primeiros minutos após um teste de esforço é rotineiramente interpretado como um indicador de atividade parassimpática, especificamente da capacidade de reativação vagal.

Estudos recentes têm demostrado uma interação coordenada entre a reativação vagal e a retirada simpática, no qual, a reativação vagal ocorre mais rapidamente e, portanto, desempenha papel mais importante na desaceleração precoce da frequência cardíaca durante a recuperação $(14,16,17)$. Ao observar o comportamento da atividade vagal durante a recuperação da FC (mensurada com e sem atropina) foi observado que a reativação vagal ocorreu rapidamente no primeiro minuto da recuperação $(14,17)$, com aumento até o $4^{\circ}$ minuto de recuperação e a partir do $4^{\circ}$ minuto de recuperação, o estímulo da atividade vagal sobre a FC, permaneceu relativamente constante (14).

Contudo, as pesquisas supracitadas estão relacionadas com o comportamento da FAC após uma sessão de exercício aeróbio. Logo, percebe-se que existe uma necessidade de conhecimento do comportamento da FAC após uma sessão de TR.

\subsubsection{VISÃO PANORÂMICA DO TREINO RESISTIDO NA RESPOSTA CARDIOVASCULAR}

O exercício resistido, também conhecido como treinamento contra resistência, treinamento de força, treinamento com pesos ou treinamento resistido são formas utilizadas para descrever um tipo de exercício onde a contração muscular voluntária de um determinado seguimento corporal exerce uma força oposta ao movimento, geralmente exercida por um equipamento de musculação, peso livre, elástico, ou até pela própria massa corporal (53). 
Durante bem pouco tempo, apenas os exercícios aeróbios eram recomendados e utilizados visando a melhora e manutenção da saúde cardiovascular, e, os exercícios resistidos eram ignorados ou não recomendados para a manutenção e/ou melhora da saúde do sistema cardiovascular. Contudo, nas últimas décadas cresceu o interesse da comunidade científica acerca dos efeitos agudos e crônicos do exercício resistido no sistema cardiovascular.

Assim, o exercício resistido é capaz de induzir uma melhora do desempenho físico com aumento da força muscular e potência muscular, ganhos de hipertrofia muscular, melhora na resistência muscular localizada, melhora no desempenho motor, melhora no equilíbrio e melhora na coordenação. E, apresenta também, melhora na função cardiovascular, reduz os fatores de risco associados com a doença cardíaca coronária, diabetes, previne a osteoporose, reduz o risco de câncer do cólon, promove a perda e manutenção da massa corporal, melhora a estabilidade dinâmica, preserva a capacidade funcional e promove o bem-estar psicológico (6), e é seguramente recomendado em diversas populações com e sem risco cardiovascular $(1,54)$.

Também, entre os estudos que correlacionaram a força com a mortalidade, foi observado que obter uma baixa força, avaliada pelo teste de preensão manual, teste de sentar e levantar e/ou teste de uma repetição máxima (RM), apresenta um aumento no risco de mortalidade (55-58). Desta forma, os altos níveis de força muscular, obtidos nestes testes, reduzem os fatores de risco cardiovascular (59-61) e cardiometabólicos (62-64), diabetes $(65)$, câncer $(60,66,67)$ e hipertensão arterial sistêmica $(68,69)$.

Para que as adaptação crônicas ao treinamento resistido possam ocorrer, há a necessidade da manipulação das variáveis durante uma sessão de TR. Assim, as variáveis agudas, originalmente definidas por Kraemer em 1983 (70) como a carga, escolha dos exercícios, ordem dos exercícios, número de séries, número de repetições e intervalo de recuperação podem determinar a magnitude da resposta a uma sessão de TR. Outras variáveis como o tempo sob tensão, a falha muscular voluntária, velocidade de execução e volume (número de repetições $\times$ número de séries $\times$ carga) também podem ser modificadas afim de determinar as respostas de uma sessão de TR $(6,7)$. 
Durante uma sessão de treino aeróbio as respostas cardiovasculares apresentam um comportamento diferente da sessão de TR. Durante uma sessão de treino aeróbio ocorre o aumento no consumo de oxigênio ( $\dot{\mathrm{V}}_{2}$ ), débito cardíaco e FC em paralelo com o aumento da intensidade do exercício, bem como, um aumento inicial seguido de um platô do volume sistólico. Ocorre também, um aumento progressivo na pressão arterial sistólica (PAS), com manutenção ou uma ligeira redução da pressão arterial diastólica (PAD), o que resulta em um aumento concomitante da pressão de pulso e um aumento modesto na pressão arterial média, com um decréscimo na resistência vascular periférica. Assim, o exercício aeróbico impõe uma sobrecarga de volume no sistema cardiovascular (54).

Durante uma sessão de TR, ocorre o aumento da FC, PAS e PAD, resultando em um aumento moderado do débito cardíaco, com pouco aumento no consumo de oxigênio. Apesar do aumento do débito cardíaco, o fluxo sanguíneo para os músculos inativos não aumenta de forma expressiva, provavelmente por causa da vasoconstrição reflexa. Assim, a pressão intramuscular excede a pressão intravascular durante a contração muscular reduzindo o fluxo sanguíneo localizado, ocasionando isquemia e hipóxia muscular localizada. A combinação da vasoconstrição e o aumento do débito cardíaco resulta em um aumento desproporcional da PAS, PAD e pressão arterial média, e, aumento da resistência vascular periférica. Essas pressões continuam a subir durante toda a duração do exercício. Assim, o exercício resistido impõe uma sobrecarga de pressão sobre o sistema cardiovascular, afim de aumentar a perfusão para o músculos ativos (54).

Um dos primeiros estudos a mostrar este comportamento durante uma sessão de TR, foi o estudo de McDougal et. al. (71) Eles verificaram que a medida que as repetições eram realizadas ao longo de uma série de 10RM no exercício de leg press, a FC, PAS e PAD aumentaram até atingir os valores mais altos próximos das últimas repetições máximas. Outras pesquisas com o enfoque no comportamento da pressão arterial e FC na avaliação da sobrecarga cardíaca observaram semelhante comportamento (72-74), ou seja, observaram aumento da PAS, PAD e FC durante a execução de uma 
série de TR, e redução da FC logo após o termino da série. Contudo, nenhum destes trabalhos teve como enfoque a avaliação da regulação da FAC, durante e após uma sessão de TR.

Um dos primeiros artigos com ênfase na regulação da FAC no TR foi realizado por Heffernan et. al. (20) que avaliaram o comportamento da FAC, por meio da VFC, após uma sessão de TR em adultos ativos que realizaram três séries de 10RM em oito exercícios para membros superiores e inferiores comparativamente a uma sessão de treino aeróbio realizado no cicloergômetro na intensidade de $65 \%$ do consumo de oxigênio máximo. Foi observado que após 30 minutos de recuperação em comparação a condição repouso foi insuficiente para a FC (+24\%) e a atividade vagal (-27\%) retornarem próxima aos níveis basais após uma sessão TR, com maior magnitude na modificação da FAC após a sessão de TR comparativamente a sessão de treino aeróbio.

Kingsley et. al. (75) avaliaram tanto em mulheres sadias quanto em mulheres com fibromialgia, a resposta de uma sessão de TR composta por cinco séries de 10RM com dois minutos de intervalo de recuperação no leg press. Foi observado que, ambos os grupos apresentaram aumento do balanço simpatovagal, ao longo de 25 minutos, após uma sessão de TR.

Figueiredo et. al. (76) avaliaram, em homens treinado em exercício resistido, a resposta de uma, três ou cinco séries de 8-10RM em oito exercício de membros superiores e inferiores na FAC avaliada pela VFC, ao longo de 60 minutos, após sessão de TR. Observou-se que uma série de TR reduziu a atividade vagal por 10 minutos, e que o TR com três e cinco séries reduziu a atividade vagal por 60 minutos. Contudo, o marcador de atividade vagal utilizada neste estudo foi o desvio padrão dos iRR normais, chamado de rMSSD, ou seja, o desvio padrão dos iRR normais é um marcador de modulação global e não o marcador de atividade cardíaca vagal, assim as conclusões deste estudo estão equivocadas.

Até o presente momento, apenas 32 artigos foram publicados com vistas no comportamento da FAC durante o período de recuperação após uma sessão de TR (5, 20, 27, 76-104). Destes 32 artigos, 19 artigos com homens saudáveis (20, 27, 76, 78-83, 85-90, 92, 101, 103, 104) e 13 artigos 
com homens e mulheres, mulheres, idosos, fibromialgia, hipertensão, doença pulmonar obstrutiva crônica, doença arterial periférica, síndrome metabólica e adolescentes. (75, 77, 84, 91, 93-100, 102).

Como existe diferentes combinações entre as variáveis do treinamento resistido, há uma dificuldade na comparação entre os estudos devido a heterogeneidade das amostras, protocolos de TR, formas de análise da VFC e o tempo de monitoramento da FAC após uma sessão de TR. Assim, mais dados são necessários para o melhor entendimento dos efeitos de uma sessão de TR, com vistas no comportamento da FAC durante o período de recuperação (28).

Considerando o que foi descrito anteriormente, uma mitigada reativação vagal apresenta uma maior suscetibilidade de arritmias cardíacas malignas e risco de mortalidade aumentada, logo, percebe-se a carência de dados na literatura sobre o curso temporal da restauração da FAC, bem como a magnitude do comportamento e/ou o cenário da FAC após uma sessão de TR.

Como é o comportamento da FAC após uma sessão de TR? Ou qual será o mínimo de estímulo para causar alterações na FAC após a realização de uma sessão de TR? Uma vez que, o conhecimento relacionados a este tópico tem grande valor profissional, devido a prescrição mais adequada de TR para indivíduos saudáveis, com ou sem risco de doença cardiovascular.

$\mathrm{Na}$ literatura, existem poucos dados que relacionaram os métodos de análise da VFC no repouso com o comportamento da FAC e o decremento da FC na fase de recuperação após o teste de esforço máximo ou submáximo. Entretanto, até o presente momento, não é de nosso conhecimento a existência de qualquer estudo sobre este tema e que tenha analisado a correlação entre a FAC na condição de repouso com a FAC, avaliadas pela VFC, e a resposta cronotrópica após uma sessão de TR, com vistas à compreensão dos possíveis mecanismos fisiológicos envolvidos na regulação cardiovascular. Assim, surge a pergunta: existe correlação entre a VFC no repouso, com a VFC após uma sessão de TR? Ou, os mecanismos regulatórios da resposta cronotrópica da FC após uma sessão de TR independem da VFC de repouso? 
Destaca-se a importância desta pesquisa ora formulada no sentido de aprofundar a avaliação de mecanismos fisiológicos de repouso-recuperação, no TR, que possam contribuir na compreensão dos mecanismos de regulação cardiovascular. 


\section{OBJETIVOS}

\subsection{OBJETIVO GERAL}

Baseado na análise da variabilidade da frequência cardíaca, verificar as alterações na função autonômica cardíaca de homens adultos clinicamente normais a cada 5 minutos $(0-5,5-10$ e $10-15$ min) durante 15 minutos após uma sessão de treino resistido e comparar com a condição inicial.

\subsection{OBJETIVOS SECUNDÁRIOS}

a) Realizar a análise comparativa, da função autonômica cardíaca durante a caracterização da amostra com a função autonômica cardíaca antes da sessão de TR, por meio da variabilidade da frequência cardíaca.

b) Correlacionar os índices da variabilidade da frequência cardíaca na condição inicial, na posição supina, com os índices da variabilidade da frequência cardíaca, na posição supina, ao longo de15 minutos, após sessão de TR.

c) Correlacionar os índices da variabilidade da frequência cardíaca condição de repouso, na posição supina, com a resposta cronotrópica cardíaca, na posição supina, após 5,10 e 15 minutos de uma sessão de TR. 


\section{MATERIAIS E MÉTODOS}

\subsection{AMOSTRA ESTUDADA}

Trata-se de pesquisa pré-experimental como amostra não probabilística por conveniência. A amostra foi composta por 14 homens adultos do sexo masculino, clinicamente normais e com idade entre 19 e 40 anos. Todos os voluntários participaram da pesquisa de forma voluntária, cientes dos objetivos e métodos do estudo, no qual, cada voluntário assinou o termo de consentimento livre e esclarecido, cujo modelo encontra-se em anexo (ANEXO 1). A presente pesquisa foi aprovada pelo comitê de ética e pesquisa da Universidade de Brasília conforme parecer de CAEE: 39511114.7.0000.0030.

Todos os voluntários que apresentaram interesse em participar da pesquisa foram aceitos, desde que, estivesse dentro dos critérios de inclusão estipulados. Todos os voluntários desenvolviam normalmente suas atividades habituais normalmente. Os critérios de inclusão e/ou exclusão são de natureza variável, afim de atender as necessidades de pressupostos clínico-funcionais e metodológicos na análise da VFC. Na FIGURA 04, estão descritos os critérios de exclusão que não atendem aos critérios de inclusão apresentado na FIGURA 03. O voluntário que apresenta -se uma ou mais características, que sabidamente possa afetar o prosseguimento dos procedimentos experimentais e da análise dos registros, era excluído da amostra.

\begin{tabular}{|l|l|}
\hline Critérios & Limite \\
\hline Idade & Entre 18 e 40 anos \\
\hline Gênero & Masculino \\
\hline Fumante & Não \\
\hline Índice de massa corporal (IMC) & $\geq 18,5 \mathrm{~kg} / \mathrm{m}^{2} \mathrm{e} \leq 29,9 \mathrm{~kg} / \mathrm{m}^{2}$ \\
\hline Atividade Física & Ativos fisicamente (não atletas) pelo menos 150 minutos/semanais \\
\hline Exercício Físico & Não realizar treinamento resistido nos últimos 3 meses \\
\hline
\end{tabular}

FIGURA 03 - Critérios de inclusão dos voluntários na amostra. 


\begin{tabular}{|l|l|}
\hline Critérios & Limite \\
\hline Ritmo Cardíaco & Não apresentar ritmo sinusal ao longo de todos os registros do ECG \\
\hline Frequência Respiratória & $<9$ incursões respiratórias por minuto \\
\hline Consumo Máximo de Oxigênio & $\leq 51,2 \mathrm{~mL}(\mathrm{~kg} \cdot \mathrm{min})^{-1}$ \\
\hline Estado Emocional & Alterado, de acordo relato do voluntário durante a anamnese \\
\hline Treino resistido & Não realizar entre 8-12 RM \\
\hline
\end{tabular}

FIGURA 04 - Critérios de exclusão dos voluntários na amostra.

Como o grau de obesidade pode influenciar a análise da FAC (105), dois voluntários foram excluídos, por apresentaram um índice de massa corpórea $>29,9 \mathrm{~kg} / \mathrm{m}^{2}$. E, para a análise e interpretação correta da VFC, é necessário que o ritmo cardíaco seja derivado do nodo sinusal, ou seja, todos os voluntários deveriam apresentar ritmo sinusal ao longo do traçado eletrocardiográfico, na condição de repouso. Apenas um voluntário foi excluído da amostra por apresentar ritmo do seio coronário.

A amostra foi composta por $64,3 \%$ de estudantes universitários e $35,7 \%$ por profissionais de diversas áreas do mercado de trabalho. Todas as características amostrais e variáveis funcionais na condição de repouso, estão descritas na Tabela 01.

Os voluntários responderam a anamnese previamente a todos os testes realizados, sendo constituída por dados pessoais e profissional, histórico clinico pessoal, e questões sobre: as limitações músculo-esqueléticas e articulares, o uso regular de medicamentos e /ou suplementos alimentares, histórico da condição física, histórico familiar, hábitos de vida como consumo de bebidas alcoólicas, tabagismo, nível de estresse mental e/ ou físico, qualidade e quantidade de sono e bebidas estimulantes (chá, café, refrigerantes, guaraná em pó, energéticos, achocolatados). Todos os voluntários atenderam aos critérios de inclusão e não apresentaram alguma contra-indicação à realização do protocolo experimental utilizado nesta pesquisa.

A caracterização da amostra foi iniciada com assinatura do Termo de Consentimento Livre e Esclarecimento, como instrumento de verificação da participação livre e esclarecida do voluntário 
na pesquisa, e a anamnese. Na sequência, foram medidas a massa corporal utilizando a balança digital (Welmy-W110H, São Paulo, Brasil) e estatura, utilizando estadiômetro (descalços e sem blusa), o valor mediano (quartis) da massa corporal e estatura foram 77,4 $(75,8-78,8) \mathrm{kg}$ e 177,0 $(173,0-180,0) \mathrm{cm}$, respectivamente.

$\mathrm{Na}$ sequência, os voluntários adotavam a posição supina e foram submetidos ao eletrocardiograma (ECG) de repouso, com objetivo de identificar a normalidade clínica em todos os voluntários estudados. Caso o voluntário não apresentar ritmo sinusal normal, o mesmo era excluído da pesquisa. Todos os voluntários apresentaram arritmia sinusal respiratória. As características eletrocardiográficas estão listadas na Tabela 2.

A interpretação clínica do ECG de repouso de 12 derivações, foi realizada pelo Professor Dr. Luiz Fernando Junqueira Jr - Professor Titular e cardiologista chefe do Serviço de Cardiologia da Faculdade de Medicina da Universidade de Brasília, com larga experiência clínico-cardiológica.

A amostra foi constituída por $14(\mathrm{n}=14)$ homens adultos, com idade mediana (quartis) 22,5 (20,2 - 25,7) anos. Como o grau de obesidade pode influenciar a FAC (105), foi utilizado uma faixa de normalidade do IMC como critério de inclusão: 18,5 $<$ IMC $<29,9 \mathrm{~kg} / \mathrm{m}^{2}$. O valor mediano (quartis) de IMC obtido na amostra foi $24,9(23,9-25,1) \mathrm{kg} / \mathrm{m}^{2}$.

Durante a condição de repouso, na posição supina e ortostática (ambas posições empregadas no teste de FAC), a caracterização da FC, pressão arterial (PA) e frequência respiratória (FR) foram avaliadas, conforme rotina do laboratório (45). Em cada situação, foi considerado os valores registrados após o primeiro minuto de coleta.

Foi observado o valor mediano (extremos) de FC 58,5 (51 - 70) bpm, PAS 115 (98 - 134) mmHg, PAD foi de 70 (58 - 80) mmHg e FR 14,5 (9 - 20) irpm, na posição supina. Com a mudança de decúbito, posição ortostática, observou-se valor mediano (extremos) de FC 76,5 (62 - 92) bpm, PAS 111 (92 - 136) mmHg, PAD 80 (60 - 90) mmHg e FR 15,5 (9 - 23) irpm.

Todos os valores de FC, PAS, PAD e FR na condição de supino estavam dentro da faixa de normalidade $(106,107)$. Os valores amostrais de FC, FR e PA estão indicados na Tabela 01. 
Sabe -se que os fatores psicossociais, tais como eventos de stress de vida, podem alteram a FAC (105). Desta forma, foi motivo de exclusão do voluntário, caso o mesmo relata -se estar passando por alguma circunstância atípica em sua vida ou estar em um momento de estado emocional alterado. O critério adotado foi quando o voluntário relatava que aquele momento era diferente do seu estado emocional habitual, ou quando relatava fatos considerados perturbadores do equilíbrio psicológico normal, como eventos de estresse atípico em seu ambiente de trabalho, semana de provas, problemas conjugais e etc. Nenhum voluntários necessitou remarcar os testes por manifestar estado emocional alterado.

TABELA 01 - Características antropométricas e funcionais na condição de repouso $(\mathrm{n}=14)$.

\begin{tabular}{|c|c|c|c|c|c|c|c|c|c|c|c|c|}
\hline \multirow[t]{2}{*}{ Voluntário } & \multirow{2}{*}{$\begin{array}{l}\text { Idade } \\
\text { (anos) }\end{array}$} & \multirow{2}{*}{$\begin{array}{l}\mathrm{MC} \\
(\mathrm{kg})\end{array}$} & \multirow{2}{*}{$\begin{array}{c}\text { Estatura } \\
\qquad(\mathrm{cm})\end{array}$} & \multirow{2}{*}{$\begin{array}{c}\text { IMC } \\
\left(\mathrm{kg} / \mathrm{m}^{2}\right)\end{array}$} & \multicolumn{2}{|c|}{$\begin{array}{c}\mathrm{FC} \\
(\mathrm{bpm})\end{array}$} & \multicolumn{2}{|c|}{$\begin{array}{c}\text { FR } \\
\text { (irpm) }\end{array}$} & \multicolumn{2}{|c|}{$\begin{array}{c}\text { PAS } \\
(\mathrm{mmHg})\end{array}$} & \multicolumn{2}{|c|}{$\begin{array}{c}\text { PAS } \\
(\mathrm{mmHg})\end{array}$} \\
\hline & & & & & SUP & ORT & SUP & ORT & SUP & ORT & SUP & ORT \\
\hline 1 & 20 & 73,4 & 171,0 & 25,1 & 55 & 82 & 14 & 13 & 102 & 90 & 60 & 70 \\
\hline 2 & 19 & 69,4 & 173,0 & 23,1 & 47 & 65 & 12 & 15 & 100 & 98 & 74 & 80 \\
\hline 3 & 26 & 75,1 & 173,0 & 25,1 & 55 & 72 & 20 & 17 & 102 & 100 & 62 & 72 \\
\hline 4 & 19 & 784 & 183,0 & 23,4 & 57 & 96 & 22 & 22 & 126 & 132 & 58 & 82 \\
\hline 5 & 30 & 80,5 & 180,0 & 24,8 & 55 & 66 & 17 & 18 & 110 & 114 & 70 & 90 \\
\hline 6 & 40 & 78,7 & 177,0 & 25,1 & 65 & 79 & 12 & 13 & 110 & 108 & 70 & 78 \\
\hline 7 & 22 & 83,2 & 167,0 & 29,7 & 73 & 88 & 15 & 20 & 102 & 100 & 60 & 70 \\
\hline 8 & 24 & 75,7 & 187,0 & 21,6 & 63 & 92 & 13 & 11 & 112 & 108 & 64 & 80 \\
\hline 9 & 20 & 76,7 & 177,0 & 24,5 & 65 & 89 & 14 & 16 & 106 & 106 & 60 & 82 \\
\hline 10 & 27 & 90,8 & 185,0 & 26,5 & 58 & 85 & 18 & 17 & 118 & 124 & 60 & 78 \\
\hline 11 & 21 & 78,2 & 178,0 & 24,8 & 53 & 85 & 15 & 14 & 128 & 118 & 60 & 76 \\
\hline 12 & 25 & 76,8 & 180,0 & 23,7 & 67 & 94 & 15 & 16 & 104 & 104 & 62 & 74 \\
\hline 13 & 21 & 76,4 & 171,0 & 26,1 & 77 & 97 & 11 & 11 & 106 & 98 & 62 & 60 \\
\hline 14 & 23 & 79,0 & 177,0 & 25,2 & 43 & 70 & 14 & 13 & 112 & 108 & 62 & 86 \\
\hline
\end{tabular}


TABELA 02 - Características eletrocardiográficas individuais obtidas durante o repouso na posição supina $(\mathrm{n}=14)$.

\begin{tabular}{|c|c|c|}
\hline INDIVÍDUO & $\mathrm{FC}(\mathrm{bpm})$ & CARACTERÍSTICAS ELETROCARDIOGRÁFICAS \\
\hline 1 & $52-61$ & Eixo QRS cerca de $+70^{\circ}$; Repolarização precoce \\
\hline 2 & $49-55$ & Eixo QRS cerca de $+60^{\circ}$ \\
\hline 3 & $53-55$ & $\begin{array}{l}\text { Arrtimia sinusal respiratória discreta; Eixo QRS cerca de }-60^{\circ} \text { (desviado para esquerda, sugestivo } \\
\text { de M bloqueio anterior esquerdo) }\end{array}$ \\
\hline 4 & $59-61$ & $\begin{array}{l}\text { Eixo QRS cerca de }+10^{\circ} \text {; Retardo inespecífico da condução intraventricular; Onda T bifásica de } \\
\mathrm{T}_{1}-\mathrm{T}_{3}\end{array}$ \\
\hline 5 & $47-57$ & Eixo QRS cerca de $+90^{\circ}$; Retardo Fisiológico da condução pelo ramo direito \\
\hline 6 & $62-65$ & Eixo QRS cerca de $+70^{\circ}$; Retardo Fisiológico da condução pelo ramo direito \\
\hline 7 & $65-82$ & Eixo QRS cerca de $+70^{\circ}$ \\
\hline 8 & $60-63$ & Eixo QRS cerca de $+70^{\circ}$; Repolarização precoce \\
\hline 9 & $58-60$ & Eixo QRS cerca de $+70^{\circ}$ \\
\hline 10 & $51-53$ & $\begin{array}{l}\text { Eixo QRS cerca de }+45^{\circ} \text {; Retardo Fisiológico da condução pelo ramo direito; Repolarização } \\
\text { precoce }\end{array}$ \\
\hline 11 & $59-62$ & Eixo QRS cerca de $+45^{\circ}$; Intervalo PR curto \\
\hline 12 & $57-62$ & Eixo QRS cerca de $+90^{\circ}$; Repolarização precoce \\
\hline 13 & $64-66$ & Eixo QRS cerca de $+90^{\circ}$ \\
\hline 14 & $48-54$ & Eixo QRS cerca de $+60^{\circ}$; Retardo Fisiológico da condução pelo ramo direito \\
\hline
\end{tabular}

\subsection{ASPECTOS METODOLÓGICOS GERAIS}

Todos os voluntários compareceram três vezes ao laboratório com 48 horas de intervalo entre cada visita. Todos os voluntários foram orientados a realizar uma refeição "leve”, no mínimo de uma hora antes do início dos testes. Também, foram orientados a não realizar atividade física e/ou exercício físico, não consumir bebidas alcoólicas por 24 horas e não consumir qualquer bebida estimulante por no mínimo 12 horas antes dos testes. Todos os voluntários foram orientados a ter um período de sono de pelo menos seis horas, na noite anterior aos testes.

A primeira visita ao laboratório consistia na realização da anamnese, das medidas antropométricas, do ECG de repouso, aquisição das variáveis hemodinâmicas de repouso (FC, FR e PA), aplicação do teste da FAC na condição de repouso ( $\mathrm{FAC}_{\text {repouso }}$ ) para caracterização da amostra, teste de esforço cardiopulmonar máximo e familiarização com o exercício de leg press.

Após 48 horas, na segunda visita, foi realizado o teste de força máxima de membros inferiores e ajuste da sobrecarga no exercício de leg press, para realização da sessão de TR. 
Seguidas mais 48 horas, terceira visita, foram realizados a aquisição das variáveis hemodinâmicas de repouso (FC, FR e PA), o teste de FAC na condição de repouso (FAC inicial $_{\text {) }}$ anterior à sessão de TR, sessão de treino resistido e teste de FAC, ao longo de 15 minutos, imediatamente após a sessão de TR.

A avaliação antropométrica, ECG de repouso com o registro de 12 derivações mais o traçado longo da derivação DII, o teste de FAC para caracterização da amostra e o anterior à sessão de TR, e o teste de esforço cardiopulmonar máximo, foram realizados no Laboratórios de Fisiologia do Exercício da Faculdade de Educação Física da Universidade de Brasília - UnB.

A avaliação de força máxima de membros inferiores, foi realizado no Laboratório de Treinamento de Força da Faculdade de Educação Física - UnB. E, a familiarização do exercício de leg press, sessão de TR e o teste de FAC, ao longo de 15 minutos, após a sessão de TR, foram realizados no Laboratório de Musculação da Faculdade de Educação Física da Universidade de Brasília - UnB.

Todos os testes foram realizados no período da manhã, entre sete e nove horas, e cada visita ao laboratório teve duração de 60 minutos. O ECG de repouso, o teste de FAC de repouso (para caracterização da amostra) o teste de FAC inicial (anterior à sessão de TR) e o teste de esforço cardiopulmonar máximo foram realizados em um ambiente climatizado $\left(21\right.$ a $\left.24^{\circ} \mathrm{C}\right)$, e todos os testes foram realizados em ambiente sem interferência de sons e/ou ruídos externos.

Todos os testes foram realizados por um único observador - o autor desse estudo. O posterior processamento dos dados, bem como sua análise, foi supervisionado pelos professores Dra. Keila Elizabeth Fontana e Dr. Guilherme Eckhardt Molina, orientadora e co-orientador do trabalho, com larga experiência nesta atividade. E, a interpretação clínica do ECG de repouso, foi realizado pelo Professor Dr. Luiz Fernando Junqueira Jr.

O ECG e os testes de FAC foram realizados em uma maca acolchoada, e os voluntários foram orientados a se manterem o mais relaxado possível, sem dormir, evitando alterações conscientes no 
ritmo respiratório (inspirações e/ou expirações profundas) e não conversar (exceção à situação em que eventualmente estivessem se sentindo mal por algum motivo).

Antes de iniciar o procedimento do teste cardiopulmonar máximo, os voluntários recebiam orientações prévias sobre o protocolo a ser realizado. Os voluntários foram orientados quanto ao tempo total de esforço (entre 8 e 12 minutos), e que durante os procedimentos (repouso, esforço e recuperação) a comunicação seria por meio de sinais (previamente combinados), por meio da escala subjetiva de esforço (BORG) e só falar em caso de estar se sentindo mal por qualquer motivo.

Antes de iniciar a familiarização no exercício de leg press, na primeira e segunda visita, os voluntários recebiam orientações prévias sobre o protocolo seguintes. Os voluntários foram orientados quanto a execução do movimento e quanto ao protocolo a ser realizado (número de séries, repetições e intervalo de recuperação). Nenhum voluntário foi informado sobre a carga utilizada no exercício de leg press, afim de evitar influência psicológica, entretanto, todos receberam reforço verbal de encorajamento.

Antes de iniciar o procedimento de avaliação de força máxima de membros inferiores, os voluntários foram orientados quanto ao protocolo (uma série 12 repetições para aquecimento e duas séries de quatro repetições máximas), e todos os voluntários receberam reforço verbal de encorajamento para realizar o máximo de força.

Na sessão de TR, antes de iniciar do experimento, os voluntários foram orientados quanto ao protocolo (uma série de aquecimento de 12 repetições com $20 \mathrm{~kg}$ e três séries de 8-12RM com um minuto de intervalo de recuperação entre as séries), sem ser informado sobre a carga utilizada no exercício de leg press. Durante o procedimento de recuperação (após a última repetição da última série) o voluntário deslocava-se do leg press para a maca e permanecia na posição supina por 15 minutos. Durante o procedimento de recuperação, a comunicação foi por meio de sinais (previamente combinados) e falava somente caso estivesse sentindo-se mal por qualquer motivo.

A FAC foi analisada por meio da VFC com base no registro dos iRR, em séries temporais de curto prazo de cinco minutos $(21,108)$. O registro dos $\mathrm{iRR}$ e da FC, na condição de repouso e 
recuperação, foram obtidas por meio do frequencímetro de telemetria da marca Polar® Electro Oy Finlândia, modelo RS800CX. A escolha deste frequencímetro para o registro das séries temporais de curto prazo, se deu em razão de se tratar de um instrumento validado $(109,110)$ para este fim, além de sua facilidade de operação e potenciais desdobramentos para pesquisas futuras.

$\mathrm{Na}$ condição de repouso, os registros foram realizados nas posições supina e ortostática, enquanto que na recuperação, após sessão de TR, os registros foram realizados apenas na posição supina.

Após o registro dos iRR das séries temporais, foram descarregados utilizando o software Polar ProTrainer 5 for Windows para a aquisição dos iRR no formato " $t x t$ ”. O processamento digital dos dados para a obtenção dos índices de Poincaré, no domínio temporal e espectral da VFC, foi realizada por meio do software Kubios HRV-Heart Rate Variability Analysis Software (111).

Após a aquisição de todos os registros na condição repouso, com vistas na caracterização da amostra, os voluntários foram submetidos a uma sessão de TR (três series de 8-12RM com um minuto de intervalo de recuperação entre as séries). A sessão de TR teve como objetivo induzir uma sobrecarga cardiovascular. Em seguida, após a sessão de TR, iniciava-se a fase recuperação, que teve como objetivo a obtenção dos iRR e o decremento da FC ao longo de 15 minutos de recuperação.

\subsection{AVALIAÇÃO DO ELETROCARDIOGRAMA DE REPOUSO}

O registro do ECG de repouso foi realizado em um ambiente climatizado (21 a $24^{\circ} \mathrm{C}$ ), sem interferência de sons e/ou ruídos externos, com o voluntário na posição supina. Após 10 minutos de repouso, o registro do ECG de repouso era realizado com o registro de 12 derivações, mais o traçado longo da derivação DII, por meio do eletrocardiógrafo digital (Wincardio Micromed), com duração de cinco minutos.

A interpretação clínica do ECG de repouso, foi realizada pelo Professor Dr. Luiz Fernando Junqueira Jr - Professor Titular e cardiologista chefe do Serviço de Cardiologia da Faculdade de Medicina da Universidade de Brasília, com larga experiência clínico-cardiológica. 


\subsection{AVALIAÇÃO DAS VARIÁVEIS HEMODINÂMICAS NA CONDIÇÃO DE REPOUSO}

Durante a condição de repouso, os dados de FC, PA e FR foram coletados na posição supina e posteriormente na posição ortostática. Após o voluntário ficar em repouso por 10 minutos, foi coletado os dados de PA na posição supina, e durante o registro de cinco minutos do teste de FAC, mais precisamente no terceiro minuto, os dados de FC e FR foram coletados.

Em seguida, quando o voluntário adotava a posição ortostática foram coletados no primeiro minuto os dados da PA. Durante o registro de cinco minutos do teste de FAC, no terceiro minuto foram coletados os dados de FC e FR para essa posição. Este procedimento foi sistematicamente realizado em todos os voluntários, para caracterização da amostra e previamente à sessão de TR. A medida da pressão arterial foi realizada por meio do esfigmomanômetro aneróide (Premium, Brasil) e a ausculta foi realizada pelo estetoscópio (Premium, Brasil), seguindo o método auscultatório de acordo com a Sociedade Brasileira de Cardiologia (107).

\subsection{CARACTERIZAÇÃO DA FUNÇÃO AUTONÔMICA CARDÍACA}

A FAC foi avaliada na condição de repouso $\left(\mathrm{FAC}_{\text {repouso }}\right)$, para caracterização da amostra e na condição de repouso (FAC $\left.\mathrm{F}_{\text {nicial }}\right)$ antes da sessão de $\mathrm{TR}$, na posição supina e na posição ortostática após mudança postural, e ao longo de 15 minutos na posição supina imediatamente após a sessão de TR. Foi realizada a comparação entre a $\mathrm{FAC}_{\text {repouso }}$ com a $\mathrm{FAC}_{\text {inicial, }}$ afim de observar uma possível influência dos testes na FAC antes da sessão de TR.

A FAC foi avaliada com base nos índices de Poincaré, no domínio temporal e espectral da VFC em séries temporais de curto prazo de cinco minutos $(21,108)$, e durante todo o período de registro de coleta, os voluntários foram orientados a evitarem movimentos bruscos e a não conversarem, salvo em algum caso de urgência.

A obtenção automática dos iRR e da FC, na condição de repouso e após sessão de TR, foi realizada por meio do frequencímetro de telemetria da marca Polar® Electro Oy - Finlândia, modelo 
RS800CX, por tratar -se de um instrumento validado $(109,110)$ para este fim, além de sua facilidade de operação e potenciais desdobramentos para pesquisas futuras.

Os registros dos iRR das séries temporais de curto prazo, na condição de repouso e após sessão de TR, foram descarregados utilizando o software Polar ProTrainer 5 for Windows para a aquisição dos iRR no formato “txt”. O processamento digital dos dados para a obtenção dos índices de Poincaré, no domínio temporal e espectral da VFC, foi realizada por meio do software Kubios HRV - Heart Rate Variability Analysis Software (111).

A VFC na condição de repouso, na posição supino e posição ortostático, foi avaliada com base nos índices de Poincaré, no domínio temporal e espectral. Durante a fase de recuperação (ao longo de 15 minutos após sessão de TR), por restrições metodológicas, a VFC foi avaliada durante os primeiros cinco minutos de recuperação, somente pelos índices de Poincaré, dada a não estacionariedade do sinal. Contudo, durante 10 e 15 minutos após sessão de TR, por apresentar estacionariedade do sinal, a VFC foi avaliada com base nos índices de Poincaré, no domínio temporal e espectral.

Todas as análises da VFC, na condição de repouso e recuperação, estão de acordo com as recomendações da Sociedade Europeia de Cardiologia e a Sociedade Norte Americana de Eletrofisiologia e Marcapasso que apontam como um método válido e não invasivo (21).

A plotagem de Poincaré é um diagrama (de dispersão) no qual cada iRR é plotado contra o iRR prévio, onde não há a necessidade de sinal estacionário, permitindo quantificar a VFC em diversas condições funcionais, como repouso, esforço e recuperação (44). A forma da plotagem de Poincaré pode ser usada para a extração dos dados, assim, foi utilizada como padrão de análise nesse estudo o desvio vertical (SD1), desvio horizontal (SD2) e a razão entre desvio vertical pelo horizontal (SD1/SD2).

A variável, desvio horizontal (SD2) expressa o grau de modulação global da VFC, o desvio vertical (SD1) expressa a modulação vagal amostral e a razão entre desvio vertical pelo horizontal (SD1/SD2) expressa o balanço da FAC durante o período de análise. 
Foram analisados, no domínio temporal, os seguintes índices da VFC: média de todos os iRR (média), desvio padrão de todos os iRR (DP), percentual do coeficiente de variação dos iRR (desvio padrão / média) (CV), raiz quadrada da média das diferenças sucessivas ao quadrado entre os iRR adjacentes normais (rMSSD) e porcentagem das diferenças sucessivas entre os iRR adjacentes normais maiores que 50 ms (pNN50). Os três primeiros índices traduzem a modulação autonômica simpatovagal global e os dois últimos índices a modulação exclusivamente vagal (21).

A análise do domínio espectral é expressa por suas amplitudes (power) e por suas frequências, dentro de escalas do espectro de potências. Os estudos da FAC no domínio espectral têm definido três faixas de atividade principais, relacionadas ao componente simpático e parassimpático. Contudo, ainda existem controvérsias na literatura, principalmente em relação a algumas bandas ou faixas específica (46). Na análise do domínio espectral foram adotados os componentes de área total (AT) compreendendo todo o espectro de frequências até o limite máximo de $0,40 \mathrm{~Hz}$, que expressa a modulação autonômica global combinada, simpática e parassimpática. A razão BF/AF representa o balanço relativo simpatovagal, baixa frequência $(\mathrm{BF})$ em unidades normalizadas (BFun: BF/AT x 100) e expressa a modulação simpatovagal combinada e a alta frequência (AF) em unidades normalizadas (AFun: AF/AT x 100), que por sua vez, expressa a modulação predominantemente vagal $(21,43)$. A análise espectral foi realizada com base no modelo matemático auto regressivo, com ordem de 16 e taxa de amostragem do sinal de 4Hz, conforme rotina do laboratório (45).

\subsection{CARACTERIZAÇÃO DA CAPACIDADE FÍSICA POR MEIO DO TESTE CARDIOPULMONAR}

O teste cardiopulmonar foi realizado em esteira rolante (INBRASPORT - ATL), acoplada ao analisador de gases com análise metabólica dos gases expirados em circuito aberto, disponível no Laboratório de Fisiologia do Exercício da Faculdade de Educação Física da Universidade de Brasília - UnB. 
Um coletor de gases acoplado a máscara que envolve a boca e o nariz do indivíduo estava ligado ao analisador de gases (Cortex, USA) de calorimetria indireta. Todo o sistema estava sob o controle de um microcomputador onde as informações são repassadas a cada respiração (breath-bybreath). $\mathrm{O} \dot{\mathrm{V}} \mathrm{O}_{2}$, produção de dióxido de carbono $\left(\mathrm{VCO}_{2}\right)$ e quociente respiratório $(\mathrm{QR})$ foram calculados pelas trocas gasosas. O volume ventilatório foi obtido por medida transdutora, usada para medir o diferencial de pressão instantaneamente. Além das variáveis ventilatórias como: $\mathrm{V}_{2}$, produção de dióxido de carbono, quociente respiratório, razão de trocas gasosas, fração expirada de oxigênio e dióxido de carbono. Também, foi realizado o acompanhamento cardiológico por meio traçado ECG e o registro da FC, por meio do frequencímetro Polar® RS800CX, durante todo o esforço físico e durante o período de recuperação.

O sensor de oxigênio é uma célula de combustão galvânica. O rendimento é linear e com a linha de identidade extraída do meio ambiente $20,9 \%$. O $\mathrm{CO}_{2}$ é mensurado pelo princípio da análise infravermelha não dispersiva.

$\mathrm{O}$ voluntário permanecia em repouso sentado por dois minutos, para a coleta do $\dot{\mathrm{VO}}_{2}$ na condição de repouso, e um minuto na posição ortostática conforme rotina do Laboratório de Fisiologia do Exercício - UnB. Os três minutos de repouso foi seguido de aquecimento de 3 minutos, com a velocidade de $3 \mathrm{~km} / \mathrm{h}$ e inclinação fixa de $2,5 \%$.

Após o aquecimento, iniciou-se o teste de esforço cardiopulmonar máximo com a velocidade de $4 \mathrm{~km} / \mathrm{h}$ e inclinação fixa de 2,5\%. O teste teve os incrementos de carga segundo o método de rampa ou protocolo de Harbor citado por Wasserman et al. (112), até atingir os critérios de interrupção de teste máximo, conforme rotina do Laboratório de Fisiologia do Exercício - UnB. A razão de incremento da velocidade durante o teste foi de $0,75-0,85 \mathrm{~km} / \mathrm{h}$ por minuto, e o teste de esforço teve duração entre 8-12 minutos. O teste de esforço máximo foi interrompido quando o voluntário atingia pelo menos três dos critérios a seguir: $\mathrm{QR} \geq 1,1$, pontuação na escala de $\mathrm{BORG} \geq$ 17 (de 6 - 20), manutenção da FC com o aumento da carga de trabalho, platô do $\mathrm{V}_{2}$ com o aumento da carga de trabalho e ocorrência de fadiga voluntária, em conformidade com os critérios 
estabelecidos pelo Colégio Americano de Medicina do Esporte - ACSM (113), e conforme a rotina do laboratório de Fisiologia do Exercício - UnB. A recuperação foi de cinco minutos, quando os voluntários realizavam uma caminhada com a velocidade da esteira rolante de $2,4 \mathrm{~km} / \mathrm{h}$ e inclinação em 2,5\%, segundo protocolo de Cole et al. (47).

Foi utilizado os dados da resposta cronotrópica e do $\dot{\mathrm{VO}}_{2}$ antes, durante e após teste de esforço máximo, com vistas a caracterização da amostra durante a caracterização da amostra.

\subsection{CARACTERIZAÇÃO DO DECREMENTO DA FREQUÊNCIA CARDÍACA DURANTE O PERÍODO DE RECUPERAÇÃO}

O registro da FC foi realizado por meio do frequencímetro Polar® RS800CX, ao longo de cinco minutos após o teste cardiopulmonar máximo e ao longo de 15 minutos após sessão de TR.

A FC durante o período de recuperação, após teste cardiopulmonar máximo, foi determinada após o período de cinco minutos, no qual, os voluntários realizavam uma caminhada com a velocidade da esteira rolante de $2,4 \mathrm{~km} / \mathrm{h}$ e inclinação em 2,5\%, segundo protocolo de Cole et al.(47).

Os valores de FC per si ao longo de cinco minutos de recuperação após teste cardiopulmonar, foram utilizadas para caracterizar o comportamento do decremento cronotrópico esperado nesta população estudada.

A FC na recuperação ao longo de 15 minutos de recuperação, após a sessão de TR, foi realizada, minuto a minuto, com o voluntário na posição supina em uma maca acolchoada ao lado do leg press. Após os voluntários atingirem a falha voluntária do movimento, entre 8-12RM, na última série, os voluntários deslocavam-se do leg press (sentado) para a posição supina na maca, despendendo cerca de cinco segundos para realizar essa mudança postural, onde permaneciam por 15 minutos. Durante todo o período de recuperação, os voluntários foram orientados a evitarem movimentos bruscos e a não conversarem.

Para a obtenção da variação absoluta individual da FC ( $\Delta$ absFC) na recuperação, ao longo de 15 minutos após sessão de TR, utilizou-se a subtração do valor da FC do quinto ( $\left.\Delta \operatorname{absFC}_{5 \min }\right)$, décimo 
$\left(\triangle \mathrm{absFC}_{10 \min }\right)$ e décimo quinto minuto $\left(\Delta \mathrm{absFC} \mathrm{C}_{15 \mathrm{~min}}\right)$ de recuperação da $\mathrm{FC}$ máxima obtida durante a falha voluntária do movimento, entre as 8-12RM, na última série da sessão de TR.

Para a obtenção da variação relativa individual da $\mathrm{FC}(\Delta \% \mathrm{FC})$ na recuperação, ao longo de 15 minutos após sessão de TR, utilizou-se a divisão da $\Delta$ absFC pela FC máxima obtida durante a falha voluntária do movimento, entre 8-12RM, na última série na sessão de TR multiplicado por 100, no cinco $\left(\Delta \% \mathrm{FC}_{5 \min }\right)$, dez $\left(\Delta \% \mathrm{FC}_{10 \min }\right)$ e quinze minutos $\left(\Delta \% \mathrm{FC}_{15 \min }\right)$ de recuperação após sessão de TR. Exemplo: $\Delta \% \mathrm{FC}=(\Delta \mathrm{absFC} / \mathrm{FC}$ máxima $) \times 100$.

Os valores de FC per si, $\Delta \mathrm{absFC}$ e $\Delta \% \mathrm{FC}$ do decremento cronotrópico durante a fase de recuperação, ao longo de 15 minutos, após sessão de TR, foram utilizados somente nas análises de correlação.

\subsection{CARACTERIZAÇÃO DA FORÇA POR MEIO DO TESTE DO DINAMÔMETRO} ISOCINÉTICO

O teste de força máxima de membros inferiores, foi avaliado por meio do dinamômetro isocinético Biodex 4 (Biodex Corp. Shirley, NY, USA) (FIGURA 05) no movimento de extensão de joelho, da perna dominante conforme rotina do Laboratório de Treinamento de Força da Faculdade de Educação Física - UnB. Foi escolhido este teste, por ser um teste validado, fidedigno e reprodutível $(114,115)$ para a avaliação da força máxima.

Antes de iniciar o teste, os voluntários recebiam as devidas instruções quanto ao protocolo a ser utilizado. O voluntário sentava-se com o eixo de rotação do braço do dinamômetro orientado com o eixo de rotação do joelho da perna dominante, para ajustes da altura, apoio das costas e distância do banco. O Epicôndilo lateral femoral foi usado como o marco ósseo para igualizar a articulação do joelho com o eixo de rotação do dinamômetro. Os cintos foram usados para segurar a perna, a pelve e o tronco na cadeira do dinamômetro, evitando assim o movimento adicional do corpo, como pode ser visto na FIGURA 06. A correção da gravidade foi obtida medindo-se torque realizado sobre o dinamômetro com o joelho em flexão e extensão completa. 


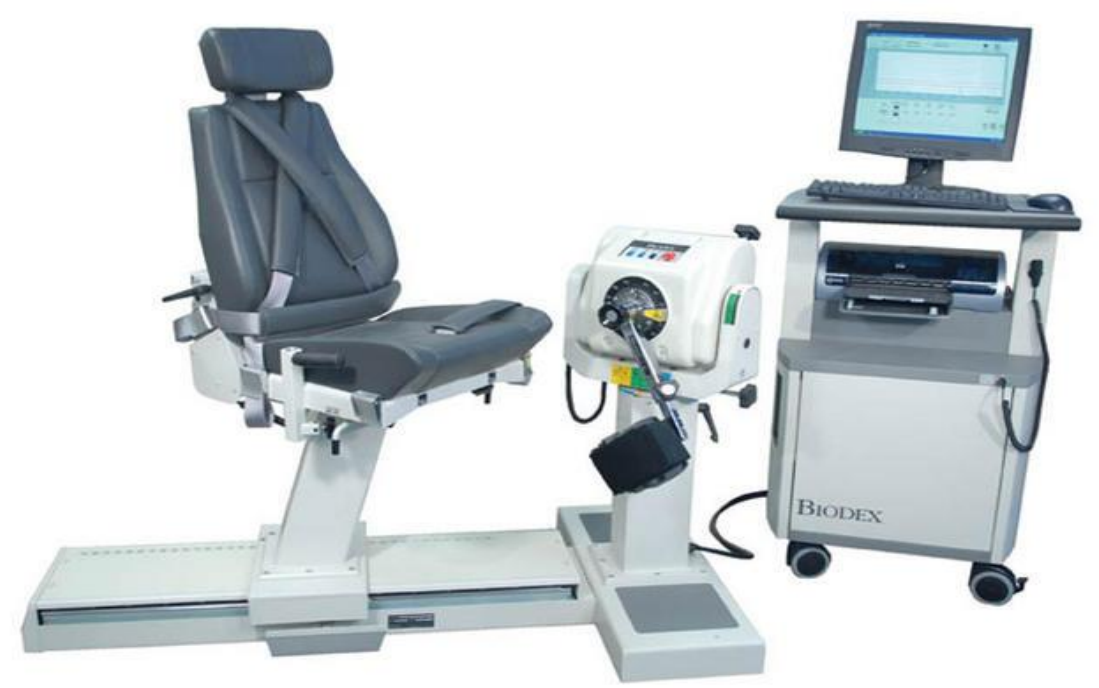

FIGURA 05 - Ilustração do dinamômetro isocinético Biodex $4^{\circledR}$ (www.biodex.com)

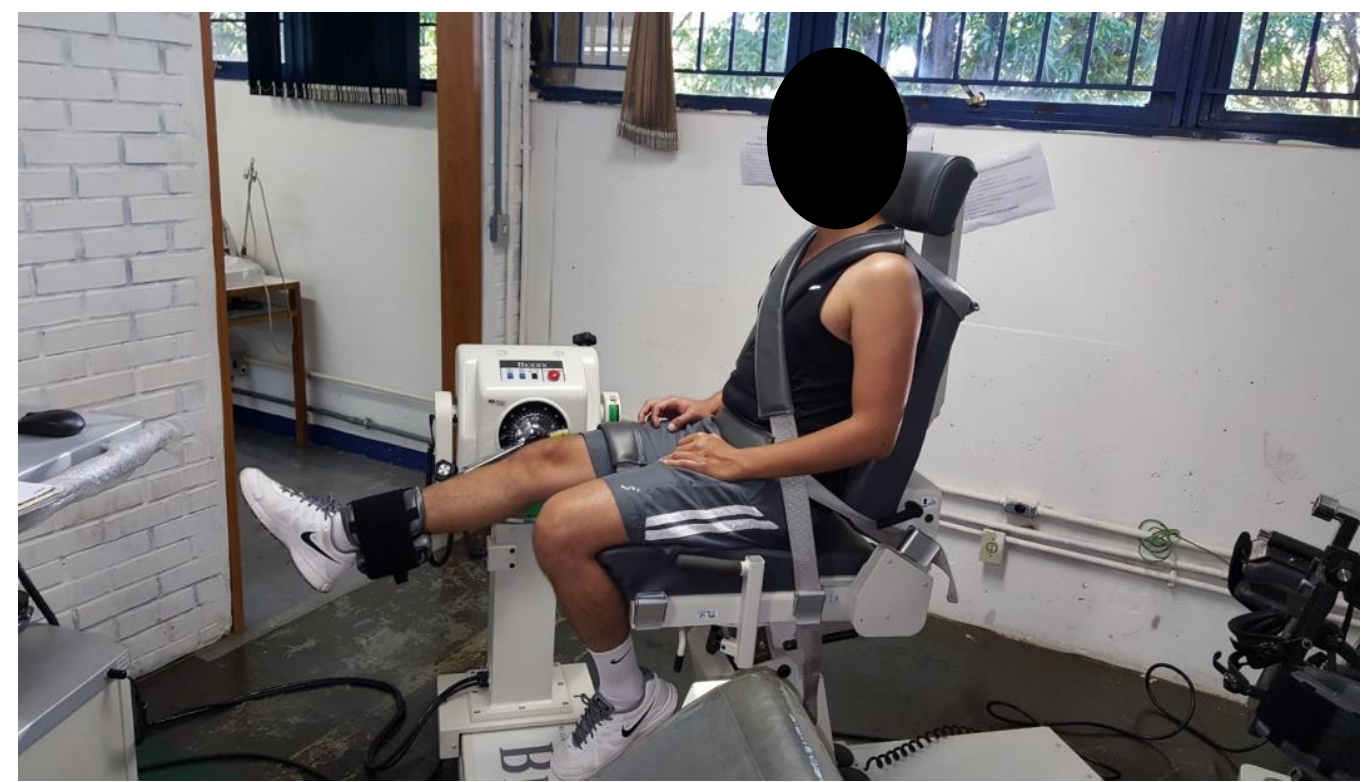

FIGURA 06 - Ilustração do posicionamento dos ajustes no dinamômetro isocinético Biodex $4^{\circledR}$

Após os devidos ajustes, os voluntários realizavam uma série de 12 repetições submáximas à uma velocidade $300^{\circ}$ s durante a extensão e flexão de joelho, como protocolo de aquecimento. Após um minuto de descanso, os voluntários foram instruídos a realizar duas séries de quatro repetições máximas na velocidade de $60 \%$ durante a extensão de joelho e velocidade de $300 \%$ s durante a flexão de joelho com intervalo de um minuto de recuperação entre as séries, conforme rotina do Laboratório de Treinamento de Força da Faculdade de Educação Física - UnB $(116,117)$. Todos os voluntários receberam encorajamento verbal para realizar o máximo de força possível. 
Foi adotado, como valor de máxima força o maior valor de pico de torque (PT) absoluto (NM) e relativo (\%) à massa corporal individual obtidos durante a extensão de joelho com $60^{\circ} / \mathrm{s}$ nas duas séries de quatro repetições máximas.

\subsection{CARACTERIZAÇÃO DA FAMILIARIZAÇÃO E SESSÃO DE TREINO RESISTIDO}

A intensidade do TR não pode ser estimada pela FC durante a sessão de TR, visto que, a FC não varia de acordo com a intensidade (53). Assim, como controle de intensidade durante a sessão de TR foi adotado a carga que o voluntario atingisse entre 8 - 12RM em todas as séries.

Os voluntários realizaram as duas familiarizações e a sessão de treino resistido no exercício de leg press ROTECH $^{\circledR}$ (Rotech Fitness, Goiânia, GO, Brasil), veja a FIGURA 07, no Laboratório de Musculação da Faculdade de Educação Física da Universidade de Brasília - UnB. A escolha deste exercício, se deu em função da segurança, do fácil aprendizado do movimento e do grande envolvimento muscular. E, Kingsley et al. (75) observaram que cinco series de 10RM foi capaz de alterar a balanço simpatovagal, ao longo de 25 minutos, após uma sessão de TR. Antes de iniciar o procedimento, os voluntários recebiam as devidas instruções quanto ao protocolo a ser utilizado.

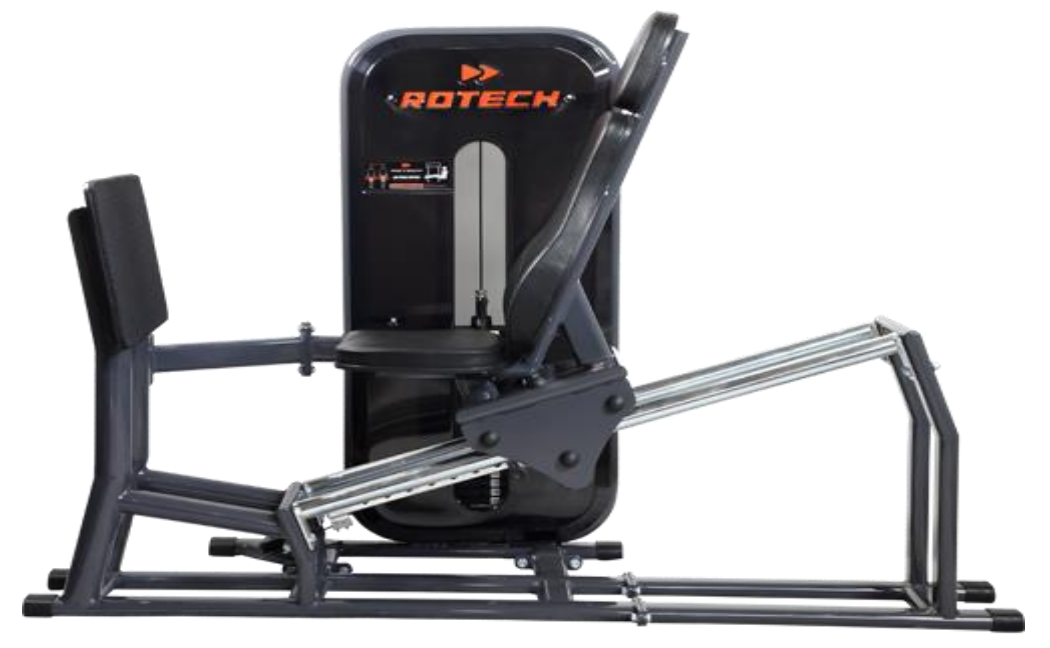

FIGURA 07 - Ilustração máquina de leg press ROTECH ${ }^{\circledR}$ (www.rotechfitness.com.br)

Na primeira familiarização, foi padronizado para todos os voluntários a posição do banco, para que todos realizassem a mesma amplitude de movimento e a velocidade de execução entre 1-2 
segundos na fase concêntrica e entre 1-2 segundos na fase excêntrica. Todos os voluntários realizaram uma série de 12 repetições com $20 \mathrm{~kg}$, com vistas no aprendizado da técnica do movimento. E, todos os voluntários relataram ter familiaridade com a execução da técnica do movimento do leg press.

Na segunda familiarização, os voluntários realizavam uma série de 12 repetições com $20 \mathrm{~kg}$ para aquecimento, e após um minuto de intervalo de recuperação, os voluntários foram encorajados a realizar uma série com o máximo de repetições até a falha voluntária do movimento. O voluntário não foi informado sobre a carga no exercício, para evitar influências psicológicas.

Caso o voluntário não atingisse a falha voluntária do movimento, entre 8-12 repetições, foi realizado um novo ajuste de carga, tanto para mais quanto para menos, e após um minuto de intervalo de recuperação, os voluntários eram encorajados novamente a realizar uma nova série com o máximo de repetições até a falha voluntária do movimento. Caso os voluntários atingissem a falha voluntária do movimento na primeira ou na segunda série, a carga foi anotada para ser a carga de início da sessão de treino resistido.

Após 48 horas da segunda familiarização, foi realizado a sessão de treino resistido. A sessão de treino resistido foi constituída de quatro séries com um minuto de intervalo de recuperação entre as séries, no qual a primeira foi de aquecimento e três séries de 8-12RM. 


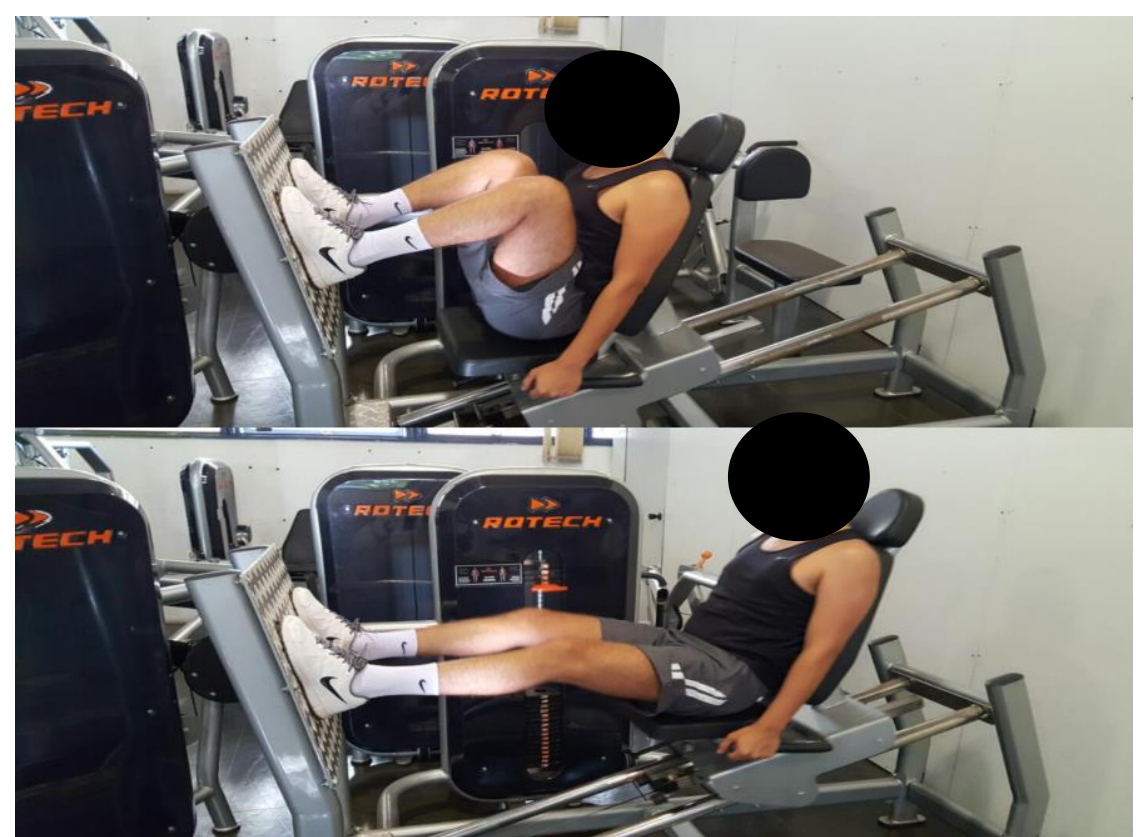

FIGURA 08 - Ilustração da execução do movimento de leg press por um voluntário. Acima a ilustração do movimento inicial no leg press e abaixo a ilustração do movimento final no leg press.

A primeira série iniciou com 12 repetições de $20 \mathrm{~kg}$ com intuito de aquecimento. Após a série de aquecimento, os voluntários realizaram três séries de 8-12RM com um minuto de intervalo entre as séries. A carga da primeira série, foi a carga anotada durante o segundo dia de familiarização com um acréscimo de 5kg, para minimizar o efeito de aprendizado. Caso o voluntário atingisse 8RM na primeira ou segunda série, a carga para a segunda ou terceira série eram ajustadas, contudo, caso o voluntário atingisse entre 10RM e 12RM, na primeira ou segunda série, a carga para as séries subsequentes eram mantidas. Todos os voluntários realizaram entre 8-12RM nas três séries na sessão de TR. A escolha deste protocolo de treino segue as recomendações do ACSM (118) na prescrição de TR. Após os voluntários realizarem até a falha voluntária do movimento na última repetição da última série, os voluntários deslocavam-se do exercício de leg press e permaneciam na posição supina sobre uma maca acolchoada por 15 minutos, após a sessão de TR. 


\subsection{PROTOCOLO EXPERIMENTAL}

O protocolo experimental utilizado no estudo foi dividido em três visitas ao laboratório com 48 horas de intervalo entre cada visita. As primeiras duas visitas tiveram finalidade de caracterização da amostra, e a terceira visita foi o procedimento experimental, propriamente dito.

Desta forma, uma vez que os voluntários atendessem os critérios de inclusão da amostra, eles assinavam o termo de consentimento livre e esclarecido, respondiam a uma anamnese clínica e seguiam para proceder os testes divididos nas três visitas no laboratório, conforme detalhado baixo e ilustrado na FIGURA 09.

$1^{\mathrm{a}}$ visita ao laboratório:

- Assinatura do termo de consentimento livre e esclarecido;

- Anamnese clínica e histórico de estilo de vida;

- Coleta dos dados antropométrico (massa corporal e estatura);

- Eletrocardiograma de repouso;

- Caracterização das variáveis funcionais de repouso (FC, PA e FR);

- Realização do teste de $\mathrm{FAC}_{\text {repouso }}$ (posição supino e ortostático);

- Índices de Poincaré, no domínio temporal e espectral da VFC;

- Realização do teste cardiopulmonar:

- Caracterização das variáveis cardiopulmonares na condição de repouso, esforço e recuperação;

- Caracterização da frequência cardíaca na condição de repouso, esforço e recuperação;

- $\quad 1^{\mathrm{a}}$ Familiarização do exercício de leg press:

- Caracterização do ajuste e técnica do movimento;

$2^{\mathrm{a}}$ visita ao laboratório (48 horas após a $1^{\mathrm{a}}$ visita):

- Realização do teste de força máxima: 
- Caracterização do pico de torque absoluto e relativo;

- $\quad 2^{\mathrm{a}}$ Familiarização do exercício de leg press:

- Caracterização da carga de sessão de treino;

$3^{\mathrm{a}}$ visita ao laboratório (48 horas após a $2^{\mathrm{a}}$ visita):

- Caracterização das variáveis funcionais de repouso (FC, PA e FR);

- Realização do teste $\mathrm{FAC}_{\text {inicial }}$ (posição supino e ortostático);

- Índices de Poincaré, no domínio temporal e espectral da VFC;

- Sessão de treino resistido:

- Caracterização das variáveis de sobrecarga;

- Caracterização da frequência cardíaca durante o esforço;

- Realização de 15 minutos de recuperação após sessão de treino resistido na posição supina:

- Caracterização do teste de FAC durante a recuperação;

- Índices de Poincaré (5, 10 e $15 \mathrm{~min})$, no domínio temporal (10 e $15 \mathrm{~min})$ e espectral (10 e 15min) da VFC;

- Caracterização da frequência cardíaca na recuperação; 


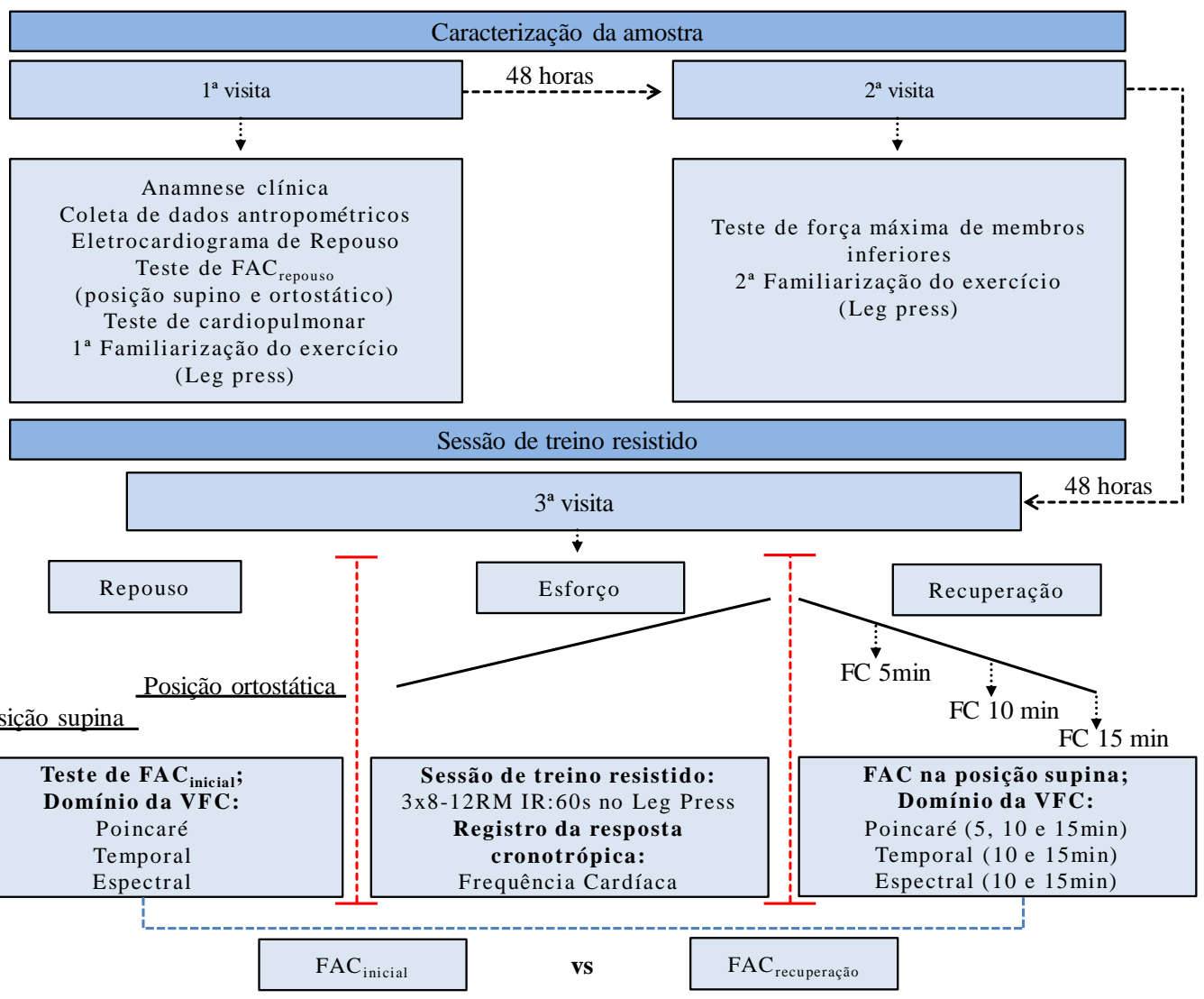

FIGURA 09 - Esquema ilustrativo do desenho experimental

\subsection{PROCEDIMENTO ESTATÍSTICO}

Para o processamento estatístico dos dados, utilizou-se os aplicativos Microsoft Excel e GraphPad Prism 6 for Windows.

A análise de normalidade dos dados foi verificada pelo teste de Kolmogorov-Smirnov e Shapiro-Wilk. Como a amostra é pequena e um maior número de dados apresentou uma distribuição não-normal, optou-se pela estatística não paramétrica para análise inferencial. Os valores de mediana e quartis foram utilizados para análise descritiva dos dados, uma vez que, em sua maioria os dados apresentaram condição não normal.

A estatística inferencial, foi utilizada nas análises de comparação entre dois momentos pareados e empregou-se o teste de Wilcoxon e nas análises de comparação entre três e / ou mais momentos pareados empregou-se o teste de Friedman com teste post hoc de Dunn, quando aplicável. 
Na análise de comparação entre dois momentos não pareados, nas diferentes variáveis adotadas no presente estudo, empregou-se o teste de Mann-Whitney.

A estatística inferencial, foi utilizada nas análises de comparação entre dois momentos pareados empregou-se o teste de Wilcoxon e nas análises de comparação entre três e / ou mais momentoss pareados empregou-se o teste de Friedman com teste post hoc de Dunn, quando aplicável. $\mathrm{Na}$ análise de comparação entre dois momentoss não pareados, nas diferentes variáveis adotadas no presente estudo, empregou-se o teste de Mann-Whitney.

Para testar a hipótese de correlação entre as diferentes variáveis adotou-se o teste de correlação de Spearman, com os seguintes critérios para interpretar o coeficiente de correlação $\left(\mathrm{r}_{\mathrm{s}}\right)$ entre as medidas: $r_{\mathrm{s}}<0,1$ : trivial; $0,1-0,3$ : pequeno; $0,3-0,5$ : moderado; 0,5 - 0,7: forte; $0,7-0,9$ : muito forte e $0,9-1,0:$ quase perfeita (119).

As diferenças entre as diversas comparações instituídas foram consideradas estatisticamente significativas quando as probabilidades bicaudais das suas ocorrências devidas ao acaso (erro do tipo I) foram menores ou iguais a $5 \%(\mathrm{p} \leq 0,05)$. Considerou-se ainda essas diferenças como tendência estatística ou significância marginal quando $0,05<\mathrm{p} \leq 0,09$. 


\section{RESULTADOS}

Os resultados foram apresentados em sete tópicos, de acordo a variável e a forma de análise estudada, conforme resumido na FIGURA 10.

Os dados da resposta da FC e do consumo máximo de oxigênio iniciais, durante e após cinco minutos do teste de esforço máximo, foram apresentados no primeiro tópico.

No segundo tópico, a FAC foi avaliada pelos índices de Poincaré, no domínio temporal e espectral da VFC, durante cinco minutos na posição supina e ortostática para caracterização da amostra.

No terceiro tópico, foi apresentada a análise comparativa entre a FAC da caracterização amostral e FAC imediatamente antes da sessão de TR, avaliada pelos índices de Poincaré, no domínio temporal e espectral da VFC.

Os valores de força na caracterização amostral e a análise comparativa entre as variáveis de controle de sobrecarga durante a sessão de TR foram descritas no capítulo tópico.

No quinto tópico, realizou-se a análise comparativa da FAC antes da sessão de TR com a FAC ao longo de 15 minutos após sessão de TR, avaliada pelos índices de Poincaré, no domínio temporal e domínio espectral da VFC.

Foram analisados os dados de correlação entre a FAC na posição supina no repouso com a FAC na posição supina ao longo 15 minutos após uma sessão de TR, avaliada pelos índices de Poincaré, no domínio temporal e domínio espectral da VFC, no sexto tópico.

E por fim no sétimo tópico os dados de correlação entre a FAC na posição supina no repouso, avaliada pelos índices de Poincaré, no domínio temporal e domínio espectral da variabilidade da frequência cardíaca foram comparadas a resposta cronotrópica cardíaca após cinco, dez e quinze minutos da sessão de TR. 
Sequência de apresentação dos resultados

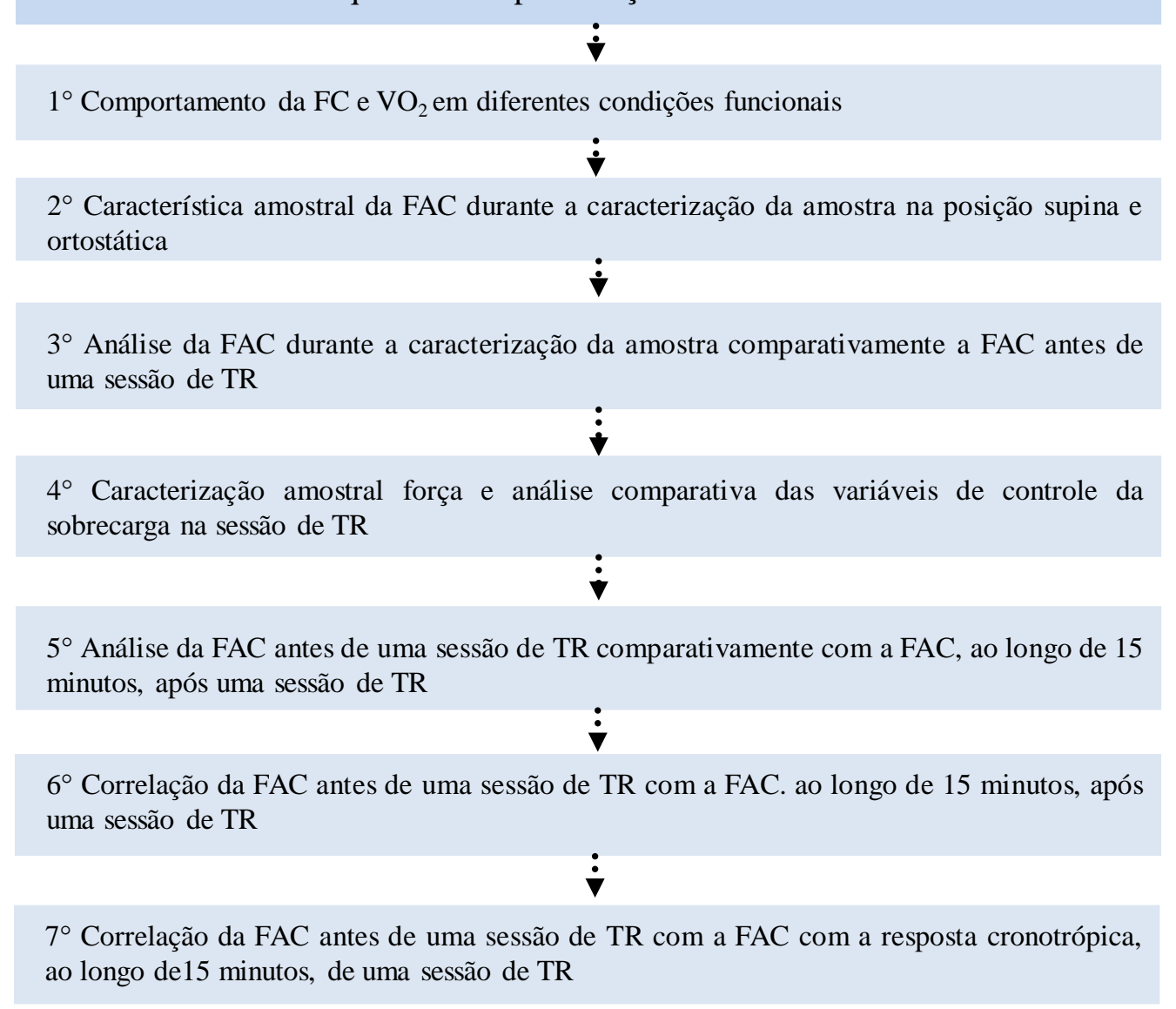

FIGURA 10 - Esquematização da apresentação dos resultados

\subsection{RESPOSTA DA FREQUÊNCIA CARDÍACA E DO CONSUMO DE OXIGÊNIO ANTES, DURANTE E APÓS TESTE DE ESFORÇO MÁXIMO}

\subsubsection{FREQUÊNCIA CARDÍACA INICIAL, DURANTE E APÓS TESTE DE ESFORÇO MÁXIMO}

A Tabela 03 apresenta os dados da $\mathrm{FC}$ na condição inicial antes do teste $\left(\mathrm{FC}_{\mathrm{rep}}\right)$, durante o esforço e, ao longo de cinco minutos, após teste de esforço máximo. A FC rep na posição supina foi menor $(\mathrm{p}<0,01)$ comparada à $\mathrm{FC}_{\text {rep }}$ na posição ortostática.

No teste de esforço o valor mediano da FC no início do esforço foi de 94,5 $(89,0$ - 98,0) bpm. O teste de esforço incremental máximo, sobrecarregou o sistema cardiovascular e metabólico, no 
qual, foi responsável pelo aumento da FC com valor mediano obtido de 198,8 (187,3 - 200,8) bpm no pico do esforço. $\mathrm{A} \mathrm{FC}_{\text {pico }}$ foi significativamente maior que a $\mathrm{FC}_{\text {inicial }}(\mathrm{p}<0,01)$.

$\mathrm{O}$ registro do decremento cronotrópico em relação à $\mathrm{FC}_{\text {pico }}$ obtida no teste de esforço máximo, ocorreu a cada minuto de recuperação. Não foi observado diferença significativa entre a $\mathrm{FC}_{\text {pico }}$ com o decremento da $\mathrm{FC}$ no primeiro minuto $\left(\mathrm{FC}_{1}{ }^{\circ} \mathrm{min}\right)$ de recuperação. Entretanto, ao comparar a $\mathrm{FC}_{\text {pico }}$ com o decremento da $\mathrm{FC}$ no segundo minuto $\left(\mathrm{FC}_{2^{\circ} \mathrm{min}}\right)$ de recuperação, foi observado uma tendência significativa $(\mathrm{p}=0,07)$, com maiores valores de $\mathrm{FC}_{\mathrm{pico}}$ comparada a $\mathrm{FC}_{2}{ }^{\circ}$ min. Contudo, observou-se diferença significativa $(\mathrm{p}<0,01)$ da $\mathrm{FC}_{\text {pico }}$ comparado com o decremento da $\mathrm{FC}$ do terceiro ao quinto minuto de recuperação.

A $\mathrm{FC}_{1}{ }^{\circ}$ min não diferiu da $\mathrm{FC}_{2}{ }^{\circ}$ min de recuperação, contudo, ao comparar o decremento da $\mathrm{FC}_{1^{\circ} \text { min }}$ com a $\mathrm{FC}_{3^{\circ}}$ min de recuperação, foi observado uma tendência significativa $(\mathrm{p}=0,07)$ com maiores valores de $\mathrm{FC}_{1^{\circ} \text { min }}$ comparado a $\mathrm{FC}_{3}{ }^{\circ}$ min. Contudo, observou-se diferença significativa $(\mathrm{p}<$ 0,01) da $\mathrm{FC}_{1^{\circ} \mathrm{min}}$ comparado com o decremento da $\mathrm{FC}$ no quarto e no quinto minuto de recuperação.

Quando comparado o decremento da $\mathrm{FC}_{2}{ }^{\circ}$ min com o decremento da $\mathrm{FC}$ no quarto e quinto minuto de recuperação, foram observadas diferenças significativas $(\mathrm{p}<0,01)$. Já para as demais combinações entre os registros dos decrementos da FC durante a recuperação, não foram observadas diferenças significativas, conforme descrito na Tabela 03.

\subsubsection{CONSUMO DE OXIGÊNIO NO REPOUSO, DURANTE E APÓS TESTE DE ESFORÇO} MÁXIMO

A Tabela 04 apresenta os dados do VंO2 na condição de repouso, início e pico do esforço e, ao longo de cinco minutos, após teste de esforço máximo. O comportamento do VंO2 foi semelhante ao da FC (TABELA 03) nas diferentes condições funcionais.

$\mathrm{O} \dot{\mathrm{VO}}_{2}$ de repouso foi significativamente menor $(\mathrm{p}<0,01)$ comparado ao $\dot{\mathrm{VO}} 2$ medido no início do esforço e ao $\dot{\mathrm{V}} \mathrm{O}_{2}$ medido no pico do esforço. $\mathrm{O} \dot{\mathrm{V}}_{2}$ medido no pico do esforço apresentou diferença significativa $(\mathrm{p}<0,01)$ comparado ao $\dot{\mathrm{V}}_{2}$ medido no início do esforço. 
Durante a recuperação, ao comparar o $\dot{\mathrm{V}}_{2}$ medido no primeiro minuto com o segundo minuto, o segundo minuto com o terceiro minuto, o terceiro minuto com o quarto e quinto minuto, e o quarto minuto com o quinto minuto de recuperação, não foram observadas diferenças significativas. Contudo, para as demais combinações, entre o $\dot{\mathrm{VO}}_{2}$ medido na recuperação foram observadas diferenças significativas $(\mathrm{P}=0,04 \mathrm{a}<0,01)$, conforme descrito na Tabela 04 .

Nas FIGURAS 09 e 10 estão descritos os comportamentos das variáveis $\mathrm{FC}$ e do $\dot{\mathrm{VO}}_{2}$ na condição de repouso, durante o esforço e, ao longo cinco minutos, após teste de esforço máximo. Observa-se uma dinâmica similar no comportamento da $\mathrm{FC}$ com o do $\dot{\mathrm{VO}}_{2}$. Tanto a FC quanto o $\dot{\mathrm{V}} \mathrm{O}_{2}$ apresentaram uma queda rápida dos seus valores até o terceiro minuto de recuperação, seguido de estabilidade, porém acima dos valores de repouso. 
TABELA 03 - Frequência cardíaca na condição repouso, no início e fim do teste de esforço e durante a recuperação após o teste de esforço máximo $(\mathrm{n}=14)$.

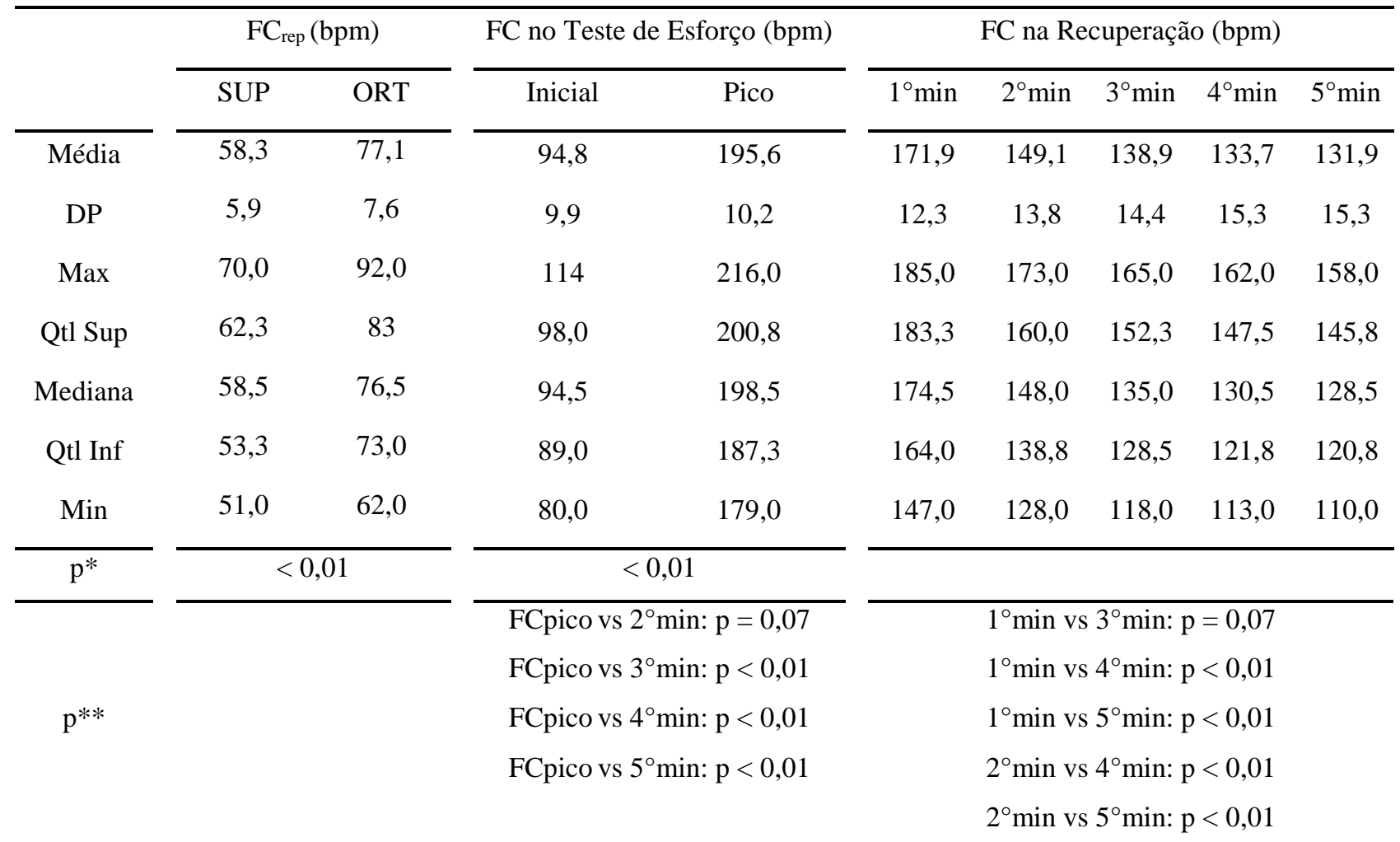

FC: frequência cardíaca; Rep = repouso; SUP = supino; ORT = ortostático; min = minuto; DP = desvio padrão; Max: Valor amostral máximo; Qtl Sup: Quartil superior; Qtl Inf: Quartil inferior; Min: valor amostral mínimo; $\mathrm{p}=$ nível de significância; $\mathrm{p}^{*}$ : teste de Wilcoxon; $\mathrm{p}^{* *}$ : teste de Friedman com post hoc Dunn.

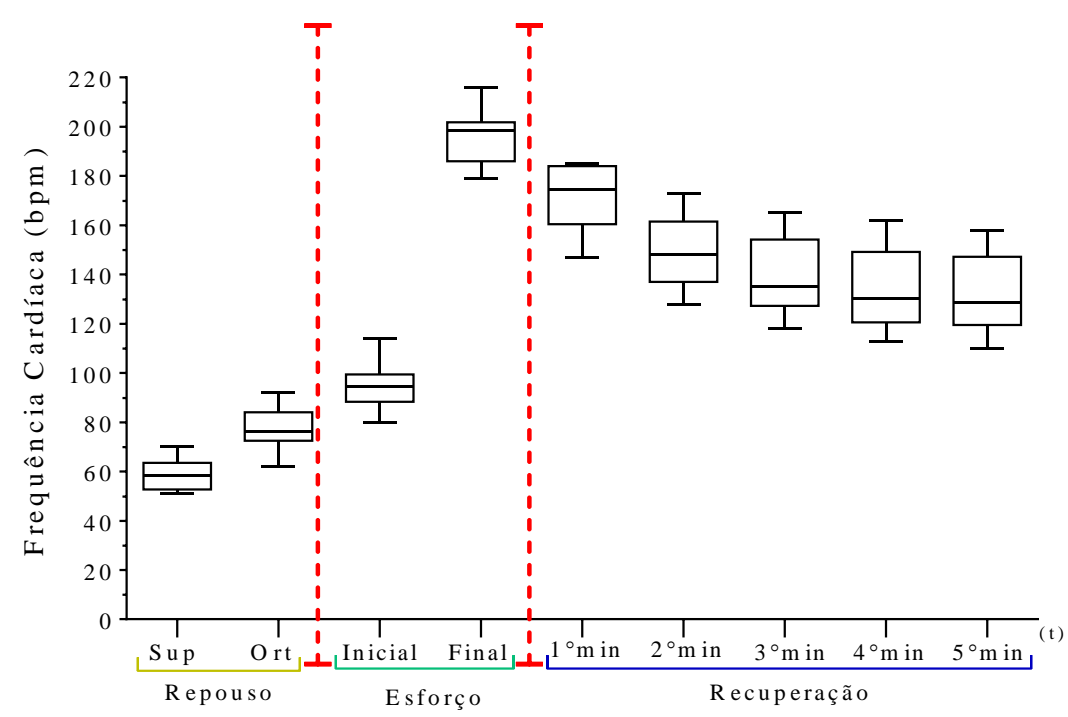

FIGURA 11 - Comportamento da frequência cardíaca na condição repouso, no início e fim do teste de esforço e durante a recuperação após o teste de esforço máximo (n=14). 
TABELA 04 - Consumo de oxigênio previamente, durante e após o teste de esforço máximo (n=14).

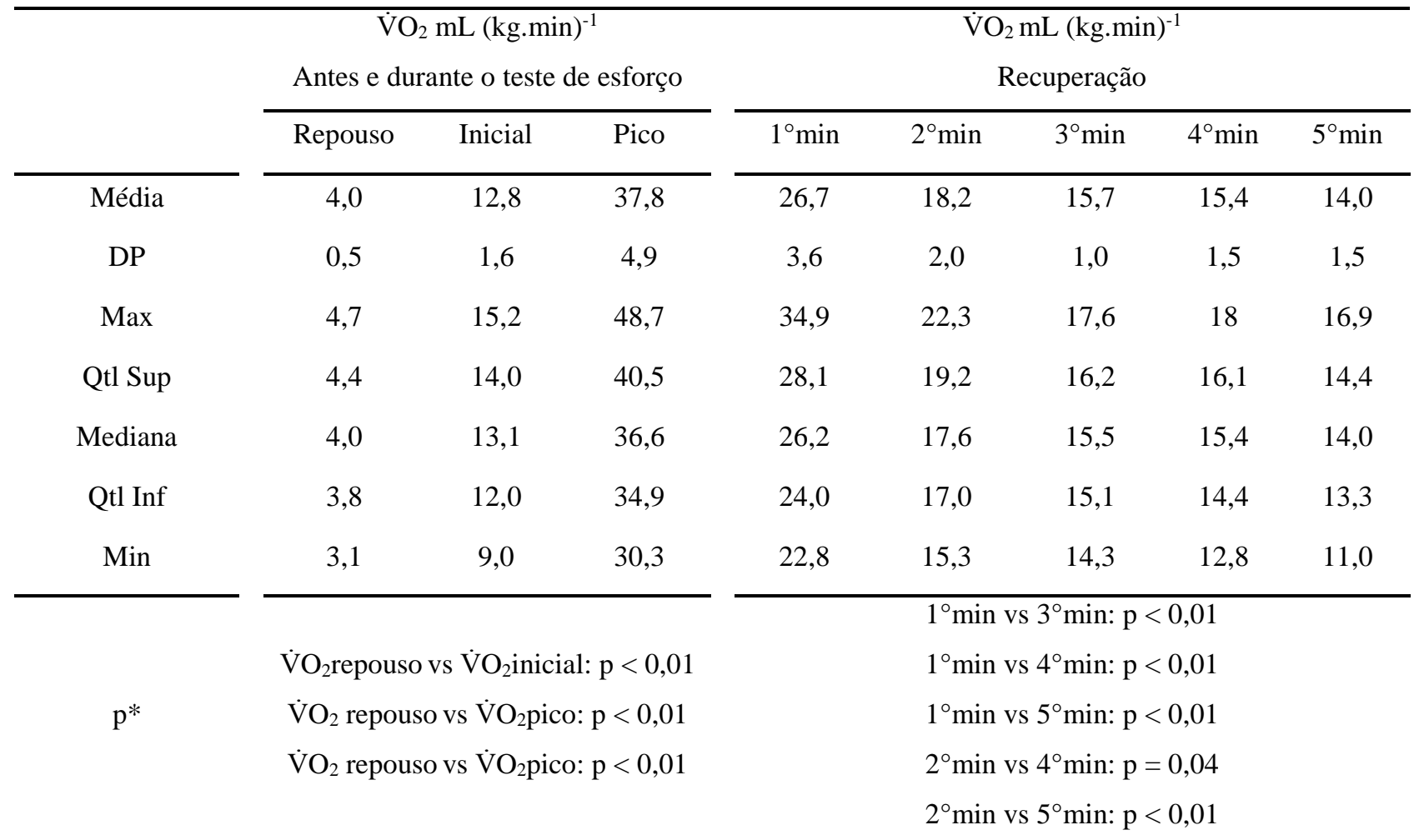

نं ${ }_{2}$ : consumo de oxigênio; min = minuto; DP = desvio padrão; Max: Valor amostral máximo; Qtl Sup: Quartil superior; Qtl Inf: Quartil inferior; Min: valor amostral mínimo; $\mathrm{p}=$ nível de significância; $\mathrm{p}^{*}$ : teste de Friedman com post hoc Dunn

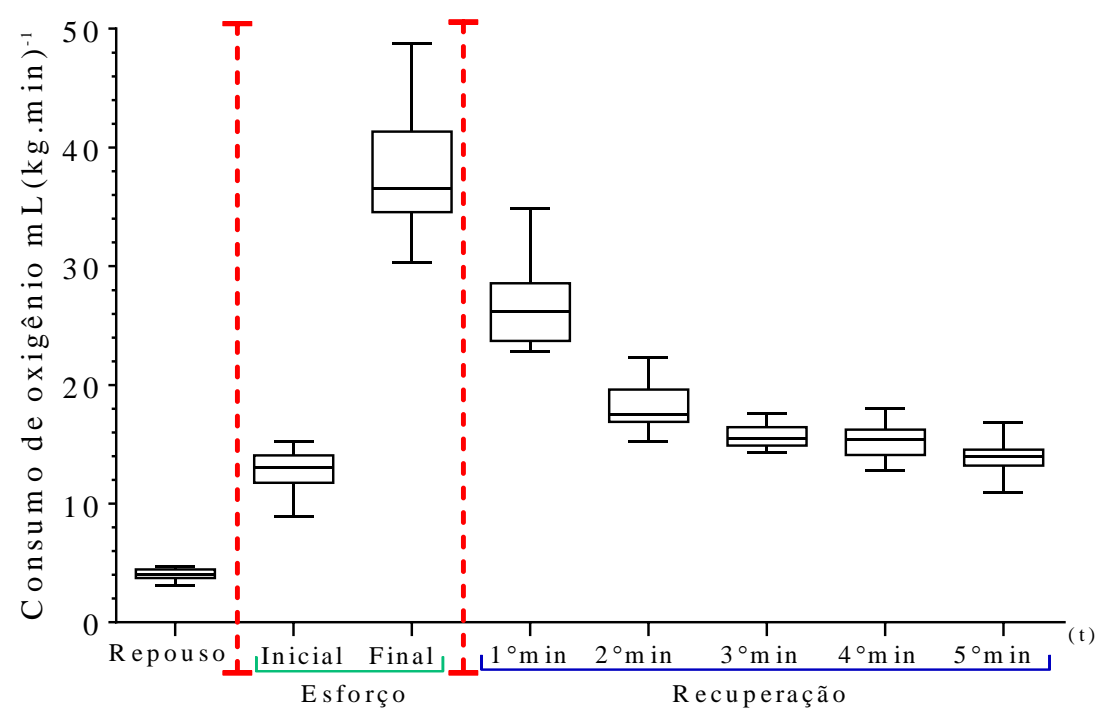

FIGURA 12 - Comportamento do consumo de oxigênio na condição de repouso, no início e fim do teste de esforço e durante a recuperação após o teste de esforço máximo, estão indicados a mediana, quartis superior e inferior, e os valores extremos $(n=14)$. 


\title{
4.2 FAC AVALIADA PELOS ÍNDICES DE POINCARÉ, NO DOMÍNIO TEMPORAL E ESPECTRAL DA VFC DURANTE CINCO MINUTOS NA POSIÇÃO SUPINA E ORTOSTÁTICA NO PERÍODO DE CARACTERIZAÇÃO DA AMOSTRA
}

\author{
4.2.1 FAC NA CONDIÇÃO DE REPOUSO AVALIADA PELOS ÍNDICES DE POINCARÉ DA \\ VFC, NAS POSIÇÕES SUPINA E ORTOSTÁTICA
}

Os valores amostrais dos índices de Poincaré da VFC na condição de repouso, na posição supina e ortostática, durante o período de caracterização da amostra são apresentados na Tabela 05.

Não foi observado diferença significante no índice de Poincaré SD2 na posição supina comparada a SD2 na posição ortostática. Contudo, observa-se diferença estatística $(p<0,01)$ com maiores valores de SD1 [50,1 $(44,6$ - 58,2) ] e da razão SD1/SD2 [0,6 $(0,5$ - 0,7) ] na posição supina comparado a SD1 [26,2 (17,5 - 37,5) ] e da razão SD1/SD2 [0,3 (0,2 -0,3) ] na posição ortostática. Ou seja, após o estresse ortostático, observou-se redução mediana tanto do marcador vagal SD1 [104,1 (-166,7 - -49,7)\%] quanto do marcador de balaço autonômico SD1/SD2 [-94,7 (-169,7 - 72,4)\%], demonstrando um comportamento esperado para indivíduos saudáveis.

\subsubsection{FAC NA CONDIÇÃO DE REPOUSO AVALIADA PELOS ÍNDICES DO DOMÍNIO TEMPORAL DA VFC, NAS POSIÇÕES SUPINA E ORTOSTÁTICA}

A Tabela 06 apresenta os valores amostrais dos índices temporais da VFC avaliadas na condição de repouso, na posição supina e ortostática, durante o período de caracterização da amostra. O índice temporal DP na posição supina não diferiu quando comparado a posição ortostática. Entretanto, foram observadas diferenças estatísticas $(p<0,01)$ com maiores valores de média de iRR [1032,1 (965,9 - 1138,6) ms], pNN50 [48,7 (44,2 - 56,3) \%] e rMSSD [70,7 (63 - 82,2) ms] na posição supina comparado a média de iRR [788,6 (743,8 - 846,7) ms], pNN50 [17,7 (3,6 - 30,2) \%] e rMSSD [37 $(24,8-52,9) \mathrm{ms}]$ na posição ortostática. 
Não foi observado diferença estatística no CV na posição supina comparado a posição ortostática. Desta forma, observou-se taquicardia e redução mediana da média de iRR [-32,4 (-39,9 - -23,3) \%] após o estresse ortostático, e os marcadores da atividade vagal reduziram após o estresse ortostático [-177,6 (-865,3 - -126,7) \% ] do pNN50 e [-104,3 (-166,5 - -49,7) \% ms] do rMSSD, apresentando um comportamento esperado para indivíduos saudáveis.

\subsubsection{FAC NA CONDIÇÃO DE REPOUSO AVALIADA PELOS ÍNDICES DO DOMÍNIO ESPECTRAL DA VFC, NAS POSIÇÕES SUPINA E ORTOSTÁTICA}

A Tabela 07 apresenta os valores amostrais dos índices espectrais da VFC na condição de repouso, na posição supina e ortostática, durante o período de caracterização da amostra.

A AT na posição supina não diferiu da posição ortostática. Entretanto, foram observadas diferenças estatísticas $(\mathrm{p}<0,01)$ com menores valores de razão BF/AF $[0,7(0,4-1,2)]$ e área normalizada de BF [42,8 (27,1 - 55,2) ] na posição supina em comparação com a razão BF/AF [2,2 $(1,5$ - 4,5) ] e área normalizada de $\operatorname{BF}[68,7(60,0$ - 81,9) ] na posição ortostática. Também foi observado diferença estatística $(\mathrm{p}<0,01)$ com maiores valores de área normalizada de AF [57,1 $(44,8$ - 72,9) ] na posição supina comparada a área normalizada de AF [31,3 (18 - 40) ] na posição ortostática.

O balanço autonômico cardíaco na posição supina foi compatível com predominância vagotônica. Contudo, após o estresse ortostático observa-se um aumento mediano de 73,3 (56,4 88,3) \% do balanço autonômico cardíaco e uma redução vagal avaliada pela área normalizada de AF de [-97,8 (-184,2 - -60,9) ], passando de uma predominância vagotônica para a predominância simpaticotônica nessa condição funcional, traduzindo-se em um comportamento esperado para indivíduos saudáveis. 
TABELA 05 - Índices de Poincaré da variabilidade da frequência cardíaca durante 5 minutos na posição supina e ortostática, na condição de repouso, no período de caracterização da amostra (n=14).

\begin{tabular}{|c|c|c|c|c|c|c|c|c|c|}
\hline & \multicolumn{3}{|c|}{ SD1 } & \multicolumn{3}{|c|}{ SD2 } & \multicolumn{3}{|c|}{ SD1/SD2 } \\
\hline & SUP & ORT & $\Delta \%$ & SUP & ORT & $\Delta \%$ & SUP & ORT & $\Delta \%$ \\
\hline Média & 55,1 & 27,3 & $-114,6$ & 91,5 & 91,6 & $-2,2$ & 0,6 & 0,3 & $-114,2$ \\
\hline DP & 21,4 & 10,3 & 76,1 & 33,0 & 26,4 & 31,7 & 0,2 & 0,1 & 59,0 \\
\hline Max & 98,3 & 39,8 & $-16,4$ & 162,9 & 148,9 & 56,2 & 1,1 & 0,4 & $-38,3$ \\
\hline Qtl Sup & 58,2 & 37,5 & $-49,7$ & 112,2 & 107,8 & 15,5 & 0,7 & 0,3 & $-72,4$ \\
\hline Mediana & 50,1 & 26,2 & $-104,1$ & 90,9 & 95,3 & 5,1 & 0,6 & 0,3 & $-94,7$ \\
\hline Qtl Inf & 44,6 & 17,5 & $-166,7$ & 67,7 & 73,8 & $-16,9$ & 0,5 & 0,2 & $-169,7$ \\
\hline Min & 16,5 & 12,3 & $-228,0$ & 43,3 & 50,6 & $-69,6$ & 0,4 & 0,2 & $-224,5$ \\
\hline $\mathrm{p}^{*}$ & & $<0,01$ & & & 0,85 & & & $<0,01$ & \\
\hline
\end{tabular}

SUP = supino; ORT $=$ ortostático; $\Delta \%=$ diferenças individuais percentuais entre a postura supina e ortostática; $\mathrm{DP}=$ Desvio padrão; Max = Valor amostral máximo; Qtl = Quartil; Sup = superior; Inf = inferior; Min = valor amostral mínimo; $\mathrm{p}^{*}=$ teste de Wilcoxon.

TABELA 07 - Índices temporais da variabilidade da frequência cardíaca durante 5 minutos na posição supina e ortostática, na condição de repouso, no período de caracterização da amostra (n=14).

\begin{tabular}{|c|c|c|c|c|c|c|c|c|c|c|c|c|}
\hline & \multicolumn{3}{|c|}{ Área Total $\left(\mathrm{ms}^{2}\right)$} & \multicolumn{3}{|c|}{ Razão BF / AF } & \multicolumn{3}{|c|}{ Área Nor. BF } & \multicolumn{3}{|c|}{ Área Nor. AF } \\
\hline & SUP & ORT & $\Delta \%$ & SUP & ORT & $\Delta \%$ & SUP & ORT & $\Delta \%$ & SUP & ORT & $\Delta \%$ \\
\hline Média & 6082,1 & 4704,0 & $-40,5$ & 0,9 & 4,3 & 70,9 & 41,6 & 71,9 & 42,8 & 58,4 & 28 & $-163,9$ \\
\hline DP & 3999,2 & 2444,0 & 78,1 & 0,7 & 4,5 & 20,1 & 18,9 & 13,6 & 22,7 & 19,0 & 13,6 & 154,7 \\
\hline Máx & 16645,2 & 10087,6 & 70,3 & 2,2 & 17,1 & 92,5 & 68,3 & 94,5 & 83,5 & 90,7 & 45,1 & $-21,3$ \\
\hline Qtl Sup & 8453,2 & 6051,3 & 18,3 & 1,2 & 4,5 & 88,3 & 55,2 & 81,9 & 64,5 & 72,9 & 40,0 & $-60,9$ \\
\hline Mediana & 5257,1 & 4737,7 & $-38,1$ & 0,7 & 2,2 & 73,3 & 42,8 & 68,7 & 33,3 & 57,1 & 31,3 & $-97,8$ \\
\hline Qtl Inf & 3291,4 & 2900,3 & $-58,3$ & 0,4 & 1,5 & 56,4 & 27,1 & 60,0 & 25,0 & 44,8 & 18,0 & $-184,2$ \\
\hline Mín & 1053,1 & 1403,5 & $-227,7$ & 0,1 & 1,2 & 32,2 & 9,3 & 54,9 & 17,6 & 31,7 & 5,5 & $-492,6$ \\
\hline $\mathrm{p}^{*}$ & & 0,13 & & & $<0,01$ & & & $<0,01$ & & & $<0,01$ & \\
\hline
\end{tabular}

SUP = supino; ORT $=$ ortostático; $\Delta \%=$ diferenças individuais percentuais entre a postura supina e ortostática; BF: baixa frequência; AF: Alta frequência; Nor.: normalizada; DP = Desvio padrão; Máx = Valor amostral máximo; Qtl = Quartil; Sup = superior; Inf = inferior; Mín = valor amostral mínimo; $\mathrm{p}^{*}=$ teste de Wilcoxon. 
TABELA 06 - Índices temporais da variabilidade da frequência cardíaca durante 5 minutos na posição supina e ortostática, na condição de repouso, no período de caracterização da amostra (n=14).

\begin{tabular}{|c|c|c|c|c|c|c|c|c|c|c|c|c|c|c|c|}
\hline & \multicolumn{3}{|c|}{ Média (ms) } & \multicolumn{3}{|c|}{$\mathrm{DP}(\mathrm{ms})$} & \multicolumn{3}{|c|}{$\mathrm{CV}(\%)$} & \multicolumn{3}{|c|}{ pNN50 (\%) } & \multicolumn{3}{|c|}{ r-MSSD (ms) } \\
\hline & SUP & ORT & $\Delta \%$ & SUP & ORT & $\Delta \%$ & SUP & ORT & $\Delta \%$ & SUP & ORT & $\Delta \%$ & SUP & ORT & $\Delta \%$ \\
\hline Média & 1046,9 & 795,6 & $-31,9$ & 76,0 & 67,7 & $-15,2$ & 7,3 & 8,5 & 12,4 & 49,7 & 17,3 & $-478,8$ & 77,8 & 38,5 & $-114,6$ \\
\hline DP & 106,5 & 72,9 & 11,0 & 26,2 & 19,6 & 33,6 & 2,5 & 2,3 & 25,4 & 17,9 & 12,9 & 572,0 & 30,2 & 14,5 & 76,1 \\
\hline Máx & 1201,3 & 925,6 & $-10,9$ & 134,4 & 108,3 & 48,9 & 11,4 & 12,9 & 61,0 & 81,0 & 34,0 & $-42,5$ & 138,8 & 56,1 & $-16,4$ \\
\hline Qtl Sup & 1138,6 & 846,7 & $-23,3$ & 94,5 & 80,3 & 5,4 & 9,1 & 9,7 & 28,9 & 56,3 & 30,2 & $-126,7$ & 82,2 & 52,9 & $-49,7$ \\
\hline Mediana & 1032,1 & 788,6 & $-32,4$ & 72,7 & 71,1 & $-17,4$ & 7,2 & 8,5 & 15,5 & 48,7 & 17,7 & $-177,6$ & 70,7 & 37,0 & $-104,3$ \\
\hline Qtl Inf & 965,9 & 743,8 & $-39,9$ & 57,9 & 53,5 & $-24,9$ & 5,2 & 6,8 & $-2,8$ & 44,2 & 3,6 & $-865,3$ & 63,0 & 24,8 & $-166,5$ \\
\hline Mín & 867,7 & 643,7 & $-51,6$ & 32,9 & 37,8 & $-84,0$ & 3,5 & 5,1 & $-37,7$ & 2,6 & 0,8 & $-1781,6$ & 23,2 & 17,3 & $-227,8$ \\
\hline $\mathrm{p}^{*}$ & \multicolumn{3}{|c|}{$<0,01$} & \multicolumn{3}{|c|}{0,09} & \multicolumn{3}{|c|}{0,15} & \multicolumn{3}{|c|}{$<0,01$} & \multicolumn{3}{|c|}{$<0,01$} \\
\hline
\end{tabular}

SUP = supino; ORT = ortostático; $\Delta \%$ = diferenças individuais percentuais entre a postura supina e ortostática; DP = Desvio padrão; CV = coeficiente de variação; Máx = Valor amostral máximo; Qtl = Quartil; Sup = superior; Inf = inferior; Mín = valor amostral mínimo; $\mathrm{p}^{*}=$ teste de Wilcoxon. 


\subsection{ANÁLISE DA FAC REPouso E DA FAC INICIAL AVALIADA PELOS ÍNDICES DE POINCARÉ, NO DOMÍNIO TEMPORAL E ESPECTRAL}

\subsubsection{COMPARAÇÃO ENTRE A FACREPOUSO, DURANTE A CARACTERIZAÇÃO DA AMOSTRA E A FAC INICIAL ANTES DA SESSÃO DE TR, AVALIADA PELOS ÍNDICES DE POINCARÉ DA VFC}

A Tabela 08 apresenta a comparação entre os valores amostrais da FAC, por meio dos índices de Poincaré da VFC na condição repouso e inicial, nas posições supina e ortostática, obtidos durante o período de caracterização da amostra e antes da sessão de TR.

As descrições a seguir, traduzem os ajustes autonômicos, por meio da variabilidade da frequência cardíaca, em duas condições funcionais (condição basal) e momentos funcionais diferentes (posição supina e posição ortostática).

Verificou-se que, na posição supina durante a caracterização da amostra comparada com a posição supina prévia a sessão de TR, não foram observadas diferenças significativas entre os índices de Poincaré: SD1, SD2 e a razão SD1/SD2. Ao passo que quando a posição ortostática durante a caracterização da amostra foi comparada a posição ortostática anterior a sessão de TR, observou-se diferença significativa $(\mathrm{p}=0,05)$ apenas no índice SD1. Não foi observado diferença significativa entre os índices de Poincaré SD2 e a razão SD1/SD2 durante a caracterização da amostra comparada a posição ortostática antes da sessão de TR.

Contudo, observa-se que ao comparar as diferenças individuais percentuais, após o estresse ortostático, o marcador SD1 de atividade vagal e do marcador SD1/SD2 de balaço autonômico, foi observado comportamento semelhante com redução mediana de -104,1 (-166,7 - -49,7)\% e de -94,7 $(-169,7--67,5) \%$, respectivamente, durante a caracterização da amostra, e uma redução mediana de $-155,1(-227,9--55) \%$ e de $-93(-157,9--72,3) \%$, respectivamente, antes da sessão de TR, e não apresentou diferença significativa $(\mathrm{p}=0,32-0,86)$. 


\subsubsection{COMPARAÇÃO ENTRE A FAC REPOUSO, DURANTE A CARACTERIZAÇÃO DA}

AMOSTRA E A FAC INICIAL ANTES DA SESSÃO DE TR, AVALIADA PELOS ÍNDICES TEMPORAIS DA VFC

A Tabela 09 e 09.1 apresenta a comparação entre os valores amostrais da FAC, por meio dos índices do domínio temporal da VFC na condição repouso e inicial, nas posições supina e ortostática, obtidos durante o período de caracterização da amostra e antes da sessão de TR.

Quando comparada a posição supina durante a caracterização da amostra com a posição supina antes da sessão de TR, não foi observado diferença significativa entre os índices temporais de média do iRR, desvio padrão, coeficiente de variação, pNN50 e rMSSD. Já quando comparada a posição ortostática durante a caracterização da amostra com a posição ortostática antes da sessão de TR, foi observado diferenças significativas $(p=0,04-0,05)$ apenas no índice média do iRR e rMSSD, respectivamente. Não foi observado diferença significativa entre os índices temporais desvio padrão, coeficiente de variação e pNN50.

Contudo, observou-se que quando comparada as diferenças individuais percentuais, após o estresse ortostático, ocorreu taquicardia com redução mediana semelhante da média iRR [-32,4 (39,9 - -23,3) ms] durante a caracterização da amostra e uma redução mediana da média iRR [-40,5 $(-46,1--23,4) \mathrm{ms}]$ antes da sessão de TR, sem apresentar diferença significativa $(p=0,26)$.

Quanto aos marcadores de atividade vagal (pNN50 e rMSSD), ao comparar as diferenças individuais percentuais, após o estresse ortostático, observou-se uma redução mediana semelhante de pNN50 [-177,6 (-865,3 - -126,7) \%] e rMSSD [-104,3 (-166,5 - -49,7) ms] durante a caracterização da amostra, e redução mediana de pNN50 [-523,3 (-1844,4 - -183,6) \% ] e de rMSSD [-164,2 (-227,7 - -54,9) ms] prévias à sessão de TR, sem diferença significativa $(\mathrm{p}=0,13-0,32)$, respectivamente. 


\subsubsection{COMPARAÇÃO ENTRE A FAC REPouso, DURANTE A CARACTERIZAÇÃO DA}

AMOSTRA E A FAC INICIAL ANTES DA SESSÃO DE TR, AVALIADA PELOS ÍNDICES ESPECTRAIS DA VFC

A Tabela 10 e 10.1 apresenta a comparação entre os valores amostrais da FAC, por meio dos índices do domínio espectral da VFC na condição repouso e inicial, nas posições supina e ortostática, obtidos durante o período de caracterização da amostra e antes da sessão de TR.

Quando comparado a posição supina durante a caracterização da amostra com a posição supina antes da sessão de TR, não foi observado diferença significativa entre os índices temporais Área Total, Razão BF/AF, Área normalizada de BF e Área normalizada de AF, o mesmo ocorreu para a posição ortostática.

Tanto na caracterização da amostra quanto antes da sessão de TR, o balanço autonômico cardíaco na posição supina na condição basal, foi compatível com a predominância vagotônica, conforme descrito na Tabela 10.

As diferenças individuais percentuais, após o estresse ortostático, apresentaram um aumento mediano de 73,3 (56,4 - 88,3)\% do balanço autonômico cardíaco e redução vagal avaliada pela área normalizada de AF [-97,8 (-184,2 - -60,9)], durante a caracterização da amostra, e aumento [81,6 (73 - 86,5)\%] do balanço autonômico cardíaco e redução vagal avaliada pela área normalizada de AF 204,4 (-233,5 - -125,9) antes da sessão de TR, sem diferença significativa $(\mathrm{p}=0,48-0,19)$ ao comparar ambas diferenças individuais percentuais, respectivamente.

Em ambas as condições funcionais, houve uma mudança de um predomínio vagotônico para a predominância simpaticotônica, apresentando uma dinâmica semelhante durante o período de caracterização da amostra e antes da sessão de TR. 
TABELA 08 - Função autonômica cardíaca durante a caracterização da amostra com a função autonômica cardíaca antes da sessão de treino resistido, avaliada pelos índices de Poincaré da variabilidade da frequência cardíaca $(\mathrm{n}=14)$.

\begin{tabular}{|c|c|c|c|c|c|c|c|c|c|c|c|c|c|c|c|c|c|c|}
\hline & \multicolumn{6}{|c|}{ SD1 } & \multicolumn{6}{|c|}{ SD2 } & \multicolumn{6}{|c|}{ SD1/SD2 } \\
\hline & $\mathrm{SUP}_{1}$ & $\mathrm{SUP}_{2}$ & $\mathrm{ORT}_{1}$ & $\mathrm{ORT}_{2}$ & $\Delta \% 1$ & $\Delta \% 2$ & $\mathrm{SUP}_{1}$ & $\mathrm{SUP}_{2}$ & $\mathrm{ORT}_{1}$ & $\mathrm{ORT}_{2}$ & $\Delta \% 1$ & $\Delta \% 2$ & $\mathrm{SUP}_{1}$ & $\mathrm{SUP}_{2}$ & $\mathrm{ORT}_{1}$ & $\mathrm{ORT}_{2}$ & $\Delta \% 1$ & $\Delta \% 2$ \\
\hline Média & 55,1 & 50 & 27,3 & 20,8 & $-114,6$ & $-206,2$ & 91,5 & 84,4 & 91,6 & 73,5 & $-2,2$ & $-26,3$ & 0,6 & 0,6 & 0,3 & 0,3 & $-114,2$ & $-126,4$ \\
\hline DP & 21,4 & 25,7 & 10,3 & 13,5 & 76,1 & 233,4 & 33,0 & 29,9 & 26,4 & 28,4 & 31,7 & 50,2 & 0,2 & 0,2 & 0,1 & 0,1 & 59,0 & 82,9 \\
\hline Max & 98,3 & 106,1 & 39,8 & 56,5 & $-16,4$ & $-23,4$ & 162,9 & 145,9 & 148,9 & 125,4 & 56,2 & 33,1 & 1,1 & 1,0 & 0,4 & 0,5 & $-38,3$ & $-46,6$ \\
\hline Qtl Sup & 58,2 & 56,0 & 37,5 & 25,8 & $-49,7$ & $-55,0$ & 112,2 & 107,9 & 107,8 & 86,7 & 15,5 & 13,9 & 0,7 & 0,7 & 0,3 & 0,3 & $-72,4$ & $-72,3$ \\
\hline Mediana & 50,1 & 43,8 & 26,2 & 16,1 & $-104,1$ & $-164,3$ & 90,9 & 82,8 & 95,3 & 70,9 & 5,1 & $-22,2$ & 0,6 & 0,5 & 0,3 & 0,2 & $-94,7$ & -93 \\
\hline Qtl Inf & 44,6 & 33,7 & 17,5 & 12,4 & $-166,7$ & $-227,9$ & 67,7 & 56,8 & 73,8 & 57,7 & $-16,9$ & $-48,5$ & 0,5 & 0,4 & 0,2 & 0,2 & $-169,7$ & $-157,9$ \\
\hline Min & 16,5 & 15,1 & 12,3 & 5,1 & $-228,0$ & $-904,7$ & 43,3 & 47,4 & 50,6 & 21,7 & $-69,6$ & $-127,8$ & 0,4 & 0,3 & 0,2 & 0,2 & $-224,5$ & $-340,9$ \\
\hline $\mathrm{p}^{*}$ & \multicolumn{2}{|c|}{0,26} & \multicolumn{2}{|c|}{0,05} & \multicolumn{2}{|c|}{0,32} & \multicolumn{2}{|c|}{0,62} & \multicolumn{2}{|c|}{0,10} & \multicolumn{2}{|c|}{0,32} & \multicolumn{2}{|c|}{0,69} & \multicolumn{2}{|c|}{0,17} & \multicolumn{2}{|c|}{0,86} \\
\hline
\end{tabular}

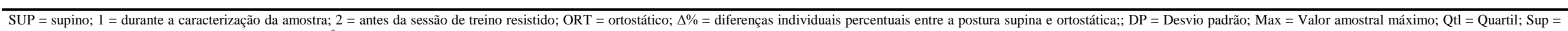
superior; Inf = inferior; Min = valor amostral mínimo; $\mathrm{p}^{*}=$ teste de Mann-Whitney. 
TABELA 09 - Função autonômica cardíaca durante a caracterização da amostra com a função autonômica cardíaca antes da sessão de treino resistido, avaliada pelos índices temporais da variabilidade da frequência cardíaca $(\mathrm{n}=14)$.

\begin{tabular}{|c|c|c|c|c|c|c|c|c|c|c|c|c|c|c|c|c|c|c|}
\hline & \multicolumn{6}{|c|}{ Média (ms) } & \multicolumn{6}{|c|}{ DP (ms) } & \multicolumn{6}{|c|}{$\mathrm{CV}(\%)$} \\
\hline & $\mathrm{SUP}_{1}$ & $\mathrm{SUP}_{2}$ & $\mathrm{ORT}_{1}$ & $\mathrm{ORT}_{2}$ & $\Delta \% 1$ & $\Delta \% 2$ & $\mathrm{SUP}_{1}$ & $\mathrm{SUP}_{2}$ & $\mathrm{ORT}_{1}$ & $\mathrm{ORT}_{2}$ & $\Delta \% 1$ & $\Delta \% 2$ & $\mathrm{SUP}_{1}$ & $\mathrm{SUP}_{2}$ & $\mathrm{ORT}_{1}$ & $\mathrm{ORT}_{2}$ & $\Delta \% 1$ & $\Delta \% 2$ \\
\hline Média & 1046,9 & 1018,7 & 795,6 & 735,7 & $-31,9$ & $-38,9$ & 76,0 & 70,0 & 67,7 & 54,2 & $-15,2$ & $-44,9$ & 7,3 & 6,8 & 8,5 & 7,2 & 12,4 & $-1,9$ \\
\hline DP & 106,5 & 163,5 & 72,9 & 103,2 & 11 & 16,2 & 26,2 & 26,3 & 19,6 & 21,8 & 33,6 & 68,0 & 2,5 & 2,1 & 2,3 & 2,4 & 25,4 & 38,6 \\
\hline Max & 1201,3 & 1340,9 & 925,6 & 965,0 & $-10,9$ & $-16,2$ & 134,4 & 127,5 & 108,3 & 94,4 & 48,9 & 29,5 & 11,4 & 10,5 & 12,9 & 11,6 & 61,0 & 41,7 \\
\hline Qtl Sup & 1138,6 & 1083,9 & 846,7 & 793,6 & $-23,3$ & $-23,4$ & 94,5 & 85,2 & 80,3 & 64,5 & 5,4 & 3,2 & 9,1 & 8,1 & 9,7 & 9,0 & 28,9 & 25,1 \\
\hline Mediana & 1032,1 & 1030,2 & 788,6 & 704,7 & $-32,4$ & $-40,5$ & 72,7 & 65,0 & 71,1 & 51,9 & $-17,4$ & $-31,2$ & 7,2 & 6,7 & 8,5 & 6,9 & 15,5 & 5,6 \\
\hline Qtl Inf & 965,9 & 916,9 & 743,8 & 656,5 & $-39,9$ & $-46,1$ & 57,9 & 51,1 & 53,5 & 41,6 & $-24,9$ & $-73,4$ & 5,2 & 5,0 & 6,8 & 6,1 & $-2,8$ & $-26,3$ \\
\hline Min & 867,7 & 767,6 & 643,7 & 628,1 & $-51,6$ & $-64,7$ & 32,9 & 35,4 & 37,8 & 15,8 & $-84,0$ & $-218,3$ & 3,5 & 3,8 & 5,1 & 2,5 & $-37,7$ & $-93,2$ \\
\hline $\mathrm{p}^{*}$ & \multicolumn{2}{|c|}{0,50} & \multicolumn{2}{|c|}{0,04} & \multicolumn{2}{|c|}{0,26} & \multicolumn{2}{|c|}{0,53} & \multicolumn{2}{|c|}{0,10} & \multicolumn{2}{|c|}{0,30} & \multicolumn{2}{|c|}{0,65} & \multicolumn{2}{|c|}{0,19} & \multicolumn{2}{|c|}{0,44} \\
\hline
\end{tabular}

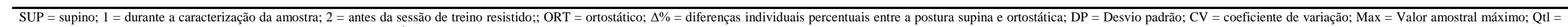
Quartil; Sup = superior; Inf = inferior; Min = valor amostral mínimo; $\mathrm{p}^{*}=$ teste de Mann-Whitney, 
TABELA. 09.1 - Função autonômica cardíaca durante a caracterização da amostra com a função autonômica cardíaca antes da sessão de treino resistido, avaliada pelos índices temporais da variabilidade da frequência cardíaca $(\mathrm{n}=14)$.

\begin{tabular}{|c|c|c|c|c|c|c|c|c|c|c|c|c|}
\hline & \multicolumn{6}{|c|}{ pNN50 (\%) } & \multicolumn{6}{|c|}{ rMSSD (ms) } \\
\hline & $\mathrm{SUP}_{1}$ & $\mathrm{SUP}_{2}$ & $\mathrm{ORT}_{1}$ & $\mathrm{ORT}_{2}$ & $\Delta \% 1$ & $\Delta \% 2$ & $\mathrm{SUP}_{1}$ & $\mathrm{SUP}_{2}$ & $\mathrm{ORT}_{1}$ & $\mathrm{ORT}_{2}$ & $\Delta \% 1$ & $\Delta \% 2$ \\
\hline Média & 49,7 & 42,6 & 17,3 & 10,5 & $-478,8$ & $-6457,1$ & 77,8 & 70,6 & 38,5 & 29,4 & $-114,6$ & $-206,0$ \\
\hline $\mathrm{DP}$ & 17,9 & 21,4 & 12,9 & 14,4 & 572,0 & 15480,5 & 30,2 & 36,2 & 14,5 & 19,0 & 76,1 & 233,1 \\
\hline Max & 81,0 & 79,7 & 34,0 & 48,9 & $-42,5$ & $-2,3$ & 138,8 & 149,8 & 56,1 & 79,8 & $-16,4$ & $-23,4$ \\
\hline Qtl Sup & 56,3 & 54,1 & 30,2 & 13 & $-126,7$ & $-183,6$ & 82,2 & 79,1 & 52,9 & 36,5 & $-49,7$ & $-54,9$ \\
\hline Mediana & 48,7 & 46,8 & 17,7 & 4,0 & $-177,6$ & $-523,3$ & 70,7 & 61,9 & 37,0 & 22,7 & $-104,3$ & $-164,2$ \\
\hline Qtl Inf & 44,2 & 31,0 & 3,6 & 1,4 & $-865,3$ & $-1844,4$ & 63,0 & 47,5 & 24,8 & 17,5 & $-166,5$ & $-227,7$ \\
\hline Min & 2,6 & 2,2 & 0,8 & 0,1 & $-1781,6$ & -55100 & 23,2 & 21,3 & 17,3 & 7,2 & $-227,8$ & $-903,3$ \\
\hline $\mathrm{p}^{*}$ & \multicolumn{2}{|c|}{0,37} & \multicolumn{2}{|c|}{0,09} & \multicolumn{2}{|c|}{0,13} & \multicolumn{2}{|c|}{0,26} & \multicolumn{2}{|c|}{0,05} & \multicolumn{2}{|c|}{0,32} \\
\hline
\end{tabular}

SUP = supino; 1 = durante a caracterização da amostra; $2=$ antes da sessão de treino resistido; ORT = ortostático; $\Delta \%=$ diferenças individuais percentuais entre a postura supina e ortostática; DP = Desvio padrão; Max = Valor amostral máximo; Qt1 = Quartil; Sup = superior; Inf = inferior; Min = valor amostral mínimo; $\mathrm{p}^{*}=$ teste de Mann-Whitney. 
TABELA 10 - Função autonômica cardíaca durante a caracterização da amostra com a função autonômica cardíaca antes da sessão de treino resistido, avaliada pelos índices espectrais da variabilidade da frequência cardíaca $(n=14)$.

\begin{tabular}{|c|c|c|c|c|c|c|c|c|c|c|c|c|}
\hline & \multicolumn{6}{|c|}{ Área Total $\left(\mathrm{ms}^{2}\right)$} & \multicolumn{6}{|c|}{ Razão BF / AF } \\
\hline & $\mathrm{SUP}_{1}$ & $\mathrm{SUP}_{2}$ & $\mathrm{ORT}_{1}$ & $\mathrm{ORT}_{2}$ & $\Delta \%_{1}$ & $\Delta \% \%_{2}$ & $\mathrm{SUP}_{1}$ & $\mathrm{SUP}_{2}$ & $\mathrm{ORT}_{1}$ & $\mathrm{ORT}_{2}$ & $\Delta \%_{1}$ & $\Delta \%{ }_{2}$ \\
\hline Média & 6082,1 & 5256,5 & 4704,0 & 3355 & $-40,5$ & $-131,3$ & 0,9 & 0,9 & 4,3 & 4,4 & 70,9 & 80,6 \\
\hline $\mathrm{DP}$ & 3999,2 & 4077,9 & 2444,0 & 2534,5 & 78,1 & 216,4 & 0,7 & 0,7 & 4,5 & 2,6 & 20,1 & 8,4 \\
\hline Max & 16645,2 & 15913,1 & 10087,6 & 9205,8 & 70,3 & 55,0 & 2,2 & 2,5 & 17,1 & 10,2 & 92,5 & 93,6 \\
\hline Qtl Sup & 8453,2 & 7263,7 & 6051,3 & 4371,9 & 18,3 & 11,6 & 1,2 & 1,2 & 4,5 & 5,7 & 88,3 & 86,5 \\
\hline Mediana & 5257,1 & 3631,1 & 4737,7 & 2707,5 & $-38,1$ & $-65,9$ & 0,7 & 0,6 & 2,2 & 4,1 & 73,3 & 81,6 \\
\hline Qtl Inf & 3291,4 & 2388,6 & 2900,3 & 1722,6 & $-58,3$ & $-198,6$ & 0,4 & 0,3 & 1,5 & 2,6 & 56,4 & 73,0 \\
\hline Min & 1053,1 & 1174,7 & 1403,5 & 252,0 & $-227,7$ & $-755,2$ & 0,1 & 0,3 & 1,2 & 1,3 & 32,2 & 66,7 \\
\hline
\end{tabular}

SUP = supino; 1 = durante a caracterização da amostra; 2 = antes da sessão de treino resistido; ORT = ortostático; $\Delta \%$ = diferenças individuais percentuais entre a postura supina e ortostática; BF: baixa frequência; AF: Alta frequência; DP = Desvio padrão; Max = Valor amostral máximo; Qtl = Quartil; Sup = superior; Inf = inferior; Min = valor amostral mínimo; $\mathrm{p}^{*}=$ teste de Mann-Whitney. 
TABELA 10.1 - Função autonômica cardíaca durante a caracterização da amostra com a função autonômica cardíaca antes da sessão de treino resistido, avaliada pelos índices espectrais da variabilidade da frequência cardíaca $(n=14)$.

\begin{tabular}{|c|c|c|c|c|c|c|c|c|c|c|c|c|}
\hline & \multicolumn{6}{|c|}{ Área Nor. BF } & \multicolumn{6}{|c|}{ Área Nor. AF } \\
\hline & $\mathrm{SUP}_{1}$ & $\mathrm{SUP}_{2}$ & $\mathrm{ORT}_{1}$ & $\mathrm{ORT}_{2}$ & $\Delta \% 1$ & $\Delta \% 2$ & $\mathrm{SUP}_{1}$ & $\mathrm{SUP}_{2}$ & $\mathrm{ORT}_{1}$ & $\mathrm{ORT}_{2}$ & $\Delta \% 1$ & $\Delta \% 2$ \\
\hline Média & 41,6 & 41,0 & 71,9 & 77,5 & 42,8 & 48,1 & 58,4 & 59,0 & 28 & 22,5 & $-163,9$ & $-187,1$ \\
\hline DP & 18,9 & 17,0 & 13,6 & 10,5 & 22,7 & 16,8 & 19,0 & 17,0 & 13,6 & 10,5 & 154,7 & 75,4 \\
\hline Max & 68,3 & 71,2 & 94,5 & 91,0 & 83,5 & 73,3 & 90,7 & 78,4 & 45,1 & 43,2 & $-21,3$ & $-65,0$ \\
\hline Qtl Sup & 55,2 & 53,3 & 81,9 & 85,0 & 64,5 & 60,2 & 72,9 & 74,9 & 40,0 & 27,7 & $-60,9$ & $-125,9$ \\
\hline Mediana & 42,8 & 38,7 & 68,7 & 80,5 & 33,3 & 47,9 & 57,1 & 61,3 & 31,3 & 19,5 & $-97,8$ & $-204,4$ \\
\hline Qtl Inf & 27,1 & 25,0 & 60,0 & 72,3 & 25 & 37,5 & 44,8 & 46,6 & 18,0 & 15,0 & $-184,2$ & $-233,5$ \\
\hline Min & 9,3 & 21,6 & 54,9 & 56,8 & 17,6 & 21,8 & 31,7 & 28,8 & 5,5 & 9,0 & $-492,6$ & $-307,8$ \\
\hline $\mathrm{p}^{*}$ & \multicolumn{2}{|c|}{0,86} & \multicolumn{2}{|c|}{0,28} & \multicolumn{2}{|c|}{0,34} & \multicolumn{2}{|c|}{0,86} & \multicolumn{2}{|c|}{0,28} & \multicolumn{2}{|c|}{0,13} \\
\hline
\end{tabular}

frequência; Nor.: normalizada; DP = Desvio padrão; Max = Valor amostral máximo; Qtl = Quartil; Sup = superior; Inf = inferior; Min = valor amostral mínimo; $\mathrm{p}^{*}=$ teste de Mann-Whitney. 


\subsection{A FORÇA E VARIÁ VEIS DE CONTROLE DE SOBRECARGA DURANTE UMA SESSÃO DE TREINO RESISTIDO}

\subsubsection{VALORES AMOSTRAIS DA FORÇA DURANTE A CARACTERIZAÇÃO DA}

AMOSTRA

A FIGURA 12 descreve o pico de torque (absoluto e relativo) dos valores amostrais (mediana e extremos) da perna dominante no teste de força máxima na extensão de joelho, avaliada pelo equipamento isocinético, durante a caracterização da amostra. O valor mediano do pico de torque absoluto foi de $251,2(232,53-268,6) \mathrm{N}-\mathrm{M}$ e de pico de torque relativo de $321,7(297,4$ - 341,2). Sete voluntários (50\%) obtiveram o pico de torque absoluto abaixo da mediana e os outros sete voluntários acima da mediana do grupo. Semelhante distribuição foi observada no pico de torque relativo. Assim, os dados apresentam uma dispersão esperada da força.

\subsubsection{ANÁLISE COMPARATIVA ENTRE AS VARIÁVEIS DE CONTROLE DA SOBRECARGA DURANTE A SESSÃO DE TREINO RESISTIDO}

Na Tabela 11 estão descritas as variáveis de controle da sobrecarga, durante a sessão de treino resistido e na FIGURA 14 estão descritos os comportamentos das variáveis de controle da sobrecarga, durante a sessão de treino resistido.

Os voluntários realizaram entre 8-12RM em todas as séries, com valor mediano número $9,5(9,0-11,8)$ na $1^{\circ}$ série, $8,5(8,0-9,8)$ na $2^{\circ}$ série e $9,0(8,0-9,0)$ repetições na $3^{\circ}$ série, durante a realização da sessão de TR. O número de repetições nas séries realizadas não diferiu significativamente $(\mathrm{p}>0,01)$. Quanto ao tempo de tensão nas séries, observou-se comportamento semelhante ao das repetições máximas, com valores medianos de 32,0 (27,6 $34,4)$ s na $1^{\circ}$ série, $29(26,7-32,2)$ s na $2^{\circ}$ série e $29(27,2-32,0)$ s na $3^{\circ}$ série.

Quando comparada as cargas $(\mathrm{kg})$ foi observado diferença significativa $(\mathrm{p} \leq 0,01)$ da $1^{\circ}$ série $[80,0(72,5-85,0) \mathrm{kg}]$ com a $3^{\circ}$ série $[75,0(62,5-80,0) \mathrm{kg}]$, e ao comparar a carga 
utilizada na $2^{\circ}$ série $[80,0(67,5-85,0) \mathrm{kg}]$ com a $3^{\circ}$ série $[75,0(62,5-80,0) \mathrm{kg}$. Não foi observado diferença significativa nas cargas utilizadas na $1^{\circ}$ série e a $2^{\circ}$ série, durante a sessão de TR.

O volume de treino apresentou diferença significativa $(p<0,01)$ apenas na $1^{\circ}$ série $\left[743,0\left(670,0\right.\right.$ - 895,0) kg] em relação a $3^{\circ}$ série $[650,0(570,0$ - 710,0) kg]. Não foi observado diferença significativa no volume de treino nas demais séries.

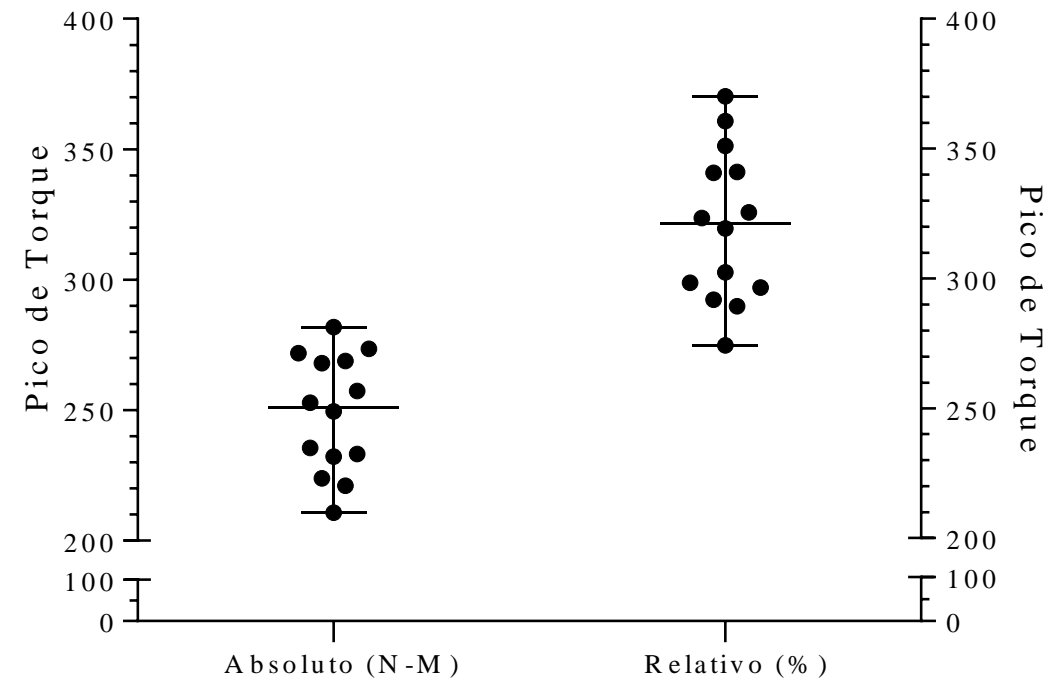

FIGURA 13 -Pico de torque, absoluto e relativo, da perna dominante no teste de força máxima na extensão de joelho durante a caracterização da amostra. Estão indicados a mediana e os valores extremos $(\mathrm{n}=14)$.

TABELA 11 - Variáveis de controle de sobrecarga durante uma sessão de treino resistido $(\mathrm{n}=14)$.

\begin{tabular}{|c|c|c|c|c|c|c|c|c|c|c|c|c|}
\hline & \multicolumn{3}{|c|}{ Tempo de tensão (s) } & \multicolumn{3}{|c|}{ Número de Repetições } & \multicolumn{3}{|c|}{ Carga (kg) } & \multicolumn{3}{|c|}{ Volume de treino $(\mathrm{kg})$} \\
\hline & $1^{\circ}$ série & $2^{\circ}$ série & $3^{\circ}$ série & $1^{\circ}$ série & $2^{\circ}$ série & $3^{\circ}$ série & $1^{\circ}$ série & $2^{\circ}$ série & $3^{\circ}$ série & $1^{\circ}$ série & $2^{\circ}$ série & $3^{\circ}$ série \\
\hline Média & 31,4 & 29,5 & 29,5 & 10,0 & 8,9 & 8,9 & 77,9 & 75,0 & 70,4 & 778,9 & 664,3 & 618,0 \\
\hline DP & 4,7 & 4,3 & 3,0 & 1,5 & 1,0 & 0,9 & 13,0 & 13,6 & 13,9 & 182,1 & 139,1 & 112,9 \\
\hline Max & 39,8 & 40,0 & 35,0 & 12,0 & 11,0 & 11,0 & 95,0 & 95,0 & 90,0 & 1140 & 850,0 & 750,0 \\
\hline Qtl Sup & 34,4 & 32,2 & 32,0 & 11,8 & 9,8 & 9,0 & 85,0 & 85,0 & 80,0 & 895,0 & 763,8 & 710,0 \\
\hline Mediana & 32,0 & 29,0 & 29,0 & 9,5 & 8,5 & 9,0 & 80,0 & 80,0 & 75,0 & 743,0 & 698,0 & 650,0 \\
\hline Qtl Inf & 27,6 & 26,7 & 27,2 & 9,0 & 8,0 & 8,0 & 72,5 & 67,5 & 62,5 & 670,0 & 600,0 & 570,0 \\
\hline Min & 24,1 & 22,5 & 25,2 & 8,0 & 8,0 & 8,0 & 55,0 & 50,0 & 45,0 & 495,0 & 440,0 & 400,0 \\
\hline $\mathrm{p}^{*}$ & & & & & & & $\begin{array}{l}1^{\circ} \text { séric } \\
2^{\circ} \text { séric }\end{array}$ & $3^{\circ}$ sér & $\begin{array}{l}<0,01 \\
=0,01\end{array}$ & $1^{\circ}$ sé & s $3^{\circ}$ sér & $0<0,01$ \\
\hline
\end{tabular}

DP = Desvio padrão; Máx = Valor amostral máximo; Qtl = Quartil; Sup = superior; Inf = inferior; Mín = valor amostral mínimo; p* = teste de Friedman com post hoc Dunn . 


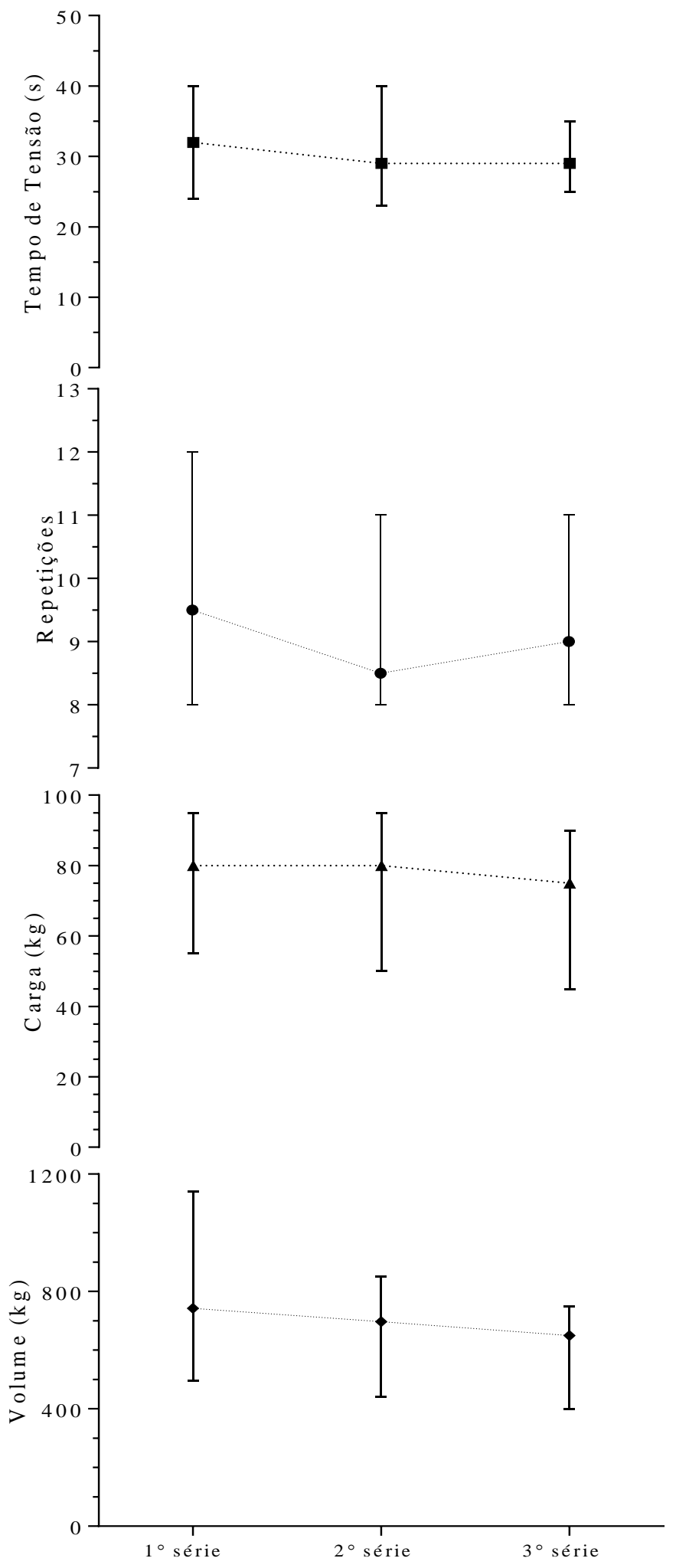

FIGURA 14 - Controle da sobrecarga durante uma sessão de treino resistido, estão indicados a mediana e extremos $(n=14)$. 


\subsection{FUNÇÃO AUTONÔMICA CARDÍACA ANTES E APÓS A SESSÃo DE \\ TREINO RESISTIDO, AVALIADA PELOS ÍNDICES DE POINCARÉ, NO \\ DOMÍNIO TEMPORAL E ESPECTRAL}

\subsubsection{FAC AVALIADA PELOS ÍNDICES DE POINCARÉ DA VFC, ANTES E AO LONGO DE 15 MINUTOS APÓS A SESSÃO DE TR}

Na Tabela 12, estão descritos os valores amostrais dos índices de Poincaré da VFC durante o registro de cinco minutos na posição supina, na condição inicial e, ao longo de 15 minutos, após a sessão de TR.

Nas FIGURAS 15 a 17 estão descritos os comportamentos da FAC, avaliada pelos índices de Poincaré da VFC, na condição inicial e, ao longo de 15 minutos, após a sessão de TR.

Observa-se que a comparação entre os dois momentos funcionais do marcador SD1, marcador da atividade vagal, apresentou uma redução significativa $(\mathrm{p}<0,01)$ ao longo de toda a fase de recuperação $10,3\left(4,4\right.$ - 24,5) SD1 $1_{\text {min, }}$ 12,3 (6,1 - 22,9) SD1 $1_{10 \min }$ e 13,3 (7 - 20,9)

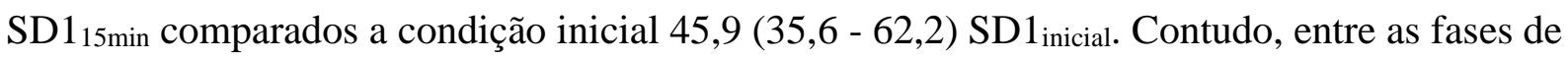
recuperação, não foi observado diferença significativa.

O SD2, marcador de modulação global, apresentou um aumento mediano [124,3 (95,1 - 145,7) SD25min] nos primeiros cinco minutos da fase de recuperação em comparação com a

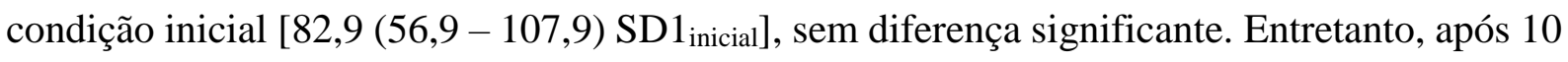
minutos [40,1 (25 - 55,1) SD2 $10 \mathrm{~min}]$ e 15 minutos $\left[49,9(33,8-54,0) \mathrm{SD} 2_{15 \mathrm{~min}}\right]$ da fase de recuperação, houve uma redução significativa $(\mathrm{p}<0,01)$ em comparação a condição inicial e com os primeiros 5 minutos de recuperação.

O marcador do balaço autonômico, razão SD1/SD2, apresentou uma redução significativa $(\mathrm{p} \leq 0,05)$ ao longo de toda a fase de recuperação $[0,08(0,05-0,1) \mathrm{SD} 1 / \mathrm{SD} 25 \min ]$ 0,2 (0,2 - 0,3) SD1/SD2 10 min e 0,2 $(0,2-0,3)$ SD1/SD2 15 min $]$ em comparação com a condição 
inicial $\left[0,5(0,4-0,7)\right.$ SD1/SD2 $\left.{ }_{\text {inicial }}\right]$. E, um aumento significativo $(p \leq 0,04)$ nos 10 e 15 minutos da fase de recuperação em comparação com cinco minutos da fase de recuperação.

\subsubsection{FAC AVALIADA PELOS ÍNDICES TEMPORAIS DA VFC ANTES E AO LONGO DE 15 MINUTOS, APÓS A SESSÃO DE TR}

As Tabela13 e Tabela 13.1, descrevem os valores amostrais dos índices temporais da VFC durante o registro de 5 minutos na posição supina, na condição inicial e ao longo de 15 minutos, após a sessão de TR.

Nas FIGURAS 18 a 22 estão descritos os comportamentos da FAC, avaliada pelos índices temporais da VFC, na condição inicial e, ao longo de 15 minutos, após a sessão de TR.

Dada a não estacionariedade do sinal, nos primeiros cinco minutos de recuperação, não foi possível realizar análise entre a condição inicial, 10 minutos e 15 minutos da fase de recuperação com os cinco minutos de recuperação imediatamente após o experimento.

Observa-se que a comparação entre os dois momentos funcionais da média iRR, diferem significativamente $(\mathrm{p} \leq 0,01)$ apresentando menores valores ao longo de toda a fase de recuperação [725,7 $(662,2$ - 762,8) ms média iRR 10 min e 752,3 $(698,4$ - 803,4) ms média iRR $15 \min$ ] comparada a condição inicial $\left[1030,2\right.$ (916,9 - 1083,9) ms média iRR inicial $_{\text {. Foi }}$ observado diferença significativa $(p=0,02)$ entre a média $i R R_{10 \min }[725,7(662,2-762,8) \mathrm{ms}]$ E a média $i_{R R} 15 \min [752,3(698,4-803,4) \mathrm{ms}]$.

Os índices pNN50 e rMSSD, ambos marcadores vagais, diferiram significativamente (p $<0,01)$ com menores valores de pNN50 $10 \min [0,6(0-9,9) \%]$, pNN50 $15 \min [2(0-6,9) \%]$, $\operatorname{rMSSD}_{10 \min }\left[17,3\left(8,6\right.\right.$ - 32,3) ms] e $\operatorname{rMSSD}_{15 \min }[18,8(9,8$ - 29,5) ms] comparados a condição

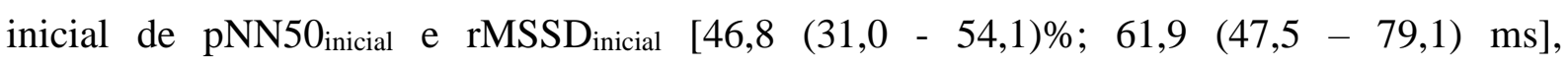
respectivamente. Contudo, não houve diferença significativa entre as fases de recuperação.

Já o DP, marcador de modulação global, ao ser comparado à condição inicial [65,0 (51,1 - 85,2) $\left.\mathrm{ms} \mathrm{DP}_{\text {inicial }}\right]$ com os 10 minutos $\left[32,9(18,3-41,5) \mathrm{ms} \mathrm{DP}_{10 \mathrm{~min}}\right]$ e 15 minutos $[37,2(24,5$ 
- 40,8) ms $\left.\mathrm{DP}_{15 \mathrm{~min}}\right]$ durante a fase de recuperação após a sessão de TR, apresentou redução significativa $(\mathrm{p}<0,01)$.

$\mathrm{O}$ índice temporal $\mathrm{CV}$, reduziu significativamente $(\mathrm{p}=0,04)$ apenas durante os 10 minutos da fase de recuperação $\left[4,2(2,7-5,5) \% \mathrm{CV}_{10 \mathrm{~min}}\right]$ comparado à condição inicial [6,7 $\left.(5-8,1) \% \mathrm{CV}_{\text {inicial }}\right]$.

\subsubsection{FAC AVALIADA PELOS ÍNDICES ESPECTRAIS DA VFC ANTES E AO LONGO DE 15 MINUTOS, APÓS A SESSÃO DE TR}

A Tabela 14 apresenta os valores amostrais dos índices espectrais da variabilidade da frequência cardíaca durante o registro de 5 minutos na posição supina, na condição inicial e, ao longo de 15 minutos, após a sessão de TR.

As FIGURAS 23 a 26 descrevem os comportamentos da FAC, avaliada pelos índices espectrais da VFC, na condição inicial e ao longo de 15 minutos, após a sessão de TR.

Dada a não estacionariedade do sinal nos primeiros cinco minutos de recuperação, não foi possível realizar análise comparativa entre a condição inicial, 10 minutos e 15 minutos da fase de recuperação com os cinco minutos de recuperação imediatamente após a sessão de TR.

O índice Área normalizada AF, marcador de atividade vagal, apresentou uma redução significativa $(\mathrm{p}<0,01)$ ao longo de toda a fase de recuperação $[29,4(20,5$ - 47,3) Área normalizada $\mathrm{AF}_{10 \mathrm{~min}}$ e $31,1\left(17,6\right.$ - 43,8) Área normalizada $\left.\mathrm{AF}_{15 \min }\right]$ comparado a condição inicial $\left[61,3\left(46,6\right.\right.$ - 74,9) Área normalizada $\left.\mathrm{AF}_{\text {inicial }}\right]$.

No sentido oposto da Área normalizada de AF, foi observado aumento significativo (p $<0,01)$ do marcador simpático, avaliada pela área normalizada de BF, ao longo de toda a fase de recuperação $\left[70,5\left(52,5\right.\right.$ - 79,5) área normalizada de $\mathrm{BF}_{10 \min }$ e 68,5 (56,2 - 82,2) área normalizada de $\left.\mathrm{BF}_{15 \mathrm{~min}}\right]$ comparativamente a condição inicial [38,7 (25,0 - 53,3) área normalizada de $\left.\mathrm{BF}_{\text {inicial }}\right]$. 
Após a sessão de TR, observou-se um aumento mediano significativo $(\mathrm{p}<0,01)$ do balanço autonômico cardíaco, avaliado pela razão BF/AF, ao longo de toda a fase de recuperação $\left[2,4\left(1,1\right.\right.$ - 3,9) Razão $B F / A_{10 \min }$ e 2,3 $(1,3$ - 4,7) Razão BF/AF 15 min $]$ comparado à

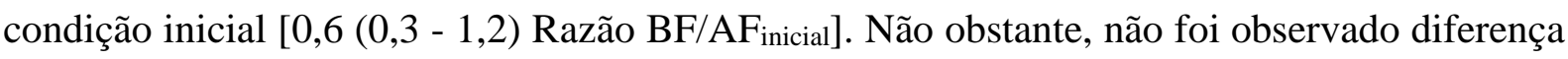
significativa quando comparado as fases de recuperações para os respectivos índices.

Durante toda a fase de recuperação, houve uma mudança de um predomínio vagotônico da condição basal para a predominância simpaticotônica na condição após a sessão de TR.

A Área Total, marcador de modulação global, ao ser comparado a condição inicial [3631,1 $\left.(2388,6-7263,7) \mathrm{ms}^{2} \mathrm{AT}_{\text {inicial }}\right]$ com os 10 minutos $\left[876,7(317,1-1583,9) \mathrm{ms}^{2} \mathrm{AT}_{10 \mathrm{~min}}\right]$ e 15 minutos [1282,0 $\left(643,8\right.$ - 1637,5) $\left.\mathrm{ms}^{2} \mathrm{AT}_{15 \mathrm{~min}}\right]$ durante a fase de recuperação após a sessão de TR, apresentou redução significativa $(\mathrm{p}<0,01)$.

TABELA 12 - Função autonômica cardíaca antes e ao longo de 15 minutos, após sessão de treino resistido, avaliada pelos índices de Poincaré da variabilidade da frequência cardíaca $(\mathrm{n}=14)$

\begin{tabular}{|c|c|c|c|c|c|c|c|c|c|c|c|c|}
\hline & \multicolumn{4}{|c|}{$\mathrm{SD} 1(\mathrm{~ms})$} & \multicolumn{4}{|c|}{$\mathrm{SD} 2(\mathrm{~ms})$} & \multicolumn{4}{|c|}{$\mathrm{SD} 1 / \mathrm{SD} 2$} \\
\hline & SUP $_{I}$ & $\mathrm{SUP}_{5 \min }$ & $\mathrm{SUP}_{10 \min }$ & $\mathrm{SUP}_{15 \min }$ & SUP $_{I}$ & $\mathrm{SUP}_{5 \text { min }}$ & $\mathrm{SUP}_{10 \min }$ & $\mathrm{SUP}_{15 \min }$ & $\mathrm{SUP}_{\mathrm{I}}$ & $\mathrm{SUP}_{5 \min }$ & $\mathrm{SUP}_{10 \min }$ & $\mathrm{SUP}_{15 \min }$ \\
\hline Média & 50 & 15,1 & 14,3 & 15,7 & 84,5 & 121,0 & 44,5 & 49 & 0,6 & 0,1 & 0,3 & 0,2 \\
\hline DP & 25,7 & 12,9 & 10,9 & 12,2 & 30,0 & 41,7 & 25,3 & 23,8 & 0,2 & 0,09 & 0,1 & 0,1 \\
\hline Max & 106,1 & 40,4 & 35,0 & 43,0 & 146,0 & 201,4 & 105,4 & 97,7 & 1,0 & 0,3 & 0,8 & 0,4 \\
\hline Qtl Sup & 56,0 & 24,5 & 22,9 & 20,9 & 107,9 & 145,7 & 55,0 & 54,0 & 0,7 & 0,1 & 0,3 & 0,3 \\
\hline Mediana & 43,8 & 10,3 & 12,3 & 13,3 & 82,9 & 124,3 & 40,1 & 49,9 & 0,5 & 0,08 & 0,2 & 0,2 \\
\hline Qtl Inf & 33,7 & 4,4 & 6,1 & 7,0 & 56,9 & 95,1 & 25,1 & 33,8 & 0,4 & 0,05 & 0,2 & 0,2 \\
\hline Min & 15,1 & 2,0 & 2,4 & 2,5 & 47,4 & 47,0 & 17,9 & 12,8 & 0,3 & 0,03 & 0,1 & 0,1 \\
\hline \multirow{4}{*}{$\mathrm{p}^{*}$} & \multicolumn{4}{|c|}{ SUP $_{I}$ vs $\operatorname{SUP}_{5 \min }: \mathrm{p}<0,01$} & \multicolumn{4}{|c|}{ SUP $_{I}$ vs SUP $_{10 \min }: \mathrm{p}<0,01$} & \multicolumn{4}{|c|}{$\operatorname{SUP}_{I}$ vs $\operatorname{SUP}_{5 \min }: \mathrm{p}<0,01$} \\
\hline & \multicolumn{4}{|c|}{ SUP $_{I}$ vs SUP $_{10 \min }: p<0,01$} & \multicolumn{4}{|c|}{ SUP $_{I}$ vs $S_{U P}{ }_{15 \min }: p<0,01$} & \multicolumn{4}{|c|}{ SUP $_{I}$ vs $S U P_{10 \min }: p=0,06$} \\
\hline & \multirow{2}{*}{\multicolumn{4}{|c|}{ SUP $_{I}$ vs $\operatorname{SUP}_{15 \min }: \mathrm{p}<0,01$}} & \multicolumn{4}{|c|}{$\operatorname{SUP}_{5 \min }$ vs $\mathrm{SUP}_{10 \min }: \mathrm{p}<0,01$} & \multicolumn{4}{|c|}{ SUP $_{I}$ vs $S_{U P}{ }_{15 \min }: p=0,01$} \\
\hline & & & & & \multicolumn{4}{|c|}{$\operatorname{SUP}_{5 \min }$ vs $\operatorname{SUP}_{15 \min }: \mathrm{p}<0,01$} & \multicolumn{4}{|c|}{$\operatorname{SUP}_{5 \min }$ vs $\mathrm{SUP}_{10 \min }: \mathrm{p}<0,01$} \\
\hline
\end{tabular}

SUP = supino; B = basal; 5min = 5 minutos de recuperação; 10min = 10 minutos de recuperação; 15min = 15 minutos de recuperação; DP = Desvio padrão; Max = Valor amostral máximo; Qtl = Quartil; Sup = superior; Inf = inferior; Min = valor amostral mínimo; $\mathrm{p}^{*}=$ teste de Friedman com post hoc Dunn. 


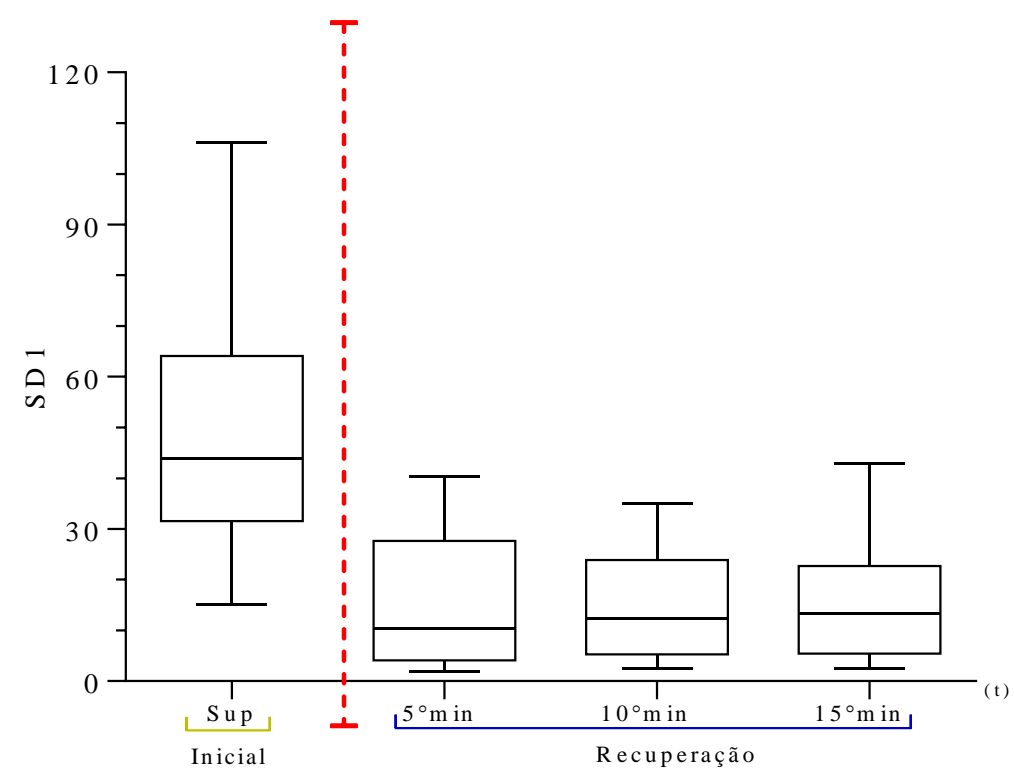

FIGURA 15 - Comportamento da função autonômica cardíaca na condição inicial e durante a recuperação após a sessão de treino resistido. Estão indicados a mediana, quartis superior e inferior, e os valores extremos $(n=14)$.

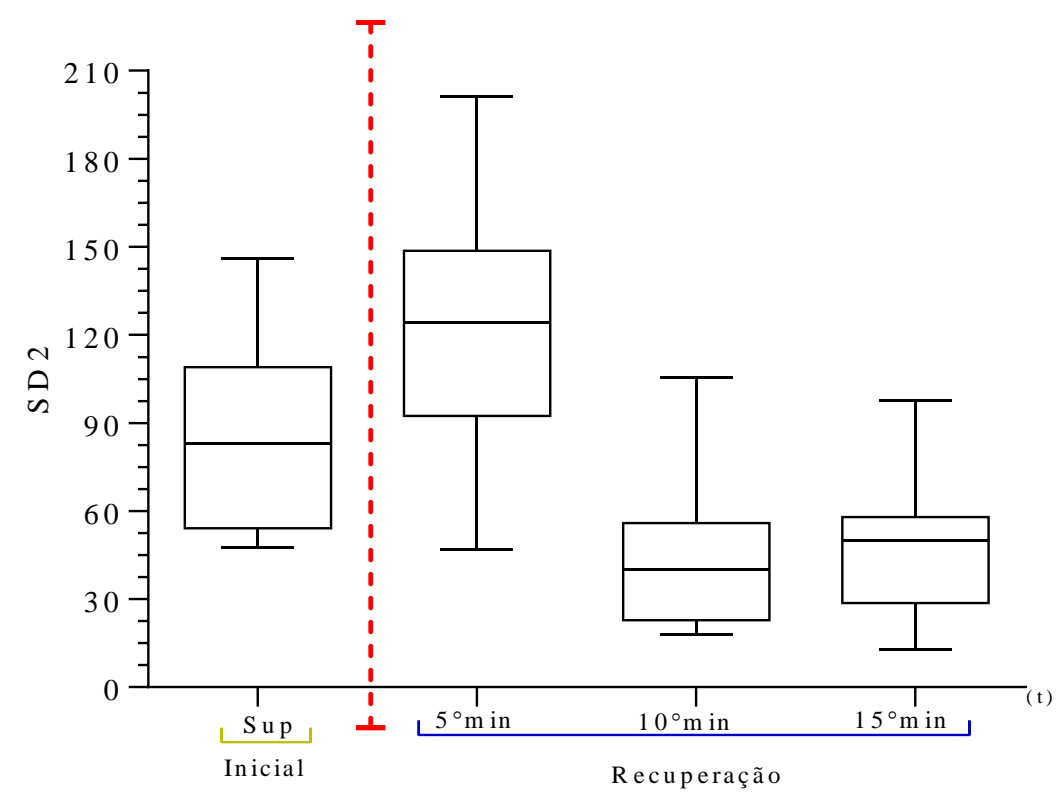

FIGURA 16 - Comportamento da função autonômica cardíaca na condição inicial e durante a recuperação após a sessão de treino resistido. Estão indicados a mediana, quartis superior e inferior, e os valores extremos $(n=14)$. 


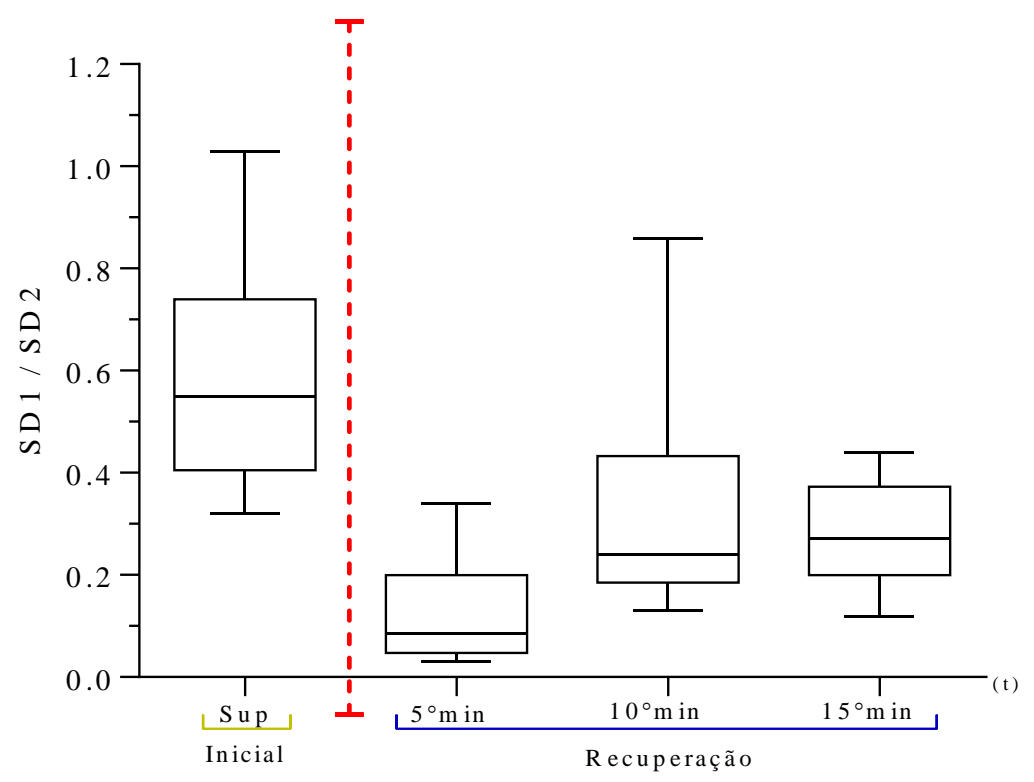

FIGURA 17 - Comportamento da função autonômica cardíaca na condição inicial e durante a recuperação após a sessão de treino resistido. Estão indicados a mediana, quartis superior e inferior, e os valores extremos $(n=14)$.

TABELA 13 - Função autonômica cardíaca antes e ao longo de 15 minutos, após sessão de treino resistido, avaliada pelos índices de temporais da variabilidade da frequência cardíaca $(n=14)$.

\begin{tabular}{|c|c|c|c|c|c|c|c|c|c|c|c|c|}
\hline & \multicolumn{4}{|c|}{ Média (ms) } & \multicolumn{4}{|c|}{$\mathrm{DP}(\mathrm{ms})$} & \multicolumn{4}{|c|}{$\mathrm{CV}(\%)$} \\
\hline & SUP $_{I}$ & $\mathrm{SUP}_{5 \min }$ & $\mathrm{SUP}_{10 \min }$ & $\mathrm{SUP}_{15 \min }$ & SUP $_{I}$ & $\mathrm{SUP}_{5 \text { min }}$ & $\mathrm{SUP}_{10 \mathrm{~min}}$ & $\mathrm{SUP}_{15 \min }$ & $\mathrm{SUP}_{\mathrm{I}}$ & $\mathrm{SUP}_{5 \min }$ & $\mathrm{SUP}_{10 \min }$ & $\mathrm{SUP}_{15 \min }$ \\
\hline Média & 1018,7 & 606,3 & 699,9 & 729,8 & 70,0 & 86,7 & 33,3 & 36,5 & 6,8 & 14,1 & 4,6 & 4,8 \\
\hline DP & 163,5 & 98,4 & 100,2 & 110,4 & 26,3 & 30,0 & 18,6 & 18,6 & 2,1 & 3,8 & 2,2 & 2,0 \\
\hline Max & 1340,9 & 790,6 & 845,5 & 884,3 & 127,5 & 145,5 & 76,5 & 75,4 & 10,5 & 19,8 & 10,0 & 8,8 \\
\hline Qtl Sup & 1083,9 & 642,5 & 762,8 & 803,4 & 85,2 & 104,5 & 41,5 & 40,8 & 8,1 & 16,0 & 5,5 & 5,2 \\
\hline Mediana & 1030,2 & 592,8 & 725,7 & 752,3 & 65,0 & 89,1 & 32,9 & 37,2 & 6,7 & 14,3 & 4,2 & 4,7 \\
\hline Qtl Inf & 916,9 & 577,2 & 662,2 & 698,4 & 51,1 & 68,4 & 18,3 & 24,5 & 5,0 & 11,5 & 2,7 & 3,5 \\
\hline Min & 767,6 & 442,1 & 497,2 & 508,1 & 35,4 & 33,4 & 12,8 & 9,3 & 3,8 & 7,6 & 2,4 & 1,6 \\
\hline \multirow{3}{*}{$\mathrm{p}^{*}$} & \multicolumn{4}{|c|}{ SUP I vs $_{\text {SUP }}$ 10min: $\mathrm{p}<0,01$} & \multicolumn{4}{|c|}{ SUP $_{I}$ vs SUP S1min: $_{1}<<0,01$} & \multicolumn{4}{|c|}{$\operatorname{SUP}_{I}$ vs $\operatorname{SUP}_{10 \min }: p=0,04$} \\
\hline & \multicolumn{4}{|c|}{ SUP $_{I}$ vs $S U P_{15 \min }: p=0,02$} & \multicolumn{4}{|c|}{ SUP $_{I}$ vs $\operatorname{SUP}_{15 \min }: \mathrm{p}<0,01$} & & & & \\
\hline & \multicolumn{4}{|c|}{$\operatorname{SUP}_{10 \min }$ vs $\mathrm{SUP}_{15 \min }: \mathrm{p}=0,02$} & & & & & & & & \\
\hline
\end{tabular}

SUP = supino; I = Inicial; 5 min = 5 minutos de recuperação; 10 min = 10 minutos de recuperação; 15 min = 15 minutos de recuperação; DP = Desvio padrão; CV = coeficiente de variação; Max = Valor amostral máximo; Qtl = Quartil; Sup = superior; Inf = inferior; Min = valor amostral mínimo; p* = teste de Friedman com post hoc Dunn. 
TABELA 13.1 - Função autonômica cardíaca antes e ao longo de 15 minutos, após sessão de treino resistido, avaliada pelos índices de temporais da variabilidade da frequência cardíaca $(n=14)$.

\begin{tabular}{|c|c|c|c|c|c|c|c|c|}
\hline & \multicolumn{4}{|c|}{ pNN50 (\%) } & \multicolumn{4}{|c|}{ rMSSD (ms) } \\
\hline & SUPI $_{I}$ & $\mathrm{SUP}_{5 \text { min }}$ & $\mathrm{SUP}_{10 \mathrm{~min}}$ & $\mathrm{SUP}_{15 \min }$ & SUPI $_{I}$ & $\mathrm{SUP}_{5 \min }$ & SUP $_{10 \min }$ & $\mathrm{SUP}_{15 \min }$ \\
\hline Média & 42,6 & 8,0 & 5,3 & 6,9 & 70,6 & 21,3 & 20,2 & 22,1 \\
\hline DP & 21,4 & 12,2 & 7,7 & 11,1 & 36,2 & 18,2 & 15,4 & 17,3 \\
\hline Max & 79,7 & 30,6 & 25 & 33,9 & 149,8 & 57,1 & 49,5 & 60,7 \\
\hline Qtl Sup & 54,1 & 8,7 & 9,9 & 6,9 & 79,1 & 34,6 & 32,3 & 29,5 \\
\hline Mediana & 46,8 & 0,9 & 0,6 & 2,0 & 61,9 & 14,5 & 17,3 & 18,8 \\
\hline Qtl Inf & 31 & 0 & 0 & 0 & 47,5 & 6,3 & 8,6 & 9,8 \\
\hline Min & 2,2 & 0 & 0 & 0 & 21,3 & 2,8 & 3,4 & 3,4 \\
\hline $\mathrm{p}^{*}$ & \multicolumn{4}{|c|}{ SUP $_{I}$ vs $S U P_{10 \min }: p<0,01$} & SUP $_{I}$ vs $S P_{15 \min }: p<0,01$ & \multicolumn{3}{|c|}{ SUP $_{I}$ vs SUP $_{10 \min }: p<0,01$} \\
\hline
\end{tabular}

SUP = supino; I = Inicial 5min = 5 minutos de recuperação; $10 \mathrm{~min}=10$ minutos de recuperação; 15 min = 15 minutos de recuperação; DP = Desvio padrão; CV = coeficiente de variação; Máx = Valor amostral máximo; Qtl = Quartil; Sup = superior; Inf = inferior; Mín = valor amostral mínimo; $\mathrm{p}^{*}=$ teste de Friedman com post hoc Dunn.

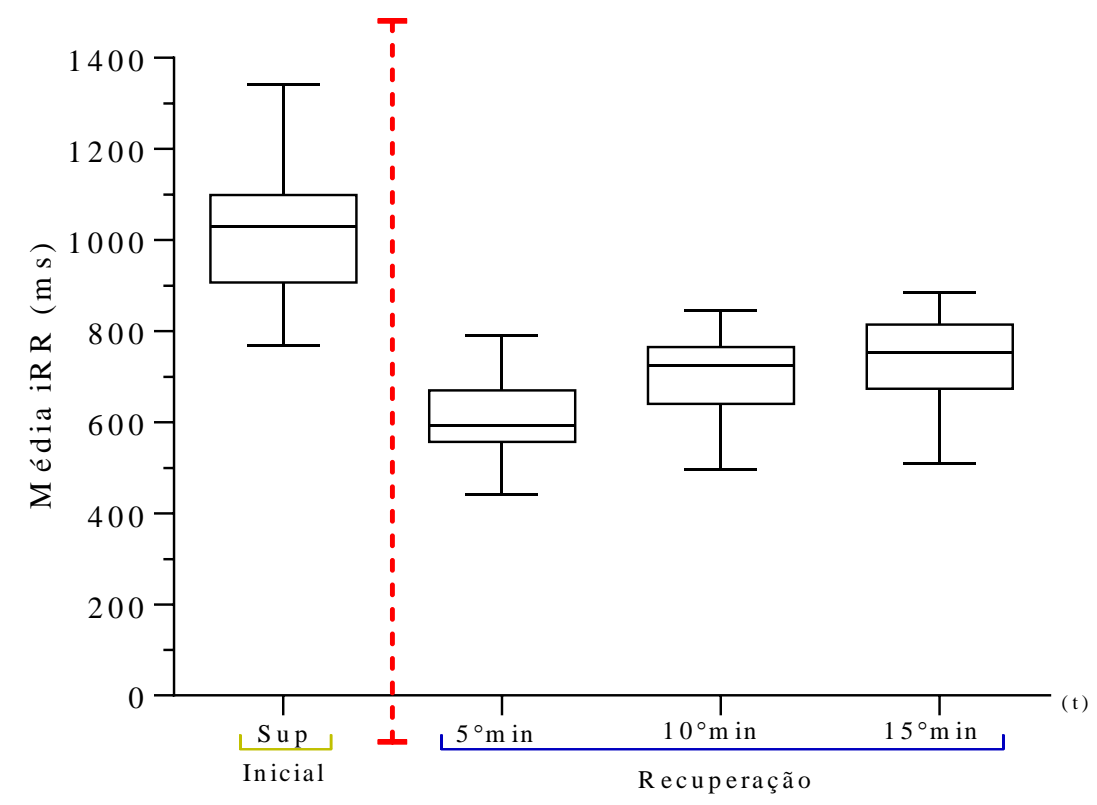

FIGURA 18 - Comportamento da função autonômica cardíaca na condição inicial e durante a recuperação após a sessão de treino resistido. Estão indicados a mediana, quartis superior e inferior, e os valores extremos $(n=14)$. 


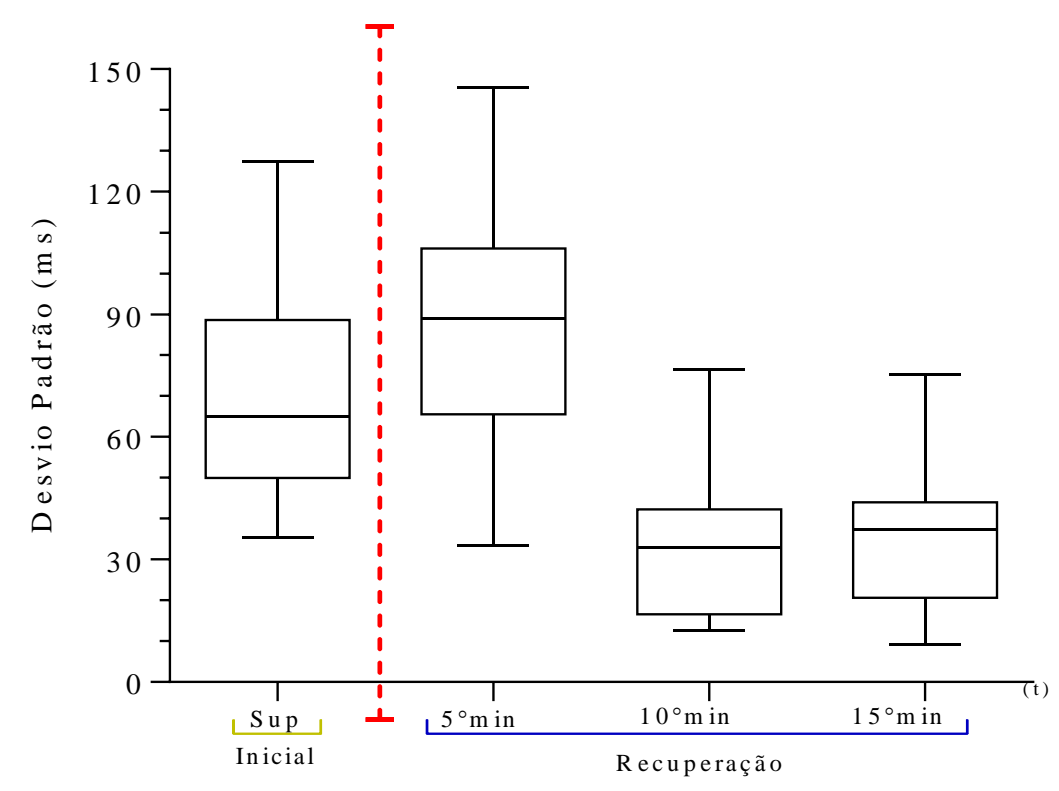

FIGURA 19 - Comportamento da função autonômica cardíaca na condição inicial e durante a recuperação após a sessão de treino resistido. Estão indicados a mediana, quartis superior e inferior, e os valores extremos $(n=14)$.

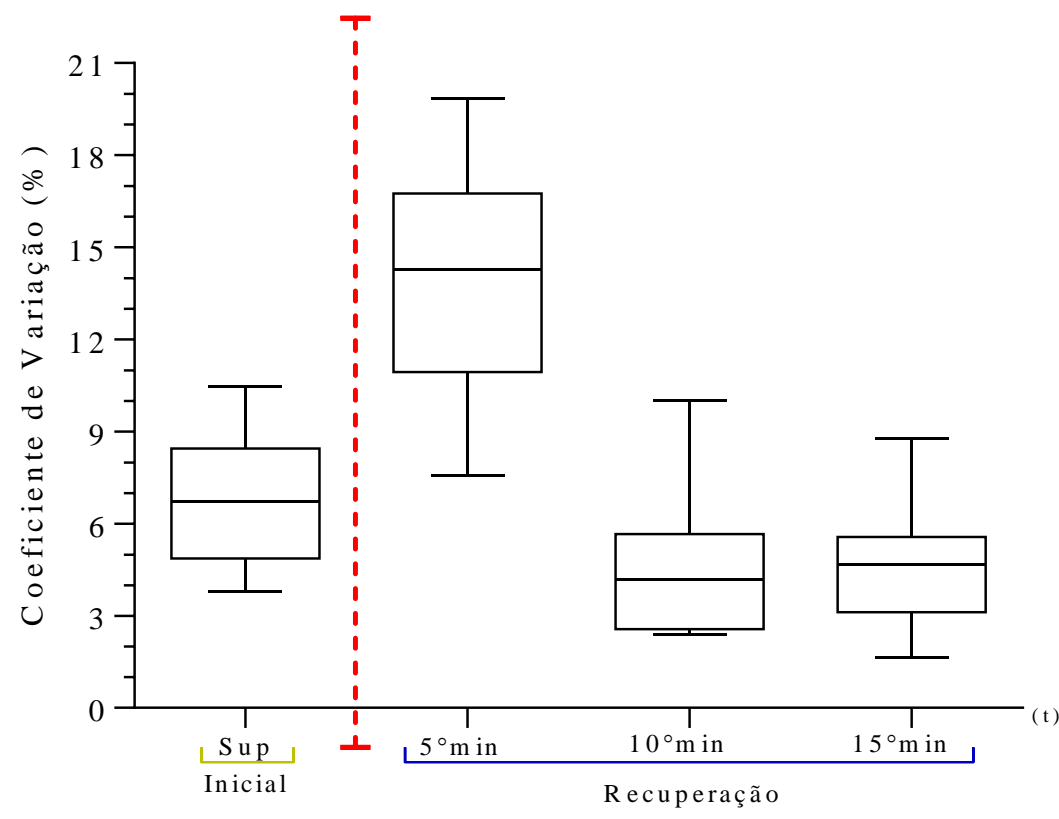

FIGURA 20 - Comportamento da função autonômica cardíaca na condição inicial e durante a recuperação após a sessão de treino resistido. Estão indicados a mediana, quartis superior e inferior, e os valores extremos $(n=14)$. 


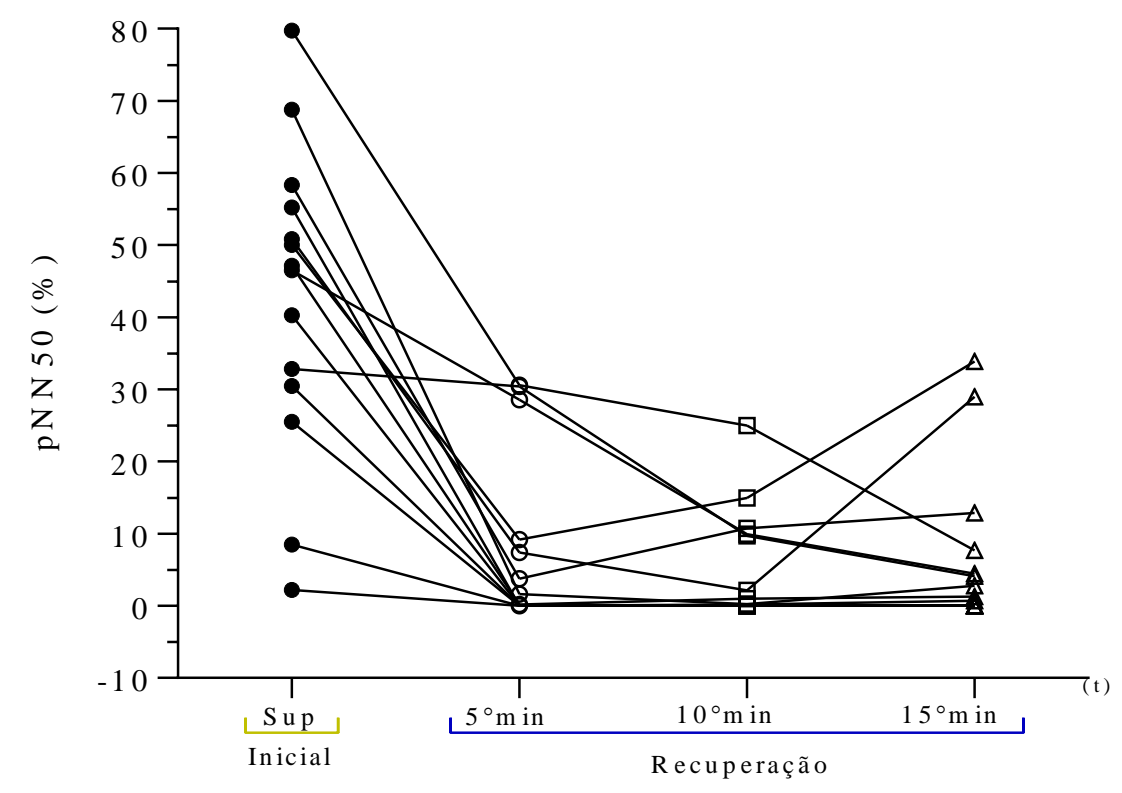

FIGURA 21 - Comportamento da função autonômica cardíaca na condição inicial e durante a recuperação após a sessão de treino resistido $(\mathrm{n}=14)$.

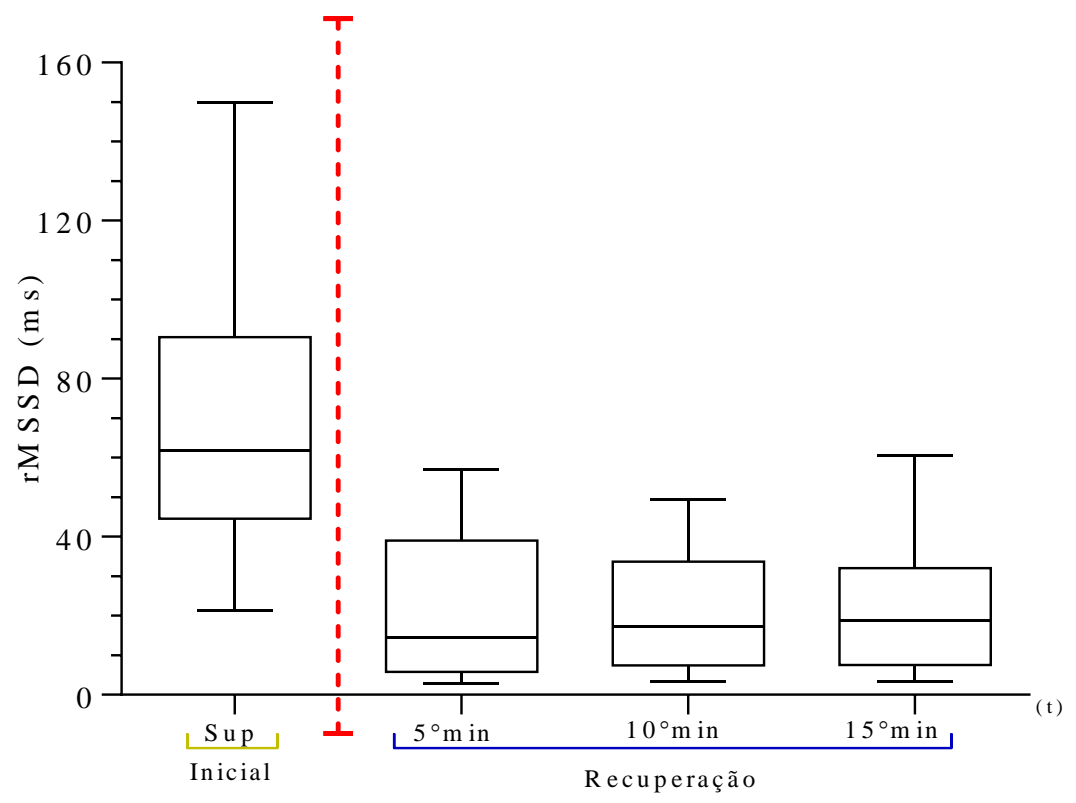

FIGURA 22 - Comportamento da função autonômica cardíaca na condição inicial e durante a recuperação após a sessão de treino resistido. Estão indicados a mediana, quartis superior e inferior, e os valores extremos $(\mathrm{n}=14)$. 
TABELA 14 - Função autonômica cardíaca previamente a uma sessão de treino resistido com a função autonômica cardíaca, ao longo de 15 minutos, após uma sessão de treino resistido, avaliada pelos índices espectrais da variabilidade da frequência cardíaca $(\mathrm{n}=14)$.

\begin{tabular}{|c|c|c|c|c|c|c|c|c|c|c|c|c|c|c|c|c|}
\hline & \multicolumn{4}{|c|}{ Área Total $\left(\mathrm{ms}^{2}\right)$} & \multicolumn{4}{|c|}{ Razão BF / AF } & \multicolumn{4}{|c|}{ Área Nor. BF } & \multicolumn{4}{|c|}{ Área Nor. AF } \\
\hline & $\mathrm{SUP}_{\mathrm{I}}$ & $\mathrm{SUP}_{5 \min }$ & $\mathrm{SUP}_{10 \mathrm{~min}}$ & $\mathrm{SUP}_{15 \min }$ & SUP $_{\mathrm{I}}$ & $\mathrm{SUP}_{5 \min }$ & $\mathrm{SUP}_{10 \mathrm{~min}}$ & $\mathrm{SUP}_{15 \min }$ & SUP $_{\mathrm{I}}$ & $\mathrm{SUP}_{5 \min }$ & $\mathrm{SUP}_{10 \min }$ & $\mathrm{SUP}_{15 \min }$ & SUP $_{I}$ & $\mathrm{SUP}_{5 \min }$ & $\mathrm{SUP}_{10 \mathrm{~min}}$ & $\mathrm{SUP}_{15 \min }$ \\
\hline DP & 4077,9 & 4418,9 & 1358,3 & 1585,1 & 0,7 & 2,9 & 3,1 & 3,7 & 17,0 & 19,9 & 17,0 & 18,8 & 17,0 & 19,7 & 16,9 & 18,8 \\
\hline Max & 15913,1 & 18259,8 & 4740,9 & 5836,4 & 2,5 & 10,7 & 9,6 & 14,4 & 71,2 & 91,4 & 90,5 & 93,5 & 78,4 & 77,0 & 58,3 & 66,9 \\
\hline Qtl Sup & 7263,7 & 8400,2 & 1583,9 & 1637,5 & 1,2 & 3,0 & 3,9 & 4,7 & 53,3 & 74,8 & 79,5 & 82,2 & 74,9 & 54,5 & 47,3 & 43,8 \\
\hline Mediana & 3631,1 & 7290,4 & 876,7 & 1282,0 & 0,6 & 1,3 & 2,4 & 2,3 & 38,7 & 55,6 & 70,5 & 68,5 & 61,3 & 44,2 & 29,4 & 31,1 \\
\hline Qtl Inf & 2388,6 & 5191,4 & 317,1 & 643,8 & 0,3 & 0,8 & 1,1 & 1,3 & 25,0 & 45,1 & 52,5 & 56,2 & 46,6 & 25,1 & 20,5 & 17,6 \\
\hline Min & 1174,7 & 1006,6 & 151,3 & 84,5 & 0,3 & 0,3 & 0,7 & 0,5 & 21,6 & 22,9 & 41,7 & 33,0 & 28,8 & 8,5 & 9,4 & 6,5 \\
\hline \multirow{2}{*}{$\mathrm{p}^{*}$} & \multicolumn{4}{|c|}{ SUP $_{I}$ vs $S P_{10 \min }: \mathrm{p}<0,01$} & \multicolumn{4}{|c|}{ SUP $_{I}$ vs $S_{U P} P_{10 \min }: p<0,01$} & \multicolumn{4}{|c|}{ SUP $_{I}$ vs $S P_{10 \min }: p<0,01$} & \multicolumn{4}{|c|}{ SUP $_{I}$ vs $S P_{10 \min }: p<0,01$} \\
\hline & \multicolumn{4}{|c|}{ SUP $_{I}$ vs $\operatorname{SUP}_{15 \min }: p<0,01$} & \multicolumn{4}{|c|}{ SUP $_{I}$ vs $\operatorname{SUP}_{15 \min }: p<0,01$} & \multicolumn{4}{|c|}{ SUP $_{I}$ vs $\operatorname{SUP}_{15 \min }: \mathrm{p}<0,01$} & \multicolumn{4}{|c|}{$\operatorname{SUP}_{\mathrm{I}}$ vs $\mathrm{SUP}_{15 \min }: \mathrm{p}<0,01$} \\
\hline
\end{tabular}




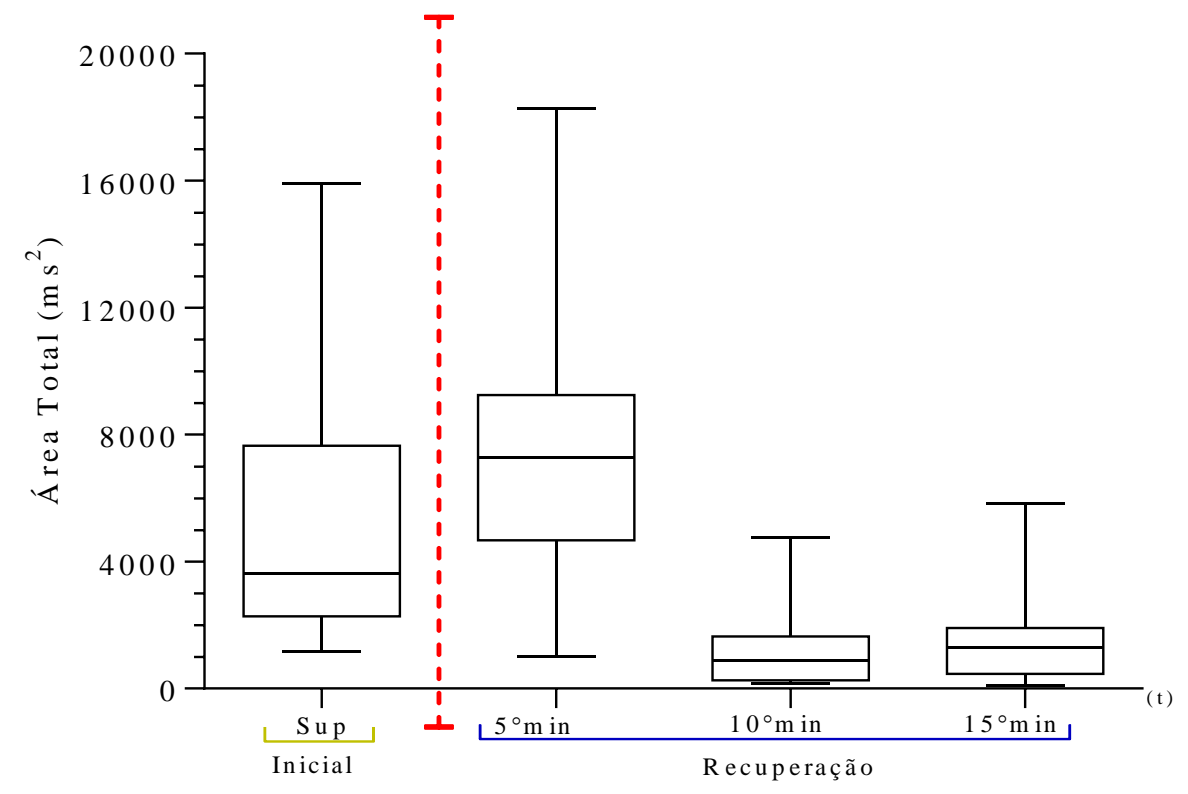

FIGURA 23 - Comportamento da função autonômica cardíaca na condição inicial e durante a recuperação após uma sessão de treino resistido. Estão indicados a mediana, quartis superior e inferior, e os valores extremos $(n=14)$.

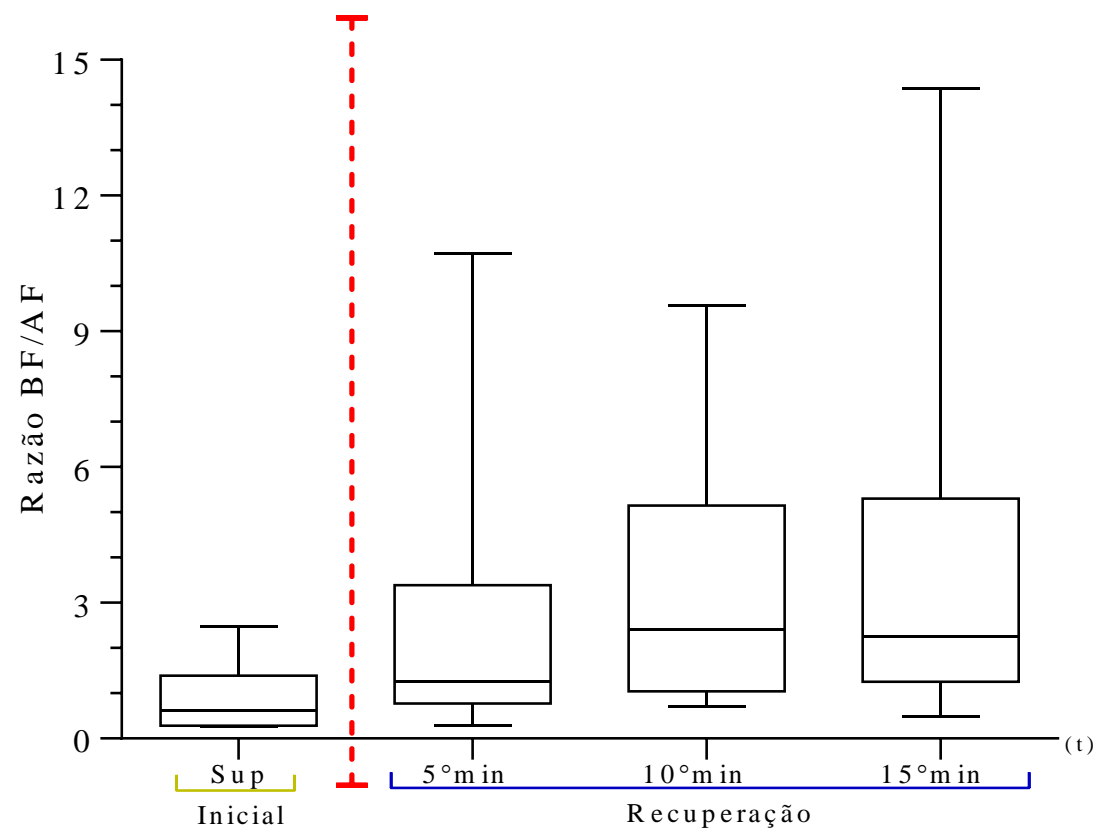

FIGURA 24 - Comportamento da função autonômica cardíaca na condição inicial e durante a recuperação após uma sessão de treino resistido. Estão indicados a mediana, quartis superior e inferior, e os valores extremos $(n=14)$. 


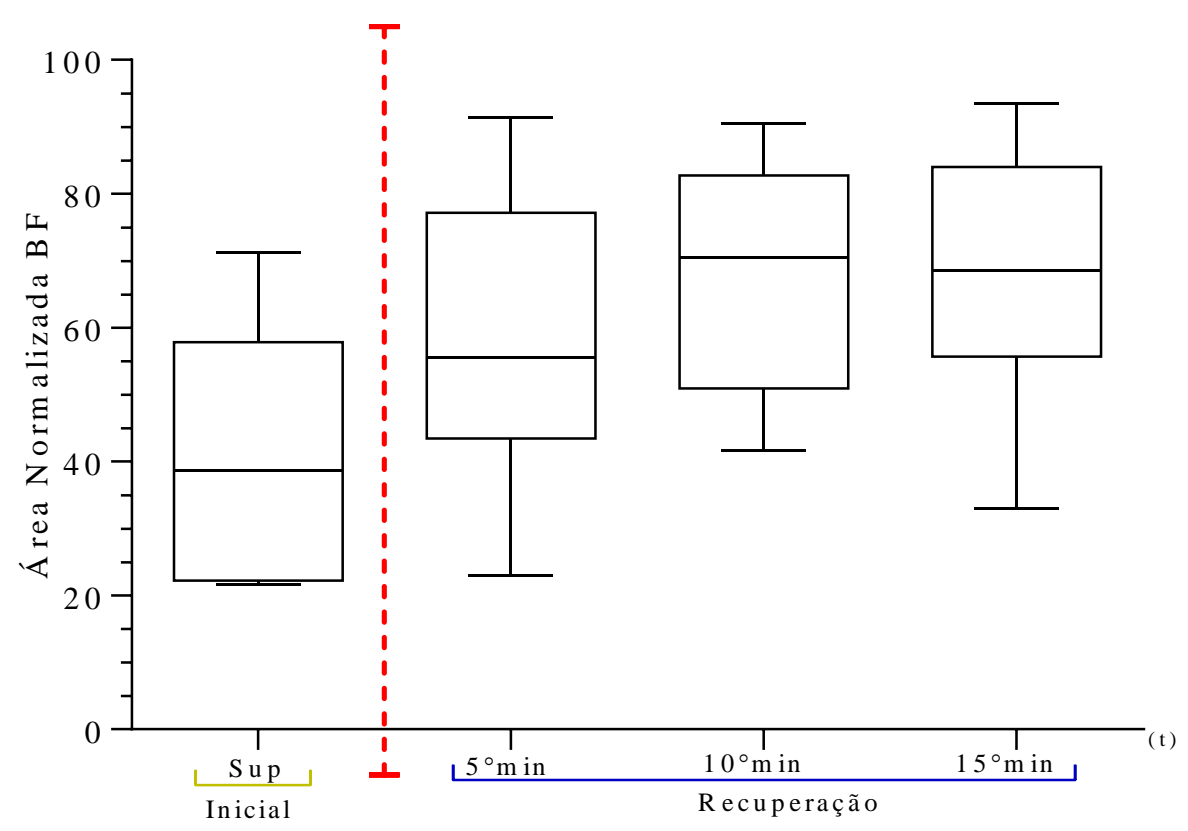

FIGURA 25 - Comportamento da função autonômica cardíaca na condição inicial e durante a recuperação após uma sessão de treino resistido. Estão indicados a mediana, quartis superior e inferior, e os valores extremos $(n=14)$.

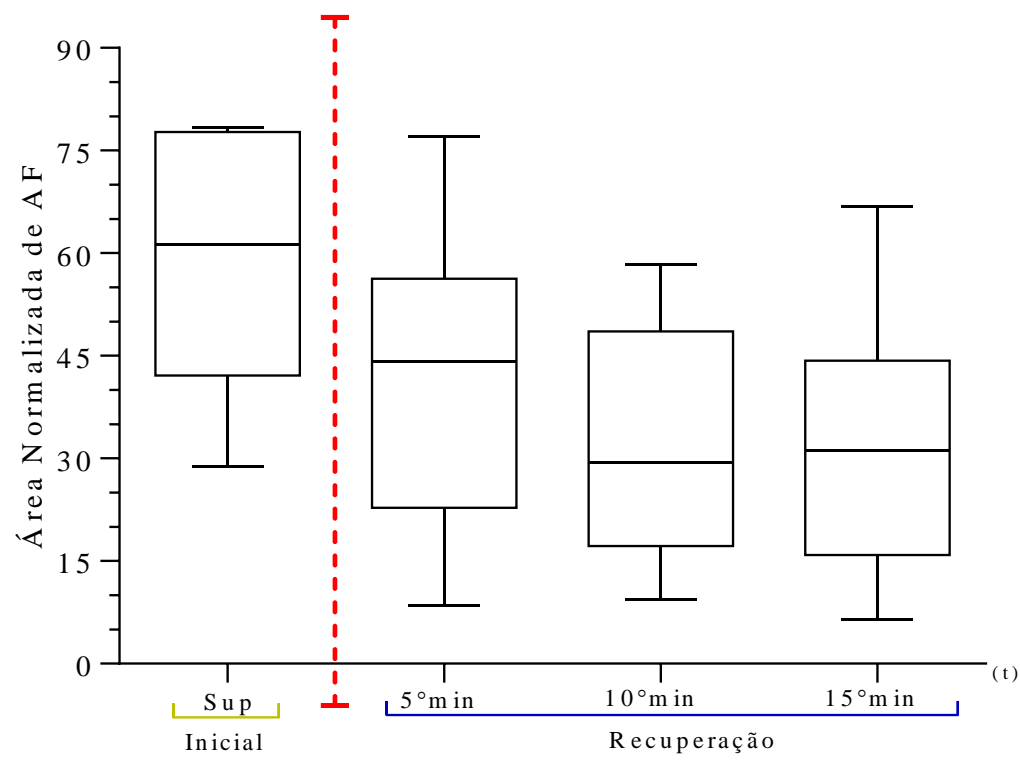

FIGURA 26 - Comportamento da função autonômica cardíaca na condição inicial e durante a recuperação após uma sessão de treino resistido. Estão indicados a mediana, quartis superior e inferior, e os valores extremos $(n=14)$. 


\subsection{CORRELAÇÃO ENTRE AS VARIÁVEIS DA FUNÇÃO AUTONÔMICA CARDÍACA AVALIADA PELOS ÍNDICES DE POINCARÉ, NOS DOMÍNIOS TEMPORAL E ESPECTRAL}

\subsubsection{CORRELAÇÃO ENTRE A FAC, AVALIADA PELOS ÍNDICES DE POINCARÉ DA VFC, ANTES DA SESSÃO DE TR E AO LONGO DE 15 MINUTOS APÓS SESSÃO DE TR}

Na Tabela 15 estão descritas as correlações entre os índices de Poincaré da VFC na posição supina durante a condição inicial, e após 15 minutos da sessão de TR. Na FIGURA 25 estão descritos os diagramas de dispersão e suas respectivas correlações.

A maioria dos índices do Poincaré na condição inicial, na posição supina, apresentou correlação $\left(\mathrm{r}_{\mathrm{s}}\right)$ de 0,48 a 0,63 , isto é, moderada para forte, moderada para forte, com os índices do Poincaré após 15 minutos da sessão de TR.

Observou-se correlações positivas e significativas entre o marcador vagal SD1 I na condição inicial com o marcador vagal SD1 e com o marcador de balanço autonômico Razão de SD1/SD2 nos cinco, dez e quinze minutos após sessão de TR.

O mesmo ocorreu quanto a correlação entre o marcador vagal SD1 I e Razão de SD1/SD2 I na condição inicial com o marcador de modulação global SD2 nos cinco e quinze minutos de recuperação, bem como, observou-se correlações positivas e significativas entre a o marcador SD1/SD2 I na condição inicial com o marcador SD1 e SD1/SD2 nos dez e quinze minutos após sessão de TR.

Não foi observado correlações significativas entre o marcador de modulação global SD2 ${ }_{\text {I }}$ na condição inicial com os marcadores de atividade vagal SD1, balanço autonômico SD1/SD2 e modulação global SD2 ao longo de 15 minutos recuperação após sessão de TR.

Destaca-se o fato de que a magnitude da correlação do marcador vagal na condição inicial com os índices de poincaré após sessão de TR, apresentam um comportamento crescente em função do tempo de recuperação. 


\subsubsection{CORRELAÇÃO ENTRE A FAC, AVALIADA PELOS ÍNDICES TEMPORAIS DA VFC,}

ANTES DA SESSÃO DE TR E AO LONGO DE 15 MINUTOS APÓS SESSÃO DE TR

Na Tabela 16 estão descritas as correlações entre os índices temporais da VFC na posição supina durante na condição inicial com os índices temporais da VFC após 15 minutos da sessão de TR. Nas FIGURAS 28 a 31 estão descritos os diagramas de dispersão e suas respectivas correlações.

Dada a não estacionariedade do sinal, nos primeiros cinco minutos de recuperação, não foi possível realizar o teste de correlação de Spearman entre a condição inicial com os cinco minutos de recuperação imediatamente após uma sessão de TR.

A maioria dos índices temporais na condição inicial, na posição supina, apresentou correlação $\left(\mathrm{r}_{\mathrm{s}}\right)$ positiva variando de 0,48 a 0,81 , isto é, moderada para muito forte, com os índices temporais após

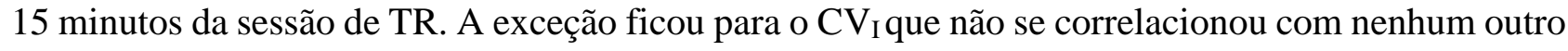
índice em qualquer minuto.

Observou-se correlações fortes positivas e significativas entre os marcadores vagal pNN50I e rMSSD I na condição inicial com os marcadores pNN50 e rMSSD nos dez e quinze minutos após sessão de TR. O mesmo ocorreu quanto a correlação entre o marcador vagal pNN50I com os marcadores média iRR, DP e CV nos dez e quinze minutos após sessão de TR, bem como, observou -se correlação fortes entre o marcador vagal rMSSD I com os marcadores média iRR, DP e CV nos quinze minutos após sessão de TR.

A média $i R R_{I}$ na condição inicial apresentou correlações positivas, muito forte, e significativas entre os marcadores vagais pNN50 e rMSSD nos dez e quinze minutos após sessão de TR. O mesmo ocorreu quanto a correlação entre média $i R_{I}$ com o marcador média iRR nos dez e quinze minutos após sessão de TR. Também, observou-se correlações positivas forte e significativas entre a média $i R R_{I}$ com o DP e CV nos dez e quinze minutos após sessão de TR.

Observou-se correlações, moderadas a forte, positivas e significativas entre o marcador de modulação global DPI na condição inicial com o marcador pNN50 nos dez e quinze minutos, e com 
o marcador rMSSD apenas nos quinze minutos após sessão de TR. Com os demais índices não foi observado diferença significativa.

Destaca-se o fato de que a magnitude das correlações na condição inicial com os índices de do domínio temporal após sessão de TR, apresentam um comportamento crescente em função do tempo de recuperação.

\subsubsection{CORRELAÇÃO ENTRE A FAC, AVALIADA PELOS ÍNDICES ESPECTRAIS DA VFC,} ANTES DA SESSÃO DE TR E AO LONGO DE 15 MINUTOS APÓS SESSÃO DE TR

Na Tabela 17 estão descritas as correlações entre os índices espectrais da VFC na posição supina durante na condição inicial com os índices espectrais da VFC após 15 minutos da sessão de TR. Nas FIGURAS 28 a 31 estão descritos os diagramas de dispersão e suas respectivas correlações.

Dada a não estacionariedade do sinal, nos primeiros cinco minutos de recuperação, não foi possível realizar o teste de correlação de Spearman entre a condição inicial com os cinco minutos de recuperação imediatamente após uma sessão de TR.

A maioria dos índices espectrais na condição inicial, na posição supina, apresentou correlação ( $\mathrm{r}_{\mathrm{s}}$ ) positiva variando entre 0,47 a 0,78 , isto é, moderada para muito forte, com os índices espectrais após 15 minutos da sessão de TR.

Observou-se correlações, forte e muito forte, positivas e significativas entre o marcador vagal Área Normalizada de AFI na condição inicial com o marcador Área Normalizada de AF nos dez e quinze minutos após sessão de TR. O mesmo ocorreu quanto a correlação entre o marcador vagal Área Normalizada de $\mathrm{AF}_{\mathrm{I}}$ com os marcadores de modulação global AT nos dez e quinze minutos após sessão de TR. E, observou -se correlação negativas, forte e muito forte, entre o marcador vagal Área Normalizada de $\mathrm{AF}_{\mathrm{I}}$ com os marcadores razão BF/AF e Área Normalizada de BF nos dez e quinze minutos após sessão de TR.

O marcador $\mathrm{AT}_{\mathrm{I}}$ na condição inicial não apresentou correlação significativa com o marcador AT nos dez e quinze minutos após sessão de TR. Contudo, observou-se correlações moderadas 
positivas e significativas entre o marcador $\mathrm{AT}_{\mathrm{I}}$ com o marcador Área Normalizada de AF nos dez e quinze minutos após sessão de TR, e correlação negativas, moderada e forte, com os marcadores razão BF/AF e Área Normalizada de BF nos dez e quinze minutos após sessão de TR.

A razão $\mathrm{BF} / \mathrm{AF}_{\mathrm{I}}$ e Área Normalizada de $\mathrm{BF}_{\mathrm{I}}$ na condição inicial apresentou correlações negativas, forte e muito forte, e significativas entre o marcador vagal Área Normalizada de AF e marcador de modulação global AT nos dez e quinze minutos após sessão de TR, bem como, observou-se correlações positivas muito fortes e significativas entre razão $B F / \mathrm{AF}_{\mathrm{I}}$ e Área Normalizada de $\mathrm{BF}_{\mathrm{I}}$ com a razão BF/AF e Área Normalizada de BF nos dez e quinze minutos após sessão de TR.

Ou seja, ao proceder à análise da correlação da FAC avaliada pelos índices de poincaré, temporal e espectral da VFC durante a posição supina, na condição inicial, com a FAC avaliada pelos índices de poincaré, temporal e espectral da VFC após 15 minutos de uma sessão de TR, foi verificado que os marcadores da atividade vagal, na condição inicial, correlacionam - se positivamente com os marcadores da atividade vagal e com os marcadores de modulação global após os 15 minutos de uma sessão TR, apresentando um comportamento semelhante de correlação em função do tempo de recuperação. 
TABELA 15 - Correlações entre os índices de Poincaré das séries de intervalo RR, na posição supina na condição inicial, com a função autonômica cardíaca, ao longo de 15 minutos, após sessão de treino resistido $(\mathrm{n}=14)$.

\begin{tabular}{|c|c|c|c|c|c|c|c|c|c|c|c|c|c|c|c|c|c|c|}
\hline & \multicolumn{2}{|c|}{$\mathrm{SD} 1_{5 \min }$} & \multicolumn{2}{|c|}{$\mathrm{SD} 1_{10 \min }$} & \multicolumn{2}{|c|}{$\mathrm{SD} 1_{15 \min }$} & \multicolumn{2}{|c|}{$\mathrm{SD} 2_{5 \min }$} & \multicolumn{2}{|c|}{$\mathrm{SD} 2{ }_{10 \mathrm{~min}}$} & \multicolumn{2}{|c|}{$\mathrm{SD} 2{ }_{15 \min }$} & \multicolumn{2}{|c|}{$\mathrm{SD} 1 / \mathrm{SD} 25 \min$} & \multicolumn{2}{|c|}{$\mathrm{SD} 1 / \mathrm{SD} 2_{10 \min }$} & \multicolumn{2}{|c|}{$\mathrm{SD} 1 / \mathrm{SD} 2{ }_{15 \mathrm{~min}}$} \\
\hline & $\mathrm{r}_{\mathrm{s}}$ & $\mathrm{p}$ & $\mathrm{r}_{\mathrm{s}}$ & $\mathrm{p}$ & $\mathrm{r}_{\mathrm{s}}$ & $\mathrm{p}$ & $\mathrm{r}_{\mathrm{s}}$ & $\mathrm{p}$ & $\mathrm{r}_{\mathrm{s}}$ & $\mathrm{p}$ & $\mathrm{r}_{\mathrm{s}}$ & $\mathrm{P}$ & $\mathrm{r}_{\mathrm{s}}$ & $\mathrm{p}$ & $\mathrm{r}_{\mathrm{s}}$ & $\mathrm{p}$ & $\mathrm{r}_{\mathrm{s}}$ & $\mathrm{p}$ \\
\hline $\mathrm{SD} 1_{\mathrm{I}}$ & $0,49 *$ & 0,07 & $0,53 *$ & 0,05 & $0,63 *$ & 0,01 & $0,53 *$ & 0,05 & 0,40 & 0,15 & $0,62 *$ & 0,02 & $0,48 *$ & 0,08 & $0,51 *$ & 0,06 & $0,60 *$ & 0,02 \\
\hline $\mathrm{SD} 2 \mathrm{I}$ & 0,16 & 0,39 & 0,33 & 0,24 & 0,38 & 0,17 & 0,30 & 0,28 & 0,18 & 0,52 & 0,35 & 0,21 & $0,48^{*}$ & 0,07 & 0,25 & 0,36 & 0,42 & 0,13 \\
\hline Razão SD1/SD2 & 0,43 & 0,11 & $0,51 *$ & 0,06 & $0,57 *$ & 0,03 & $0,54 *$ & 0,04 & 0,44 & 0,11 & $0,58 *$ & 0,03 & 0,34 & 0,22 & $0,62 *$ & 0,01 & $0,52 *$ & 0,05 \\
\hline
\end{tabular}



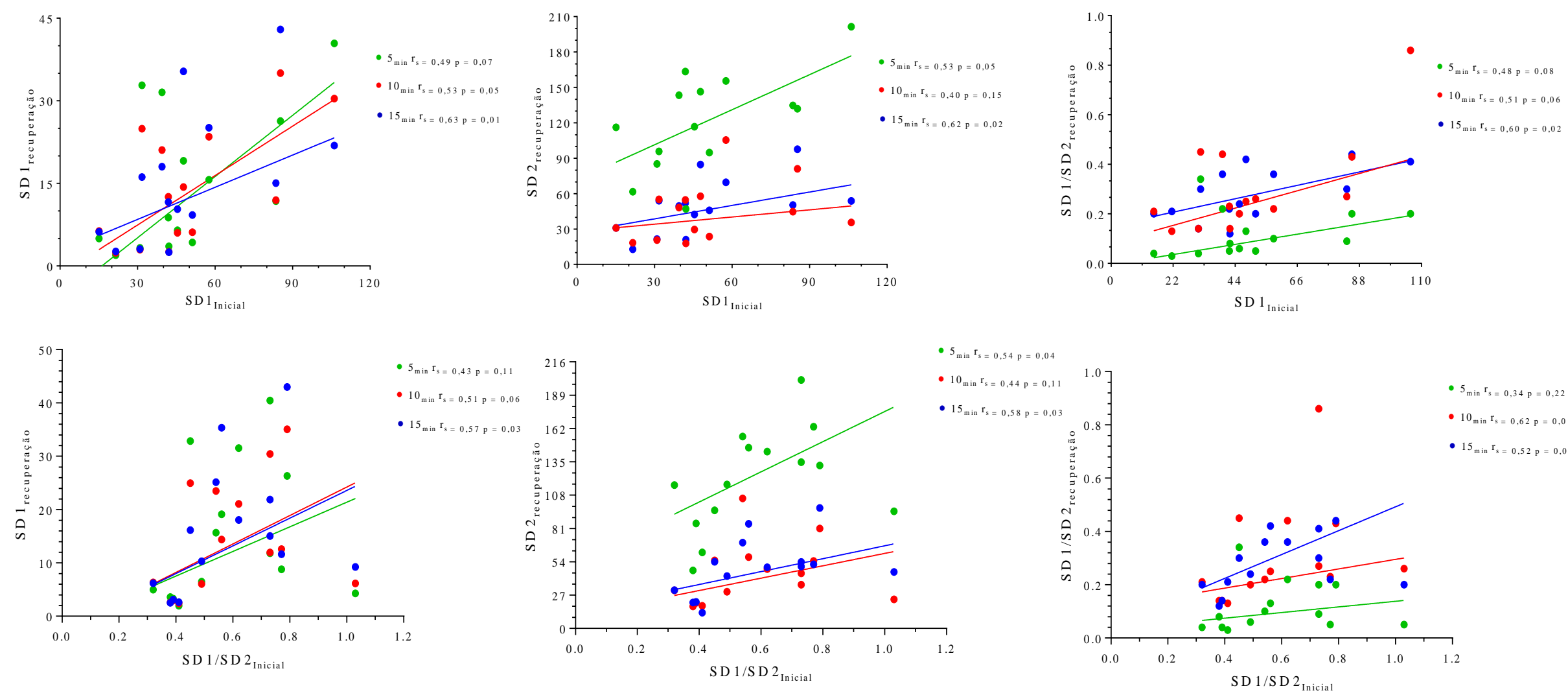

FIGURA 27 - Correlações entre função autonômica cardíaca na posição supina na condição inicial, com a função autonômica cardíaca após 5 (0 a 5) min (círculo verde), 10 (5 a 10) min (círculo vermelho) e 15 (10 a 15) min (círculo azul) de uma sessão de treino resistido, avaliada pelos índices de Poincaré. 
TABELA 16 - Correlações entre os índices temporais das séries de intervalo RR, na posição supina na condição inicial, com a função autonômica cardíaca, ao longo de 15 minutos, após uma sessão de treino resistido $(\mathrm{n}=14)$.

\begin{tabular}{|c|c|c|c|c|c|c|c|c|c|c|c|c|c|c|c|c|c|c|c|c|}
\hline & \multicolumn{2}{|c|}{ Média $_{10 \min }$} & \multicolumn{2}{|c|}{ Média $_{15 \min }$} & \multicolumn{2}{|c|}{$\mathrm{DP}_{10 \min }$} & \multicolumn{2}{|c|}{$\mathrm{DP}_{15 \min }$} & \multicolumn{2}{|c|}{$\mathrm{CV}_{10 \text { min }}$} & \multicolumn{2}{|c|}{$\mathrm{CV}_{15 \min }$} & \multicolumn{2}{|c|}{ pNN50 10 min } & \multicolumn{2}{|c|}{$\mathrm{pNN} 50_{15 \min }$} & \multicolumn{2}{|c|}{$\mathrm{rMSSD}_{10 \min }$} & \multicolumn{2}{|c|}{$\mathrm{rMSSD}_{15 \min }$} \\
\hline & $\mathrm{r}_{\mathrm{s}}$ & $\mathrm{p}$ & $\mathrm{r}_{\mathrm{s}}$ & $\mathrm{p}$ & $\mathrm{r}_{\mathrm{s}}$ & $\mathrm{p}$ & $\mathrm{r}_{\mathrm{s}}$ & $\mathrm{p}$ & $\mathrm{r}_{\mathrm{s}}$ & $\mathrm{p}$ & $\mathrm{r}_{\mathrm{s}}$ & $\mathrm{P}$ & $\mathrm{r}_{\mathrm{s}}$ & $\mathrm{p}$ & $\mathrm{r}_{\mathrm{s}}$ & $\mathrm{p}$ & $\mathrm{r}_{\mathrm{s}}$ & $\mathrm{p}$ & & \\
\hline $\operatorname{Média}_{B}(\mathrm{~ms})$ & $0,73^{*}$ & 0,02 & $0,81 *$ & 0,0007 & $0,59 *$ & 0,02 & $0,70 *$ & 0,005 & $0,57 *$ & 0,03 & $0,58 *$ & 0,03 & $0,74 *$ & 0,003 & $0,70^{*}$ & 0,006 & $0,73^{*}$ & 0,004 & $0,73^{*}$ & 0,003 \\
\hline $\mathrm{DP}_{\mathrm{I}}(\mathrm{ms})$ & 0,33 & 0,24 & 0,43 & 0,12 & 0,27 & 0,34 & 0,45 & 0,10 & 0,38 & 0,17 & 0,37 & 0,19 & $0,55^{*}$ & 0,04 & $0,56^{*}$ & 0,03 & 0,42 & 0,12 & $0,48^{*}$ & 0,08 \\
\hline $\mathrm{CV}_{\mathrm{I}}(\%)$ & 0,01 & 0,97 & 0,09 & 0,76 & $-0,01$ & 0,95 & 0,15 & 0,59 & 0,13 & 0,63 & 0,10 & 0,71 & 0,27 & 0,33 & 0,29 & 0,31 & 0,09 & 0,73 & 0,20 & 0,49 \\
\hline pNN50 $(\%)$ & $0,60 *$ & 0,02 & $0,64 *$ & 0,01 & $0,48 *$ & 0,08 & $0,67 *$ & 0,009 & $0,50 *$ & 0,06 & $0,64 *$ & 0,01 & $0,63^{*}$ & 0,01 & $0,63 *$ & 0,01 & $0,57 *$ & 0,03 & $0,67 *$ & 0,01 \\
\hline $\mathrm{rMSSD}_{\mathrm{I}}(\mathrm{ms})$ & 0,44 & 0,11 & $0,56^{*}$ & 0,03 & 0,39 & 0,16 & $0,63^{*}$ & 0,01 & 0,46 & 0,09 & $0,60 *$ & 0,02 & $0,60 *$ & 0,02 & $0,62 *$ & 0,02 & $0,53^{*}$ & 0,05 & $0,64^{*}$ & 0,01 \\
\hline
\end{tabular}



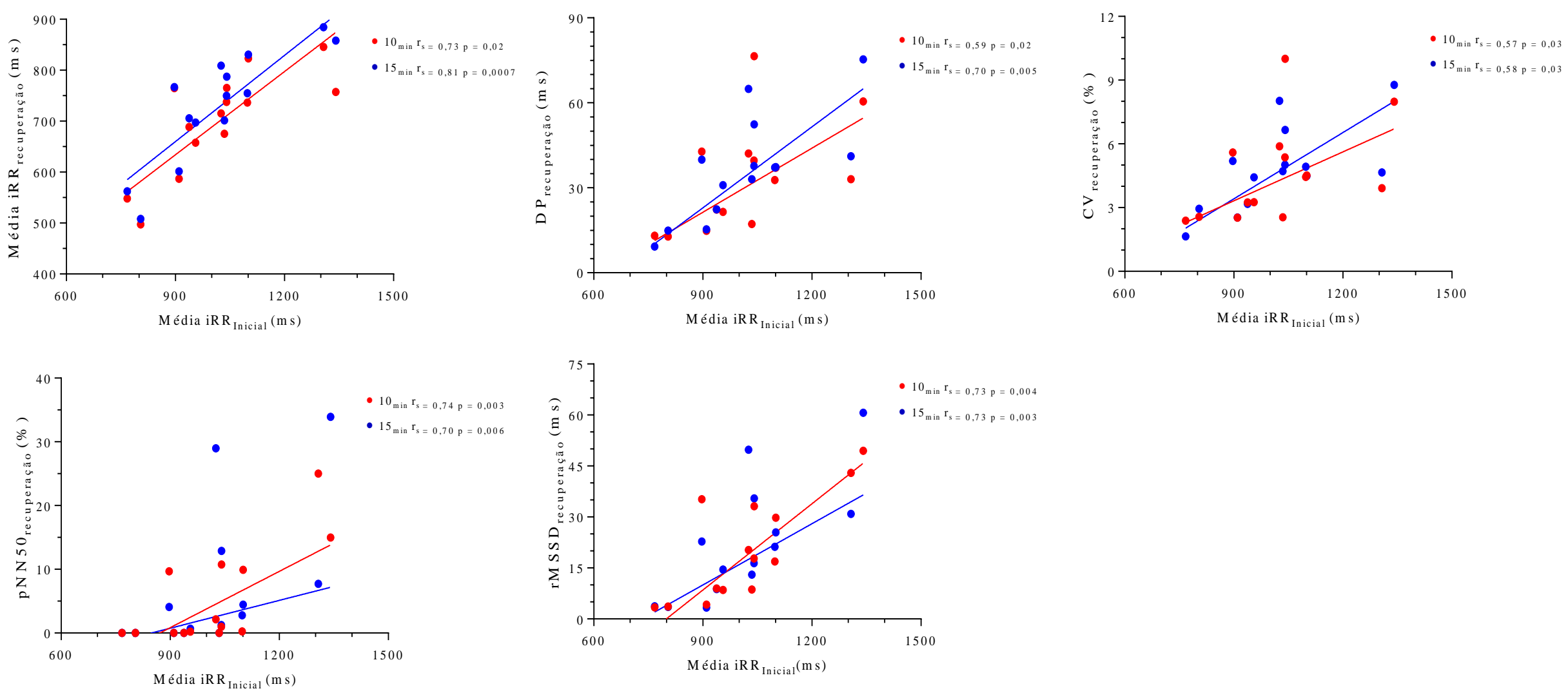

FIGURA 28 - Correlações entre função autonômica cardíaca na posição supina na condição inicial, com a função autonômica cardíaca após 5 (0 a 5 ) min (círculo verde), 10 (5 a 10) min (círculo vermelho) e 15 (10 a 15) min (círculo azul) de uma sessão de treino resistido, avaliada pelos, avaliada pelos índices de temporais. 

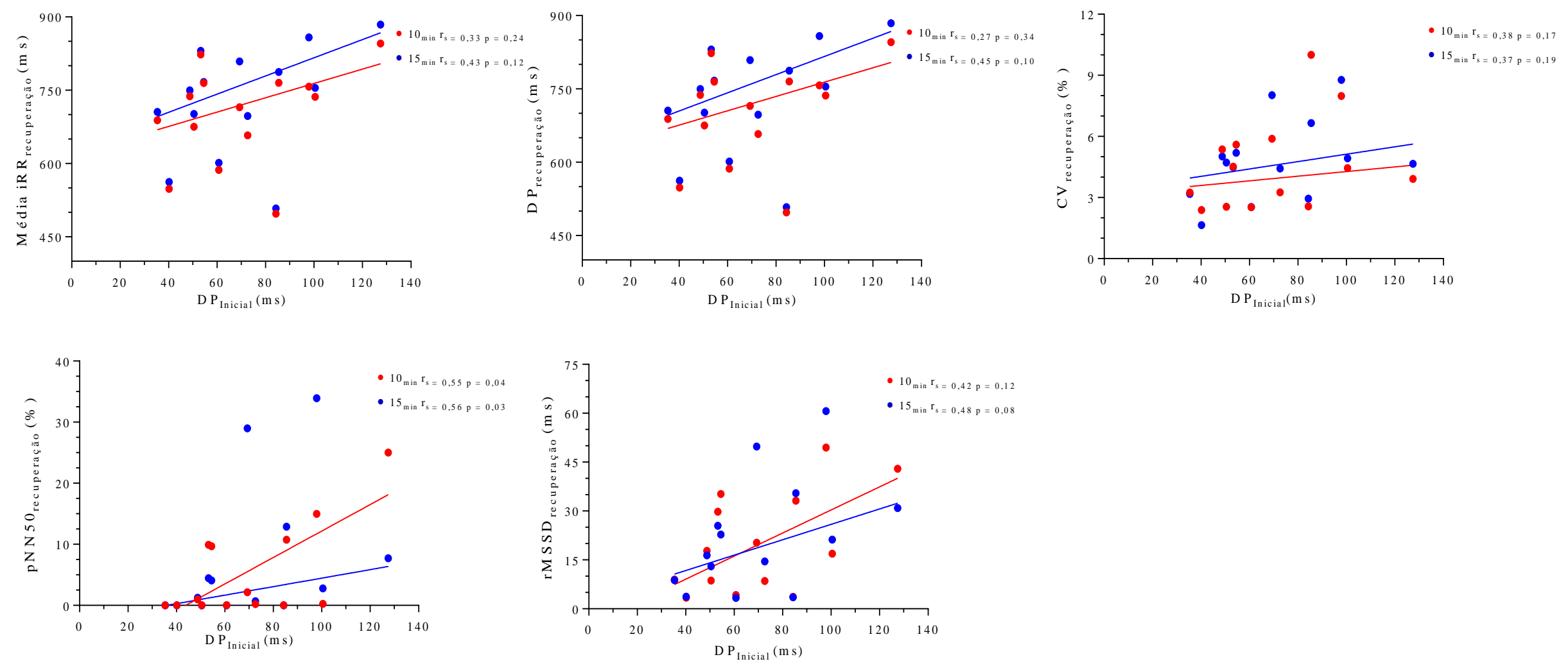

FIGURA 29 - Correlações entre função autonômica cardíaca na posição supina na condição inicial, com a função autonômica cardíaca após 5 (0 a 5 ) min (círculo verde), 10 (5 a 10) min (círculo vermelho) e 15 (10 a 15) min (círculo azul) de uma sessão de treino resistido, avaliada pelos, avaliada pelos índices de temporais. 

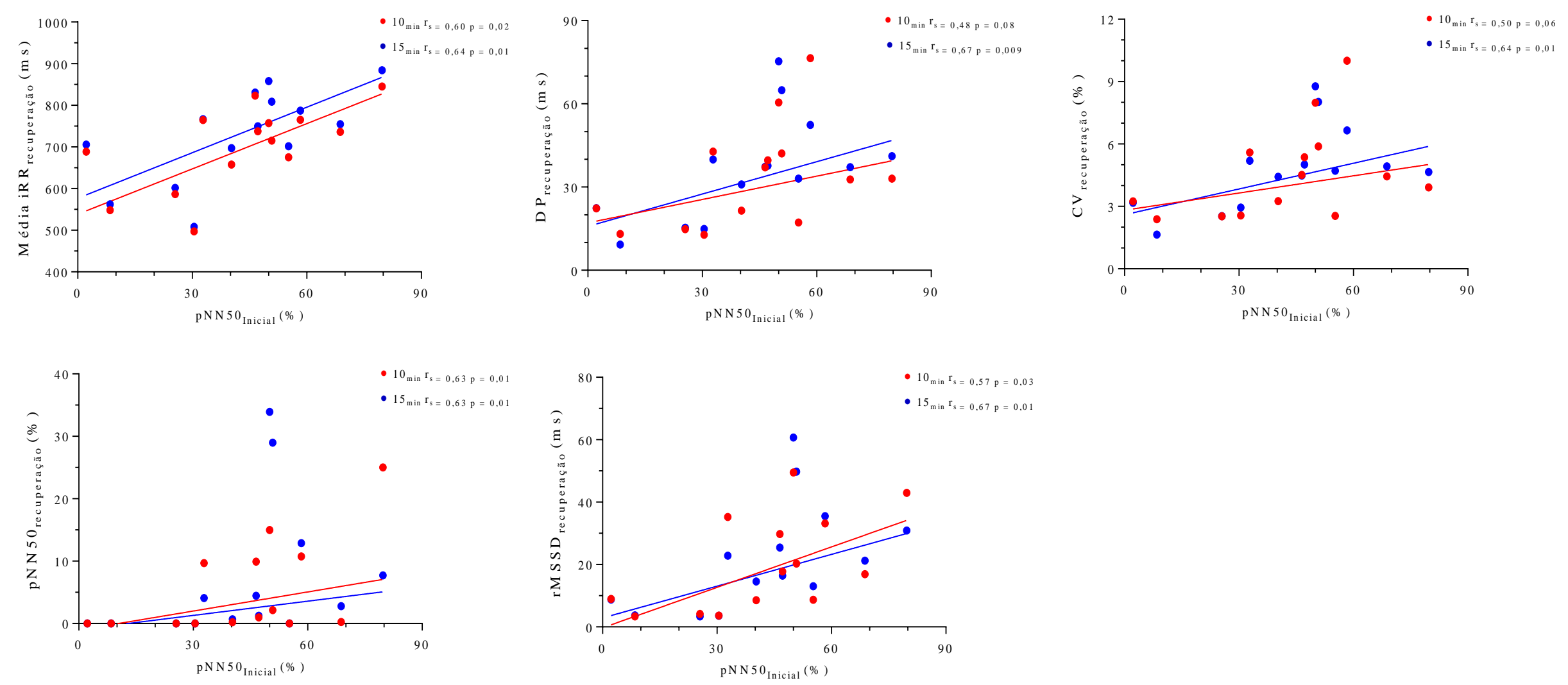

FIGURA 30 - Correlações entre função autonômica cardíaca na posição supina na condição inicial, com a função autonômica cardíaca após 5 (0 a 5 ) min (círculo verde), 10 (5 a 10) min (círculo vermelho) e 15 (10 a 15) min (círculo azul) de uma sessão de treino resistido, avaliada pelos, avaliada pelos índices de temporais. 

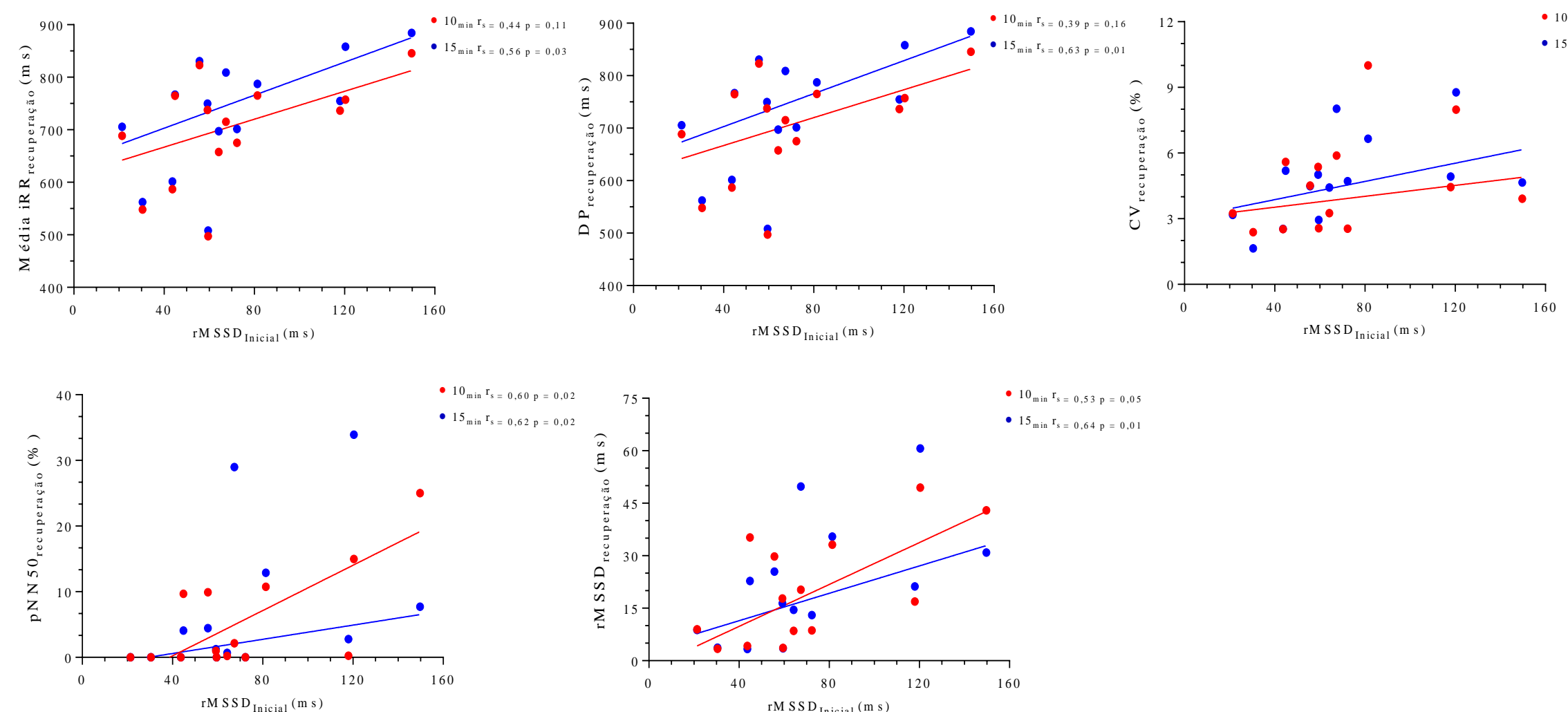

FIGURA 31 - Correlações entre função autonômica cardíaca na posição supina na condição inicial, com a função autonômica cardíaca após 5 (0 a 5 ) min (círculo verde), 10 (5 a 10) min (círculo vermelho) e 15 (10 a 15) min (círculo azul) de uma sessão de treino resistido, avaliada pelos, avaliada pelos índices de temporais. 
TABELA 17 - Correlações entre os índices espectrais das séries de intervalo RR, na posição supina na condição inicial, com a função autonômica cardíaca, ao longo de 15 minutos, após uma sessão de treino resistido $(\mathrm{n}=14)$.

\begin{tabular}{|c|c|c|c|c|c|c|c|c|c|c|c|c|c|c|c|c|}
\hline & \multicolumn{2}{|c|}{ Área Total $10 \mathrm{~min}$} & \multicolumn{2}{|c|}{ Área Total $15 \min$} & \multicolumn{2}{|c|}{ Razão BF/AF 10 min } & \multicolumn{2}{|c|}{ Razão BF/AF $15 \min$} & \multicolumn{2}{|c|}{ Área Nor. $\mathrm{BF}_{10 \mathrm{~min}}$} & \multicolumn{2}{|c|}{ Área Nor. $\mathrm{BF}_{15 \min }$} & \multicolumn{2}{|c|}{ Área Nor. $\mathrm{AF}_{10 \mathrm{~min}}$} & \multicolumn{2}{|c|}{ Área Nor. $\mathrm{AF}_{15 \min }$} \\
\hline & $\mathrm{r}_{\mathrm{s}}$ & $\mathrm{p}$ & $\mathrm{r}_{\mathrm{s}}$ & $\mathrm{p}$ & $r_{s}$ & $\mathrm{p}$ & $r_{s}$ & $\mathrm{p}$ & $\mathrm{r}_{\mathrm{s}}$ & $\mathrm{p}$ & $\mathrm{r}_{\mathrm{s}}$ & $\mathrm{P}$ & $\mathrm{r}_{\mathrm{s}}$ & $\mathrm{p}$ & $\mathrm{r}_{\mathrm{s}}$ & $\mathrm{p}$ \\
\hline Área Total $(\mathrm{ms})$ & 0,23 & 0,40 & 0,45 & 0,10 & $-0,51^{*}$ & 0,06 & $-0,47 *$ & 0,08 & $-0,51 *$ & 0,06 & $-0,47^{*}$ & 0,08 & $0,49 *$ & 0,07 & $0,47 *$ & 0,08 \\
\hline Razão BF/AF & $-0,65^{*}$ & 0,01 & $-0,72 *$ & 0,004 & $0,78^{*}$ & 0,001 & $0,69 *$ & 0,006 & $0,78^{*}$ & 0,001 & $0,69^{*}$ & 0,006 & $-0,77 *$ & 0,006 & $-0,69 *$ & 0,006 \\
\hline Área Nor. $\mathrm{BF}_{\mathrm{I}}$ & $-0,66^{*}$ & 0,01 & $-0,74 *$ & 0,003 & $0,79 *$ & 0,001 & $0,71^{*}$ & 0,005 & $0,79^{*}$ & 0,001 & $0,71^{*}$ & 0,005 & $-0,78^{*}$ & 0,001 & $-0,71 *$ & 0,005 \\
\hline Área Nor. $\mathrm{AF}_{\mathrm{I}}$ & $0,65^{*}$ & 0,01 & $0,72 *$ & 0,004 & $-0,78^{*}$ & 0,001 & $-0,67 *$ & 0,01 & $-0,78 *$ & 0,001 & $-0,67 *$ & 0,01 & $0,77 *$ & 0,001 & $0,67 *$ & 0,01 \\
\hline
\end{tabular}



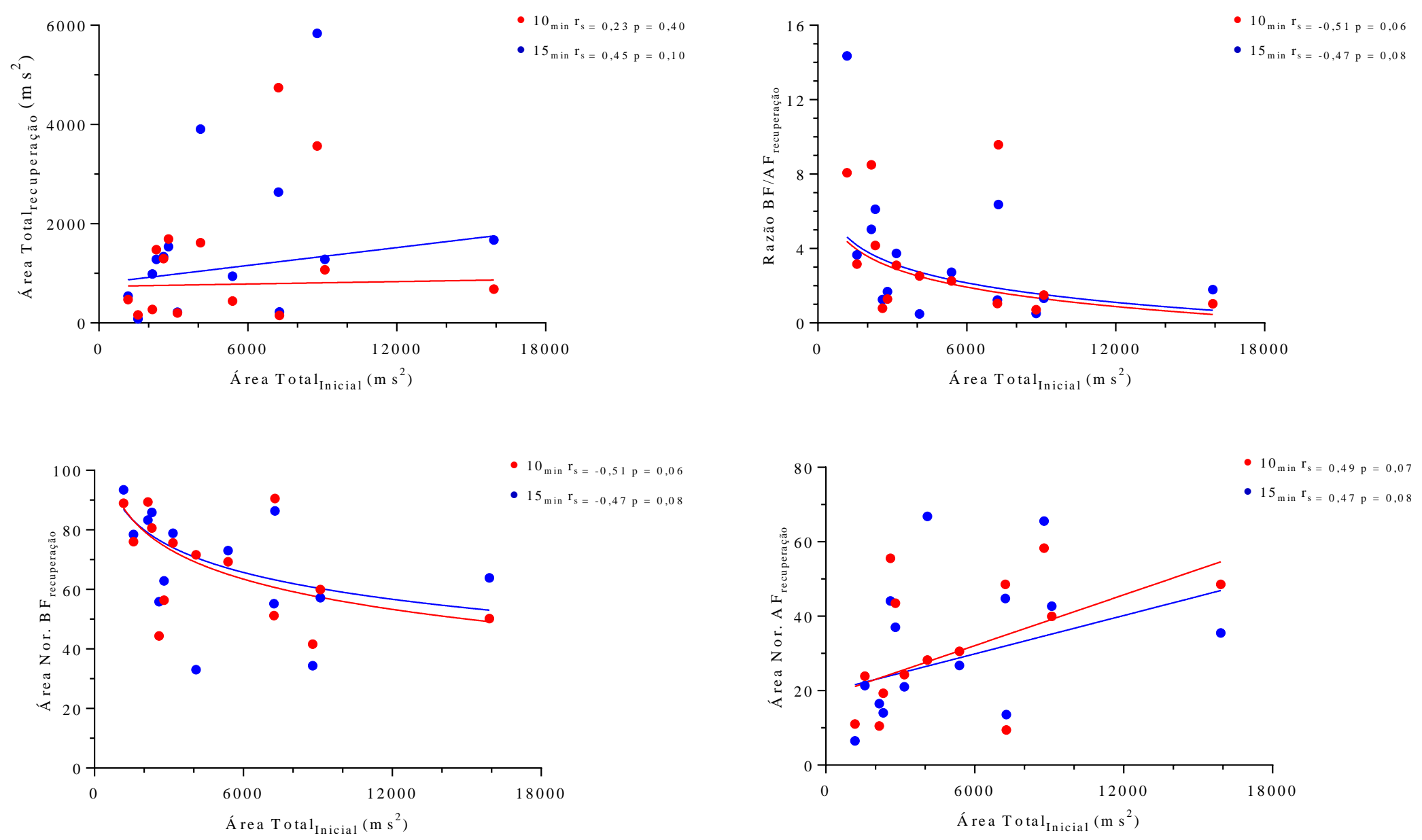

FIGURA 32 - Correlações entre função autonômica cardíaca na posição supina na condição inicial, com a função autonômica cardíaca após 5 (0 a 5 ) min (círculo verde), 10 (5 a 10) min (círculo vermelho) e 15 (10 a 15) min (círculo azul) de uma sessão de treino resistido, avaliada pelos, avaliada pelos índices espectrais. 

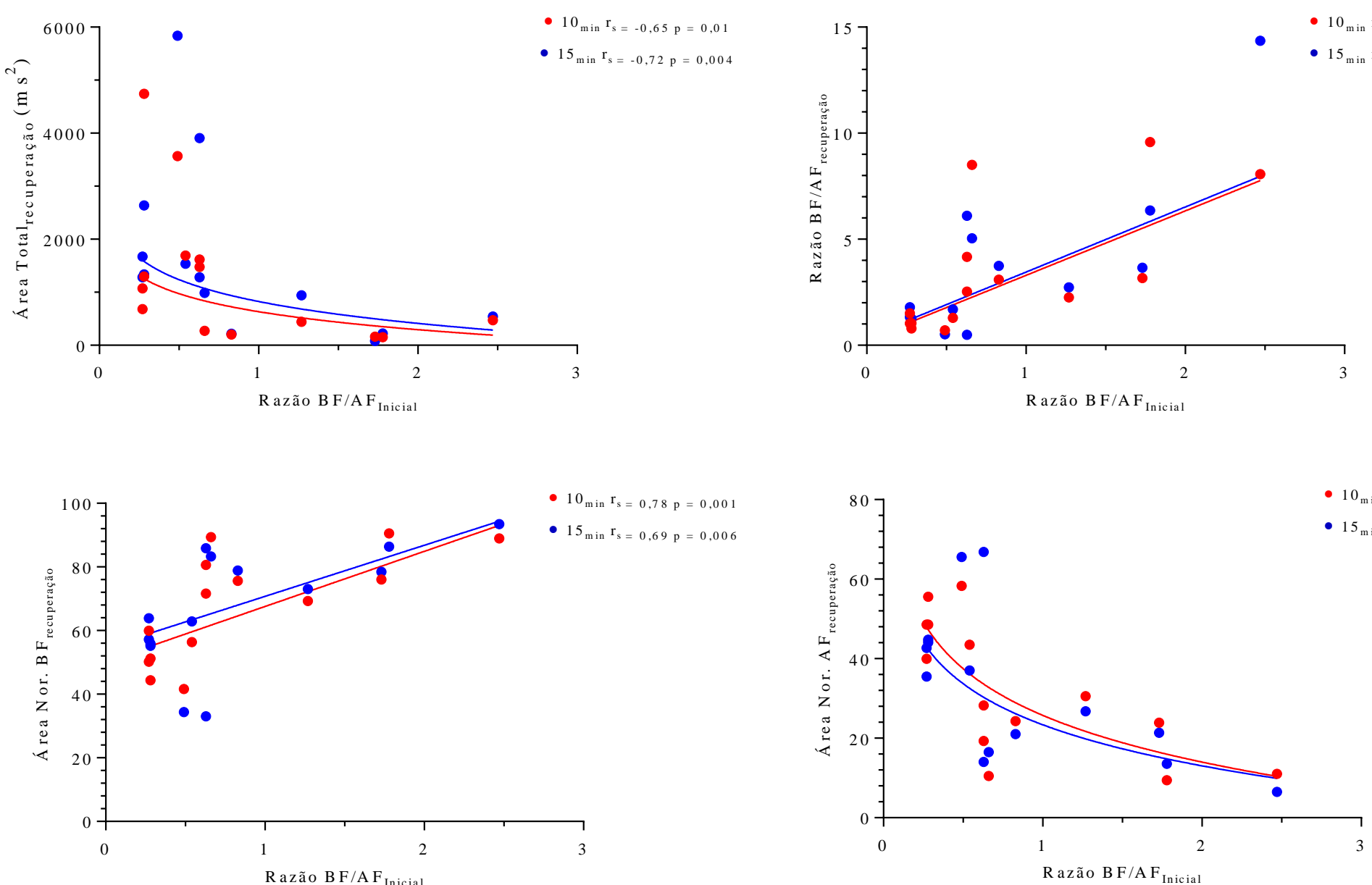

FIGURA 33 - Correlações entre função autonômica cardíaca na posição supina na condição inicial, com a função autonômica cardíaca após 5 (0 a 5 ) min (círculo verde), 10 (5 a 10) min (círculo vermelho) e 15 (10 a 15) min (círculo azul) de uma sessão de treino resistido, avaliada pelos, avaliada pelos índices espectrais. 

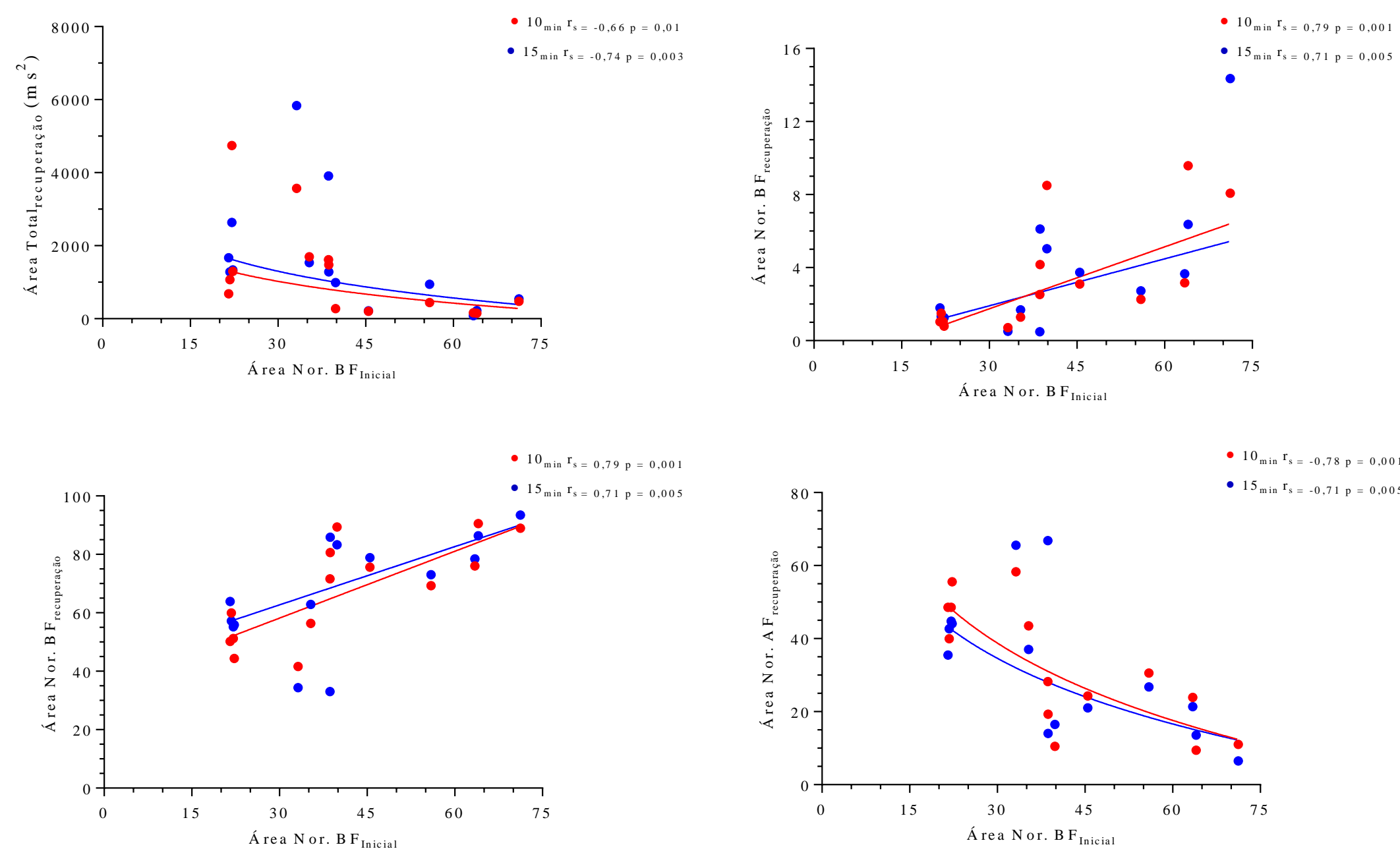

FIGURA 34 - Correlações entre função autonômica cardíaca na posição supina na condição inicial, com a função autonômica cardíaca após 5 (0 a 5 ) min (círculo verde), 10 (5 a 10) min (círculo vermelho) e 15 (10 a 15) min (círculo azul) de uma sessão de treino resistido, avaliada pelos, avaliada pelos índices espectrais. 

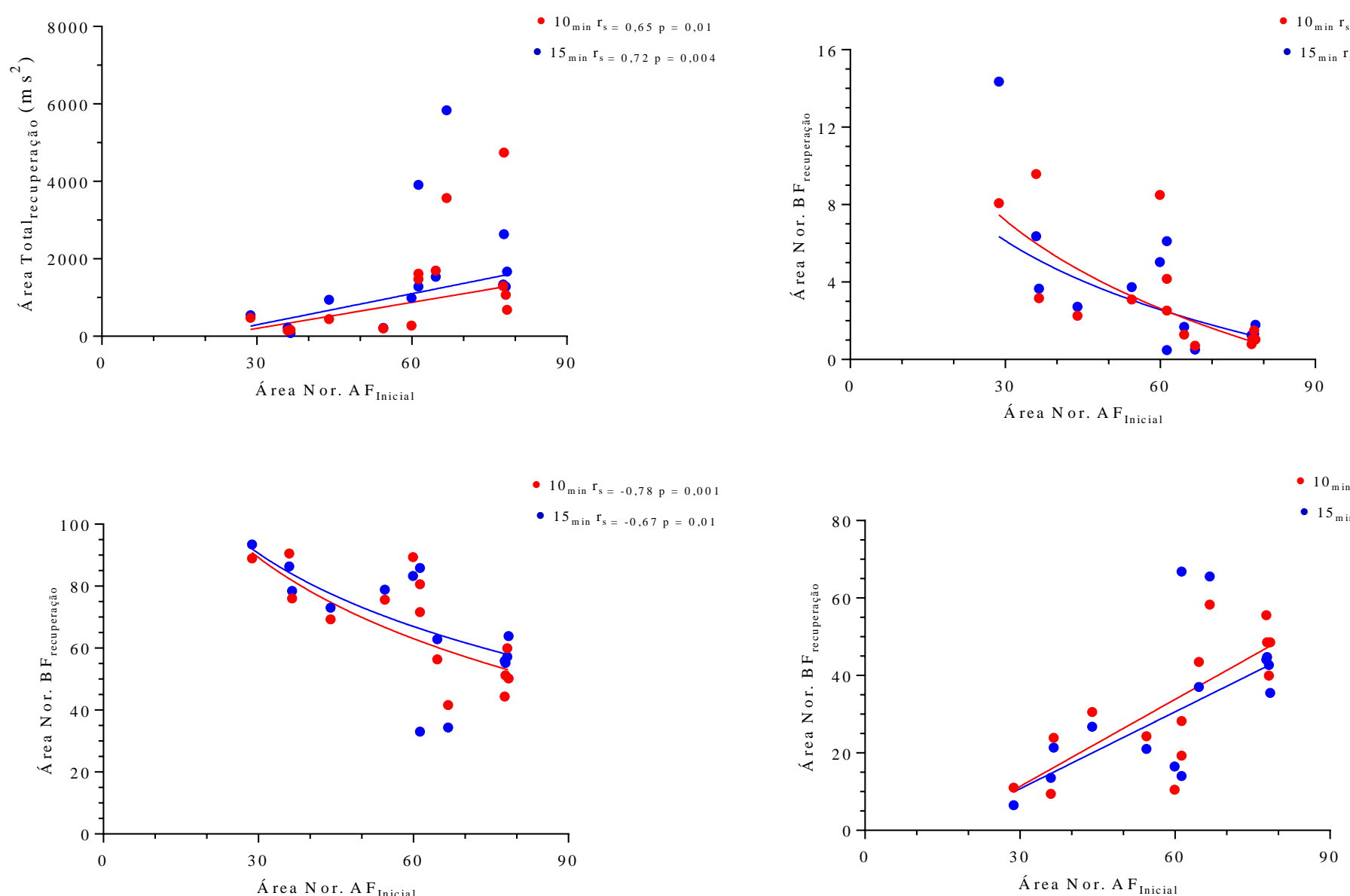

FIGURA 35 - Correlações entre função autonômica cardíaca na posição supina na condição inicial, com a função autonômica cardíaca após 5 (0 a 5 ) min (círculo verde), 10 (5 a 10) min (círculo vermelho) e 15 (10 a 15) min (círculo azul) de uma sessão de treino resistido, avaliada pelos, avaliada pelos índices espectrais 


\subsection{CORRELAÇÕES DA FUNÇÃO AUTONÔMICA CARDÍACA, AVALIADA PELOS ÍNDICES DE POINCARÉ, NO DOMÍNIO TEMPORAL E ESPECTRAL COM A RESPOSTA CRONOTRÓPICA CARDÍACA APÓS SESSÃO DE TREINO RESISTIDO}

\subsubsection{CORRELAÇÃO ENTRE A FAC AVALIADA PELOS ÍNDICES DE POINCARÉ DA VFC COM A RESPOSTA CRONOTRÓPICA CARDÍACA APÓS SESSÃO DE TR}

Na Tabela 18 estão descritas as correlações entre os índices de Poincaré da VFC na posição supina durante a condição inicial, com a resposta cronotrópica cardíaca após cinco, dez e quinze minutos da sessão de TR. Na FIGURA 36 estão descritos os diagramas de dispersão e suas respectivas correlações.

A maioria dos índices de Poincaré na condição inicial e posição supina, apresentou $\left(\mathrm{r}_{\mathrm{s}}\right)$ moderada para forte $(0,48$ a 0,59), com a resposta cronotrópica cardíaca após 15 minutos de uma sessão de TR.

O marcador vagal SD1 I na condição inicial apresentou correlação negativa forte e significativa com a FC nos dez e quinze minutos após sessão de TR e correlação positiva, moderada a forte, e significativa com a $\Delta \% \mathrm{FC}$ nos cinco, dez e quinze minutos após sessão de TR. Não foi observado correlação significativa com a FCR após sessão de TR.

Observou correlações positivas fortes com o marcador de modulação global SD2 ${ }_{I}$ na condição inicial com a FCR e a $\Delta \% \mathrm{FC}$ apenas nos cinco minutos de recuperação após sessão de TR. Não foi observado correlação significativa com os demais momentos, bem como, como a FC na recuperação.

Ao correlacionar o marcador de balanço autonômico SD1/SD2 I na condição inicial com a FC nos dez e quinze minutos após sessão de TR, observou-se correlações negativas fortes e significativas nos dez e quinze minutos após sessão de TR. Não foi observado correlação significativa a FCR e a $\Delta \%$ FC após sessão de TR. 
Destaca-se o fato de que a magnitude da correlação do marcador vagal e marcador de balaço autonômico na condição inicial com a FC após sessão de TR, apresentam um comportamento crescente em função do tempo de recuperação.

\subsubsection{CORRELAÇÃO ENTRE A FAC AVALIADA PELOS ÍNDICES TEMPORAIS DA VFC COM A RESPOSTA CRONOTRÓPICA CARDÍACA APÓS SESSÃO DE TR}

Na Tabela 19 estão descritas as correlações entre os índices de Poincaré da VFC na posição supina durante a condição inicial, com a resposta cronotrópica cardíaca após cinco, dez e quinze minutos da sessão de TR. Nas FIGURAS 37 e 38 estão descritos os diagramas de dispersão e suas respectivas correlações.

A maioria dos índices do domínio temporal na condição inicial e posição supina, apresentou $\left(\mathrm{r}_{\mathrm{s}}\right)$ moderada para forte $(0,48$ a 0,87), com a resposta cronotrópica cardíaca após 15 minutos de uma sessão de TR. A exceção ficou para o $\mathrm{CV}_{\text {I }}$ que não se correlacionou com nenhum outro índice em qualquer minuto.

Observou-se correlações fortes negativas e significativas entre o marcador vagal pNN50I na condição inicial com a FC nos cinco, dez e quinze minutos após sessão de TR. O mesmo ocorreu na correlação entre o marcador vagal $\mathrm{rMSSD}_{\mathrm{I}}$ com a FC nos dez e quinze minutos após sessão de TR. Bem como, observou -se correlações positivas, moderadas a fortes, entre os marcadores vagais pNN50 I e rMSSD I com a $\Delta \%$ FC nos cinco, dez e quinze minutos após sessão de TR. Não foi observado correlações significativa entre pNN50I e rMSSDI com a FCR após sessão de TR.

A média $i R_{I}$ na condição inicial apresentou correlações negativas, fortes a muito forte, e significativas com a FC nos cinco, dez e quinze minutos após sessão de TR, e correlações positivas, moderadas a fortes, com a $\Delta \% \mathrm{FC}$ nos cinco, dez e quinze minutos após sessão de TR. Não foi observado correlações significativa entre média iRR I com a FCR após sessão de TR.

Observou correlações positivas fortes com o marcador de modulação global SD2 Ina condição inicial com a FCR apenas nos cinco minutos de recuperação e com a $\Delta \% \mathrm{FC}$ nos cinco e quinze 
minutos de recuperação após sessão de TR. Não foi observado correlação significativa com os a FC na recuperação.

Destaca-se o fato de que a magnitude da correlação dos marcadores vagais e média $i R R_{I}$ na condição inicial com a FC após sessão de TR, apresentam um comportamento crescente em função do tempo de recuperação.

\subsubsection{CORRELAÇÃO ENTRE A FAC AVALIADA PELOS ÍNDICES ESPECTRAIS DA VFC} COM A RESPOSTA CRONOTRÓPICA CARDÍACA APÓS SESSÃO DE TR

Na Tabela 20 estão descritas as correlações entre os índices de Poincaré da VFC na posição supina durante a condição inicial, com a resposta cronotrópica cardíaca após cinco, dez e quinze minutos da sessão de TR. Nas FIGURAS 39 e 40 estão descritos os diagramas de dispersão e suas respectivas correlações.

A maioria dos índices do domínio espectral na condição inicial e posição supina, apresentou $\left(\mathrm{r}_{\mathrm{s}}\right)$ moderada para forte $(0,49$ a 0,85), com a resposta cronotrópica cardíaca após 15 minutos de uma sessão de TR.

Observou-se correlações, forte a muito forte, negativas e significativas entre o marcador vagal Área Normalizada de $\mathrm{AF}_{\mathrm{I}}$ na condição inicial com a FC nos cinco, dez e quinze minutos após sessão de TR. Bem como, observou-se correlações, forte e muito forte, positivas entre a Área Normalizada de $\mathrm{AF}_{\mathrm{I}}$ na condição inicial $\Delta \% \mathrm{FC}$ nos cinco, dez e quinze minutos após sessão de $\mathrm{TR}$. Não foi observado correlações significativa entre Área Normalizada de AFI com a FCR após sessão de TR.

O marcador $\mathrm{AT}_{\mathrm{I}}$ na condição inicial não apresentou correlação significativa com a FC nos cinco, dez e quinze minutos após sessão de TR. Contudo, observou-se correlações, moderadas a forte, positiva e significativa entre o marcador $\mathrm{AT}_{\mathrm{I}}$ com a FCR apenas nos cinco minutos, e com a $\Delta \% \mathrm{FC}$ nos cinco e quinze minutos após sessão de TR.

A razão $\mathrm{BF} / \mathrm{AF}_{\mathrm{I}}$ e Área Normalizada de $\mathrm{BF}_{\mathrm{I}}$ na condição inicial apresentou correlações positivas, muito forte, e significativas com a FC nos cinco, dez e quinze minutos após sessão de TR, 
bem como, observou-se correlações negativas fortes e significativas entre razão $B F / \mathrm{AF}_{\mathrm{I}}$ e Área Normalizada de $\mathrm{BF}_{\mathrm{I}}$ com a $\Delta \% \mathrm{FC}$ nos cinco e dez minutos após sessão de TR. Não foi observado correlações significativa entre a razão $\mathrm{BF} / \mathrm{AF}_{\mathrm{I}}$ e Área Normalizada de $\mathrm{BF}$ I com a FCR após sessão de TR.

Assim, ao proceder à análise da correlação da FAC na posição supina inicial, avaliada pelos índices de Poincaré, no domínio temporal e domínio espectral da VFC, com a resposta cronotrópica cardíaca após cinco, dez e quinze minutos de uma sessão de TR, os marcadores da atividade vagal na condição basal, correlacionam - se negativamente com o decremento da FC nos cinco, dez e quinze minutos de recuperação, e correlacionaram-se positivamente com o decremento individual relativo da FC nos cinco, dez e quinze minutos de recuperação, após uma sessão de TR.

No sentido oposto desta análise, os dados demonstram que os marcadores de tônus simpático na condição inicial correlacionaram-se positivamente com o decremento da FC nos cinco, dez e quinze minutos de recuperação, e correlacionaram-se negativamente com o decremento individual relativo da FC nos cinco, dez e quinze minutos de recuperação, após uma sessão de TR.

E, os marcadores da atividade de modulação global na condição inicial, correlacionam - se positivamente com o decremento individuais absoluto da FC nos cinco minutos de recuperação, e com o decremento individual relativo da FC nos cinco e quinze de recuperação, após uma sessão de TR. 
TABELA 18 - Correlações entre os índices de Poincaré das séries de intervalo RR, na posição supina inicial, com a resposta cronotrópica cardíaca após $5^{\circ}$, $10^{\circ}$ e $15^{\circ}$ minuto de uma sessão de treino resistido $(n=14)$.

\begin{tabular}{|c|c|c|c|c|c|c|c|c|c|c|c|c|c|c|c|c|c|c|}
\hline & \multicolumn{2}{|c|}{$\mathrm{FC}_{5 \min }$} & \multicolumn{2}{|c|}{$\mathrm{FC}_{10 \text { min }}$} & \multicolumn{2}{|c|}{$\mathrm{FC}_{15 \min }$} & \multicolumn{2}{|c|}{$\Delta \mathrm{absFC}_{5 \min }$} & \multicolumn{2}{|c|}{$\Delta \mathrm{absFC}_{10 \min }$} & \multicolumn{2}{|c|}{$\Delta \mathrm{absFC}_{15 \min }$} & \multicolumn{2}{|c|}{$\Delta \% \mathrm{FC}_{5 \min }$} & \multicolumn{2}{|c|}{$\Delta \% \mathrm{FC}_{10 \min }$} & \multicolumn{2}{|c|}{$\Delta \% \mathrm{FC}_{15 \min }$} \\
\hline & $\mathrm{r}_{\mathrm{s}}$ & $\mathrm{p}$ & $\mathrm{r}_{\mathrm{s}}$ & $\mathrm{p}$ & $\mathrm{r}_{\mathrm{s}}$ & $\mathrm{P}$ & $\mathrm{r}_{\mathrm{s}}$ & $\mathrm{p}$ & $\mathrm{r}_{\mathrm{s}}$ & $\mathrm{p}$ & $\mathrm{r}_{\mathrm{s}}$ & $\mathrm{p}$ & $\mathrm{r}_{\mathrm{s}}$ & $\mathrm{p}$ & $\mathrm{r}_{\mathrm{s}}$ & $\mathrm{p}$ & $\mathrm{r}_{\mathrm{s}}$ & $\mathrm{p}$ \\
\hline $\mathrm{SD}_{\mathrm{I}}$ & $-0,42$ & 0,12 & $-0,53 *$ & 0,04 & $-0,58^{*}$ & 0,03 & 0,43 & 0,12 & 0,27 & 0,33 & 0,42 & 0,13 & $0,55^{*}$ & 0,04 & $0,48^{*}$ & 0,08 & $0,59 *$ & 0,02 \\
\hline $\mathrm{SD} 2_{\mathrm{I}}$ & $-0,29$ & 0,30 & $-0,27$ & 0,33 & $-0,35$ & 0,20 & $0,50 *$ & 0,06 & 0,29 & 0,29 & 0,46 & 0,09 & $0,51^{*}$ & 0,06 & 0,31 & 0,27 & 0,45 & 0,10 \\
\hline Razão SD1/SD2 & $-0,46$ & 0,09 & $-0,54 *$ & 0,04 & $-0,59 *$ & 0,02 & 0,04 & 0,86 & 0,03 & 0,90 & 0,09 & 0,75 & 0,36 & 0,19 & 0,38 & 0,17 & 0,35 & 0,21 \\
\hline
\end{tabular}



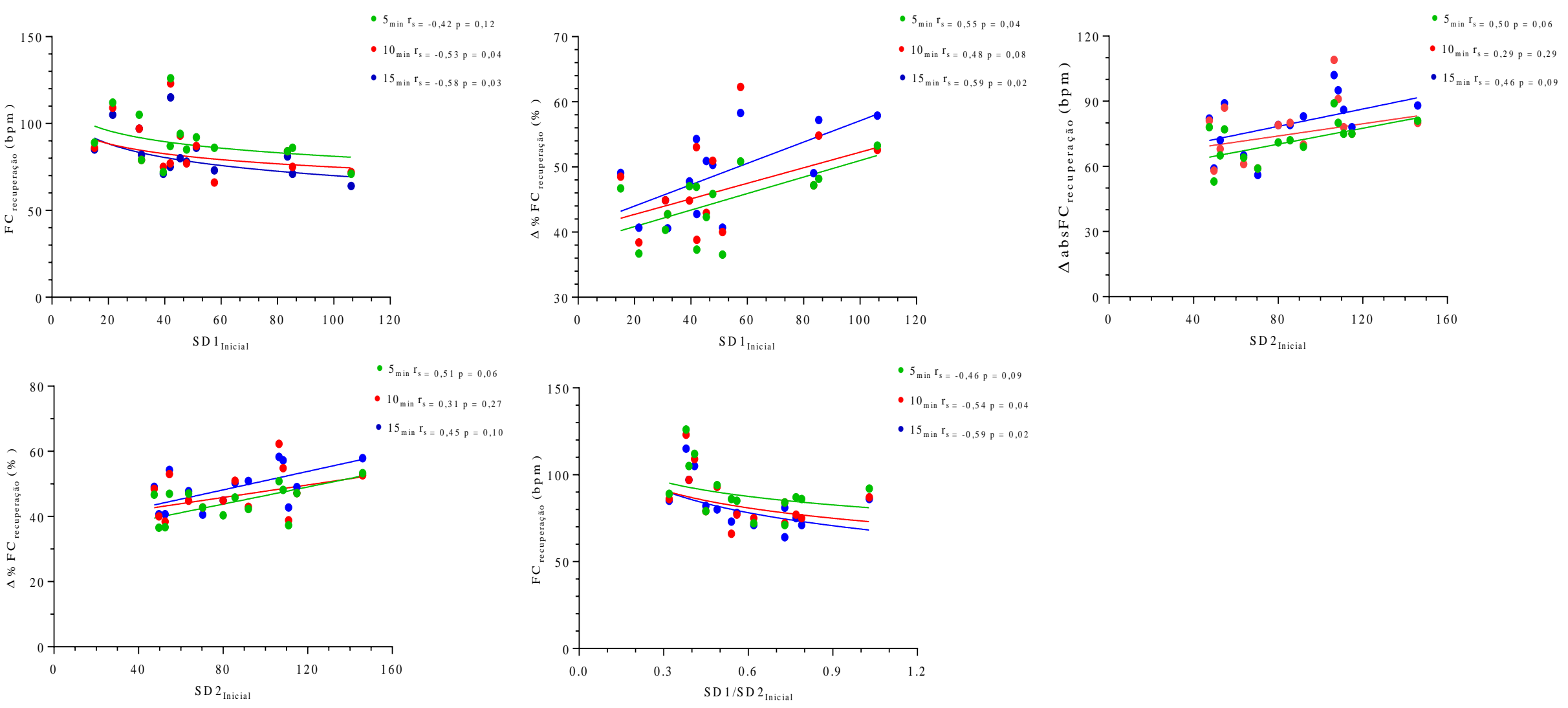

FIGURA 36 - Correlações entre função autonômica cardíaca na posição supina inicial, avaliada pelos índices de Poincaré da variabilidade da frequência cardíaca, com a resposta cronotrópica cardíaca após $5^{\circ} \min$ (círculo verde), $10^{\circ} \mathrm{min}$ (círculo vermelho) e $15^{\circ} \mathrm{min}$ (círculo azul) de uma sessão de treino resistido. 
TABELA 19 - Correlações entre os índices temporais das séries de intervalo RR, na posição supina inicial, com a resposta cronotrópica cardíaca após $5^{\circ}$, $10^{\circ}$ e $15^{\circ}$ minutos de uma sessão de treino resistido $(n=14)$.

\begin{tabular}{|c|c|c|c|c|c|c|c|c|c|c|c|c|c|c|c|c|c|c|}
\hline & \multicolumn{2}{|c|}{$\mathrm{FC}_{5 \min }$} & \multicolumn{2}{|c|}{$\mathrm{FC}_{10 \min }$} & \multicolumn{2}{|c|}{$\mathrm{FC}_{15 \min }$} & \multicolumn{2}{|c|}{$\Delta \mathrm{absFC}_{5 \min }$} & \multicolumn{2}{|c|}{$\Delta \mathrm{absFC}_{10 \min }$} & \multicolumn{2}{|c|}{$\Delta \mathrm{absFC}_{15 \min }$} & \multicolumn{2}{|c|}{$\Delta \% \mathrm{FC}_{5 \min }$} & \multicolumn{2}{|c|}{$\Delta \% \mathrm{FC}_{10 \min }$} & \multicolumn{2}{|c|}{$\Delta \% \mathrm{FC}_{15 \min }$} \\
\hline & $\mathrm{r}_{\mathrm{s}}$ & $\mathrm{p}$ & $\mathrm{r}_{\mathrm{s}}$ & $\mathrm{p}$ & $\mathrm{r}_{\mathrm{s}}$ & $\mathrm{P}$ & $\mathrm{r}_{\mathrm{s}}$ & $\mathrm{p}$ & $\mathrm{r}_{\mathrm{s}}$ & $\mathrm{p}$ & $\mathrm{r}_{\mathrm{s}}$ & $\mathrm{p}$ & $\mathrm{r}_{\mathrm{s}}$ & $\mathrm{p}$ & $\mathrm{r}_{\mathrm{s}}$ & $\mathrm{p}$ & $\mathrm{r}_{\mathrm{s}}$ & $\mathrm{p}$ \\
\hline $\operatorname{Média}_{I}(\mathrm{~ms})$ & $-0,67 *$ & 0,008 & $-0,80 *$ & 0,0007 & $-0,87 *$ & $<0,0001$ & 0,44 & 0,10 & 0,36 & 0,19 & 0,37 & 0,18 & $0,80^{*}$ & 0,0008 & $0,70 *$ & 0,006 & $0,69 *$ & 0,007 \\
\hline $\mathrm{DP}_{\mathrm{I}}(\mathrm{ms})$ & $-0,36$ & 0,20 & $-0,37$ & 0,18 & $-0,43$ & 0,11 & $0,48 *$ & 0,07 & 0,29 & 0,30 & 0,44 & 0,11 & $0,55^{*}$ & 0,04 & 0,38 & 0,17 & $0,49 *$ & 0,07 \\
\hline $\mathrm{CV}_{\mathrm{I}}(\%)$ & $-0,05$ & 0,84 & $-0,05$ & 0,85 & $-0,10$ & 0,71 & 0,38 & 0,16 & 0,17 & 0,55 & 0,39 & 0,16 & 0,26 & 0,36 & 0,09 & 0,75 & 0,29 & 0,31 \\
\hline pNN50 I $(\%)$ & $-0,61^{*}$ & 0,02 & $-0,66^{*}$ & 0,01 & $-0,64 *$ & 0,01 & 0,32 & 0,25 & 0,18 & 0,51 & 0,24 & 0,40 & $0,59 *$ & 0,02 & $0,51^{*}$ & 0,06 & $0,53 *$ & 0,05 \\
\hline $\mathrm{rMSSD}_{\mathrm{I}}(\mathrm{ms})$ & $-0,42$ & 0,12 & $-0,53^{*}$ & 0,04 & $-0,58 *$ & 0,03 & 0,43 & 0,12 & 0,27 & 0,33 & 0,42 & 0,13 & $0,55^{*}$ & 0,04 & $0,48 *$ & 0,08 & $0,59 *$ & 0,02 \\
\hline
\end{tabular}



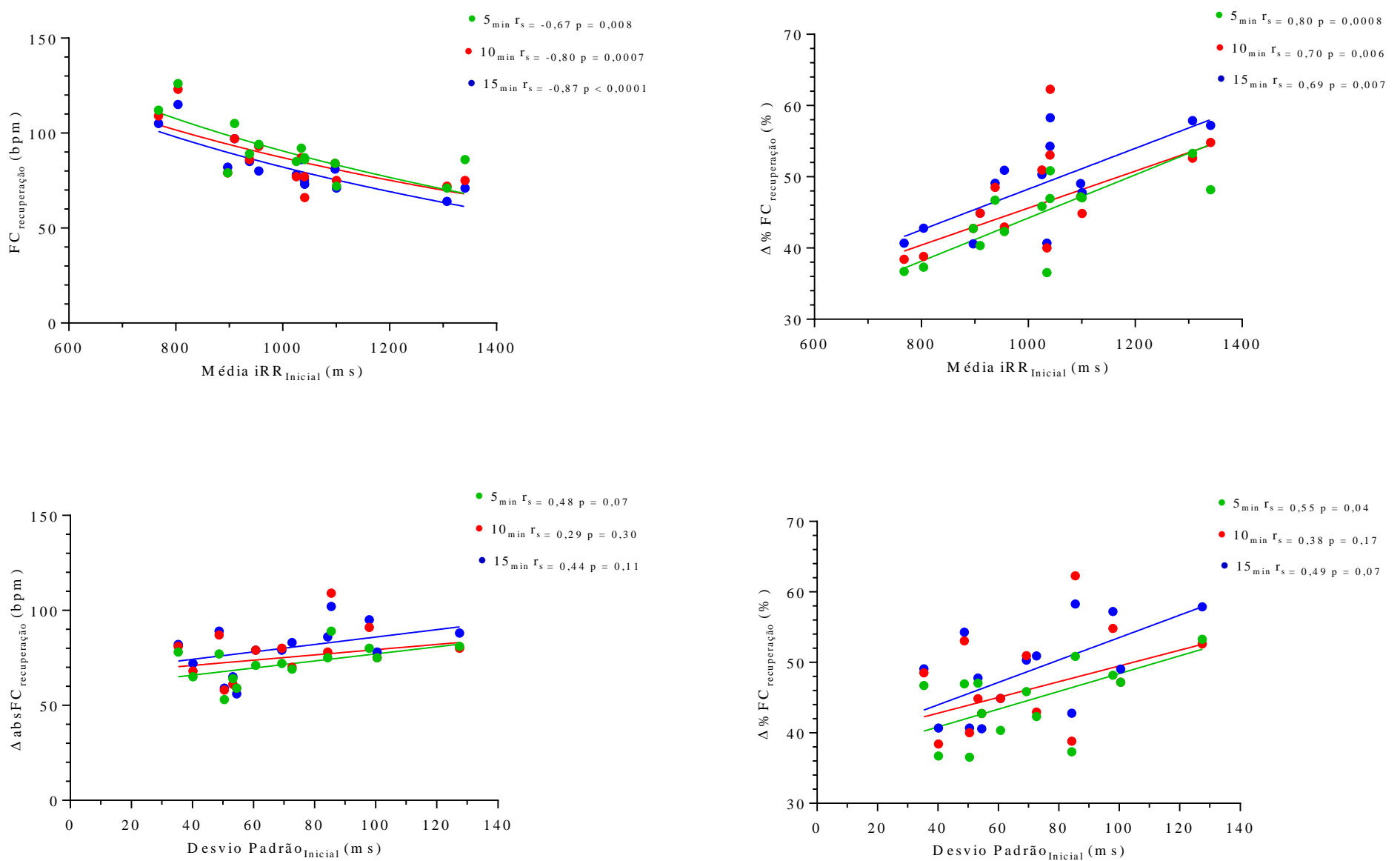

FIGURA 37 - Correlações entre função autonômica cardíaca na posição supina inicial, avaliada pelos índices temporais da variabilidade da frequência cardíaca, com a resposta cronotrópica cardíaca após $5^{\circ}$ min (círculo verde), $10^{\circ} \mathrm{min}$ (círculo vermelho) e $15^{\circ}$ min (círculo azul) de uma sessão de treino resistido. 

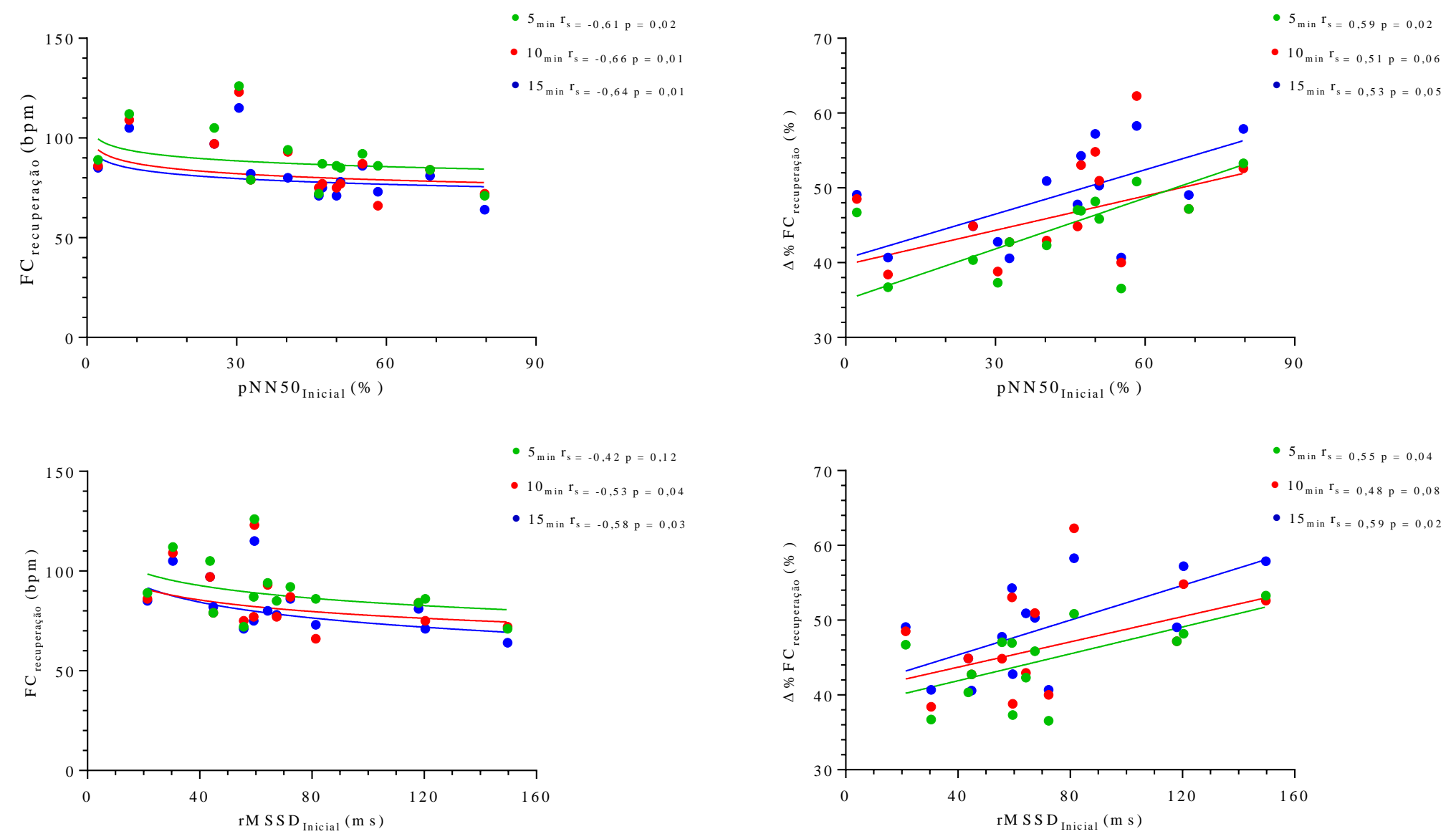

FIGURA 38 - Correlações entre função autonômica cardíaca na posição supina inicial, avaliada pelos índices temporais da variabilidade da frequência cardíaca, com a resposta cronotrópica cardíaca após $5^{\circ} \min$ (círculo verde), $10^{\circ} \mathrm{min}$ (círculo vermelho) e $15^{\circ}$ min (círculo azul) de uma sessão de treino resistido 
TABELA 20 - Correlações entre os índices espectrais das séries de intervalo RR, na posição supina inicial, com a resposta cronotrópica cardíaca após $5^{\circ}$, $10^{\circ}$ e $15^{\circ}$ minutos de uma sessão de treino resistido $(n=14)$.

\begin{tabular}{|c|c|c|c|c|c|c|c|c|c|c|c|c|c|c|c|c|c|c|}
\hline & \multicolumn{2}{|c|}{$\mathrm{FC}_{5 \min }$} & \multicolumn{2}{|c|}{$\mathrm{FC}_{10 \min }$} & \multicolumn{2}{|c|}{$\mathrm{FC}_{15 \min }$} & \multicolumn{2}{|c|}{$\Delta \mathrm{absFC}_{5 \min }$} & \multicolumn{2}{|c|}{$\Delta \mathrm{absFC}_{10 \min }$} & \multicolumn{2}{|c|}{$\Delta \mathrm{absFC}_{15 \min }$} & \multicolumn{2}{|c|}{$\Delta \% \mathrm{FC}_{5 \min }$} & \multicolumn{2}{|c|}{$\Delta \% \mathrm{FC}_{10 \min }$} & \multicolumn{2}{|c|}{$\Delta \% \mathrm{FC}_{15 \min }$} \\
\hline & $r_{s}$ & $\mathrm{p}$ & $r_{s}$ & $\mathrm{p}$ & $r_{s}$ & $\mathrm{P}$ & $r_{s}$ & $\mathrm{p}$ & $\mathrm{r}_{\mathrm{s}}$ & $\mathrm{p}$ & $r_{s}$ & $\mathrm{p}$ & $\mathrm{r}_{\mathrm{s}}$ & $\mathrm{p}$ & $r_{s}$ & $\mathrm{p}$ & $r_{s}$ & $\mathrm{p}$ \\
\hline Área Total $\left(\mathrm{ms}^{2}\right)$ & $-0,33$ & 0,23 & $-0,33$ & 0,23 & $-0,41$ & 0,13 & $0,50^{*}$ & 0,06 & 0,31 & 0,27 & 0,47 & 0,09 & $0,54^{*}$ & 0,04 & 0,37 & 0,19 & $0,49 *$ & 0,07 \\
\hline Razão BF/AF & $0,85^{*}$ & 0,0002 & $0,79 *$ & 0,001 & $0,75^{*}$ & 0,002 & $-0,26$ & 0,34 & $-0,13$ & 0,64 & $-0,09$ & 0,72 & $-0,76^{*}$ & 0,001 & $-0,52 *$ & 0,05 & $-0,42$ & 0,12 \\
\hline Área Nor. $\mathrm{BF}_{\mathrm{I}}$ & $0,85^{*}$ & 0,0002 & $0,81 *$ & 0,0007 & $0,76^{*}$ & 0,002 & $-0,29$ & 0,30 & $-0,15$ & 0,58 & $-0,12$ & 0,66 & $-0,77^{*}$ & 0,001 & $-0,54 *$ & 0,04 & $-0,45$ & 0,10 \\
\hline Área Nor. $\mathrm{AF}_{\mathrm{I}}$ & $-0,83 *$ & 0,0003 & $-0,81^{*}$ & 0,0006 & $-0,77 *$ & 0,001 & 0,30 & 0,29 & 0,16 & 0,56 & 0,14 & 0,61 & $0,78^{*}$ & 0,001 & $0,55^{*}$ & 0,04 & 0,49 & 0,10 \\
\hline
\end{tabular}
Nor. = normalizada; rs = Coeficiente de correlação de Spearman; *p = nível de significância; 

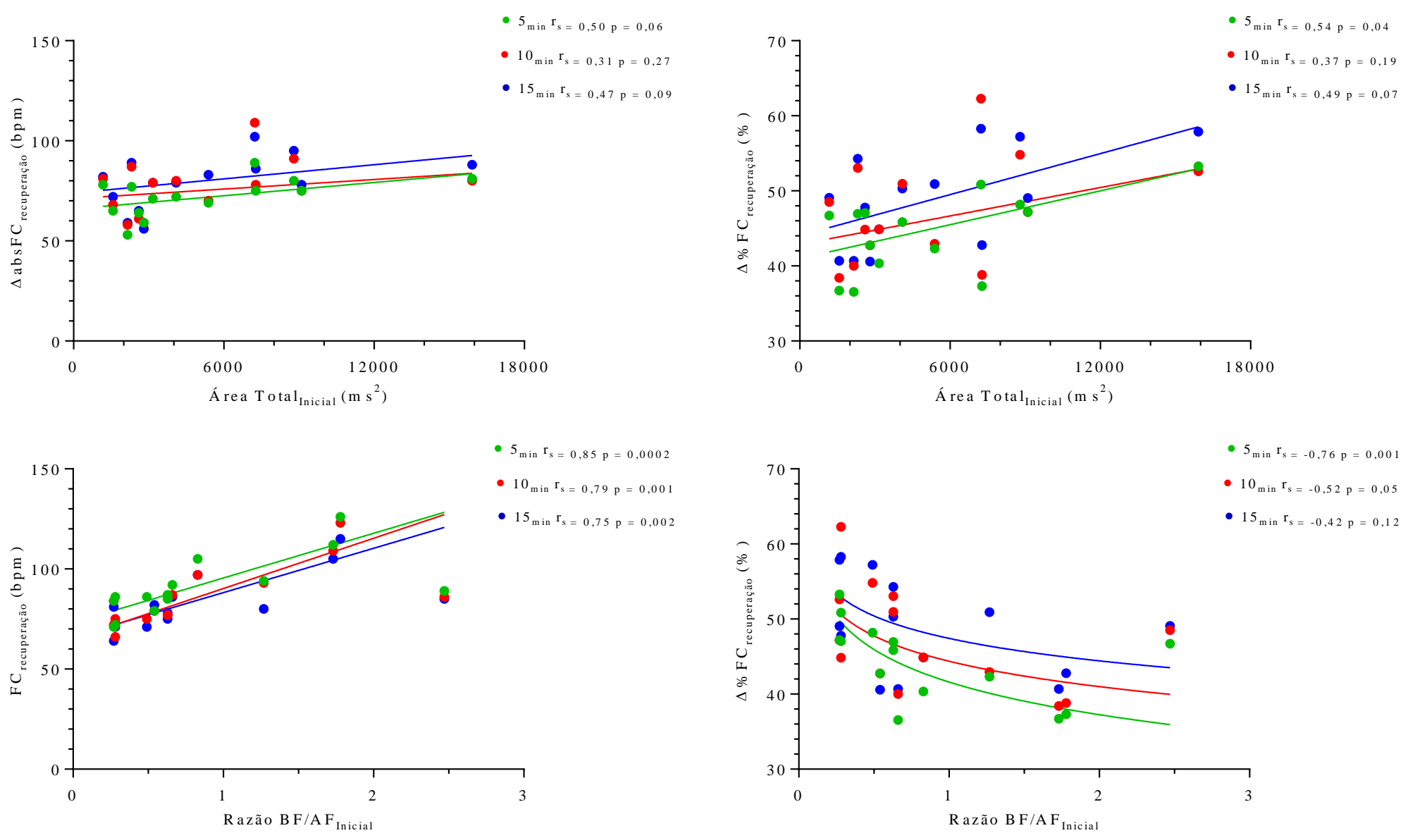

FIGURA 39 - Correlações entre função autonômica cardíaca na posição supina inicial, avaliada pelos índices Espectrais da variabilidade da frequência cardíaca, com a resposta cronotrópica cardíaca após $5^{\circ} \mathrm{min}$ (círculo verde), $10^{\circ} \mathrm{min}$ (círculo vermelho) e $15^{\circ} \mathrm{min}$ (círculo azul) de uma sessão de treino resistido 

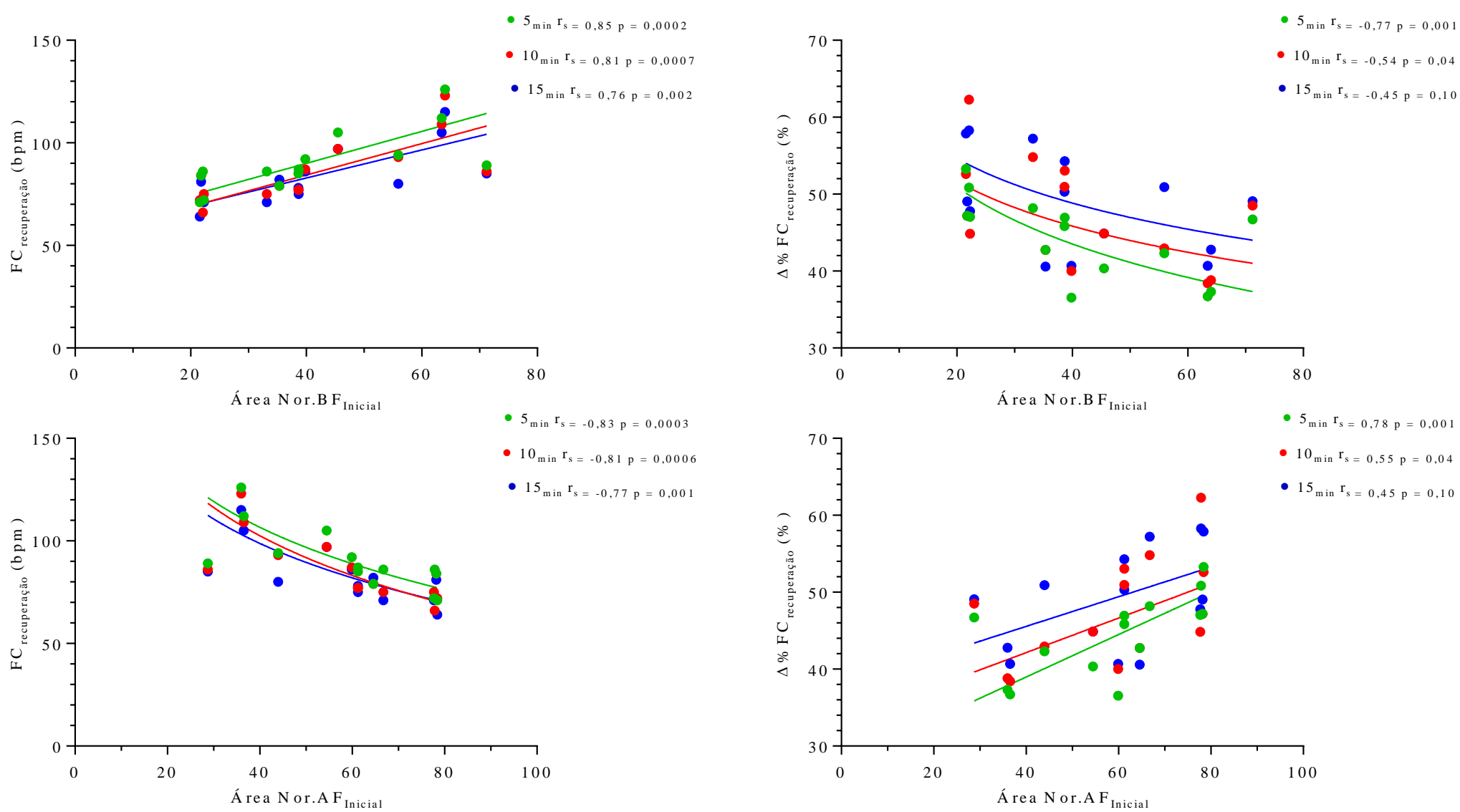

FIGURA 40 - Correlações entre função autonômica cardíaca na posição supina inicial, avaliada pelos índices Espectrais da variabilidade da frequência cardíaca, com a resposta cronotrópica cardíaca após $5^{\circ} \mathrm{min}$ (círculo verde), $10^{\circ} \mathrm{min}$ (círculo vermelho) e $15^{\circ} \mathrm{min}$ (círculo azul) de uma sessão de treino resistido 


\section{Discussão}

A discussão será apresentada em tópicos conforme a sequência anteriormente proposta nos resultados. Entretanto, algumas análises possuem relação entre si, logo, em alguns casos não foi possível realizar a separação didática da discussão.

\subsection{CARACTERIZAÇÃO AMOSTRAL E RESPOSTA DA FREQUÊNCIA CARDÍACA E DO CONSUMO DE OXIGÊNIO ANTES, DURANTE E APÓS TESTE DE ESFORÇO MÁXIMO}

\subsubsection{CARACTERIZAÇÃO AMOSTRAL}

A amostra foi composta por indivíduos do gênero masculino, jovens adultos e clínicocardiológico normais determinado por exame ECG. Este cenário de condição clínico-funcional é pressuposto básico para a realização do método de análise da FAC por meio da VFC na condição de repouso e de recuperação após o exercício físico.

A VFC é uma medida não invasiva, que descreve as oscilações dos intervalos entre os batimentos cardíacos consecutivos (iRR) com influência do sistema nervoso autônomo (SNA), com seus ramos simpático e parassimpático, sobre o nódulo sinusal. Assim, a VFC pode ser utilizada para identificar fenômenos relacionados ao SNA em indivíduos saudáveis, atletas e portadores de doenças $(21,120)$. O ritmo sinusal é pressuposto básico em indivíduos saudáveis na análise da FAC por meio da VFC (120), assim todos os voluntários apresentavam ritmo sinusal avaliado por meio do ECG.

Diversos fatores como o fumo, a obesidade, as doenças cardiometabólicos (hipertensão ou diabetes), a idade e o gênero $(21,105,121)$ demonstram que a VFC apresenta uma comportamento diferente de indivíduos jovens saudáveis. As mulheres apresentam menores marcadores de modulação global e maiores marcadores vagais comparado aos homens para a mesma idade (121), assim a amostra foi composta apenas por homens. Todos os voluntários relatam viver sempre na cidade, não fumantes e relataram não apresentar qualquer problema cardiometabólico conhecido. 
O avançar da idade é um fator que contribui para a redução da VFC $(105,121,122)$, com uma redução de 6,6 ms no índice SDNN e 3,6 ms no rMSSD por década (121). Contudo, a amostra estudada, com idade mediana (quartis) de 22,5 (20,2 - 25,7) anos, pode ser considerada estando no auge da capacidade de modulação da FAC.

Conforme citado anteriormente, o grau de obesidade pode influenciar a FAC, assim uma delimitação da amplitude do IMC durante o procedimento experimental foi adotada (105). Foi utilizado uma faixa de normalidade entre $18,5 \mathrm{~kg} / \mathrm{m}^{2}$ e $29,9 \mathrm{~kg} / \mathrm{m}^{2}$ como critério de inclusão, entretanto, o valor mediano (quartis) de IMC obtido na amostra foi de $24,9(23,9-25,1) \mathrm{kg} / \mathrm{m}^{2}$.

Existe a recomendação da necessidade de controlar a FR, podendo ter implicações importantes no uso e na interpretação dos índices da VFC (123). Todos os voluntários respiravam de forma espontânea e tinham as suas incursões respiratórias contadas, ao longo de um minuto. O controle da FR visava excluir o voluntário que apresentava a FR menor do que 9 irpm, já que Bloomfield et. al. (124) não terem encontrado diferenças na análise do domínio espectral da VFC com a FR espontânea dentro da faixa normalidade (9-20 irpm).

$\mathrm{O} \dot{\mathrm{VO}}_{2}$ máximo, foi considerado como o consumo de oxigênio de pico, alcançado ao final do teste progressivo de esforço cardiopulmonar máximo. Considerado o padrão ouro é a melhor forma de medir de aptidão cardiovascular e a capacidade física (125). O nível de aptidão física pode influenciar a FAC, logo, atletas apresentam comportamento da FAC diferente de outras populações, como os indivíduos ativos $(126,127)$. Assim, a aptidão cardiorrespiratória na forma do consumo máximo de oxigênio ( $\dot{\mathrm{V}}_{2 \text { pico }}$ ) foi utilizado como critério de exclusão de voluntários na amostra. Durante o procedimento experimental foi adotado um $\dot{\mathrm{V}} \mathrm{O}_{2 \text { pico }} \leq 51,2 \mathrm{~mL}(\mathrm{~kg} \cdot \mathrm{min})^{-1}$. Os voluntário atingiram valores medianos (quartis) de $\dot{\mathrm{V}} \mathrm{O}_{2 \text { pico }}$ de $36,6(34,9-40,5) \mathrm{mL}(\mathrm{kg} \cdot \mathrm{min})^{-1}$ e foram classificados, com aptidão cardiorrespiratória de ruim a boa, sendo que nenhum foi classificado como atleta (113).

Outro ponto de observação, com relação à característica da amostra, foi o controle da pressão arterial dos voluntários. Todos os voluntários foram considerados normotensos independentemente 
da posição corporal de análise, supina e/ou ortostática, de acordo com a classificação da VI Diretrizes Brasileiras de Hipertensão arterial (107).

Desta forma, as características amostrais baseadas nas variáveis analisadas durante o repouso, podem-se considerar, em princípio dentro da normalidade em razão da ausência de qualquer manifestação clínica que sugira interpretação diferente. Portanto, todos os indivíduos que participaram do estudo estavam sob um controle rígido dos critérios de inclusão/exclusão utilizados para caracterização amostral conferindo ao grupo semelhança entre os indivíduos.

\subsubsection{RESPOSTA DA FREQUÊNCIA CARDÍACA E DO CONSUMO DE OXIGÊNIO ANTES, DURANTE E APÓS TESTE DE ESFORÇO MÁXIMO}

Ainda como parte da caracterização da amostra, o objetivo da avaliação do comportamento cronotrópico e do consumo de oxigênio antes, durante e após teste de cardiopulmonar máximo, visou demonstrar normalidade clínica e funcional da amostra estudada.

A regulação postural do sistema nervoso autônomo e cardiovascular é refletido em mudanças na FC e PA. Durante a mudança postural, da posição supina para a posição ortostática, ocorre uma taquicardia reflexa com alterações na FAC, ou seja, uma integração coordenada reflexa com um aumento da atividade simpática associada com uma retirada vagal sobre o nodo sino atrial $(128,129)$ em indivíduos normais, afim de evitar a hipotensão postural.

Esta alteração com a mudança postural está bem estabelecida na literatura, ou seja, após a mudança postural (na posição ortostática) o retorno venoso diminui, porém, há a necessidade de manter o débito cardíaco para que a pressão arterial seja mantida, logo, o débito cardíaco vai apresentar um menor volume diastólico final com menor volume sistólico e consequentemente maior FC. Com vistas nos ajustes hemodinâmicos, a FC na posição ortostática é maior quando comparada a FC na posição supina (130).

Assim, conforme os dados apresentados na Tabela 03 e na FIGURA 09, a FC comportou-se como esperado após a mudança postural. Foi verificado uma taquicardia reflexa, com diferença 
significativa $(\mathrm{p}<0,01)$ e menores valores de $\mathrm{FC}_{\text {rep }}$ na posição supina 58,5 $(53,3$ - 62,3) bpm comparada à posição ortostática 76,5 $(73,0$ - 83,0) bpm, após a mudança postural. Nenhum voluntário apresentou intolerância ortostática após a mudança postural, ou seja, todos os voluntários apresentaram o comportamento esperado.

O teste incremental cardiopulmonar máximo foi utilizado para avaliar os ajustes da FC e do VंO ${ }_{2}$ durante e após o esforço físico máximo. O teste de esforço cardiopulmonar é um método utilizado como avaliação diagnóstica e prognóstica, na avaliação clínica e na funcional em diversas populações, do indivíduo saudável ao patológico (112).

Durante o teste progressivo de esforço cardiopulmonar máximo, o aumento do $\mathrm{V}_{2}$ é proporcional ao trabalho realizado, assim, o débito cardíaco deve ser ajustado para essa maior demanda de oxigênio para os músculos ativos. Consequentemente, aumenta a FC e a contratilidade miocárdica. O aumento da FC faz com que o tempo de enchimento ventricular seja reduzido, assim, as câmaras ventriculares passam a funcionar num ponto mais baixo da curva de Frank-Starling. O volume sistólico aumenta, porque a melhoria da contratilidade miocárdica faz com que o esvaziamento sistólico, traduzido pela fração de ejeção, seja aumentado. Assim, o aumento do débito cardíaco é dependente tanto de um ligeiro aumento do volume sistólico como da elevação FC (30, 130). Com vistas no SNA, durante o teste progressivo de esforço cardiopulmonar máximo o aumento da FC ocorre em parte devido a integração coordenada de uma redução da atividade vagal, com progressivo aumento da atividade simpática $(8-10,131)$.

Os resultados do presente estudo, vão ao encontro aos descritos na literatura. É consenso na literatura, a crescente FC ao longo de um esforço progressivo, ou seja, o aumento do FC é proporcional ao trabalho realizado $(30,130,131)$. Conforme apresentado na Tabela 03 e FIGURA 09, os dados obtidos no presente estudo demonstraram que durante o esforço progressivo, a FC comportou-se como o esperado. Verificou-se o aumento progressivo da FC em função do aumento da taxa de trabalho até o esforço máximo. 
Por outro lado, imediatamente após o esforço, o decremento da FC no período de recuperação está na dependência da reativação da modulação vagal com simultânea retirada da atividade simpática com vistas, ao retorno da FC próximo aos níveis de repouso $(8,12,13,15,132)$. Assim, a lenta queda da FC nos primeiros minutos da recuperação pode refletir de forma generalizada, a diminuição da reativação vagal e a incapacidade da FC de voltar aos níveis basais $(47,48,51)$.

Diversos pontos de corte para a FCR nos primeiros minutos de recuperação foram estabelecidos na literatura. Cole et. al. (47) observaram em uma coorte de 2428 homens sem história prévia de insuficiência cardíaca, ou revascularização coronariana e angiografia coronariana que, após teste de esforço máximo, os indivíduos que apresentaram FCR menor que 12 bpm após o primeiro minuto de recuperação ativa, foi classificado com uma resposta anormal de FCR. A FCR é um poderoso preditor de mortalidade e apresenta uma mitigada reativação vagal. Ou seja, o grupo com um valor de FCR < 12 bpm apresentaram uma taxa de mortalidade de 19\%, enquanto que o grupo com um valor de FCR > 12 bpm apresentaram uma taxa de mortalidade de 5\% durante o período de seis anos de acompanhamento.

Cole et. al. (48) observaram em uma corte de 5234 homens assintomáticos submetidos a teste de esforço submáximo ( 85 a 90\% da $\mathrm{FC}_{\text {pico }}$ ), que apresentaram uma $\mathrm{FCR} \leq 42$ bpm após o segundo minuto de recuperação passiva, foi classificado como uma resposta anormal. A FCR continua a ser um forte preditor de mortalidade, ou seja, FCR $\leq 42 \mathrm{bpm}$ apresenta uma taxa de mortalidade de $10 \%$, enquanto que uma FCR > 42 bpm apresenta uma taxa de mortalidade de 4\% em um período de 12 anos de acompanhamento. Dadas as diferenças no protocolo de recuperação, as comparações diretas entre os dois estudos não são possíveis, devido as diferenças no protocolo de recuperação, mas o segundo estudo confirmou a recuperação da FC como uma medida de prognóstico poderoso (22).

Afim de reforçar a importância do dado da FCR em outras populações, Nishime et. al. (51) observaram em uma coorte de 9454 composta de homens e mulheres, que após o teste de esforço máximo apresentaram FCR < 12 bpm após o primeiro minuto de recuperação ativa. Como a definição de uma resposta anormal, continua a ser um poderoso preditor de mortalidade e apresenta um 
comprometimento da reativação vagal. Ou seja, o grupo com um valor de FCR < 12 bpm apresentaram uma taxa de mortalidade de $8 \%$, enquanto que o grupo com um valor de FCR > 12 bpm apresentaram uma taxa de mortalidade de $2 \%$ durante o período de 5,2 anos de acompanhamento.

Jouven et. al. (133) observaram ainda em uma coorte de 5713 homens assintomáticos acompanhados por 23 anos, que após o teste de esforço submáximo uma FCR $<25$ bpm após o primeiro minuto de recuperação passiva, como a definição de uma resposta anormal, é um poderoso preditor de mortalidade e apresentava comprometimento na reativação vagal.

Logo, é importante ressaltar que os dados obtidos da FCR nos momentos iniciais da recuperação após o teste de esforço máximo são classificados como normal do ponto de vista clínicocardiológico segundo os trabalhos citados anteriormente.

A FCR após o esforço é composta por duas fases, uma fase, até dois minutos de recuperação, chamada de rápida, no qual é aceita por ser predominantemente promovida pela reativação vagal. Enquanto que a chamada fase lenta, do terceiro ao quinto minutos, ocorre uma interação entre reativação vagal e da retirada simpática (134).

Os dados obtidos no presente estudo, demonstraram que o comportamento da FC, imediatamente após o esforço, apresentou uma fase de recuperação rápida, uma queda acentuada e rápida da $\mathrm{FC}$ até o segundo minuto de recuperação, e após o segundo minuto de recuperação, o comportamento da FC apresentou fase de recuperação mais lenta comparada aos momentos iniciais de recuperação, assim, o comportamento do decremento (queda) cronotrópico durante a recuperação, nesta pesquisa, corrobora com os estudos, que demonstram o comportamento de decremento da FC após o esforço máximo (134). Desta forma, o comportamento da FCR nos momentos iniciais da recuperação mais as demais informações supracitadas, demostraram a condição clínica e funcional normal dos voluntários.

Simultaneamente ao aumento da resposta cronotrópica antes, durante e após o teste de cardiopulmonar progressivo máximo, foi observado um comportamento semelhante do $\dot{\mathrm{V}} \mathrm{O}_{2}$. 
Verificou-se o aumento linear entre ambas as varáveis até o fim do esforço (inspeção visual), conforme apresentado nas FIGURAS 09 e 10.

O comportamento do $\dot{\mathrm{V}}_{2}$ antes, durante e após o teste progressivo de esforço cardiopulmonar máximo, está bem estabelecido na literatura. $\mathrm{O} \dot{V}_{2}$ na condição de repouso apresenta valores médios de 3,5 mL (kg.min) ${ }^{-1}$, contudo, durante o teste progressivo de esforço cardiopulmonar máximo, o aumento do $\dot{\mathrm{VO}}_{2}$ é proporcional ao trabalho realizado. Após o término esforço, o $\dot{\mathrm{V}}_{2}$ não retorna aos valores de repouso imediatamente, apresenta uma rápida queda nos primeiros minutos de recuperação (até o segundo minuto) seguido de queda mais lenta, apresentando uma estabilização a partir do terceiro minuto de recuperação $(30,130)$.

Algumas anormalidades, durante o teste cardiopulmonar progressivo máximo, podem ser observadas. Uma delas é o aumento da $\mathrm{FC}$ mais acentuado do que o aumento do $\dot{\mathrm{V}}_{2}$, pelo fato de um déficit no volume de ejeção, ou o $\dot{\mathrm{VO}}_{2}$ pode apresentar um comportamento mais lento em relação ao aumento da taxa de trabalho, apresentando um quadro de isquemia do miocárdio em pacientes com doença arterial coronariana, ou seja, o aumento no débito cardíaco não acompanha o aumento da taxa de trabalho devido ao baixo volume de ejeção (112). Esse é um exemplo que demonstra diferentes interpretações do comportamento da resposta cronotrópica e do $\dot{\mathrm{V}} \mathrm{O}_{2}$ diante de um esforço controlado.

Os resultados do presente estudo, estão de acordo com os descritos na literatura. É consenso na literatura, o aumento do $\dot{\mathrm{VO}}_{2}$ ao longo de um esforço progressivo e durante a fase de recuperação o $\dot{\mathrm{V}}_{2}$ apresentou um declínio rápido nos momentos iniciais da recuperação (até o segundo minuto de recuperação) e em sequência, uma estabilização do $\dot{\mathrm{VO}}_{2}$ a partir do terceiro minuto de recuperação, conforme apresentado na Tabela 04 e FIGURA 10. Assim, foi verificada semelhança no comportamento do $\dot{\mathrm{VO}}_{2}$ e na FC antes, durante e após o esforço controlado. 


\subsection{FAC AVALIADA PELOS ÍNDICES DE POINCARÉ, NO DOMÍNIO TEMPORAL E ESPECTRAL, NA POSIÇÃO SUPINA E ORTOSTÁTICA INICIAIS}

Como parte da caracterização da amostra, o objetivo da avaliação na cinética da função autonômica cardíaca após a mudança postural, visou demonstrar normalidade clínica e funcional da amostra estudada.

Como citado no capítulo anterior, a regulação postural do sistema nervoso autônomo e cardiovascular é refletido em mudanças na FC e PA. Durante a mudança postural, da posição supina para a posição ortostática, ocorre uma taquicardia reflexa com alterações na FAC, ou seja, uma integração coordenada reflexa com um aumento da atividade simpática associada com uma retirada vagal sobre o nodo sino atrial $(128,129)$ em indivíduos normais, afim de evitar a hipotensão postural, com vistas a desempenhar um papel nesta resposta homeostática.

O aumento inicial na FC é mediado pela inibição súbita da atividade vagal, enquanto o aumento mais gradual é devido a uma maior inibição vagal e aumento da atividade simpática. O aumento da FC ocorre provavelmente pela integração de sinais aferentes da contração muscular com sinais dos centros superiores do cérebro (comando central) (135).

A avaliação de diferentes condições funcionais (supino e ortostático) com a mudança postural, é bem reproduzível na literatura e conhecida por gerar níveis distintos de atividade simpática e parassimpática e, portanto, uma perturbação no balanço autonômico cardíaco na condição basal (136). Ou seja, apesar de bem controlado o protocolo, a mudança postural induz de imediato uma variabilidade das variáveis quantificadas e analisadas por meio da VFC nos índices de Poincaré, no domínio temporal e espectral.

Logo, o funcionamento autonômico cardíaco esperado como normal, em resposta a mudança postural, é a mudança do predomínio da atividade parassimpático (na posição supina) para o predomínio da atividade simpática (na posição ortostática), contudo, uma redução na capacidade de 
resposta do balanço simpatovagal é marcada por um ajuste autonômico anormal, presente em diversas condições patológicas $(137,138)$.

Portanto, conforme apresentado nas Tabelas 05, 06 e 07, após a mudança postural observouse que o marcador da atividade vagal, SD1 de Poincaré, apresentou redução mediana das médias individuais de $-104,1 \%$. No domínio temporal, observou-se que o marcador da atividade vagal, pNN50 e rMSSD, apresentaram reduções medianas das médias individuais de -177,6 e -104,3\%, respectivamente. $\mathrm{E}$, no domínio espectral, o marcador da atividade vagal de área normalizada de $\mathrm{AF}$ demonstrou similar comportamento frente a mudança postural, com redução mediana das médias individuais de $-97,8 \%$. Todos os marcadores da atividade vagal no índice de Poincaré, no domínio temporal e espectral, apresentaram diferença estatística $(p<0,01)$ com maiores valores na posição supina comparado a posição ortostática. Desta forma, os dados obtidos no presente estudo, apresentaram um comportamento amostral semelhante após a mudança postural, com redução absoluta e relativa da atividade vagal em todas as formas de análise da VFC.

Estes resultados obtidos indicam que a diminuição da atividade vagal após a mudança postural é um dos principais mecanismos de ajuste como vistas a manutenção do equilíbrio ortostática, em homens jovens saudáveis (122).

A resposta induzida pela mudança postural na atividade vagal, tem um impacto direto na FAC, repercutindo diretamente no balanço simpatovagal. Nos dados do presente estudo, foi observado taquicardia reflexa após a mudança postural, com uma redução mediana das médias individuais de 32,4\% na média dos iRR no domínio temporal e no marcador da atividade simpatovagal área normalizada de BF, no domínio espectral, apresentou aumento mediano de 33,3\%, conforme descrito nas Tabelas 06 e 07.

O marcador de balanço autonômico cardíaco SD1/SD2, apresentou uma redução mediana das médias individuais de $-94,7 \%$ após a mudança postural, com menores valores SD1/SD2 na posição supina em comparação à posição ortostática. Também, foi observado que na posição supina os voluntários eram vagotônicos em relação a posição ortostática (simpatectómicos), apresentando um 
aumento mediano das médias individuais da razão $\mathrm{BF} / \mathrm{AF}$ de $73,3 \%$, após a mudança postural, e menores valores medianos das médias individuais de razão $\mathrm{BF} / \mathrm{AF}$ de 0,7 na posição supina comparado aos valores medianos das médias individuais de razão BF/AF 2,2 na posição ortostática, conforme descrito nas Tabelas 05 e 07.

Os dados do presente estudo, após a mudança postural, traduzem a capacidade do sistema cardiovascular em realizar os ajustes necessários para a manutenção do equilíbrio frente ao estresse ortostático. A redução do balanço autonômico cardíaco devido a retirada absoluta e relativa da atividade vagal e o aumento absoluto e relativo do balanço simpatovagal na posição ortostática, corroboram com o esperado para indivíduos clinicamente normais (122, 136, 137). 


\subsection{FACrepouso NA CARACTERIZAÇÃO DA AMOSTRA E FACINICIAL ANTES DA}

SESSÃO DE TR, AVALIADA PELOS ÍNDICES DE POINCARÉ, NO DOMÍNIO

\section{TEMPORAL E ESPECTRAL}

Como parte da caracterização da amostra, o objetivo desta comparação, visou demonstrar normalidade clínica e funcional da amostra estudada, após o período de testes durante a caracterização da amostra.

Diversas pesquisas são realizadas sem o registro prévio de um período de repouso, determinando um padrão inicial para alcançar o equilíbrio homeostático, violando assim um pressuposto importante na análise da VFC, o de estacionariedade. E, é de suma importância a padronização dos tempos e momentos de registro durante a avaliação da resposta da FAC ao estresse ortostático, na condição de repouso. Informações distintas sobre as variações de tempos de registro resulta em dados não apropriados para comparação (137).

Em ambos os testes, os voluntários permaneceram 10 minutos de repouso em um ambiente controlado, antes do registro de curta duração de cinco minutos dos iRR. Após três minutos da mudança postural, foi iniciado o registro de curta duração (durante cinco minutos) dos iRR na posição ortostática. Foi rigorosamente seguido o mesmo protocolo do teste de FAC na caracterização da amostra, bem como, como antes da sessão de TR, em todos os voluntários.

Além disso, como discutido anteriormente, fica evidente que para o funcionamento autonômico cardíaco normal esperado, em resposta à mudança postural, no que se refere ao ajuste rápido do predomínio da atividade vagal (na posição supina) para o predomínio da atividade simpática (na posição ortostática) é um dos principais mecanismos de ajuste para a manutenção do equilíbrio ortostático tido como normal, em homens jovens adultos saudáveis. Contudo, é considerado ajuste autonômico anormal a redução na capacidade de resposta do balanço simpatovagal, que está presente em diversas condições patológicas $(137,138)$.

Conforme apresentado nas Tabelas 08 - 10.1, ao analisar o comportamento da FAC após a mudança postural, antes da sessão de TR, observou-se que os marcadores da atividade vagal SD1 de 
Poincaré, apresentou redução mediana das médias individuais de -164,3\%. No domínio temporal, o pNN50 e rMSSD, também apresentaram reduções medianas das médias individuais de -523,3 e 164,2\%, respectivamente. E, no domínio espectral, a área normalizada de AF, demonstrou similar comportamento frente a mudança postural, com redução mediana das médias individuais de -204,4\%.

Os valores dos marcadores de atividade vagal, em todas as formas de análise da VFC antes da sessão de TR, diferiram significativamente $(\mathrm{p}<0,01)$, apresentaram menores valores na posição supina em comparação a posição ortostática. Contudo, o marcador SD1 e rMSSD antes da sessão de TR em comparação a caracterização da amostra apresentou diferença estatística $(p=0,05)$ registrando menores valores na posição ortostática. Assim, o comportamento da FAC avaliada antes da sessão de TR, comportou-se semelhante a FAC avaliada durante a caracterização da amostra (registro controle), sem diferença estatística significativa nos dois momentos funcionais. Desta forma, nossos dados apresentaram um comportamento amostral semelhante, em ambos os momentos funcionais após a mudança postural, com redução absoluta e relativa da atividade vagal em todas as formas de análise da VFC.

Foi observada taquicardia reflexa após a mudança postural, com redução mediana das médias individuais de $-40,5 \%$ na média dos iRR no domínio temporal, como também, no marcador da atividade simpatovagal área normalizada de BF, no domínio espectral, de 47,9\%, antes da sessão de TR, conforme descrito na Tabela 09 e 10.1. Contudo, a média iRR antes da sessão de TR quando comparada à média $\mathrm{iRR}$ durante a caracterização da amostra, apresentou diferença estatística $(\mathrm{p}=$ $0,04)$ com menores valores na posição ortostática.

O marcador de balanço autonômico cardíaco SD1/SD2, antes da sessão de TR, apresentou uma redução mediana das médias individuais de $-93,0 \%$ após a mudança postural, com menores valores SD1/SD2 na posição supina comparado a posição ortostática. Também, foi observado que na posição supina os voluntários apresentaram-se vagotônicos em relação a posição ortostática (simpatectómicos), apresentando aumento mediano das médias individuais da razão BF/AF de 81,6\%, 
após a mudança postural. Ou seja, a análise de FAC previamente a sessão de TR comportou-se de forma semelhante a FAC avaliada durante a caracterização da amostra.

Ambos os momentos funcionais $\left(\mathrm{FAC}_{\text {repouso }}\right.$ e $\left.\mathrm{FAC}_{\text {inicial }}\right)$ traduzem a capacidade do sistema cardiovascular realizar os ajustes necessários na manutenção do equilíbrio frente mudança postural, corroborando com o esperado para indivíduos clinicamente normais (122, 136, 137). Em outras palavras, durante o período de testes, com vistas a caracterização da amostra, o comportamento da FAC antes da sessão de TR foi semelhante ao comportamento da FAC avaliada durante a caracterização da amostra, após a mudança postural. 


\subsection{FORÇA E VARIÁVEIS DE CONTROLE DE SOBRECARGA DURANTE A SESSÃO DE TREINO RESISTIDO}

\subsubsection{CARACTERIZAÇÃO DOS VALORES AMOSTRAIS DA FORÇA}

Para avaliar a força e demonstrar a dispersão e a normalidade na amostra estudada, foi aplicado o teste de força máxima na extensão de joelho no dinamômetro isocinético.

A força muscular desempenha um papel importante para a sobrevivência e nas atividades de vida diária. A força voluntária máxima significa que, o músculo deve contrair contra uma resistência que apresente uma fadiga suportável, ou seja, força que o músculo gera durante a força máxima não é tão grande quanto a gerada na fadiga máxima $(53,139)$.

A literatura relata que a força diminui em torno de 1,5\% por ano até os 60 anos, contudo, após os 60 anos ocorre um aumento da perda é em torno de 3,0\% por ano. Estas taxas de declínio na força são ainda maiores em indivíduos sedentários e duas vezes mais elevada nos homens em relação as mulheres (139-141). Desta forma, apresentar baixa força aumenta os fatores de risco de mortalidade (55-58), e consequentemente, altos níveis de força muscular, reduzem o risco cardiovascular (59-61)

e cardiometabólicos (62-64), diabetes (65), câncer $(60,66,67)$ e hipertensão arterial sistêmica (68, 69).

Utilizou-se o padrão ouro na análise da força máxima por meio do dinamômetro isocinético, por ser considerado válido, fidedigno e reprodutível. Além disso, em comparação com outras técnicas, a medida no isocinético tem maior confiabilidade $(114,115,139)$. Nossos dados demostraram o pico de torque absoluto [251,2 (210,8 - 281,8) N-M] dentro da normalidade para jovens adultos saudáveis (139). 


\subsubsection{ANÁLISE DAS VARIÁVEIS DE CONTROLE DE SOBRECARGA DURANTE SESSÃO DE TREINO RESISTIDO}

Verificada a normalidade clínica e cardiológica dos voluntários nas diversas condições e momentos funcionais, discutiremos o controle da sobrecarga durante a sessão de TR.

A intensidade do TR foi determinada pela a carga utilizada na sessão de treino. Utilizou -se a RM (repetição máxima), ou seja, a carga que possibilita a realização de um determinado número de repetições por série até a falha muscular voluntária ou falha concêntrica. Utilizou-se um alvo de RM (8-12RM). Isto porque, a intensidade do TR não pode ser ajustada pela FC ao longo da sessão de TR, uma vez que a FC não varia de acordo com a intensidade (53).

Kraemer et. al. (142) analisaram em jogadores de futebol americano, o comportamento do número de repetições realizadas em três séries consecutivos com uma carga constante para 10RM no exercício de leg press. Observaram que os voluntários realizaram em média 10RM, 8RM e 7RM na primeira, segunda e terceira séries, respectivamente, com um minuto de intervalo de recuperação (IR) entre as séries.

Willardson e Burkett (143) analisaram em jovens adultos saudáveis o comportamento das repetições, ao longo das séries, no exercício de agachamento. Foi realizado quatro séries com uma carga constante para 8RM e um minuto IR entre as séries. Observou-se uma queda no número de repetições no decorrer das séries realizadas com médias de 7,8, 5,9, 4,4 e 4,2 repetições na primeira, segunda, terceira e quarta séries, respectivamente.

Willardson et. al. (144) analisaram em homens treinados o comportamento das repetições por série durante quatro sessões de TR para membros inferiores. Foram realizadas três séries com agachamento, cadeira flexora e extensora, nesta ordem dos exercícios durante todas as sessões. Cada sessão foi realizada sob diferentes regimes de carga ordenadas aleatoriamente, na primeira sessão uma carga constante para 10RM nas três séries de exercícios. Na segunda sessão a houve redução de $5 \%$ após a primeira e a segunda série de exercícios, na terceira sessão uma redução de 10\% após a 
primeira e a segunda série de exercícios, e na quarta sessão uma redução de 15\% após a primeira e a segunda série de exercícios, com um intervalo IR entre as séries e dois minutos IR entre os exercícios. Observou-se que no agachamento, uma redução de carga 15\% foi necessária após a primeira e a segunda série afim de manter a realização das 10RM.

Afim de manter o desempenho dentro de uma determinada margem de repetições foi essencial o ajuste da carga ao longo das séries com intervalo de recuperação de um minuto entre elas (144).

O controle da intensidade, na sessão de TR, foi determinado por meio da carga de forma que os voluntários conseguissem realizar no mínimo 8RM e no máximo 12RM, nas três series, com um minuto de IR entre elas. Conforme apresentado na Tabela 11 e FIGURA 14, os dados do presente estudo corroboram com a literatura, ou seja, todos os voluntários realizaram as séries dentro da intensidade determinada (8-12RM).

O número de repetições e o tempo de tensão entre as séries não apresentaram diferenças significativas. Foi observado redução na carga mediana das médias individuais de 5,7\% da primeira para a segunda série; $11,4 \%$ da primeira para terceira e $6,2 \%$, da segunda para a terceira série, respectivamente.

Para reforçar o controle da intensidade o volume do treino foi calculado como o produto do número de repetições pelo número de séries e a carga expressa em quilogramas (kg) (6). Foi observado redução mediana das médias individuais de $14,6 \%$ do volume de treino na primeira para a terceira série e menores valores do volume da primeira para a terceira série $(\mathrm{p}<0,01)$.

Essa análise demonstra que a sessão de TR foi controlada, e as variáveis de controle citadas traduzem a sobrecarga imposta sobre o sistema cardiovascular visando o desequilíbrio da FAC. 


\subsection{FAC ANTES E APÓS A SESSÃO DE TREINO RESISTIDO, AVALIADA PELOS ÍNDICES DE POINCARÉ, NO DOMÍNIO TEMPORAL E ESPECTRAL DA VFC}

Analisaremos a FAC antes e ao longo de 15 minutos, após sessão de treino resistido avaliada pelos índices de Poincaré, no domínio temporal e espectral da VFC.

Objetivando avaliar o grau de variação da FAC no período de recuperação após a sessão de TR, foi comprada a VFC na posição supina da condição inicial, com a posição supina durante a fase de recuperação, por meio da análise de Poincaré, no domínio temporal e espectral.

As alterações induzidas pelo exercício na homeostase da FAC, requerem ajustes coordenados do sistema nervoso autônomo simpático e parassimpático (18). Há um crescente interesse na literatura na análise dos efeitos de uma sessão de TR no comportamento da FAC durante a fase de recuperação. Foi observado que um quadro de desequilíbrio autonômico, como uma sustentada atividade simpática e/ou redução da atividade vagal cardíaca, pode apresentar uma condição para o surgimentos de arritmias ventriculares malignas e morte súbita, durante a fase de recuperação (21, $22,24-26,42)$.

Os estudos que avaliaram o efeito de uma sessão de TR em jovens adultos saudáveis, mostram que o TR é capaz de induzir alterações na FAC avaliada pela VFC (20, 27, 76, 78, 80-82, 85-90, 92, 99, 101, 103, 104), contudo, por existir diferentes combinações entre as variáveis do treinamento resistido, há uma dificuldade na comparação entre os estudos devido a heterogeneidade das amostras, dos protocolos de TR, formas de análise da VFC e o tempo de monitoramento da FAC após a sessão de TR. Até o presente momento, não há registro na literatura sobre a avalição da FAC, por meio dos índices de Poincaré.

Heffernan et. al. (20) avaliaram o comportamento da FAC, após sessão de TR em adultos ativos que realizaram três séries de 10RM em oito exercícios para membros superiores e inferiores comparado a outra sessão de treino aeróbio realizado no cicloergômetro na intensidade de $65 \%$ do $\dot{\mathrm{V}} \mathrm{O}_{2 \text { max. }}$ Foi observado que após 30 minutos de recuperação comparado a condição de repouso, foi insuficiente para a FC (+24\%) e a atividade vagal (-27\%) retornarem próximas aos níveis iniciais 
após a sessão TR, com maior magnitude na modificação da FAC após a sessão de TR comparada a sessão de treino aeróbio.

Niemela et. al. (78) avaliaram em jovens adultos saudáveis quatro diferentes intervenções randomizadas: (1) 40 min cicloergômetro com 50\% carga máxima; (2) três séries de 20 repetições a 30\%1RM em 4 exercícios; (3) três séries de 12 repetições a 80\%1RM em 4 exercícios; (4) sessão controle onde os voluntários permaneciam 40 min sentados. Observaram que o marcador vagal (AF do domínio espectral) reduziu e a razão BF/AF aumentou após o TR com carga mais intensa (80\%) comparada às medidas de controle por 30 min. Em contraste, a FAC foi semelhante ao controle após o TR leve (30\%) e o exercício no cicloergômetro. Parece que o padrão de recuperação da FAC após o TR tem relação com a intensidade do exercício, mostrando um retardo no comportamento da recuperação após o TR intenso em homens saudáveis.

González-Badillo et. al. (104) avaliaram em jovens adultos saudáveis o curso temporal de recuperação da FAC após dois protocolos de TR diferentes quanto no nível de esforço realizado, até a falha muscular voluntária $(8 \mathrm{RM})$ ou realizado até a metade do número de repetições máximo (quatro repetições) nos exercícios supino e agachamento. Foi observado que após a sessão de TR realizada até a falha muscular voluntária induziu maior fadiga mecânica (avaliada pelo comprometimento no desempenho neuromuscular durante todo o período de recuperação pósexercício), maior estresse cardiovascular autonômica (redução do rMSSD e SampEn), aumento da resposta hormonal (cortisol) e maior dano muscular (CPK) em comparação a sessão submáxima.

Também, Pereja-Blanco et. al. (103) avaliaram em jovens adultos saudáveis o curso temporal de recuperação da FAC após dois protocolos de TR, realizado com dois níveis de esforço: até a falha muscular voluntária (12RM) ou até a metade do número de repetições máximo (seis repetições) nos exercícios supino e agachamento. Observaram que após a sessão de TR realizada até a falha muscular voluntária, houve maior fadiga mecânica (avaliada pelo comprometimento no desempenho neuromuscular durante todo o período de recuperação pós-exercício), maior estresse cardiovascular (redução do rMSSD e SampEn), aumento da resposta hormonal (cortisol) e maior dano muscular 
(CK) comparado à sessão submáxima. Estes resultados são ainda mais interessantes, se considerarmos que foi realizado somente dois exercícios (o supino e o agachamento) na sessão de TR, ao passo que as sessões típicas de TR são geralmente mais exigentes e consistem em, pelo menos, 5-8 exercícios e pelo menos três series em cada exercício.

Apenas um artigo avaliou o comportamento da FAC após sessão de TR utilizando apenas um exercício (leg press) em dois grupos de mulheres (saudáveis e com fibromialgia). Kingsley et. al. (5) observaram que cinco series de 10RM foi capaz de alterar a balanço simpatovagal, ao longo de 25 minutos, após uma sessão de TR.

O registro prévio da condição inicial, como um padrão inicial do equilíbrio homeostático, é um pressuposto de estacionariedade importante na análise da VFC (137). Como a plotagem de Poincaré não necessita de estacionariedade (44) foi comparado a condição inicial e com os cinco, dez e quinze minutos de recuperação. Contudo, não foi possível comparar a condição inicial, dez e quinze minutos da fase de recuperação com os cinco minutos de recuperação no domínio temporal e espectral.

Assim, observou-se uma taquicardia, ao longo de 15 minutos, após uma sessão de TR, com redução mediana das médias individuais de $-30,7$ e 27,5\% na média dos iRR nos 10 e 15 minutos de recuperação, respectivamente. Com menores valores na média dos $i R R$ nos 10 e 15 minutos de recuperação comparativamente a condição basal $(\mathrm{p} \leq 0,02)$, conforme apresentado na Tabela 13 e FIGURA 16.

A taquicardia apresentada ao longo da recuperação após sessão de TR, pode ser explicada pelo marcador da atividade vagal SD1 de Poincaré, que sofreu redução mediana das médias individuais de 76, 70,7 e 74,8\% no cinco, dez e quinze minutos de recuperação, respectivamente. No domínio temporal, observou-se que os marcadores da atividade vagal (pNN50 e rMSSD), apresentaram reduções medianas das médias individuais nos dez minutos (98,6 e 70,7\%) e nos quinze minuto $(96,7$ e 74,8\%). E, no domínio espectral, o marcador da atividade vagal área normalizada de $\mathrm{AF}$, demonstrou comportamento similar (-43,5 e -44,3\%) nos dez e quinze minutos de recuperação. 
Os valores dos marcadores de atividade vagal, em todas as formas de análise da VFC apresentaram diferenças estatísticas $(\mathrm{p}<0,01)$ e menores valores na condição inicial comparada ao período de recuperação após a sessão de TR. Desta forma, os dados deste estudo apresentaram um comportamento amostral semelhante após sessão de TR com redução absoluta e relativa da atividade vagal em todas as formas de análise da VFC (Tabelas 12, 13.1 e 14, e FIGURAS 15, 21, 22 e 26).

O marcador de balanço autonômico cardíaco SD1/SD2 ao longo de 15 minutos, após sessão de TR, apresentou redução mediana das médias individuais de 84, 58,9 e 46,9\% no cinco, dez e quinze minutos de recuperação, respectivamente, e menores valores na condição inicial em comparação ao período de recuperação após sessão de TR. Também, foi observado que na condição inicial os voluntários apresentaram uma característica vagotônica e no período de recuperação, apresentaramse simpatectómicos. Houve aumento mediano das médias individuais da razão BF/AF de 274,2 e 344,6\% nos dez e quinze e minutos após sessão de TR, respectivamente, e menores valores dessa razão BF/AF na condição inicial (Tabela 12 e 14, e FIGURAS 17 e 24). Foi observado redução dos marcadores da atividade vagal com o respectivo aumento relativo e/ou absoluto da atividade simpática em ambas as formas de análise (Poincaré, temporal e espectral). Entretanto, ao analisar os marcadores (SD2, DP e AT) que quantificam a capacidade de modulação global, foram observadas diferenças significativas entre os dois momentos funcionais. Observou-se o aumento no grau de modulação da função autonômica global, avaliada pelo SD2, nos cinco minutos da fase de recuperação comparada a condição de inicial, e não apresentou diferença estatística. Contudo, observou-se redução, relativa e absoluta, no grau de modulação da função autonômica global, em todas as formas de análise da VFC, nos dez e quinze minutos da fase de recuperação após sessão de TR comparado a condição de inicial (Tabela 12, 13 e 14, e FIGURAS 16, 19 e 23).

As diferenças verificadas no presente estudo, talvez possam ser explicadas em função da condição funcional analisada (repouso-recuperação) com os voluntários posicionados na posição supina em ambos os momentos de análise. Em outras palavras, os mecanismos de regulação da FAC de ambos os momentos funcionais podem ser diferentes para a manutenção da pressão arterial. 
No início do exercício, a rápida alteração da FC e a redução da variabilidade se deve ao metaborreflexo com a ação dos aferentes periféricos do grupo III (mecanorreceptores) e IV (metaborreceptores), induzindo a redução da atividade vagal e o aumento da atividade simpática. Portanto, durante o exercício tais receptores são ativados imediatamente após a contração muscular e por alteração do pH local, no qual contribuem para as alterações na FC, barorreflexo e comando central $(11,12)$. Durante a recuperação, o exercício de alta intensidade associados ao elevado nível de recrutamento de fibras de contração (contração máxima), ao estresse comando central, à liberação de catecolaminas e ao acúmulo de lactato e íon $\mathrm{H}^{+}$, são de primordial importância na determinação do nível de reativação parassimpática após o exercício (145). O metaboreflexo é ativado pela isquemia pós-exercício e a atividade simpática elevada é regulada pela atividade parassimpática aumentada devido à retirada de comando central e ao efeito simpático da ativação baroreflexa (146).

Não visamos avaliar os mecanismos que regulam a FAC durante a fase de recuperação após sessão de TR, no entanto, estes mecanismos podem possivelmente explicar a "upregulation" e a elevada modulação global avaliada pelo marcador SD2 de Poincaré ao longo de cinco minutos da sessão de TR, e a redução dos marcadores da atividade parassimpática e de modulação global, bem como, o aumento dos marcadores simpatovagal. Este comportamento foi semelhante em todas as formas de análise da VFC ao longo de 15 minutos, após sessão de TR.

Nós investigamos a dinâmica da FAC em homens saudáveis e começamos por indivíduos saudáveis do sexo masculino, pois, é importante primeiro entender o comportamento da FAC em amostra homogênea de voluntários, contudo, o interessante dessa análise reside no fato da redução da atividade vagal por 15 minutos após três séries de 8-12RM no exercício de Leg press, que é usualmente aplicado nas rotinas de exercício resistido. 
5.6 CORRELAÇÕes ENTRE A FAC INICIAL E A FAC AO LONGO DE 15 MINUTOS, APÓS SESSÃo DE TR, AVALIADA PELOS ÍNDICES DE POINCARÉ, NO DOMÍNIO TEMPORAL E ESPECTRAL

Em tópicos anteriores foi discutido as características clínica e funcional da amostra, onde foi verificado o comportamento fisiológico "normal” das variáveis durante período de caracterização da amostra, visando descartar as possíveis variáveis intervenientes na variável dependente, dessa forma, buscou-se abordar as correlações entre a FAC na condição inicial e a FAC ao longo de 15 minutos, após sessão de TR.

$\mathrm{Na}$ literatura, há poucos dados que relacionaram os métodos de análise da VFC no repouso ao comportamento da FAC e o decremento da FC na fase de recuperação após o teste de esforço máximo ou submáximo. Entretanto, com o melhor de nosso conhecimento sobre este tema não encontramos nenhum estudo até o presente momento, que tenha analisado a correlação entre a FAC avaliada pela VFC na condição de repouso com a FAC após sessão de TR, com vistas à compreensão dos possíveis mecanismos fisiológicos envolvidos na regulação cardiovascular.

Desta forma, surge a pergunta: existe correlação entre a VFC no repouso, com a VFC após uma sessão de TR? Os mecanismos regulatórios da FAC após sessão de TR independem da FAC de repouso?

Como a plotagem de Poincaré não necessita de estacionariedade (44), foi realizado a análise de correlação da VFC na condição inicial com os cinco, dez e quinze minutos de recuperação. Contudo, foi realizado a análise de correlação na condição inicial com dez e quinze minutos de recuperação no domínio temporal e espectral

A regulação da FAC após o exercício na posição ortostática é diferente da posição supina, devido a hemodinâmica diferenciada entre essas posições. O retorno venoso após o exercício é maior na posição supina do que na posição ortostática, assim, essa diferença resulta em uma reativação vagal mais acelerada. A posição corporal pode influenciar no grau de associação entre VFC na 
condição de repouso dos diversos marcadores, em diferentes momentos funcionais (146-148). Diante disso, optamos por realizar as correlações entre os diferentes momentos funcionais (repousorecuperação) na mesma posição corporal (posição supina).

Inicialmente, os dados demostraram correlações positivas crescentes (moderada - muito forte) nos marcadores da VFC de atividade vagal no repouso com os marcadores da VFC de atividade vagal, durante o período de recuperação após a sessão de TR, em todos índices analisados da VFC. Quanto maior é a atividade vagal na condição de repouso (posição supina) maior é a reativação vagal após sessão de TR (na posição supina).

Para reforçar este achado, verificou-se correlações positivas (muito forte) entre a média iRR na condição de repouso, com a média iRR e os marcadores de atividade vagal (pNN50 e rMSSD) após dez e quinze minutos da sessão de TR. E, observou-se correlações positivas forte entre o marcador de atividade vagal pNN50 na condição inicial e a média iRR após dez e quinze minutos, e o marcador de atividade vagal rMSSD no repouso com a média iRR após quinze minutos da sessão de TR. Assim, o aumento da média iRR, após sessão TR, está na dependência da reativação vagal após o esforço e da atividade vagal na condição de repouso. Estes achados podem contribuir para a melhor compreensão da fisiologia do comportamento da FAC após sessão de TR.

Os marcadores de balanço simpatovagal apresentaram comportamento inverso dos marcadores da atividade vagal, e foi observado correlações negativas (forte - muito forte) entre os marcadores de balanço simpatovagal na condição de repouso com o marcador de atividade vagal após dez e quinze minutos da sessão de TR. Quanto menor for os marcadores de balanço simpatovagal maior será a reativação vagal, após sessão de TR.

É possível prever o comportamento FAC após sessão de TR, visto que quanto maior for atividade vagal no repouso maior será a reativação vagal após sessão de TR. Logo, é possível dizer que a magnitude da atividade vagal no repouso está diretamente associada à capacidade de recuperação da atividade vagal após sessão de TR. 
O grande interesse na avaliação deste fenômeno reside na capacidade prognóstica de risco cardiovascular. A predominância da atividade vagal demonstrada possivelmente exercer efeito cardioprotetor através de uma melhor estabilidade eléctrica cardíaca (23), reduzindo assim, a possibilidade do surgimento de arritmias ventriculares malignas e morte súbita no pós esforço (2226).

Uma questão importante na literatura, é a controvérsia entre a correlação dos diversos marcadores da VFC na condição de repouso, com os marcadores da VFC no período de recuperação. Alguns estudos têm mostrado que a recuperação da FC durante o período de recuperação correlaciona-se aos índices da VFC no repouso (13, 145, 146, 149-155). Contudo, há estudos que demonstraram a dissociação entre a recuperação da FC durante o período de recuperação com os índices da VFC no repouso $(17,156-158)$.

Entre os trabalhos que apresentaram controvérsia, apenas três artigos correlacionaram os marcadores da VFC na condição de repouso com os marcadores da VFC no período de recuperação. Javorka et. al. (17) foram os primeiros a descrever a correlação entre as medidas da VFC no repouso, na posição supina, com a VFC e a FCR no período de recuperação na posição supina. Observaram a dissociação entre as medidas da VFC no repouso com a VFC e a recuperação relativa da FC no primeiro minuto de recuperação, em 17 homens não treinados saudáveis.

Tulppo et. al. (146) avaliaram 16 homens ativos saudáveis após sessão de exercício aeróbio em um ergômetro de braço, e verificaram que, a alta atividade vagal na condição de pós-exercício está associada com a elevada atividade vagal no repouso. Cunha et. al. (150) observando jovens adultos saudáveis, verificaram correlação da VFC no repouso com a reativação vagal após teste de esforço máximo realizado na bicicleta, caminhada e corrida. Foi observado que a reativação vagal após o exercício, independente da modalidade, parece ser influenciada pelo controle vagal no repouso, através do qual, indivíduos caracterizados por uma maior atividade vagal no repouso, apresentam maior reativação vagal. Do ponto de vista prático, a atividade vagal no repouso parece 
desempenhar um papel chave na reativação vagal após o exercício, independentemente da modalidade.

Os estudos citados $(13,17,145,146,149-154,156-158)$ realizaram a análise de correlação após exercício aeróbico, não permitindo, dessa forma, a comparação dos resultados com os do nosso estudo. Nossos achados abrem uma nova possibilidade na interpretação do comportamento da FAC após sessão de TR em jovens adultos saudáveis. Até o momento, parece ser este o primeiro estudo que realizou analisou a correlação dos marcadores de atividade vagal na condição de repouso com a reativação vagal após sessão de TR. 


\subsection{CORRELAÇÕES ENTRE A FAC INICIAL, AVALIADA PELOS ÍNDICES DE}

\section{POINCARÉ, NO DOMÍNIO TEMPORAL E ESPECTRAL E A RESPOSTA CRONOTRÓPICA CARDÍACA APÓS SESSÃO DE TR}

Conforme o tópico anterior, alguns estudos demostram que a recuperação da FC correlacionase aos índices da VFC no repouso $(13,145,146,149-154,159)$ e, há estudos que demonstraram a dissociação entre a recuperação da FC com os índices da VFC no repouso (17, 156-158).

Evrengul et. al. (13) observaram que a FCR no $3^{\circ}$ minuto de recuperação após teste de esforço submáximo correlacionou positivamente aos índices da VFC, que indicam atividade vagal no repouso, e negativamente com os índices da VFC, que indicam atividade simpática, no repouso.. Por outro lado, Molina et. al. (159) não verificaram correlações entre os índices da VFC no repouso, na posição supina, com a FCR após teste de esforço máximo, em homens. Entretanto, verificou-se correlação negativa dos marcadores da atividade vagal e positiva dos marcadores simpatovagais da VFC no repouso, na posição ortostática, com a FCR no $3^{\circ}, 4^{\circ}$ e $5^{\circ}$ minutos após teste de esforço máximo.

Buchheit et. al. (145) observaram correlação significativas de moderada a forte $\left(0,53<\mathrm{r}_{\mathrm{s}}<\right.$ 0,81) entre os índices da VFC no repouso com o $1^{\circ}$ minuto da FCR, após sessão de repetidos “sprints". Contudo, os índices da VFC no repouso, foram coletados nos cinco minutos iniciais após a rotina de exercício, e sabe-se que o exercício induz modificações na FAC após uma sessão de exercício aeróbio (19).

No estudo realizado por Nunan et. al. (149) foram observadas correlações moderadas entre os marcadores de atividade vagal da VFC no repouso com a FCR no $1^{\circ}, 2^{\circ}$ e $3^{\circ}$ minutos de recuperação após teste de esforço máximo. Outro estudos observaram correlação entre os índices da VFC no repouso e a recuperação da $\mathrm{FC}$ no $2^{\circ}$ minuto de recuperação após teste de esforço máximo(154), com a FCR aos 30, 60 e 120 segundos de recuperação após teste de esforço submáximo (152), com a FCR aos 90 segundos e $4^{\circ}$ minuto de recuperação após exercício 
submáximo (146) e ainda, com a FCR no $4^{\circ}$ minuto de recuperação após teste de esforço máximo (153). Contudo, em outras pesquisas foi observado uma dissociação entre a FCR no primeiro minuto de recuperação com os índices da VFC no repouso $(17,156-158)$.

Os artigos realizaram a análise de correlação após exercício aeróbico, dificultando a comparação com os resultados desse estudo. Não foi observado correlação entre os marcadores da atividade vagal com a FCR ao longo de 15 minutos de recuperação após sessão de TR. Contudo, Foi observado correlação negativa entre os marcadores de atividade vagal da VFC no repouso com a FC per si durante os cinco, dez e quinze minutos de recuperação e correlação positiva entre os marcadores de atividade vagal da VFC no repouso com a $\Delta \% \mathrm{FC}$ durante os cinco, dez e quinze minutos após sessão de TR. Quanto maior o grau de atividade vagal no repouso menor será a FC e maior será a recuperação relativa da FC ao longo dos 15 minutos após sessão de TR. Foi observado o mesmo comportamento dos marcadores de atividade vagal no repouso com a média iRR no repouso, ou seja, quanto maior a média $\mathrm{iRR}$ no repouso, menor será a $\mathrm{FC}$ e maior será a recuperação relativa da FC ao longo de 15 minutos após sessão de TR.

Com os marcadores de modulação global da VFC no repouso, foi observada correlação positiva, moderada a forte, com a FCR durante cinco minutos de recuperação e com a $\Delta \% \mathrm{FC}$ durante os cinco e quinze minutos de recuperação após sessão de TR. Assim, quanto maior for a capacidade de modulação global no repouso, mais acelerada é a recuperação da FC nos cinco minutos de recuperação após sessão de TR.

A importância desse fenômeno reside na capacidade prognóstica de risco cardiovascular. Uma lenta recuperação da FC nos momentos iniciais de recuperação, apresenta um risco aumentado de mortalidade (49-52). Assim, nossos achados abrem uma nova possibilidade na interpretação do comportamento da resposta cronotrópica após sessão de TR em jovens adultos saudáveis. Até o momento, este é o primeiro estudo a correlacionar os marcadores de atividade vagal e modulação global, na condição de repouso, com a resposta cronotrópica após sessão de TR. Do ponto de vista 
prático, a atividade vagal no repouso parece desempenhar um papel chave na redução da FC até os níveis de repouso após sessão de TR. 


\section{CONCLUSÃO}

Nesta pesquisa desenvolvida em homens adultos clinicamente normais, observou-se que:

$\checkmark \quad$ Uma sessão de três séries de 8-12RM no exercício de Leg press, induziu uma taquicardia, com progressiva redução durante os 15 minutos, após sessão de TR. E, reduziu a atividade vagal e a modulação global por até 15 minutos, em comparação a condição inicial, após sessão de TR.

A FAC avaliada antes da sessão de TR, comportou-se de forma semelhante a FAC avaliada durante a caracterização da amostra (registro controle). O comportamento da FAC na sessão anterior ao TR não se alterou quando comparado com o comportamento da FAC durante a caracterização da amostra, após a mudança postural.

$\checkmark \quad$ Os marcadores de atividade vagal, da VFC, na condição inicial e posição supina correlacionaram-se positivamente (moderado a muito forte) com os marcadores de atividade vagal, da VFC, ao longo de 15 minutos, após sessão de TR.

$\checkmark \quad$ Foram observadas, correlações positivas (forte a muito forte) significativas, entre os marcadores de atividade vagal, da VFC, na condição inicial e supina com os marcadores de modulação global, da VFC, nos cinco e quinze minutos após sessão de TR.

$\checkmark \quad$ Os marcadores de atividade vagal, da VFC, na condição inicial e posição supina correlacionaram-se significativamente (moderado a forte) à a $\mathrm{FC}$ e à $\Delta \% \mathrm{FC}$ no quinto, décimo e décimo quinto minuto após sessão de TR.

$\checkmark \quad$ Não foram observadas, de forma consistente, correlações significativas entre os diversos marcadores de atividade vagal, da VFC, na condição inicial e posição supina, e a FCR ao longo de 15 minutos, após sessão de TR.

$\checkmark \quad$ Foram observadas, correlações positivas (moderado a forte) significativas, entre os marcadores de modulação global, da VFC, na condição inicial e supina com a FCR no quinto minuto e com a $\Delta \% \mathrm{FC}$ no quinto e décimo quinto minuto após sessão de TR. 
Não foram observadas, de forma consistente, correlações significativas, entre os diversos marcadores de modulação global, da VFC, na condição inicial e posição supina com a FC ao longo de 15 minutos após sessão de TR.

No contexto da fisiologia clínica e do exercício, o conhecimento relacionados a este tópico tem grande valor profissional, devido a prescrição mais adequada de TR para diversas populações. Os dados disponíveis na literatura sobre a restauração da atividade vagal após o TR, bem como a sua relação com o repouso, são insuficientes e/ou inexistentes. Os desdobramentos desta pesquisa, indicam que uma sessão de TR induzir modificações na FAC por até 15 minutos, após a sessão de treino resistido, e o comportamento da frequência cardíaca e da reativação vagal, em jovens adultos clinicamente normais, parece estar na dependência do grau de modulação da função autonômica cardíaca na condição de repouso. 


\section{REFERÊNCIAS BIBLIOGRÁFICAS}

1. POLLOCK ML, FRANKLIN BA, BALADY GJ, CHAITMAN BL, FLEG JL, FLETCHER B, et al. AHA Science Advisory. Resistance exercise in individuals with and without cardiovascular disease: benefits, rationale, safety, and prescription: An advisory from the Committee on Exercise, Rehabilitation, and Prevention, Council on Clinical Cardiology, American Heart Association; Position paper endorsed by the American College of Sports Medicine. Circulation. 2000;101(7):828-33.

2. SELIG SE, CAREY MF, MENZIES DG, PATTERSON J, GEERLING RH, WILLIAMS AD, et al. Moderateintensity resistance exercise training in patients with chronic heart failure improves strength, endurance, heart rate variability, and forearm blood flow. Journal of Cardiac Failure. 2004;10(1):21-30.

3. MAYO JJ, KRAVITZ L. A Review of the Acute Cardiovascular Responses to Resistance Exercise of Healthy Young and Older Adults. Journal of Strength and Conditioning Research. 1999;13(1):90-6.

4. GARBER CE, BLISSMER B, DESCHENES MR, FRANKLIN BA, LAMONTE MJ, LEE I-M, et al. American College of Sports Medicine position stand. Quantity and quality of exercise for developing and maintaining cardiorespiratory, musculoskeletal, and neuromotor fitness in apparently healthy adults: guidance for prescribing exercise. Medicine and science in sports and exercise. 2011;43(7):1334-59.

5. KINGSLEY JD, MCMILLAN V, FIGUEROA A. The effects of 12 weeks of resistance exercise training on disease severity and autonomic modulation at rest and after acute leg resistance exercise in women with fibromyalgia. Archives of physical medicine and rehabilitation. 2010;91(10):1551-7.

6. RATAMESS N, ALVAR B, EVETOCH T, HOUSH T, KIBLER W, KRAEMER W. Progression models in resistance training for healthy adults [ACSM position stand]. Medicine and science in sports and exercise. 2009;41(3):687-708.

7. SPIERING BA, KRAEMER WJ, ANDERSON JM, ARMSTRONG LE, NINDL BC, VOLEK JS, et al. Resistance exercise biology. Sports Medicine. 2008;38(7):527-40.

8. ARAIY, SAULJP, ALBRECHT P, HARTLEY LH, LILLY LS, COHEN RJ, et al. Modulation of cardiac autonomic activity during and immediately after exercise. American Journal of Physiology-Heart and Circulatory Physiology. 1989;256(1 Pt 2):H132-41.

9. ROBINSON BF, EPSTEIN SE, BEISER GD, BRAUNWALD E. Control of heart rate by the autonomic nervous system. Studies in man on the interrelation between baroreceptor mechanisms and exercise. Circulation Research. 1966;19(2):400-11.

10. CHAPLEAU MW, SABHARWAL R. Methods of assessing vagus nerve activity and reflexes. Heart failure reviews. 2011;16(2):109-27.

11. NOBREGA AC, O'LEARY D, SILVA BM, MARONGIU E, PIEPOLI MF, CRISAFULLI A. Neural regulation of cardiovascular response to exercise: role of central command and peripheral afferents. BioMed research international. 2014;2014.

12. COOTE JH, BOTHAMS VF. Cardiac vagal control before, during and after exercise. Experimental physiology. 2001;86(6):811-5.

13. EVRENGUL H, TANRIVERDI H, KOSE S, AMASYALI B, KILIC A, CELIK T, et al. The relationship between heart rate recovery and heart rate variability in coronary artery disease. Annals of Noninvasive Electrocardiology. 2006;11(2):154-62.

14. KANNANKERIL PJ, LE FK, KADISH AH, GOLDBERGER JJ. Parasympathetic effects on heart rate recovery after exercise. Journal of investigative medicine. 2004;52(6):394-401.

15. IMAI K, SATO H, HORI M, KUSUOKA H, OZAKI H, YOKOYAMA H, et al. Vagally mediated heart rate recovery after exercise is accelerated in athletes but blunted in patients with chronic heart failure. Journal of the American College of Cardiology. 1994;24(6):1529-35.

16. KANNANKERIL PJ, GOLDBERGER JJ. Parasympathetic effects on cardiac electrophysiology during exercise and recovery. American Journal of Physiology-Heart and Circulatory Physiology. 2002;282(6): H2091-H8.

17. JAVORKA M, ZILA I, BALHAREK T, JAVORKA K. Heart rate recovery after exercise: relations to heart rate variability and complexity. Brazilian Journal of Medical and Biological Research. 2002;35(8):991-1000.

18. BORRESEN J, LAMBERT MI. Autonomic control of heart rate during and after exercise. Sports medicine. 2008;38(8):633-46. 
19. STANLEY J, PEAKE JM, BUCHHEIT M. Cardiac parasympathetic reactivation following exercise: implications for training prescription. Sports Medicine. 2013;43(12):1259-77.

20. HEFFERNAN KS, KELLY EE, COLLIER SR, FERNHALL B. Cardiac autonomic modulation during recovery from acute endurance versus resistance exercise. European Journal of Cardiovascular Prevention \& Rehabilitation. 2006;13(1):80-6.

21. CAMM A, MALIK M, BIGGER J, BREITHARDT G, CERUTTI S, COHEN R, et al. Heart rate variability: standards of measurement, physiological interpretation and clinical use. Task Force of the European Society of Cardiology and the North American Society of Pacing and Electrophysiology. Circulation. 1996;93(5):104365.

22. LAHIRI MK, KANNANKERIL PJ, GOLDBERGER JJ. Assessment of autonomic function in cardiovascular disease: physiological basis and prognostic implications. Journal of the American College of Cardiology. 2008;51(18):1725-33.

23. BILLMAN GE. Aerobic exercise conditioning: a nonpharmacological antiarrhythmic intervention. Journal of applied physiology. 2002;92(2):446-54.

24. BILLMAN GE. Heart rate response to onset of exercise: evidence for enhanced cardiac sympathetic activity in animals susceptible to ventricular fibrillation. American Journal of Physiology-Heart and Circulatory Physiology. 2006;291(1):H429-H35.

25. WILLICH SN, LEWIS M, LOWEL H, ARNTZ H-R, SCHUBERT F, SCHRODER R. Physical exertion as a trigger of acute myocardial infarction. New England Journal of Medicine. 1993;329(23):1684-90.

26. TSUJI H, VENDITTI FJ, JR., MANDERS ES, EVANS JC, LARSON MG, FELDMAN CL, et al. Reduced heart rate variability and mortality risk in an elderly cohort. The Framingham Heart Study. Circulation. 1994;90(2):878-83.

27. HEFFERNAN KS, SOSNOFF JJ, JAE SY, GATES GJ, FERNHALL B. Acute resistance exercise reduces heart rate complexity and increases QTc interval. International Journal of Sports Medicine. 2008;29(4):289-93.

28. KINGSLEY JD, FIGUEROA A. Acute and training effects of resistance exercise on heart rate variability. Clinical physiology and functional imaging. 2014.

29. MELO RC, QUITERIO RJ, TAKAHASHI AC, SILVA E, MARTINS LE, CATAI AM. High eccentric strength training reduces heart rate variability in healthy older men. British Journal of Sports Medicine. 2008;42(1):59-63.

30. KOEPPEN BM, STANTON BA. Berne \& Levy: Fisiologia, 6a edição. Ed Elsevier, Rio de Janeiro, RJ 2009. 31. KRAEMER WJ, FLECK SJ, DESCHENES MR. Exercise physiology: integrating theory and application: Lippincott Williams \& Wilkins; 2011.

32. ICHINOSE M, MAEDA S, KONDO N, NISHIYASU T. Blood pressure regulation II: what happens when one system must serve two masters-oxygen delivery and pressure regulation? European journal of applied physiology. 2014;114(3):451-65.

33. JUNQUEIRA JR LF. Considerações básicas sobre a organização estrutural e a fisiologia do aparelho cardiovascular. http://wwwfmunbbr/labcor/Panoramica-Fisiopdf. 2007.

34. COOTE JH. Recovery of heart rate following intense dynamic exercise. Experimental physiology. 2010;95(3):431-40.

35. MITCHELL JH, KAUFMAN MP, IWAMOTO GA. The exercise pressor reflex: its cardiovascular effects, afferent mechanisms, and central pathways. Annual Review of Physiology. 1983;45(1):229-42.

36. MACIEL BC, GALLO JUNIOR L, MARIN NETO JA, MARTINS LE. Autonomic nervous control of the heart rate during isometric exercise in normal man. Pflügers Archiv: European Journal of Physiology. 1987;408(2):173-7.

37. KAUFMAN MP, FORSTER HV. Reflexes controlling circulatory, ventilatory and airway responses to exercise. Comprehensive Physiology. 1996.

38. ROWELL LB, O'LEARY DS. Reflex control of the circulation during exercise: chemoreflexes and mechanoreflexes. Journal of Applied Physiology. 1990;69(2):407-18.

39. CORRÊA LDMA, SANTOS T, MOURA THP, NEGRÃO CE. Alterações autonômicas na insuficiência cardíaca: benefícios do exercício físico. Revista SOCERJ. 2008;21(2):106-11.

40. BILLMAN GE. Heart rate variability-a historical perspective. 2011.

41. BERRYMAN JW. Motion and rest: Galen on exercise and health. The Lancet. 2012;380(9838):210-1. 
42. THAYER JF, YAMAMOTO SS, BROSSCHOT JF. The relationship of autonomic imbalance, heart rate variability and cardiovascular disease risk factors. International journal of cardiology. 2010;141(2):122-31.

43. KLEIGER RE, STEIN PK, BIGGER JT. Heart rate variability: measurement and clinical utility. Annals of Noninvasive Electrocardiology. 2005;10(1):88-101.

44. TULPPO MP, MAKIKALLIO T, TAKALA T, SEPPANEN T, HUIKURI HV. Quantitative beat-to-beat analysis of heart rate dynamics during exercise. American Journal of Physiology-Heart and Circulatory Physiology. 1996;271(1):H244-H52.

45. MOLINA GE, PORTO LGG, FONTANA KE, JUNQUEIRA JR LF. Unaltered R-R interval variability and bradycardia in cyclists as compared with non-athletes. Clinical Autonomic Research. 2013;23(3):141-8.

46. BILLMAN GE. The LF/HF ratio does not accurately measure cardiac sympatho-vagal balance. Heart Rate Variability: Clinical Applications and Interaction between HRV and Heart Rate. 2007:54.

47. COLE CR, BLACKSTONE EH, PASHKOW FJ, SNADER CE, LAUER MS. Heart-rate recovery immediately after exercise as a predictor of mortality. New England Journal of Medicine. 1999;341(18):1351-7.

48. COLE CR, FOODY JM, BLACKSTONE EH, LAUER MS. Heart rate recovery after submaximal exercise testing as a predictor of mortality in a cardiovascularly healthy cohort. Annals of internal medicine. 2000;132(7):552-5.

49. SHETLER K, MARCUS R, FROELICHER VF, VORA S, KALISETTI D, PRAKASH M, et al. Heart rate recovery: validation and methodologic issues. Journal of the American College of Cardiology. 2001;38(7):1980-7.

50. JAE SY, CARNETHON MR, HEFFERNAN KS, CHOI Y-H, LEE M-K, PARK WH, et al. Slow heart rate recovery after exercise is associated with carotid atherosclerosis. Atherosclerosis. 2008;196(1):256-61.

51. NISHIME EO, COLE CR, BLACKSTONE EH, PASHKOW FJ, LAUER MS. Heart rate recovery and treadmill exercise score as predictors of mortality in patients referred for exercise ECG. Jama. 2000;284(11):1392-8.

52. VIVEKANANTHAN DP, BLACKSTONE EH, POTHIER CE, LAUER MS. Heart rate recovery after exercise is apredictor of mortality, independent of the angiographic severity of coronary disease. Journal of the American College of Cardiology. 2003;42(5):831-8.

53. FLECK SJ, KRAEMER WJ, MADURO CR. Fundamentos do treinamento de força muscular: Artmed; 1999.

54. WILLIAMS MA, HASKELL WL, ADES PA, AMSTERDAM EA, BITTNER V, FRANKLIN BA, et al. Resistance exercise in individuals with and without cardiovascular disease: 2007 update a scientific statement from the american heart association council on clinical cardiology and council on nutrition, physical activity, and metabolism. Circulation. 2007;116(5):572-84.

55. SHANNON J. FITZGERALD, CAROLYN E. BARLOW, JAMES B. KAMPERT, JAMES R. MORROW J, ALLEN W. JACKSON, BLAIR SN. Muscular Fitness and All-Cause Mortality: Prospective Observations. Journal of Physical Activity and Health. 2004;1:7-18.

56. NEWMAN AB, KUPELIAN V, VISSER M, SIMONSICK EM, GOODPASTER BH, KRITCHEVSKY SB, et al. Strength, But Not Muscle Mass, Is Associated With Mortality in the Health, Aging and Body Composition Study Cohort. Journal of Gerontology: MEDICAL SCIENCES. 2006;61A(1):72-7.

57. SASAKI H, KASAGI F, YAMADA M, FUITA S. Grip strength predicts cause-specific mortality in middleaged and elderly persons. The American Journal of Medicine. 2007;120(4):337-42.

58. RUIZ JR, SUI X, LOBELO F, MORROW JR JR, JACKSON AW, SJO"STRO"M M, et al. Association between muscular strength and mortality in men: prospective cohort study. BMJ. 2008;337(a439):1-9.

59. TANASESCU M, LEITZMANN MF, RIMM EB, WILLETT WC, STAMPFER MJ, HU FB. Exercise type and intensity in relation to coronary heart disease in men. Jama. 2002;288(16):1994-2000.

60. GALE CR, MARTYN CN, COOPER C, SAYER AA. Grip strength, body composition, and mortality. International Journal of Epidemiology: Oxford Journals 2007;36(1):228-35.

61. FAHS CA, HEFFERNAN KS, RANADIVE S, JAE SY, FERNHALL B. Muscular strength is inversely associated with aortic stiffness in young men. Medicine and science in sports and exercise. 2010;42(9):1619-24.

62. JURCA R, LAMONTE MJ, BARLOW CE, KAMPERT JB, CHURCH TS, BLAIR SN. Association of muscular strength with incidence of metabolic syndrome in men. Medicine and science in sports and exercise. 2005;37(11):1849-55. 
63. JURCA R, LAMONTE MJ, CHURCH TS, EARNEST CP, FITZGERALD SJ, BARLOW CE, et al. Associations of muscle strength and fitness with metabolic syndrome in men. Medicine and science in sports and exercise. 2004;36(8):1301-7.

64. WIJNDAELE K, DUVIGNEAUD N, MATTON L, DUQUET W, THOMIS M, BEUNEN G, et al. Muscular strength, aerobic fitness, and metabolic syndrome risk in Flemish adults. Medicine and science in sports and exercise. 2007;39(2):233-40.

65. CHENG YJ, GREGG EW, DE REKENEIRE N, WILLIAMS DE, IMPERATORE G, CASPERSEN CJ, et al. Musclestrengthening activity and its association with insulin sensitivity. Diabetes Care. 2007;30(9):2264-70.

66. STRASSER B, STEINDORF K, WISKEMANN J, ULRICH CM. Impact of resistance training in cancer survivors: a meta-analysis. Medicine and science in sports and exercise. 2013;45(11):2080-90.

67. RUIZ JR, SUI X, LOBELO F, LEE DC, MORROW JR, JR., JACKSON AW, et al. Muscular strength and adiposity as predictors of adulthood cancer mortality in men. Cancer Epidemiology, Biomarkers \& Prevention. 2009;18(5):1468-76.

68. ARTERO EG, LEE DC, RUIZ JR, SUI X, ORTEGA FB, CHURCH TS, et al. A prospective study of muscular strength and all-cause mortality in men with hypertension. Journal of the American College of Cardiology. 2011;57(18):1831-7.

69. MASLOW AL, SUI X, COLABIANCHI N, HUSSEY J, BLAIR SN. Muscular strength and incident hypertension in normotensive and prehypertensive men. Medicine and science in sports and exercise. 2010;42(2):288-95.

70. KRAEMER WJ. Exercise Prescription in Weight Training: Manipulating Program Variables. Strength \& Conditioning Journal. 1983;5(3):58-61.

71. MACDOUGALL J, TUXEN D, SALE D, MOROZ J, SUTTON J. Arterial blood pressure response to heavy resistance exercise. Journal of Applied Physiology. 1985;58(3):785-90.

72. GOTSHALL R, GOOTMAN J, BYRNES W, FLECK S, VALOVICH T. Noninvasive characterization of the blood pressure response to the double-leg press exercise. JEPonline. 1999;2(4):1-6.

73. MCCARTNEY N. Acute responses to resistance training and safety. Medicine and Science in Sports and Exercise. 1999;31(1):31-7.

74. MCCARTNEY N, MCKELVIE R, MARTIN J, SALE D, MACDOUGALL J. Weight-training-induced attenuation of the circulatory response of older males to weight lifting. Journal of applied physiology. 1993;74(3):1056-60.

75. Kingsley JD, McMillan V, Figueroa A. The effects of 12 weeks of resistance exercise training on disease severity and autonomic modulation at rest and after acute leg resistance exercise in women with fibromyalgia. Arch Phys Med Rehabil. 2010;91(10):1551-7.

76. FIGUEIREDO T, RHEA MR, PETERSON M, MIRANDA H, BENTES CM, DOS REIS VMDR, et al. Influence of Number of Sets on Blood Pressure and Heart Rate Variability After a Strength Training Session. The Journal of Strength \& Conditioning Research. 2015;29(6):1556-63.

77. REZK C, MARRACHE R, TINUCCI T, MION JR D, FORJAZ C. Post-resistance exercise hypotension, hemodynamics, and heart rate variability: influence of exercise intensity. European journal of applied physiology. 2006;98(1):105-12.

78. NIEMELA TH, KIVINIEMI AM, HAUTALA AJ, SALMI JA, LINNAMO V, TULPPO MP. Recovery pattern of baroreflex sensitivity after exercise. Medicine and science in sports and exercise. 2008;40(5):864.

79. MAIOR AS, NETTO CF, EICHWALD A, DRUCK G, VILLAÇA G, FOSCHIERA RDS, et al. Influência da intensidade e do volume do treinamento resistido no comportamento autonômico cardíaco. Revista SOCERJ. 2009;22(4):201-9.

80. RUIZ RJ, SIMÃO R, SACCOMANI MG, CASONATTO J, ALEXANDER JL, RHEA M, et al. Isolated and combined effects of aerobic and strength exercise on post-exercise blood pressure and cardiac vagal reactivation in normotensive men. The Journal of Strength \& Conditioning Research. 2011;25(3):640-5.

81. ANUNCIACAO PG, CASONATTO J, POLITO MD. Blood pressure responses and heart rate variability after resistance exercise with different intensities and same workload: original research article. International SportMed Journal. 2011;12(2):53-67. 
82. LIMA AHRDA, FORJAZ CLDM, SILVA GQDM, MENÊSES AL, SILVA AJMR, RITTI-DIAS RM. Acute effect of resistance exercise intensity in cardiac autonomic modulation after exercise. Arquivos brasileiros de cardiologia. 2011;96(6):498-503.

83. CHEN J-L, YEH D-P, LEE J-P, CHEN C-Y, HUANG C-Y, LEE S-D, et al. Parasympathetic nervous activity mirrors recovery status in weightlifting performance after training. The Journal of Strength \& Conditioning Research. 2011;25(6):1546-52.

84. TEIXEIRA L, RITTI-DIAS RM, TINUCCI T, JÚNIOR DM, DE MORAES FORJAZ CL. Post-concurrent exercise hemodynamics and cardiac autonomic modulation. European journal of applied physiology. 2011;111(9):2069-78.

85. OLIVEIRA R, DA COSTA MV, PEDRO R, POLITO M, AVELAR A, CYRINO E, et al. Acute cardiac autonomic responses after a bout of resistance exercise. Science \& Sports. 2012;27(6):357-64.

86. GOESSLER KF, POLITO MD. Effect of fixed and self-suggested rest intervals between sets of resistance exercise on post-exercise cardiovascular behavior. Revista Brasileira de Cineantropometria \& Desempenho Humano. 2013;15(4):467-75.

87. ROCHA AC, SARTORI M, RODRIGUES B, DE ANGELIS K. Influência do número de séries nos ajustes cardiovasculares e autonômicos ao exercício resistido em homens fisicamente ativos. Revista Brasileira de Mededicina do Esporte. 2013;19(5):332-5.

88. FIGUEIREDO T, MENEZES P, KATTENBRAKER M, POLITO M, REIS V, SIMÃO R. Influence of exercise order on blood pressure and heart rate variability after a strength training session. The Journal of Sports Medicine and Physical Fitness. 2013;53:12-7.

89. OKUNO NM, PEDRO RE, LEICHT AS, DE PAULA RAMOS S, NAKAMURA FY. Cardiac autonomic recovery after a single session of resistance exercise with and without vascular occlusion. The Journal of Strength \& Conditioning Research. 2014;28(4):1143-50.

90. IGLESIAS-SOLER E, BOULLOSA DA, CARBALLEIRA E, SÁNCHEZ-OTERO T, MAYO X, CASTRO-GACIO X, et al. Effect of set configuration on hemodynamics and cardiac autonomic modulation after high-intensity squat exercise. Clinical physiology and functional imaging. 2014.

91. KINGSLEY JD, HOCHGESANG S, BREWER A, BUXTON E, MARTINSON M, HEIDNER G. Autonomic modulation in resistance-trained individuals after acute resistance exercise. International Journal of Sports Medicine. 2014;35(10):851-6.

92. FIGUEIREDO T, WILLARDSON JM, MIRANDA H, BENTES CM, REIS VM, SIMÃO R. Influence of load intensity on post exercise hypotension and heart rate variability following a strength training session. The Journal of Strength \& Conditioning Research. 2015.

93. QUEIROZ A, KANEGUSUKU H, CHEHUEN M, COSTA L, WALLERSTEIN L, DIAS DA SILVA V, et al. Cardiac work remains high after strength exercise in elderly. International Journal of Sports Medicine. 2013;34(5):391-7.

94. NICOLINO J, RAMOS D, LEITE MR, RODRIGUES FMM, DE ALENCAR SILVA BS, TACAO GY, et al. Analysis of autonomic modulation after an acute session of resistance exercise at different intensities in chronic obstructive pulmonary disease patients. International journal of chronic obstructive pulmonary disease. 2015;10:223.

95. ANDRADE LIMA AH, FARAH BQ, RODRIGUES LB, MIRANDA AS, RODRIGUES SL, DE A CORREIA M, et al. Low-intensity resistance exercise does not affect cardiac autonomic modulation in patients with peripheral artery disease. Clinics. 2013;68(5):632-7.

96. KINGSLEY JD, PANTON LB, MCMILLAN V, FIGUEROA A. Cardiovascular autonomic modulation after acute resistance exercise in women with fibromyalgia. Archives of physical medicine and rehabilitation. 2009;90(9):1628-34.

97. TIBANA RA, BOULLOSA DA, LEICHT AS, PRESTES J. Women with metabolic syndrome present different autonomic modulation and blood pressure response to an acute resistance exercise session compared with women without metabolic syndrome. Clinical physiology and functional imaging. 2013;33(5):364-72.

98. MIRANDA JMDQ, DIAS LDC, MOSTARDA CT, ANGELIS KD, JUNIOR AJF, WICHI RB. Efeito do treinamento de força nas variáveis cardiovasculares em adolescentes com sobrepeso. Revista Brasileira de Medicina do Esporte. 2014;20(02):125-30. 
99. QUEIROZ A, SOUSA J, CAVALLI A, SILVA N, COSTA L, TOBALDINI E, et al. Post-resistance exercise hemodynamic and autonomic responses: Comparison between normotensive and hypertensive men. Scandinavian journal of medicine \& science in sports. 2015;25(4):486-94.

100. FREITAS BRITO AD, BRASILEIRO-SANTOS MDS, DE OLIVEIRA CVC, DA NÓBREGA TKS, DE MORAES FORJAZ CL, DA CRUZ SANTOS A. High-Intensity Resistance Exercise Promotes Postexercise Hypotension Greater than Moderate Intensity and Affects Cardiac Autonomic Responses in Women Who Are Hypertensive. The Journal of Strength \& Conditioning Research. 2015;29(12):3486-93.

101. KLISZCZEWICZ BM, ESCO MR, QUINDRY JC, BLESSING DL, OLIVER GD, TAYLOR KJ, et al. Autonomic Responses to an Acute Bout of High-Intensity Body Weight Resistance Exercise vs. Treadmill Running. The Journal of Strength \& Conditioning Research. 2016;30(4):1050-8.

102. FIGUEIREDO T, WILLARDSON JM, MIRANDA H, BENTES CM, MACHADO REIS V, FREITAS DE SALLES B, et al. Influence of Rest Interval Length Between Sets on Blood Pressure and Heart Rate Variability After a Strength Training Session Performed By Prehypertensive Men. journal of strength \& conditioning research. 2016;30(7):1813-24.

103. PAREJA-BLANCO F, RODRÍGUEZ-ROSELL D, SÁNCHEZ-MEDINA L, RIBAS-SERNA J, LÓPEZ-LÓPEZ C, MORA-CUSTODIO R, et al. Acute and delayed response to resistance exercise leading or not leading to muscle failure. Clinical physiology and functional imaging. 2016.

104. GONZÁLEZ-BADILLO J, RODRÍGUEZ-ROSELL D, SÁNCHEZ-MEDINA L, RIBAS J, LÓPEZ-LÓPEZ C, MORACUSTODIO R, et al. Short-term Recovery Following Resistance Exercise Leading or not to Failure. International journal of sports medicine. 2015.

105. THAYER JF, LANE RD. The role of vagal function in the risk for cardiovascular disease and mortality. Biological psychology. 2007;74(2):224-42.

106. GUYTON AC, HALL JEAC, JOHN E, GUYTON AC, GUYTON AC, GUYTON AC, et al. Tratado de fisiologia médica: Elsevier; 2011.

107. CARDIOLOGIA SBD, HIPERTENSÃO SBD, NEFROLOGIA SBD. VI Diretrizes Brasileira de Hipertensão Arterial. Arquivos Brasileiros de Cardiologia 2010;95(1 supl.1):1-51.

108. VASCONCELOS DF, JUNQUEIRA LF, JR. Distinctive impaired cardiac autonomic modulation of heart rate variability in chronic Chagas' indeterminate and heart diseases. Journal of Electrocardiology. 2009;42(3):281-9.

109. PORTO LGGLFJJ. Comparison of time-domain short-term heart interval variability analysis using a wrist-worn heart rate monitor and the conventional electrocardiogram.Pacing Clin Electrophysiol. The Authors Journal compilation. 2009;32(January):43-51.

110. WALLEN MB, HASSON D, THEORELL T, CANLON B, OSIKA W. Possibilities and limitations of the Polar RS800 in measuring heart rate variability at rest. European Journal of Applied Physiology. 2012;112(3):115365.

111. TARVAINEN MP, NISKANEN J-P, LIPPONEN JA, RANTA-AHO PO, KARJALAINEN PA. Kubios HRV-heart rate variability analysis software. Computer methods and programs in biomedicine. 2014;113(1):210-20.

112. WASSERMAN K, HANSEN J, SUE D, WHIPP B. Principles of exercise testing and Interpretations. Philadelphia: Lea \& Febiger. 1989;3

113. ACSM ACOSM. Diretrizes do ACSM para os testes de esforço e sua prescrição. Guanabara Koogan. 2006;7th Ed.

114. DROUIN JM, VALOVICH-MCLEOD TC, SHULTZ SJ, GANSNEDER BM, PERRIN DH. Reliability and validity of the Biodex system 3 pro isokinetic dynamometer velocity, torque and position measurements. European Journal of Applied Physiology. 2004;91(1):22-9.

115. PINCIVERO DM, LEPHART SM, KARUNAKARA RA. Reliability and precision of isokinetic strength and muscular endurance for the quadriceps and hamstrings. Int J Sports Med. 1997;18(2):113-7.

116. PARCELL AC, SAWYER RD, TRICOLI VA, CHINEVERE TD. Minimum rest period for strength recovery during a common isokinetic testing protocol. Medicine and science in sports and exercise. 2002;34(6):101822.

117. BOTTARO M, RUSSO AF, DE OLIVEIRA RJ. The effects of rest interval on quadriceps torque during an isokinetic testing protocol in elderly. Journal of Sports Science and Medicine. 2005;4(3):285-90. 
118. GARBER CE, BLISSMER B, DESCHENES MR, FRANKLIN BA, LAMONTE MJ, LEE IM, et al. American College of Sports Medicine position stand. Quantity and quality of exercise for developing and maintaining cardiorespiratory, musculoskeletal, and neuromotor fitness in apparently healthy adults: guidance for prescribing exercise. Medicine and science in sports and exercise. 2011;43(7):1334-59.

119. HOPKINS W, MARSHALL S, BATTERHAM A, HANIN J. Progressive statistics for studies in sports medicine and exercise science. Medicine and Science in Sports Exercise. 2009;41(1):3.

120. PUMPRLA J, HOWORKA K, GROVES D, CHESTER M, NOLAN J. Functional assessment of heart rate variability: physiological basis and practical applications. International Journal of Cardiology. 2002;84(1):114.

121. ANTELMI I, DE PAULA RS, SHINZATO AR, PERES CA, MANSUR AJ, GRUPI CJ. Influence of age, gender, body mass index, and functional capacity on heart rate variability in a cohort of subjects without heart disease. The American journal of cardiology. 2004;93(3):381-5.

122. BARANTKE M, KRAUSS T, ORTAK J, LIEB W, REPPEL M, BURGDORF C, et al. Effects of gender and aging on differential autonomic responses to orthostatic maneuvers. Journal of cardiovascular electrophysiology. 2008;19(12):1296-303.

123. BROWN TE, BEIGHTOL LA, KOH J, ECKBERG DL. Important influence of respiration on human RR interval power spectra is largely ignored. Journal of Applied Physiology. 1993;75(5):2310-7.

124. BLOOMFIELD DM, MAGNANO A, BIGGER JT, RIVADENEIRA H, PARIDES M, STEINMAN RC. Comparison of spontaneous vs. metronome-guided breathing on assessment of vagal modulation using RR variability. American Journal of Physiology-Heart and Circulatory Physiology. 2001;280(3):H1145-H50.

125. FLETCHER G, ADES P, KLIGFIELD P, ARENA R, BALADY G, BITTNER V, et al. Exercise standards for testing and training: a scientific statement from the American Heart Association. Circulation. 2013;128(8):873-934.

126. BUCHHEIT M, GINDRE C. Cardiac parasympathetic regulation: respective associations with cardiorespiratory fitness and training load. American Journal of Physiology-Heart and Circulatory Physiology. 2006;291(1):H451-H8.

127. SMITH ML, HUDSON DL, GRAITZER HM, RAVEN PB. Exercise training bradycardia: the role of autonomic balance. Medicine and Science in Sports and Exercise. 1989;21(1):40-4.

128. FREY MAB, TOMASELLI CM, HOFFLER WG. Cardiovascular responses to postural changes: differences with age for women and men. The Journal of Clinical Pharmacology. 1994;34(5):394-402.

129. Montano N, Ruscone TG, Porta A, Lombardi F, Pagani M, Malliani A. Power spectrum analysis of heart rate variability to assess the changes in sympathovagal balance during graded orthostatic tilt. Circulation. 1994;90(4):1826-31.

130. AIRES MDM. Fisiologia. 3a edição. Rio de Janeiro: G Koogan. 2008.

131. MACEEL B, GALLO L, NETO JM, LIMA FILHO E, MARTINS L. Autonomic nervous control of the heart rate during dynamic exercise in normal man. Clinical Science. 1986;71(4):457-60.

132. PIERPONT GL, STOLPMAN DR, GORNICK CC. Heart rate recovery post-exercise as an index of parasympathetic activity. Journal of the autonomic nervous system. 2000;80(3):169-74.

133. JOUVEN X, EMPANA J-P, SCHWARTZ PJ, DESNOS M, COURBON D, DUCIMETIÈRE P. Heart-rate profile during exercise as a predictor of sudden death. New England Journal of Medicine. 2005;352(19):1951-8.

134. PEÇANHA T, SILVA-JÚNIOR ND, FORJAZ CLDM. Heart rate recovery: autonomic determinants, methods of assessment and association with mortality and cardiovascular diseases. Clinical physiology and functional imaging. 2014;34(5):327-39.

135. FREEMAN R. Assessment of cardiovascular autonomic function. Clinical Neurophysiology. 2006;117(4):716-30.

136. MALLIANI A. Principles of cardiovascular neural regulation in health and disease: Springer Science \& Business Media; 2000.

137. GRANT CC, VAN RENSBURG DC, STRYDOM N, VILOEN M. Importance of tachogram length and period of recording during noninvasive investigation of the autonomic nervous system. Annals of Noninvasive Electrocardiology. 2011;16(2):131-9. 
138. CARNETHON MR, LIAO D, EVANS GW, CASCIO WE, CHAMBLESS LE, ROSAMOND WD, et al. Does the cardiac autonomic response to postural change predict incident coronary heart disease and mortality? The Atherosclerosis Risk in Communities Study. American journal of epidemiology. 2002;155(1):48-56.

139. DANNESKIOLD-SAMS $\varnothing E$ B, BARTELS E, BÜLOW P, LUND H, STOCKMARR A, HOLM C, et al. Isokinetic and isometric muscle strength in a healthy population with special reference to age and gender. Acta physiologica. 2009;197(s673):1-68.

140. TIMOTHY J. Physiology of aging invited review: Aging and sarcopenia. Journal Applied Physiology. 2003;95:1717-27.

141. VAN KAN GA. Epidemiology and consequences of sarcopenia. JNHA-The Journal of Nutrition, Health and Aging. 2009;13(8):708-12.

142. KRAEMER WJ. A Series of Studies-The Physiological Basis for Strength Training in American Football: Fact Over Philosophy. The Journal of Strength \& Conditioning Research. 1997;11(3):131-42.

143. WILLARDSON J, BURKETT L. A comparison of 3 different rest intervals on the exercise volume completed during a workout. Journal of strength and conditioning research. 2005;19(1):23-6.

144. WILLARDSON JM, KATTENBRAKER MS, KHAIRALLAH M, FONTANA FE. Research note: effect of load reductions over consecutive sets on repetition performance. The Journal of Strength \& Conditioning Research. 2010;24(3):879-84.

145. BUCHHEIT M, LAURSEN PB, AHMAIDI S. Parasympathetic reactivation after repeated sprint exercise. American Journal of Physiology-Heart and Circulatory Physiology. 2007;293(1):H133-H41.

146. TULPPO MP, KIVINIEMI AM, HAUTALA AJ, KALLIO M, SEPPÄNEN T, TIINANEN S, et al. Sympatho-vagal interaction in the recovery phase of exercise. Clinical physiology and functional imaging. 2011;31(4):272-81. 147. GONÇALVES TR, FARINATTI PDTV, GURGEL JL, DA SILVA SOARES PP. Correlation between cardiac autonomic modulation in response to orthostatic stress and indicators of quality of life, physical capacity, and physical activity in healthy individuals. The Journal of Strength \& Conditioning Research. 2015;29(5):1415-21.

148. BUCHHEIT M, AL HADDAD H, LAURSEN PB, AHMAIDI S. Effect of body posture on postexercise parasympathetic reactivation in men. Experimental physiology. 2009;94(7):795-804.

149. NUNAN D, JAKOVLEVIC DG, DONOVAN G, SINGLETON LD, SANDERCOCK GR, BRODIE DA. Resting autonomic modulations and the heart rate response to exercise. Clinical Autonomic Research. 2010;20(4):213-21.

150. CUNHA FA, MIDGLEY AW, GONCALVES T, SOARES PP, FARINATTI P. Parasympathetic reactivation after maximal CPET depends on exercise modality and resting vagal activity in healthy men. SpringerPlus. 2015;4:100.

151. DUARTE A, SOARES PP, PESCATELLO L, FARINATTI P. Aerobic training improves vagal reactivation regardless of resting vagal control. Medicine and science in sports and exercise. 2015;47(6):1159-67.

152. DANIELI A, LUSA L, POTOČNIK N, MEGLIČ B, GRAD A, BAJROVIĆ FF. Resting heart rate variability and heart rate recovery after submaximal exercise. Clinical Autonomic Research. 2014;24(2):53-61.

153. CHEN JY, LEE YL, TSAI WC, LEE CH, CHEN PS, LI YH, et al. Cardiac autonomic functions derived from short-term heart rate variability recordings associated with heart rate recovery after treadmill exercise test in young individuals. Heart and vessels. 2011;26(3):282-8.

154. ESCO MR, OLSON MS, WILLIFORD HN, BLESSING DL, SHANNON D, GRANDJEAN P. The relationship between resting heart rate variability and heart rate recovery. Clinical Autonomic Research. 2010;20(1):338.

155. MOLINA GE, FONTANA KE, PORTO LGG, JUNQUEIRA LF. Post-exercise heart-rate recovery correlates to resting heart-rate variability in healthy men. Clinical Autonomic Research. 2016:1-7.

156. DEWLAND TA, ANDRONE AS, LEE FA, LAMPERT RJ, KATZ SD. Effect of acetylcholinesterase inhibition with pyridostigmine on cardiac parasympathetic function in sedentary adults and trained athletes. American Journal of Physiology - Heart and Circulatory Physiology. 2007;293(1):H86-92.

157. BOSQUET L, GAMELIN FX, BERTHOIN S. Is aerobic endurance a determinant of cardiac autonomic regulation? European Journal of Applied Physiology. 2007;100(3):363-9.

158. LEE CM, MENDOZA A. Dissociation of heart rate variability and heart rate recovery in well-trained athletes. European Journal of Applied Physiology. 2012;112(7):2757-66. 
159. MOLINA GE. Relação entre a modulação autonômica cardíaca no repouso supino e ortostático e o decremento cronotrópico após o teste de esforço máximo em indivíduos normais. http://repositoriounbbr/bitstream/10482/14357/1/2013 GuilhermeEckhardtMolinapdf. 2013. 


\section{APÊNDICE}

\subsection{APÊNDICE I}

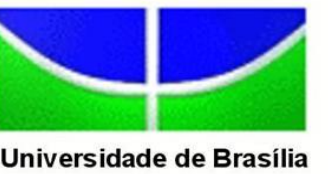

Universidade de Brasília - UnB

Faculdade de Educação Física - UnB

Programa de Pós-Graduação em Educação Física - UnB

\section{Termo de Consentimento Livre e Esclarecido - TCLE}

Convido o senhor a participar do projeto de pesquisa "Efeito imediato de uma sessão de exercício resistido na função autonômica cardíaca em jovens adultos saudáveis", sob a responsabilidade do pesquisador Giliard Lago Garcia com a aprovação do comitê de ética pelo parecer número: 39511114.7.0000.0030. O Objetivo desta pesquisa é avaliar o efeito imediato de uma sessão de exercício resistido na função autonômica cardíaca em jovens adultos sadios ativos. O senhor receberá todos os esclarecimentos necessários antes e no decorrer da pesquisa e lhe asseguramos que seu nome não aparecerá. No qual será mantido o mais rigoroso sigilo pela omissão total de quaisquer informações que permitam identificá-lo. A sua participação se dará por meio de três visitas com $48 \mathrm{~h}$ entre a primeira, segunda e terceira visita. Os testes serão realizados nos Laboratório de Fisiologia do Exercício, Laboratório de Treinamento de Força e Laboratório de biomecânica do movimento da Faculdade da Educação Física da Universidade de Brasília. Na primeira visita, será realizado uma anamnese (entrevista sobre características e hábitos pessoais), eletrocardiograma (ECG), medida de massa corporal, estatura, teste de avaliação da função autonômica cardíaca, teste de capacidade aeróbia e familiarização do exercício. Na segunda visita, será realizado teste de força (membros inferiores e superiores) e familiarização do exercício. Na terceira visita, será realizado o teste de avaliação da função autonômica cardíaca e sessão aguda exercício resistido. Após a sessão aguda o senhor ficará 15 min de monitorização no pós-esforço na posição supina. Será utilizado o frequencímetro, para registro do intervalo R-R, na posição supina e na posição ortostática. Em cada uma das situações de teste, a contagem dos batimentos do coração terá a duração de 5 minutos, com intervalo de alguns minutos entre uma situação e outra. O teste de capacidade aeróbia será realizado em esteira rolante e com analisadores de gases expirados. Será realizado, para membros superiores, o teste de força de preensão manual e teste de força de membros inferiores no isocinético. E a familiarização do exercício resistido de leg press e determinação de sua carga para a sessão aguda. Na sessão aguda de exercício resistido, será aplicado o teste de avaliação da função autonômica cardíaca pré (10 minutos) e pós (15 minutos) intervenção aguda. Se o senhor aceitar participar, estará contribuindo para a avaliação das aptidões físicas da saúde e força muscular. $\mathrm{O}$ exercício resistido e testes utilizados oferecem pequenos riscos que são equivalentes ao de qualquer aula de educação física, e serão minimizados pela presença de profissional especializado. O Senhor pode se recusar a responder ou participar de qualquer questão ou procedimento que lhe traga constrangimento, podendo desistir de participar da pesquisa em qualquer momento sem nenhum prejuízo para o senhor. Sua participação é voluntária, isto é, não há pagamento por sua colaboração. As despesas de locomoção (passagens) para as visitas aos laboratórios serão cobertas pelo pesquisador responsável, caso o voluntário não apresente condição de locomoção. Caso haja algum dano direto ou indireto resultante dos procedimentos de pesquisa, você poderá ser indenizado, obedecendo-se as disposições legais vigentes no Brasil. Os resultados da pesquisa serão divulgados na Universidade de Brasília - UnB, podendo ser publicados posteriormente. Os dados e materiais utilizados na pesquisa ficarão sob a guarda do pesquisador por um período de no mínimo cinco anos, após isso serão destruídos ou mantidos na instituição. Se o Senhor tiver qualquer dúvida em relação à pesquisa, por favor telefone para Giliard Lago Garcia no telefone (61) 3021-2906 / 8128-2745, no horário de 08:00 às 19:00 h. Este projeto foi Aprovado pelo Comitê de Ética em Pesquisa da Faculdade de Ciências da Saúde (CEP/FS) da Universidade de Brasília. O CEP é composto por profissionais de diferentes áreas cuja função é defender os interesses dos participantes da pesquisa em sua integridade e dignidade e contribuir no desenvolvimento da pesquisa dentro de padrões éticos. As dúvidas com relação à assinatura do TCLE ou os direitos do sujeito da pesquisa podem ser obtidas através do telefone: (61) 3107 1947 ou do e-mail cepfs@ unb.br, horário de atendimento de 10hs às 12hs e de 14hs às 17hs, de segunda a sexta-feira. Este documento foi elaborado em duas vias, uma ficará com o pesquisador responsável e a outra com o sujeito da pesquisa.

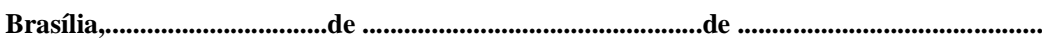

Nome:

Assinatura:

Voluntário

Giliard Lago Garcia

Pesquisador Responsável 


\section{ANEXOS}

ANEXO I

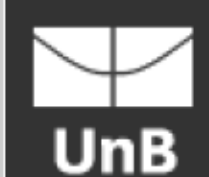

FACULDADE DE CIÊNCIAS DA SAÚDE DA UNIVERSIDADE DE QRatoril BRASÍLIA - CEP/FS-UNB

\section{PARECER CONSUBSTANCIADO DO CEP}

\section{DADOS DO PROJETO DE PESQUISA}

Título da Pesquisa: IMPACTO DO TREINAMENTO RESISTIDO SOBRE A FUNÇÃO AUTONÔMICA CARDÍACA

Pesquisador: Giliard Lago Garcia

Área Temática:

Versão: 1

CAAE: 39511114.7 .0000 .0030

Instituição Proponente: Faculdade de Educação Física - UnB

Patrocinador Principal: Financiamento Próprio

DADOS DO PARECER

Número do Parecer: 914.929

Data da Relatoria: 09/12/2014

\section{Apresentação do Projeto:}

"Resumo:

INTRODUÇÃO: A variabilidade da frequência cardíaca (VFC) representa uma das mais promissoras medidas da modulação autonômica cardiaca (MAC). A avaliação da MAC está fortemente associada com diversos prognósticos, especialmente, quando observado o aumento da MAC simpática com simultânea redução da MAC parassimpática na condição de repouso, relacionando-se com aumento de morte súbita e/ou suscetibilidade a arritmias ventriculares. O treinamento aeróbio melhora o balanço simpatovagal avaliado por meio da VFC, no qual ocorre o aumentando absoluto e/ou relativo da atividade parassimpática e/ou redução absoluta e/ou relativa a atividade simpática, sendo que o primeiro tem efeito cardioprotetor de longo prazo. Por outro lado, há escassez sobre o impacto do treinamento resistido como possível efeito cardioprotetor. Ou seja, não se sabe como é o comportamento da MAC em indivíduos jovens adultos sadios. Se não sabemos como é o comportamento no individuo normal, como podemos tirar conclusões em diferentes patologias? Constata-se então a importância de mais estudos para averiguar o impacto agudo e crônico do treinamento resistido sobre a modulação autonômica cardiaca. OBJETIVO: Neste contexto, o presente trabalho tem como objetivo avaliar o impacto do treinamento resistido sobre a modulação autonômica cardíaca em jovens sedentários adultos sadios. MÉTODO: Serão

Endereço: Faculdade de Ciências da Saúde - Campus Darcy Ribeiro

Bairro: Asa Norte

UF: DF Município: BRASILIA

CEP: $70.910-900$

Telefone: (61)3107-1947

E-mail: cepfsunb@gmail.com 


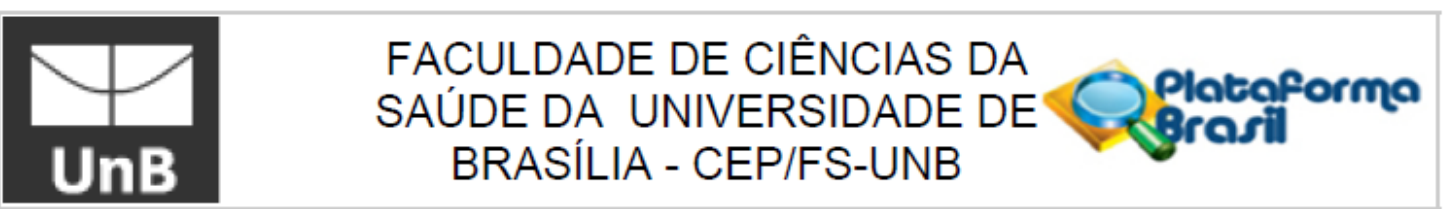

Continuação do Parecer: 914.929

- Termo de concordância do diretor da Faculdade de Educação Física, Prof. Jake Carvalho do Carmo, assinada e carimbada pelo mesmo, assinada também pelo chefe da Coordenação de Pós-graduação e pelo pesquisador responsável - "termo de concordância.jpg" postado em 30/11/2014;

- Carteira Nacional de Habilitação de Giliard Lago Garcia - "chn_giliard_lago_garcia.pdf" postado em 15/11/2014.

\section{Recomendaçöes:}

Quanto ao TCLE, solicita-se:

1) atualizar os dados do CEP/FS

e-mail: cepfs@unb.br ou cepfsunb@gmail.com;

horário de atendimento de $10: 00 \mathrm{hs}$ às $12: 00 \mathrm{hs}$ e de $13: 30 \mathrm{hs}$ às $15: 30 \mathrm{hs}$, de segunda a sexta-feira

2) O termo "sujeito" deverá ser substituído por "participante".

\section{Conclusões ou Pendências e Lista de Inadequaçōes:}

O projeto de pesquisa, bem como os documentos apresentados, estão em acordo com a Res. CNS 466/2012 e complementares.

Situação do Parecer:

Aprovado

Necessita Apreciação da CONEP:

Não

Consideraçôes Finais a critério do CEP:

Em acordo com a Resolução 466/12 CNS, ítens X.1.- 3.b. e XI.2.d, os pesquisadores responsáveis deverão apresentar relatórios parcial semestral e final do projeto de pesquisa, contados a partir da data de aprovação do protocolo de pesquisa.

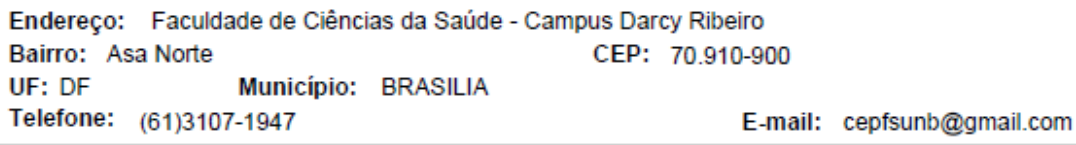

